Portland State University

PDXScholar

$10-2002$

\title{
The Role of Trust, Leader-Member Exchange, and Organizational Justice in Employee Attitudes and Behaviors: A Laboratory and Field Investigation
}

Rudolph Joseph Sanchez

Portland State University

Follow this and additional works at: https://pdxscholar.library.pdx.edu/open_access_etds

Part of the Industrial and Organizational Psychology Commons

Let us know how access to this document benefits you.

\section{Recommended Citation}

Sanchez, Rudolph Joseph, "The Role of Trust, Leader-Member Exchange, and Organizational Justice in Employee Attitudes and Behaviors: A Laboratory and Field Investigation" (2002). Dissertations and Theses. Paper 3728.

https://doi.org/10.15760/etd.5612

This Dissertation is brought to you for free and open access. It has been accepted for inclusion in Dissertations and Theses by an authorized administrator of PDXScholar. Please contact us if we can make this document more accessible: pdxscholar@pdx.edu. 
THE ROLE OF TRUST, LEADER-MEMBER EXCHANGE, AND

ORGANIZATIONAL JUSTICE IN EMPLOYEE ATTITUDES AND BEHAVIORS:

A LABORATORY AND FIELD INVESTIGATION

By

RUDOLPH JOSEPH SANCHEZ

A dissertation submitted in partial fulfillment of the requirements for the degree of

DOCTOR OF PHILOSOPHY

in

SYSTEMS SCIENCE: PSYCHOLOGY

Portland State University

2002 


\section{DISSERTATION APPROVAL}

The abstract and dissertation of Rudolph Joseph Sanchez for the Doctor of Philosophy in Systems Science: Psychology were presented October 18, 2002, and accepted by the dissertation committee and the doctoral program.

\section{COMMITTEE APPROVALS:}

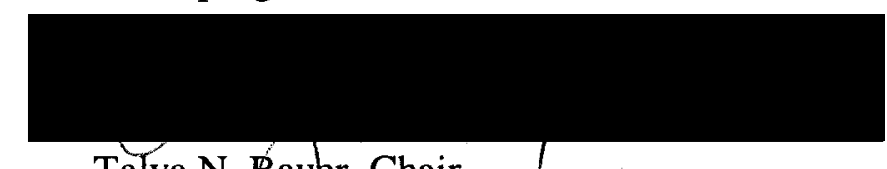

Talya N. Bauer, Chair

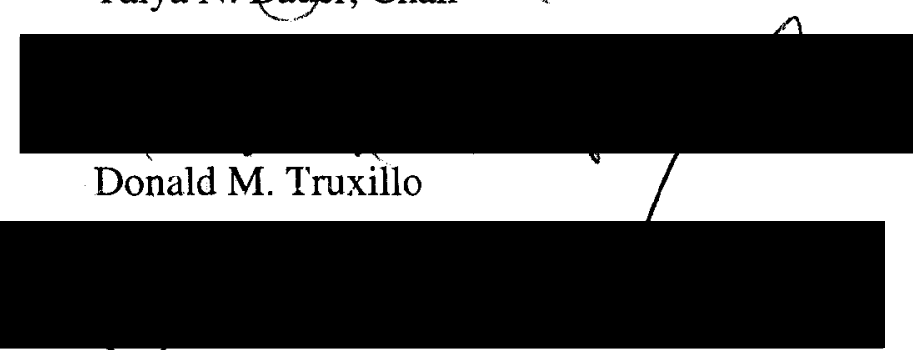

James Pfoulson

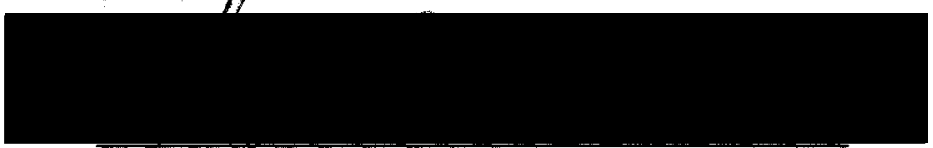

Georged Lendaris

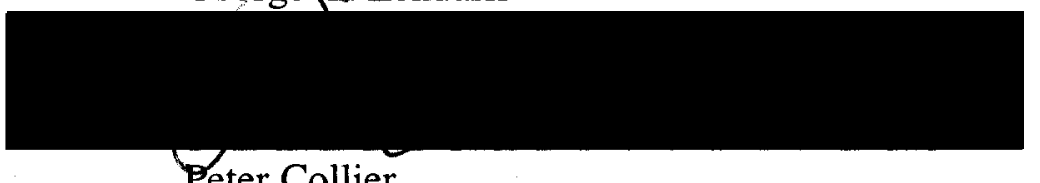

Collier

Representative of the Office of Graduate Studies

DOCTORAL PROGRAM APPROVAL:

George G. Lendaris

Systems Science Ph. D. Program 


\begin{abstract}
An abstract of the dissertation of Rudolph Joseph Sanchez for the Doctor of Philosophy in Systems Science: Psychology were presented October 18, 2002.
\end{abstract}

Title: The Role of Trust, Leader-Member Exchange, and Organizational Justice in Employee Attitudes and Behaviors: A Laboratory and Field Investigation

The study of interpersonal relationships continues to be a major focus of theory and research in a wide array of disciplines. The present research examined one of the most prevalent and significant interpersonal relationships in the workplace context the dyadic relationship between a supervisor and a subordinate. This research examined the relationships between trust, quality of the leader-member exchange relationship (LMX; a measure of the quality of the dyadic relationship), perceived organizational justice, and several employee attitudes and behaviors that are important to individual workers and the organizations in which they work.

Data were collected in both laboratory and field settings. The laboratory setting allowed for the manipulation of organizational justice, which permitted inferences regarding the causal effects of organizational justice on the relationships between trust and LMX and the outcome variables examined. The field setting allowed for the testing of the hypothesized relationships in a "real world" environment in which external contextual factors (e.g., industry and organizational differences) were naturally controlled. 
Two-hundred and twenty-three currently employed undergraduate students participated in the laboratory study. In the field study, data were collected in a Fortune 500 company from 113 subordinates and their supervisors. Results from both studies indicated that perceptions of trust in one's supervisor were strongly related to LMX. Importantly, in the field study, quality of the dyadic relationship was modeled as an emergent property of the perceptions of both subordinates and supervisors.

Perceptions of LMX were related to a sense of overall fairness, which was jointly determined by procedural and distributive justice. Perceptions of overall fairness were related to job satisfaction, intention to quit, organizational commitment, in-role job performance, organizational citizenship behavior, and organizational retaliatory behaviors. Additionally, results of the laboratory study indicated that established perceptions of trust in one's supervisor and LMX were adversely affected by violations of either procedural or distributive justice. This adverse effect was greatest when both procedural and distributive justice were low. The theoretical and practical implications of the research are discussed. 
Dedication

For Mom and Dad 
Acknowledgements

It is my firm belief that no project of this nature is accomplished by a single individual. Certainly, a person's educational achievements culminating in a doctorate requires what I term "a conspiracy of success". There are too many people to name individually who have positively impacted me in one way or another. However, I want to acknowledge some of those whom have encouraged me throughout my education and without whom I would not have completed this degree.

All members of my immediate family have been unwavering in their support of my education. They have made untold sacrifices. I want to thank them all Rosemarie Sanchez, Juliette Sanchez, Jo-anna Sanchez, Dolores Sanchez, Julia Ornelas. Although, my father, Rudolph Sanchez, and my maternal grandfather, Joe Ornelas, did not live to see me reach this milestone, I know that they have cheered me along the way both when they were living and after they passed away.

The faculty at California State University, San Bernardino, especially Jan Kottke (chair of my thesis committee) and Matt Riggs, were essential in my preparation for a Ph.D. program. My colleagues at San Bernardino also were very important in my success and their encouragement has always been uplifting.

I am also indebted to the Systems Science and Industrial/Organizational faculty at Portland State University. I am particularly grateful to Talya Bauer and Donald Truxillo who guided me not only in completing the Ph.D., but also in preparing me for a rewarding and successful career in academia. I will always remember their willingness to share their lives with me; challenge me to do more than 
I perhaps thought I was ready for; and sticking with me when things got difficult. George Lendaris was the only Systems Science professor I had in my career at Portland State. He helped to simultaneously broaden and sharpen my thinking regarding the application of systems science concepts to my field. This has proved very helpful in my career already. I also thank Jim Paulson and Peter Collier, the other two members of my dissertation committee for their willingness to serve on the committee and their insightful suggestions on this research.

There are others who have put their confidence in me at critical points in time. I thank the following people: Leslie Hammer for recruiting me to Portland State University and offering me my first teaching assistant position; Roger Jennings for offering me my first teaching opportunity at Portland State University; Ellen West from the School of Business, who offered me my first full-time teaching position.

I also acknowledge my colleagues in the industrial and organizational psychology program and other graduate students in the psychology department who have been an invaluable source of support, intellectual stimulation, and most importantly friendship. I especially want to thank John Hunthausen, Cybelle Lyon, Krista Brockwood, Carl Azar, Johanna Glode, Joni Jansenn, Matt Paronto, and Mindy Ing.

I also thank Mary Alice Bielenberg for her help in obtaining a data site. Most importantly, however, I thank her for her patience, support, and love during the writing of my dissertation. She has brought incredible joy into my life and I look forward to wonderful life with her. 
Acknowledgements.....................................................ii

List of Tables ....................................................................... vii

List of Figures.........................................................

Glossary ..........................................................................

Chapter 1

Introduction........................................................ 1

Figures ........................................................... 6

Chapter 2 Trust

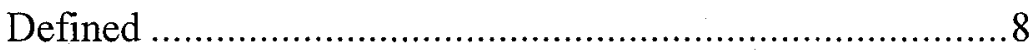

Characteristics of the Trustor......................................... 9

Characteristics of the Trustee........................................ 11

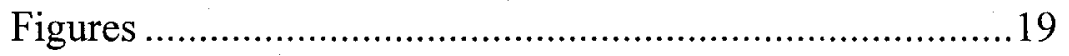

Chapter 3 Leader-Member Exchange Theory

Development ......................................................22

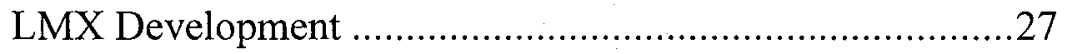

LMX as a System .................................................. 34

Antecedents and Consequences ................................... 38

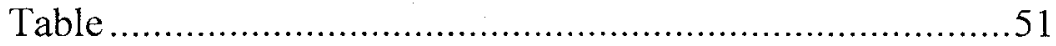

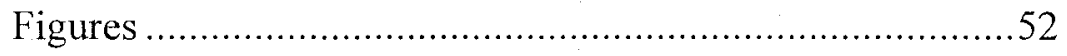

Chapter 4 Organizational Justice

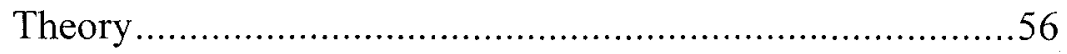




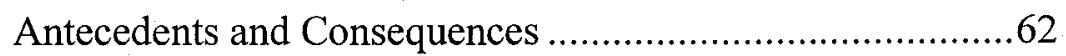

Interaction of Procedural and Distributive Justice .................68

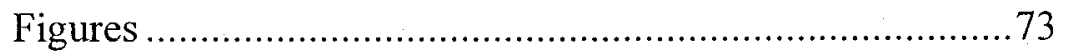

Chapter 5 Model Summary

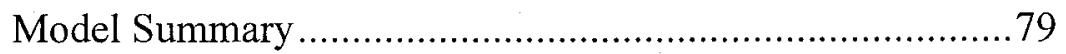

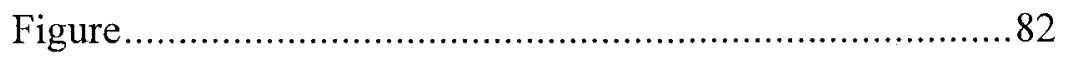

Chapter 6 Laboratory Study Method

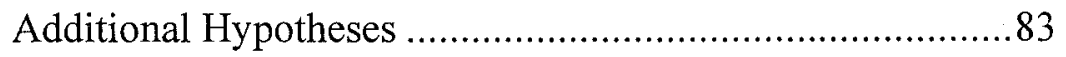

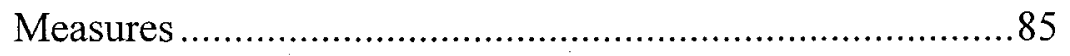

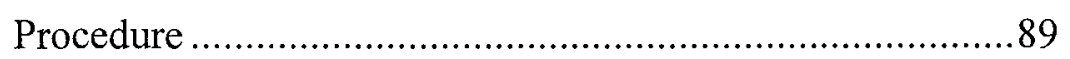

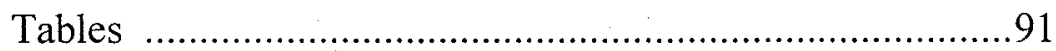

Chapter 7 Laboratory Study Results

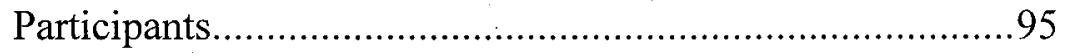

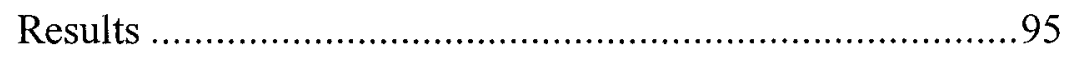

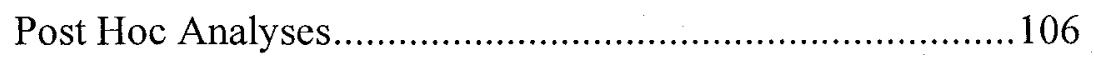

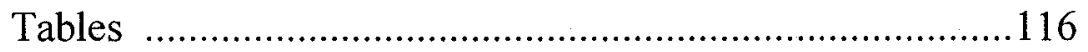

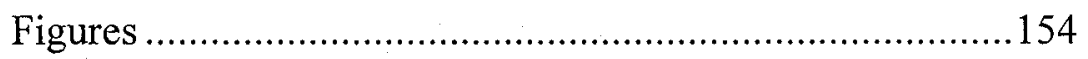

Chapter 8 Field Study Method

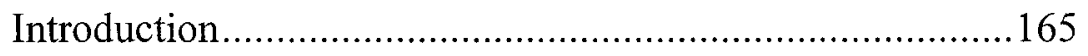

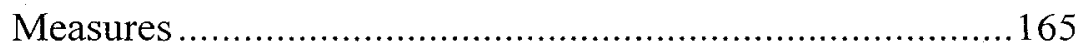

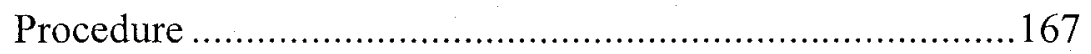

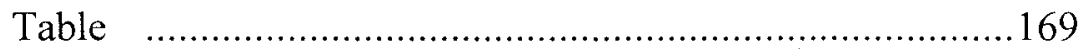


Chapter 9 Field Study Results

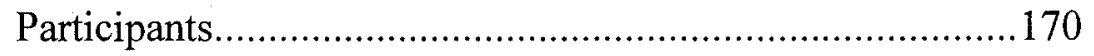

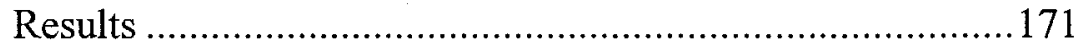

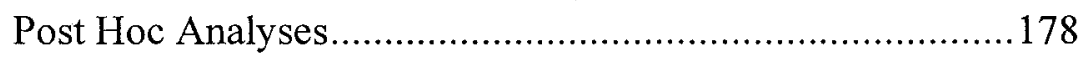

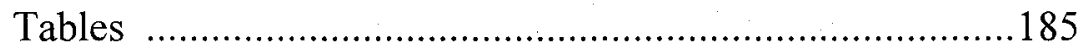

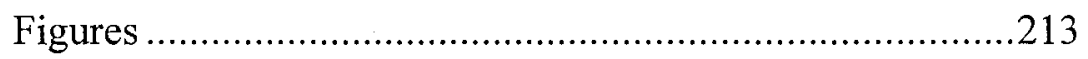

Chapter 10 Discussion

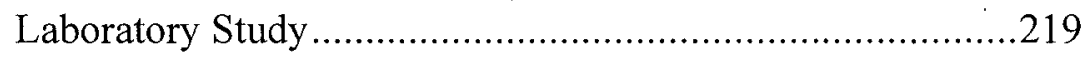

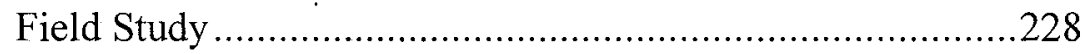

Theoretical Implications ....................................................240

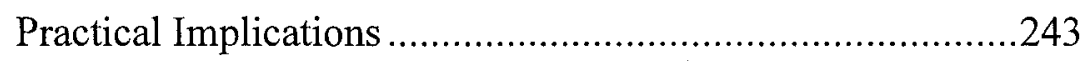

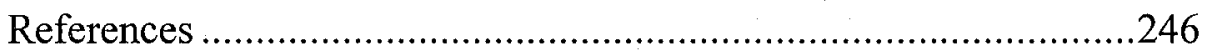

Appendix A: Laboratory Study Cover Letter..................................268

Appendix B: Laboratory Study Pre-Manipulation Survey ................269

Appendix C: Laboratory Study Post-Manipulation Survey ...............274

Appendix D: Field Study Subordinate Cover Letter ........................279

Appendix E: Field Study Subordinate Survey ……........................28

Appendix F: Field Study Supervisor Cover Letter .........................287

Appendix G: Field Study Supervisor Instruction Set ......................288

Appendix H: Field Study Supervisor Survey ................................28 
List of Tables

1 Perceptual Levels of the Leader-Member Exchange Relationship ........ 51

2 Summary of Survey Plan for Study One (Laboratory) ...................... 91

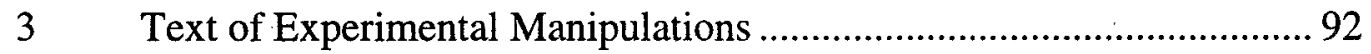

4 Summary of Experimental Conditions............................................. 94

5 Pre-Manipulation Descriptive Statistics and Correlations for Laboratory Study

6 Post-Manipulation Descriptive Statistics for Laboratory Study ........... 118

7 Post-Manipulation Condition 1 Correlations for Laboratory Study....... 120

8 Post-Manipulation Condition 2 Correlations for Laboratory Study....... 122

9 Post-Manipulation Condition 3 Correlations for Laboratory Study....... 124

10 Post-Manipulation Condition 4 Correlations for Laboratory Study....... 126

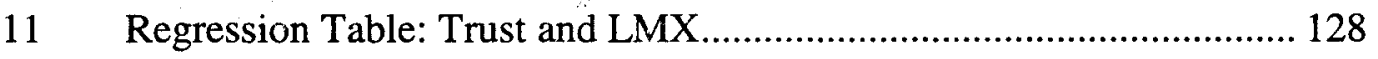

12 Regression Table: Distributive Justice by Procedural Justice Interaction

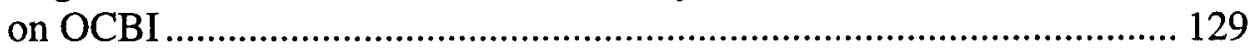

13 Regression Table: Distributive Justice by Procedural Justice Interaction

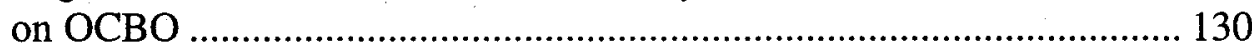

14 Regression Table: Distributive Justice by Procedural Justice Interaction on In-Role Performance ............................................................... 131

15 Steps for Testing Mediation ..................................................... 132

16 Mediation Step 1: Effect of Distributive Justice on LMX-Outcome Relationships for Laboratory Pre-Manipulation Data....................... 133

17 Mediation Step 2: Effect of Distributive Justice on LMX-Outcome Relationships for Laboratory Pre-Manipulation Data......................... 134

18 Mediation Step 3: Effect of Distributive Justice on LMX-Outcome Relationships for Laboratory Pre-Manipulation Data. 
19 Reduction in Variance Accounted by Distributive Justice on LMX-Outcome Relationships

20 Mediation Step 1: Effect of Procedural Justice on LMX-Outcome

Relationships for Laboratory Pre-Manipulation Data.

21 Mediation Step 2: Effect of Procedural Justice on LMX-Outcome

Relationships for Laboratory Pre-Manipulation Data.

22 Mediation Step 3: Effect of Procedural Justice on LMX-Outcome

Relationships for Laboratory Pre-Manipulation Data.

23 Reduction in Variance Accounted by Procedural Justice on

LMX-Outcome Relationships

24 Goodness-of-Fit Indices for Laboratory Study Models........................... 141

25 Pre- Post-Manipulation Mean Differences of Trust in Supervisor ........ 142

26 Pre- Post-Manipulation Mean Differences of LMX ……..................... 143

27 Mediation Step 1: Effect of Distributive Justice on LMX-Outcome

Relationships for Laboratory Post-Manipulation Data

28 Mediation Step 2: Effect of Distributive Justice on LMX-Outcome

Relationships for Laboratory Post-Manipulation Data

29. Mediation Step 3: Effect of Distributive Justice on LMX-Outcome

Relationships for Laboratory Post-Manipulation Data

30 Reduction in Variance Accounted by Distributive Justice on

LMX-Outcome Relationships

31 Mediation Step 1: Effect of Procedural Justice on LMX-Outcome

Relationships for Laboratory Post-Manipulation Data

32 Mediation Step 2: Effect of Procedural Justice on LMX-Outcome

Relationships for Laboratory Post-Manipulation Data

33 Mediation Step 3: Effect of Procedural Justice on LMX-Outcome

Relationships for Laboratory Post-Manipulation Data

34 Reduction in Variance Accounted by Procedural Justice on

LMX-Outcome Relationships

35 Post-Manipulation Mean Differences between the Four Manipulation

Conditions of the Laboratory Study 152 
36 Goodness-f-Fit Indices for Laboratory Post Hoc Models

37 Summary of Survey Plan for Study Two (Field)

38 Power Analysis for Study Two (Field)

39 Descriptive Statistics and Correlations for Field Study Subordinates ... 186

40 Descriptive Statistics and Correlations for Field Study Supervisors ..... 188

41 Descriptive Statistics and Correlations for Matched Field Study Data.. 189

42 Regression Table: Trust and LMX from Subordinate's Perspective ..... 194

43 Regression Table: Trust and LMX from Supervisor's Perspective ....... 195

44 Mediation Step 1: Effect of Distributive Justice on LMX-Outcome

Relationships for Field Study Self-Report Data ................................ 196

45 Mediation Step 2: Effect of Distributive Justice on LMX-Outcome

Relationships for Field Study Self-Report Data

46 Mediation Step 3: Effect of Distributive Justice on LMX-Outcome Relationships for Field Study Self-Report Data

47 Distributive Justice as Mediator Variance Accounted for (Self-Report) 199

48 Mediation Step 1: Effect of Procedural Justice on LMX-Outcome Relationships for Field Study Self-Report Data 200

49 Mediation Step 2: Effect of Procedural Justice on LMX-Outcome Relationships for Field Study Self-Report Data 201

50 Mediation Step 3: Effect of Procedural Justice on LMX-Outcome Relationships for Field Study Self-Report Data 202

51 Procedural Justice as Mediator Variance Accounted for (Self-Report). 203

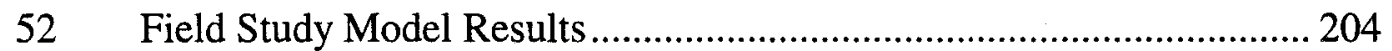

53 Field Study Post Hoc Model Results with Subordinate Reports of Outcomes 205

$54 \quad$ Field Study Post Hoc Model Results with Supervisor Reports of Outcomes 206

55 Summary of Findings 207 


\section{List of Figures}

1 General Systems Model 6

$2 \quad$ Hypothesized Model .................................................................... 7

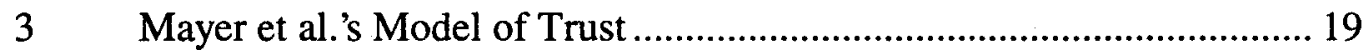

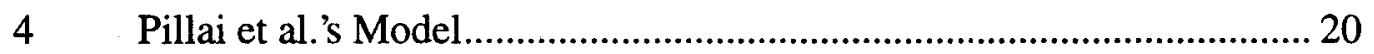

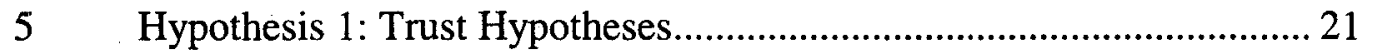

$6 \quad$ Sahlins' Continuum of Reciprocity ........................................... 52

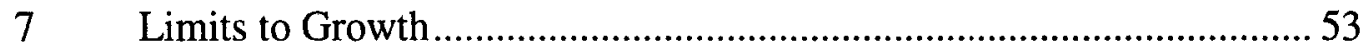

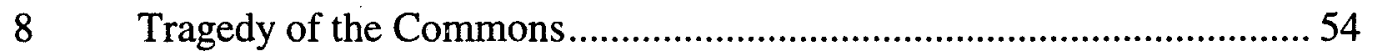

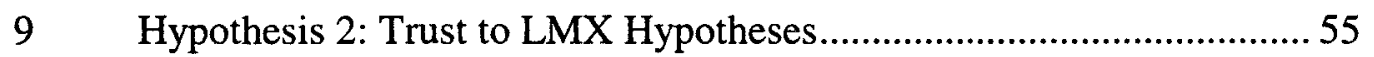

10 Hypotheses 3 and 4: Organizational Justice to Outcomes Hypotheses.. 73

11 Procedural Justice by Distributive Justice Interaction ......................... 74

12 Hypothesis 5: Procedural Justice by Distributive Justice Interaction .... 75

13 Hypotheses 6 and 7 : Mediating Hypotheses ................................... 76

14. Hypothesis 6: Mediating Effect of Distributive Justice .......................77

15 Hypothesis 7: Mediating Effect of Procedural Justice ........................ 78

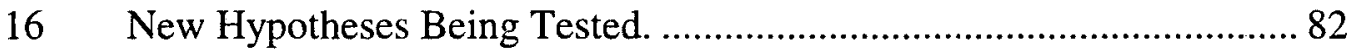

17 Laboratory Study: Distributive Justice by Procedural Justice Interaction Effect on OCBI ......................................................... 154

18 Laboratory Study: Distributive Justice by Procedural Justice Interaction Effect on OCBO.

19 Laboratory Study: Distributive Justice by Procedural Justice Interaction Effect on In-Role Performance

$20 \quad$ Step One of Mediator Analysis ....................................................... 157

21 Step Two of Mediator Analysis .................................................... 158

22 Step Three of Mediator Analysis ................................................... 159 
23 Laboratory Study Hypothesized Model Results.............................. 160

24 Laboratory Study Alternative Model Results.................................. 161

25 Laboratory Study Final Model Results ..................................... 162

26 Laboratory Study Post Hoc Initial Model Results ............................. 163

27 Laboratory Study Post Hoc Final Model Results ............................. 164

28 Field Study Hypothesized Model Results ..................................... 213

$29 \quad$ Field Study Final Model Results................................................. 214

30 Field Study Post Hoc Initial Model Results with Subordinate Reports of

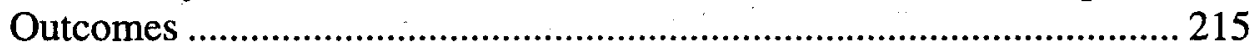

31 Field Study Post Hoc Final Model Results with Subordinate Reports of Outcomes ............................................................................... 216

32 Field Study Post Hoc Initial Model Results with Supervisor Reports of

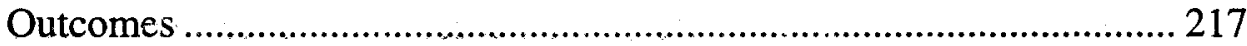

33 Field Study Post Hoc Final Model Results with Supervisor Reports of Outcomes ............................................................................. 218 
Chapter One

\section{Introduction}

The study of interpersonal relationships continues to be a major focus of theory and research in a wide array of disciplines including psychology, sociology, economics, business, and political science. The present research examined one of the most prevalent and significant interpersonal relationships in the workplace context the dyadic relationship between a supervisor and a subordinate. The general model examined is shown in Figure 1. The general model indicates that perceptions of trust of one person of another influence perceptions of the quality of the dyadic relationship. The quality of the relationship, then, influences attitudinal outcomes (e.g., satisfaction, commitment to the other person) and behavioral outcomes (e.g., performance, extra effort). However, perceptions of fairness are hypothesized to mediate the relationship between the quality of the dyadic relationship and outcomes. Note that this model is not context dependent. That is, it is possible to apply this general model to many situations in which dyadic relationships exist (e.g., family, school, and workplace).

The purpose of this research was to examine the relationships between trust, quality of the leader-member exchange (LMX) relationship (a measure of the quality of the dyadic relationship), perceived organizational justice, and several outcome variables that are important to individual workers and the organization in which they work.

It is important to study relationships in the workplace for a variety of reasons. First, the incidence of workplace violence and aggression has been associated with 
perceptions of interpersonal unfairness, which is an emergent property of

interpersonal relationships in the workplace. While considerable media attention has been focused on extreme and tragic incidents of workplace violence (e.g., homicides, physical assaults), it is important to note that overt physical violence is only one form of dysfunctional organizational behavior. For example, Folger and Baron (1996) defined workplace aggression as "any form of behavior by individuals that is intended to harm current or previous coworkers or their organization" (p. 52). Folger and Baron called on a long line of research (cf. Brown \& Herrnstein, 1975) to argue that one fundamental cause of workplace aggression is a sense of injustice or betrayal of trust.

A second reason for examining relationships in the workplace concerns the change in the United States' economy from industrial to service (Moskowitz \& Warwick, 1996). The service economy puts a premium on all types of interpersonal relationships (e.g., collegial, employee-client, supervisor-subordinate). Fewer and fewer employees work in jobs where interpersonal interaction is limited.

Third, many organizations have moved from "tall", hierarchically structured organizations to more "flat" and team based structures (Morhman, Galbraith, \& Lawler, 1998). This change has been brought about, in part, by the need for organizations to be more adaptive to fluid environments (Conger, 1998). In order for these team-based organizations to be effective, it is necessary for workers to regulate their own behavior and this may be facilitated by trust and perceived fairness in the organization.

Lastly, as compared to the past, a majority of workers no longer expect to work for the same organization for the duration of their careers, nor do a majority of 
workers expect to stay in one career for their entire lives (Bridges, 1994). The very nature of a job (i.e., a static set of tasks completed by an individual) is also changing to a set of flexible roles that organizational members fill. There exists an amorphous connection between the employee and the organization often referred to as the psychological contract (Rousseau, 1995). A psychological contract "is a mental model that people use to frame events such as promises, acceptance, and reliance" (Rousseau, 1995, p. 27). One of the hallmarks of relationship research is the issue of trust (e.g., Blau, 1964; Granovetter, 1985; Rotter, 1967). Trust has been associated with key behaviors and attitudes such as organizational citizenship behavior (Konovsky \& Pugh, 1994), organizational commitment (Liou, 1995), and job satisfaction (Lagace, 1991).

The present research examined a model of the effects of trust between a supervisor and subordinate on the quality of that relationship and the role of perceptions of organizational justice on the relationship between the quality of the dyadic relationship and important employee (i.e., member) attitudinal and behavioral outcomes. Figure 2 depicts the model examined and is presented as an overview. This model was examined in a laboratory setting in which organizational justice was manipulated and in a field setting using a cross-sectional methodology.

Trust is defined as a belief that one can expect another person to act in a way that will not harm him or her. Further, trust in a specific person is theorized to be partly determined by a person's general tendency to trust others (Hypotheses 1a and $1 \mathrm{~b}$ in Figure 2). Person-specific trust is then believed to be related to the quality of the interpersonal relationship between the leader (i.e., supervisor) and the member (i.e., 
subordinate) or the LMX relationship (Hypothesis 2). LMX is then hypothesized to be related to several member attitudes (i.e., overall job satisfaction, intention to quit, and organizational commitment) and behaviors (i.e., job performance, organizational citizenship behavior directed toward the organization, organizational citizenship behavior directed toward the supervisor, and organizational retaliatory behaviors). Importantly, the relationship between LMX and these outcome variables is hypothesized to be mediated by perceptions of organizational justice (Hypotheses 6a-g and Hypotheses 7a-g). Organizational justice can be thought of as a member's general perception of fair treatment in the workplace. Organizational justice is often conceptualized as comprising two related yet distinct constructs. Distributive justice concerns perceptions of fairness regarding the distribution of resources within an organization. Procedural justice refers to the fairness of the process or how the distribution of resources occurred.

The major variables of interest in this research are presented in the order in which they appear in the model. First, the concept of trust is explored, including the importance of trust as a possible dispositional variable. Second, leader-member exchange (LMX) theory is explicated. This theory of leadership emphasizes the dyadic and unique relationship a leader has with each individual subordinate or member in his or her workgroup. Third, the literature on organizational justice is reviewed.

Organizational justice deals with perceptions of fair treatment in the workplace. The hypothesized relationships presented in Figure 2 is explained as each variable is presented. The data collection and data analytic methods utilized in this two-study research project are then presented. This is followed by the results of the two studies. 
Lastly, a discussion of the implications of this study for researchers and practitioners is presented.

In exploring this model, the present research contributed to the existing industrial and organizational psychological literature in several significant ways. First, this research was the first to examine the role of trust in relationship to the quality of LMX. Importantly, trust is conceptualized as both trust in a specific other and as an individual difference construct. Second, this research was the first empirical test of the relationship between LMX, organizational justice and several important individual and organizational variables. Third, this was the first empirical test of the relationship between LMX and negative organizational behaviors called organizational retaliatory behaviors. Fourth, in the spirit of general systems theory (Kozlowski \& Klein, 2000), the model can be made generic enough to be tested in a variety of contexts, including parent-child and teacher-student relationships. Importantly, the model was tested in both a field setting and in a laboratory setting. The laboratory setting allowed for the manipulation of organizational justice, which permitted inferences regarding the causal effects of organizational justice on the relationships between LMX and the outcome variables examined here. The field setting allowed for the testing of the hypothesized relationships in a "real world" environment in which external contextual factors (e.g., industry and organizational differences) were naturally controlled. 


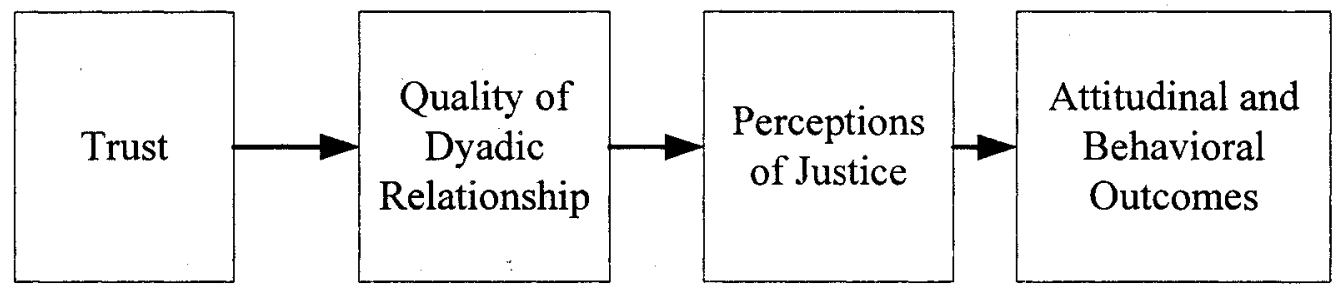

Figure 1. General Model. The direction of the arrows indicates theoretical causality. 


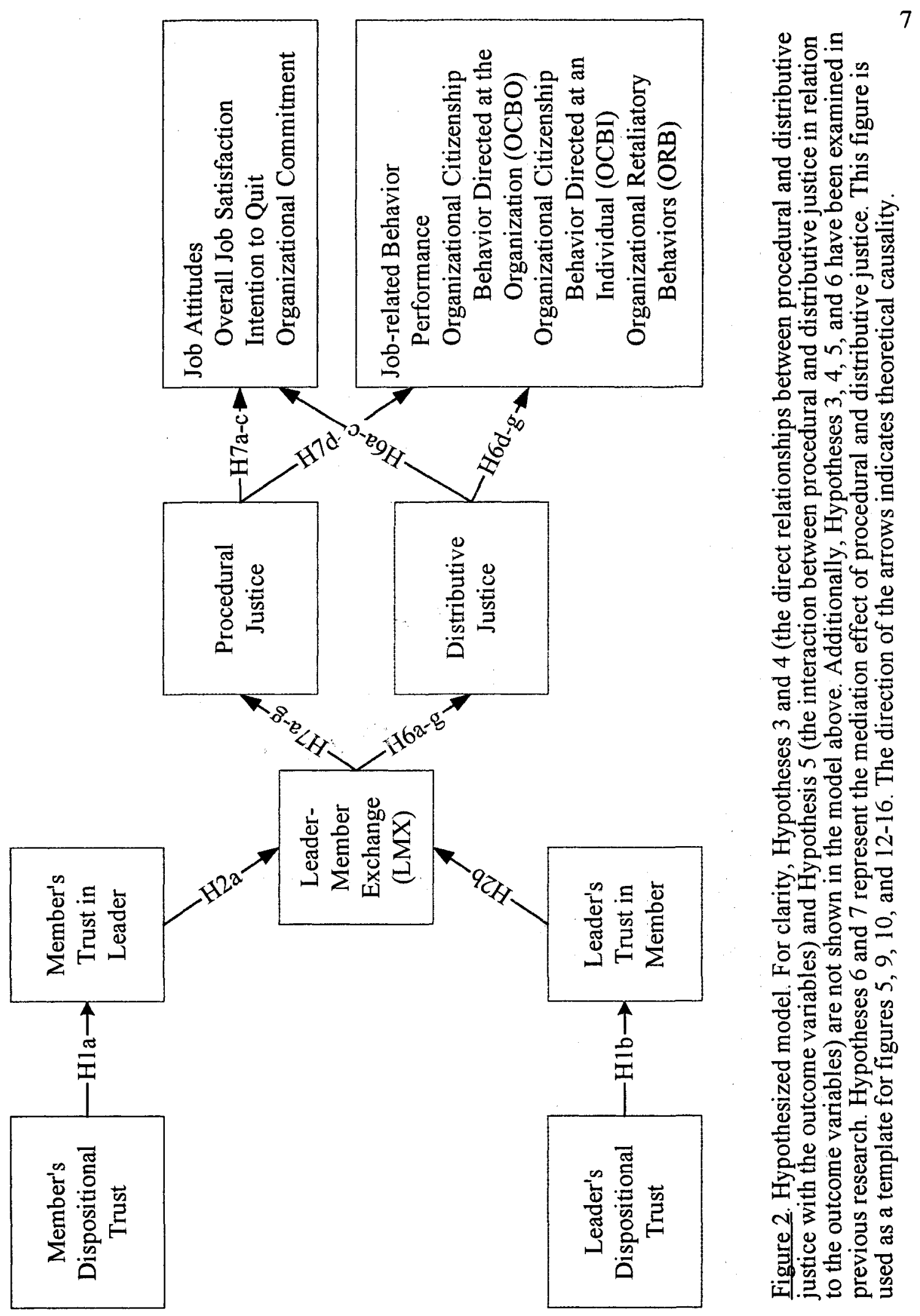


Chapter Two

Trust

Trust in interpersonal relationships has been the focus of research in several disciplines including economics (e.g., Williamson, 1993), sociology (e.g., Granovetter, 1985), psychology (Rotter, 1967), and management (e.g., Mayer, Davis, \&

Schoorman, 1995). This review focuses on trust as it applies to relationships within organizations. Throughout this research, the terms trustee and trustor are used to describe each of the parties in a dyadic interpersonal relationship. Consistent with the literature on trust (e.g., Driscoll, 1978; Mayer et al., 1995), the trustor is the person in the relationship who is trusting another, and the trustee is the person who is being trusted.

In merging the trust literature from both organizational theory and philosophical ethics, Hosmer (1995) defined trust as: "the expectation by one person, group, or firm of ethically justifiable behavior - that is, morally correct decision and actions based upon ethical principles of analysis - on the part of the other person, group, or firm in a joint endeavor or economic exchange" (p. 399). In building a theoretical model of trust specifically for the research in organizations, Mayer et al. (1995) defined trust as: "the willingness of a party to be vulnerable to the action of another party based on the expectation that the other will perform a particular action important to the trustor, irrespective of the ability to monitor or control the other party" (p. 712). The definitions proposed by Hosmer (1995) and Mayer et al. (1995) are quite similar. One advantage of Mayer et al.'s approach is that these theoreticians proposed a model through which trust may be developed (Figure 3). 
Several researchers have noted that, theoretically, trust may develop as a unique facet of a specific relationship and from a general personality disposition or trait (e.g., Creed \& Miles, 1996; Driscoll, 1978; Mayer et al., 1995; Rotter, 1971; Scott, 1980). Mayer et al. suggested that trust is the result of characteristics of both the trustee and the trustor. Similarly, Lewis and Weigert (1985) asserted that trust is a "collective attribute" of the relationships between people. Using systems science terminology, trust can be thought of as an emergent property of interpersonal relationships. In the case of hierarchically arranged relationships in an organization, trust can be viewed as an emergent property of the supervisor-subordinate relationship. Trust between a supervisor and subordinate would then influence the overall quality of the leader-member exchange relationship.

The primary characteristic of the trustor that Mayer et al. (1995) discussed was the propensity to trust. Similar to Rotter's $(1967 ; 1971)$ approach to trust, propensity to trust is viewed as a "stable with-in person factor that affects the likelihood that a person will trust" (Mayer et al., 1995, p. 715). In the psychology literature, factors that are stable, within person traits are often referred to as dispositions; therefore, the type of trust just defined is herein called dispositional trust. Measurement of dispositional trust generally consists of asking respondents the degree to which they trust a generalized other (versus a specific person, group, or institution). For example, "In dealing with strangers one is better off to be cautious until they have provided evidence that they are trustworthy" (Rotter, 1967).

Prior research has shown that dispositional trust is related to performance (Conlon \& Mayer, 1994), performance in zero-sum games (Moore, Shaffer, Pollak, \& 
Taylor-Lemke, 1987), and nonverbal communication (Sabatelli, Buck, \& Dreyer, 1983). Based on these empirical findings and theory, Mayer et al. (1995) recommended that dispositional trust be included in research examining the role of trust in organizational behavior.

In Mayer et al.'s model, dispositional trust of the trustor moderated the relationship between the characteristics of the trustee as perceived by the trustor and eventual trust in the trustee (Figure 3). For example, it may be possible for an individual to not trust Person A even in the presence of information about Person A that indicates that s/he can be trusted (i.e., high ability, benevolence, and integrity). Conversely, it may be possible for an individual to trust another even in the presence of information about the trustee that indicates the person should not be trusted because their tendency is trust others (e.g., give others the benefit of the doubt).

\section{Characteristics of the Trustee}

Mayer et al. (1995), further proposed that three characteristics of the trustee (as perceived by the trustor) lead to that person being trusted. The first of these characteristics is ability. Ability refers to a set of skills in a specific domain that allows the person who possesses ability to have some influence. The second characteristic is benevolence. Benevolence refers to the motivation for behavior toward the trustor. A trustee is benevolent if $s /$ he intends to do good to the trustor. Note that benevolence is more than the absence of malice. The third characteristic proposed by Mayer et al. is integrity. Integrity refers to the "trustor's perception that the trustee adheres to a set of principles that the trustor finds acceptable" (p. 119). Consistency is the hallmark of integrity. Behavioral consistency over time and consistency between the words and 
actions of the trustee contribute to a trustee being perceived as having integrity. In Mayer et al.'s model of trust, dispositional trust of the trustor moderates the relationship between these three trustee characteristics as perceived by the trustor and actual trust in the trustee.

Contrary to the approach recommended by Mayer et al. (1995), Butler (1991) implied that the only aspect of trust relevant to organizational behavior is trust in a specific other. While there is some empirical evidence that person-specific trust is generally more related to organizational outcomes than dispositional trust (e.g., Driscoll, 1978; Scott, 1980), most researchers do not suggest that dispositional trust be abandoned. Discoll noted that perhaps situational differences (i.e., person-specific trust) are "more compelling" (p. 54) than trustor personality traits (i.e., dispositional trust). It may be the case that with little or no information about a specific other, dispositional trust is the mechanism through which trust is built and therefore may be more related to organizational outcomes in the early development of relationships. Following this logic and assuming a normal distribution of dispositional trust in the population, for most people who have a significant amount of information about a specific other (e.g., a supervisor), person-specific trust is more salient and therefore, more likely to be related to organizational outcomes. However, for those who are extremely trustful or distrustful at a dispositional level, the amount of information they have about a specific other regarding their trustworthiness may not be as salient. It is also possible that dispositional trust will be more salient in perceptions of trust of a specific other (e.g., supervisor, organization) when there is relatively little information known about the specific other in terms of ability, integrity, and benevolence. For 
example, a subordinate's dispositional trust may be more relevant to trust in a supervisor early in the dyadic relationship when the subordinate lacks a lot of information about the supervisor.

In 1984, Butler and Cantrell synthesized two earlier explorations of trust dealing with subordinate/supervisor relationships (i.e., Gabarro, 1978; Jennings, 1971). Butler and Cantrell suggested that there were five trustee characteristics that would lead to trust. These five characteristics were integrity, competence, consistency, loyalty, and openness. Integrity refers to the reputation of the trustee has for honesty. Competence refers to the trustee's job related technical and interpersonal skills. Consistency reflects the reliability and predictability of the trustee in handling situations. The willingness of the trustee to protect, support, and encourage others is referred to as loyaity. Lastly, openness refers to the trustee's willingness to share ideas and information with others. Butler and Cantrell presented undergraduate students with a series of 32 hypothetical supervisors and 32 hypothetical subordinates and then measured the level of trust in each of the 64 conditions. The results indicated that integrity, competence, and consistency were stronger predictors of trust than loyalty or openness. Interestingly, this pattern of results was the same for both hypothetical supervisors and subordinates.

Butler (1991) expanded this theoretically and empirically derived set of conditions of trust through a content analysis of interviews with 84 managers. The additional conditions of trust were availability, discreteness, fairness, promise fulfillment, and receptivity. Availability refers to the extent to which a person is accessible when the other party needs him/her. Discreteness is defined as the ability to 
the trustee to keep confidences. Fairness refers to how the trustee treats the trustor (note: given the more extensive review of the organizational justice provided later in this paper, this condition of trust reflects some aspects of procedural justice). Promise fulfillment refers to the belief of the trustor that the trustee will keep his/her word. Lastly, receptivity refers to the degree to which the trustee accepts the input of the trustor.

There is a considerable degree of congruence between the characteristics of trust defined by Butler (1991) and the four dimensions of LMX (i.e., affect, loyalty, contribution, professional respect) identified by Liden and Maslyn (1998). For example, the constructs of loyalty, competence, and support appear in both sets of dimensions. Researchers in the LMX and trust literature have called for inclusion of both variables in future research (e.g., Bauer \& Green, 1996; Pillai, Schriesheim, \& Williams, 1999). The present research filled this gap in the literature.

In addition to the similarity in the nature of the trust and LMX constructs, there is similarity in terms of how LMX and trust develop in a hierarchical dyadic relationship. Specifically, the development of LMX and trust is reciprocal in nature (Butler, 1991; Larzelere \& Huston, 1980; Zand, 1972). Meeting expectations of trust on the part of the trustee begets more trust from the trustor. This process is hypothesized to be on-going and self-reinforcing (Butler, 1991).

Prior research has demonstrated that person-specific trust is related to organizational citizenship behavior (Deluga, 1994; Konovsky \& Pugh, 1994; Podsakoff, MacKenzie, Moorman, \& Fetter, 1990), organizational commitment (Folger \& Konovsky, 1989), and job satisfaction (Driscoll, 1978; Lagace, 1991). 
Organizational citizenship behaviors (OCB) are useful behaviors that employees contribute to the organization that are neither required nor expected (Bateman \& Organ, 1983): Organizational commitment is the degree to which an employee feels a sense of loyalty to an organization (Allen \& Meyer, 1990). Additionally, several studies have examined the relationships between organizational justice (i.e., distributive and procedural justice) and trust. In general, procedural justice has been shown to be more closely related to trust than distributive justice (e.g., Alexander \& Ruderman, 1987; Moorman, 1991; Pillai et al., 1999).

Comparison of Dispositional Trust and Person-Specific Trust

In attempting to make a connection between the dispositional and personspecific aspects of trust and more broad psychological principles, Scott (1980) argued that attitudes are generally thought to be composed of three components. The first component, affectivity, is believed to be a "broad-based stable component" (p. 810). In terms of trust, the affective component to attitude is similar to dispositional trust defined above. The second component of attitude is cognitive in nature. The cognitive component deals with "perceptions, beliefs, and ideas about a specific attitude object" (Scott, p. 810). The cognitive component of attitude is similar to person-specific trust defined above. The third component of attitude focuses on behavior or how a person "responds toward a specific attitude object" (p. 810). In terms of trust, this is similar to the consequences of trust in organizations (e.g., organizational citizenship behavior).

The present research utilized Mayer et al.'s (1995) suggestion to include both dispositional and person-specific trust. It is likely that person-specific trust will show a 
stronger relationship to LMX than dispositional trust; however, it is possible (cf. Scott, 1980) that both types of trust are related to LMX.

In sum, trust is believed to be essential to supervisor-subordinate relationships (e.g., Bauer \& Green, 1996; Lewicki, McAllister, \& Bies, 1998; Whitener, Brodt, Korsgaard, \& Werner, 1998) and is related to several variables of interest in the current research including leadership (Pillai et al., 1999), performance (Early, 1986), and organizational citizenship behavior (OCB; McAllister, 1995). The model of trust presented by Mayer et al. (1995) was used to explore the potential relationships of dispositional trust and person-specific trust and LMX. Accordingly, Butler's (1991) overall trust scale was used to measure person-specific trust and a modified version of Rotter's Interpersonal Trust Scale (1967) was used to measure dispositional trust.

Pillai et al. (1999) developed and tested a model that included leadership, trust, and organizational justice. The model is replicated in Figure 4. These researchers proposed that trust and positive perceptions of organizational justice were the mechanisms through which transformational leadership leads to valued personal and organizational outcomes (i.e., job satisfaction, $\mathrm{OCB}$, and organizational commitment). These researchers used the following factors of Bass and Avolio's (1993) model of transformational leadership: charisma, inspirational motivation, intellectual stimulation, and individualized consideration.

The results of Pillai et al.'s (1999) research showed that the data fit the hypothesized model fairly well. All hypothesized paths were significant except for the paths between trust and job satisfaction and trust and organizational commitment. The data also suggested that the data would fit better if a path was added directly from 
procedural justice to organizational commitment. The constructs that Pillai et al. (1999) examined are similar to those in the present research. However, there are several significant differences between the two models and how the constructs are conceived.

First, rather than focusing on transformational and transactional leadership, the hypothesized model uses LMX as the focal leadership variable. LMX is a key leadership variable that Pillai et al. (1999) suggested as an avenue for future research. Although transactional leadership and LMX both focus on an exchange in the interactions between leaders and followers, the two constructs are distinct. Transactional leadership focuses on the economic exchange between leaders and followers (e.g., does the follower complete required duties in exchange for employment and a paycheck). On the other hand, LMX is a reflection of the effectiveness of the working relationship between leaders and followers (or members).

Second, the Pillai et al. (1999) model used general justice constructs (i.e., in general, how fair is the distribution of organizational rewards, and in general, do fair procedures exist for handling disputes) and consequently, organizational justice was theorized to contribute to trust. While this is a valuable contribution in terms of practice, the results do not provide organizations with direction in terms of how to increase organizational justice. Study One of the present research focused on perceptions of a specific human resource process, determination of annual bonuses. Consequently, it was possible to examine the effects of the manipulation of organizational justice on established perceptions of LMX and trust. 
Third, all of the outcome variables of the Pillai et al. (1999) model (i.e., job satisfaction, $\mathrm{OCB}$, organizational commitment) were theorized to be positively related to trust. The model examined here includes both positive outcomes (e.g., job satisfaction, organizational commitment) and negative outcomes (e.g., organizational retaliatory behaviors, intention to quit). Organizational retaliatory behaviors (ORB) are a set of negative behaviors that employees engage in to punish an organization, its members, or both, in response to some perceived injustice (Skarlicki \& Folger, 1997). The inclusion of ORB helps to mitigate possible response bias, and permits the exploration of the possibility that the consequences of low trust, low quality LMX, and low organizational justice include both a lack of positive outcomes and the existence of negative outcomes. For example, a significant positive relationship between high quality LMX and OCB does not mean that members in low LMX relationships engage in behavior that harms the organization, co-workers, or their supervisors; however, the inclusion of ORB considers these possibilities. Overall, the hypothesized model differs significantly from the research of Pillai et al. (1999), although the results of their study provided reason for some optimism for the current research.

Fourth, Pillai et al. (1999) conceptualized trust exclusively as person-specific. The present model conceptualizes trust as an emergent property of the subordinatesupervisor relationship; however, the dispositional nature of the trustor is considered as a contributor to the development of trust in a specific other (i.e., supervisor). The research by Scott (1980) and the model of trust developed by Mayer et al. (1995), suggested the inclusion of both dispositional and person-specific trust in future research. 
Therefore, in terms of the relationship between dispositional trust and trust in a specific other, it is hypothesized that (Figure 5):

Hypothesis 1a: Members' dispositional trust positively relates to member's trust in their leader.

Hypothesis 1b: Leaders' dispositional trust positively relates to leaders' trust in members.

Hypothesis 1a is examined in the both a field and a laboratory setting. Hypothesis $1 \mathrm{~b}$ is examined in a field study where trust data were gathered from both leaders and members.

Trust is also a core construct in social exchange theory (Blau, 1964). Blau argued that social exchange relationships develop from a basis of trust. That is, in providing a service to someone or doing a favor, you do not rely on verbal or written contracts to ensure reciprocation. Rather, you trust that the other person will provide some service or favor in return. Using social exchange theory as its foundation, leadermember exchange theory explores the interpersonal relationship between a subordinate and a supervisor and has been the focus of extensive theory development and research. 


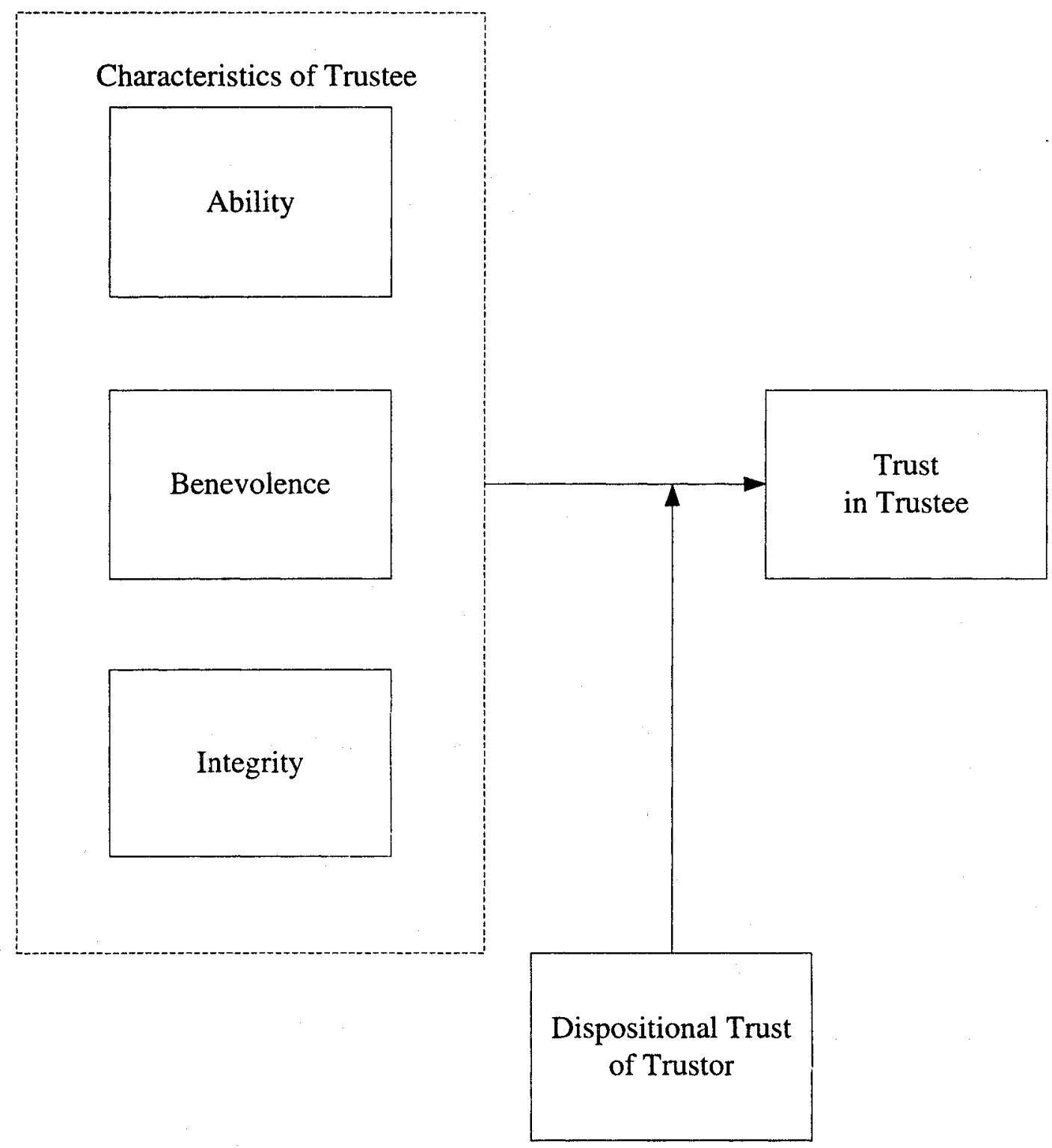

Figure 3. Partial representation of Mayer et al.'s (1995) model of trust development. The direction of the arrows indicates theoretical causality. 

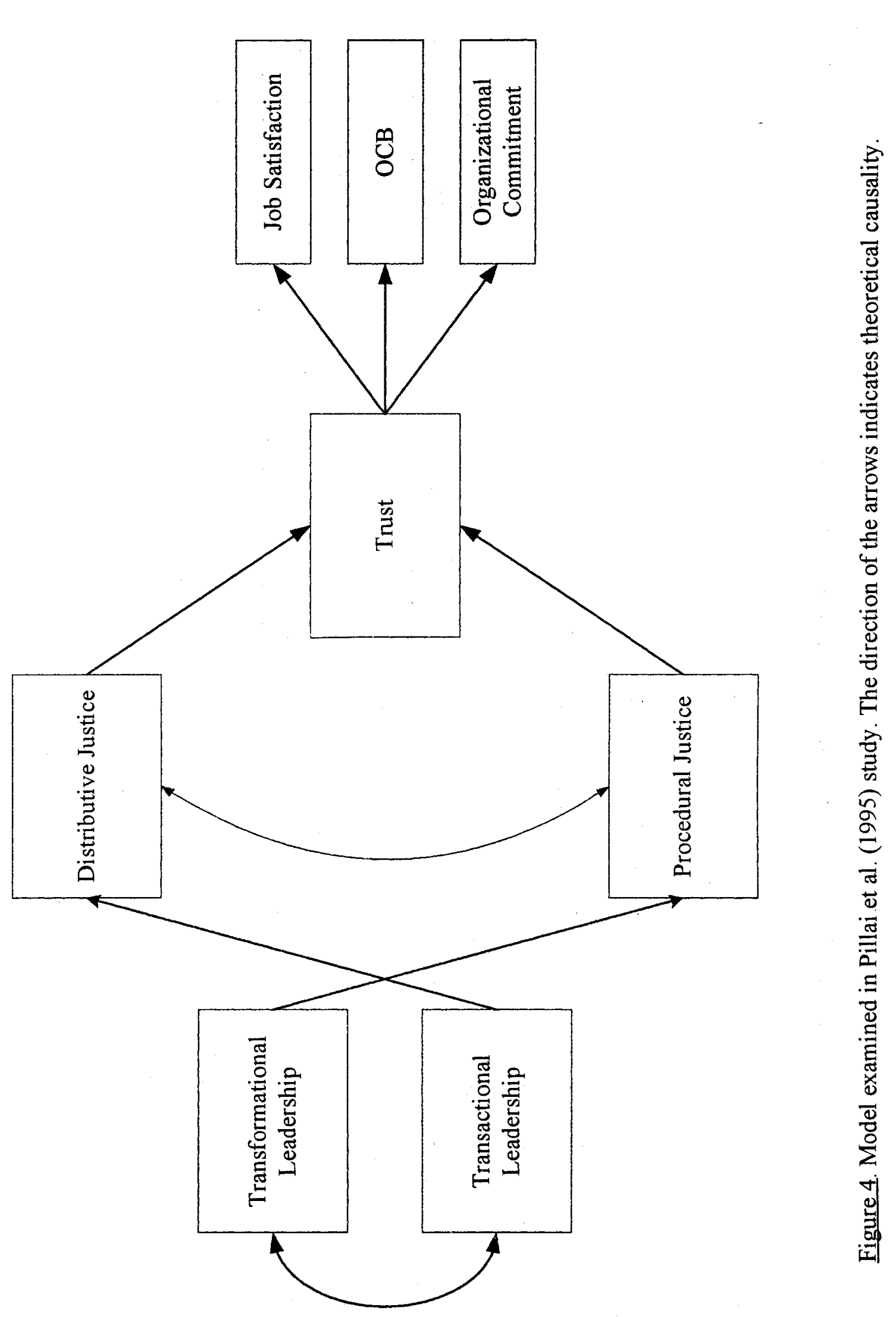


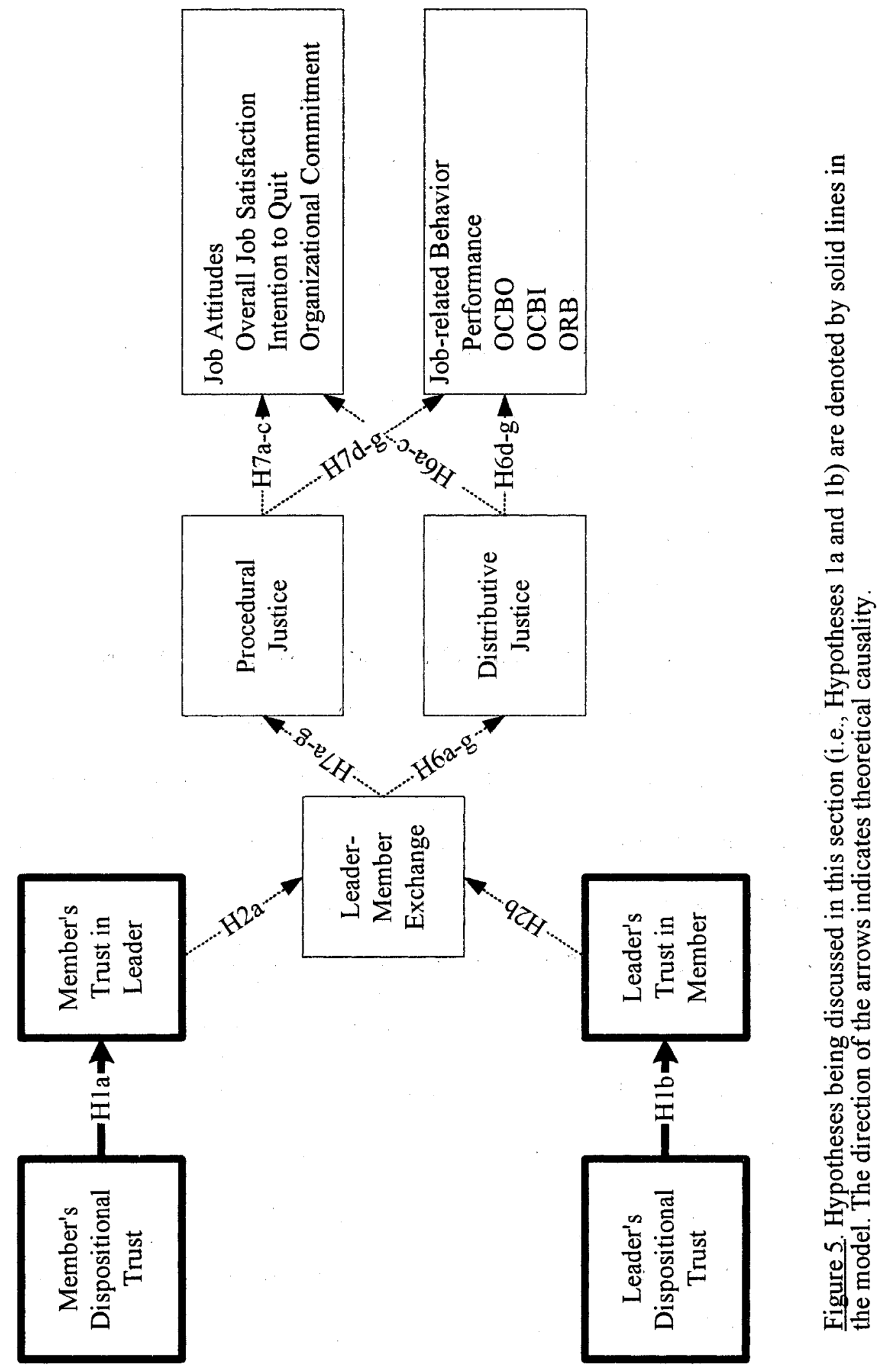


Chapter Three

\section{Leader-Member Exchange}

In the twentieth century, several theories of leadership have been popular among researchers and practitioners, including trait theories (e.g., Ghiselli, 1963; Stogdill, 1948), least preferred co-worker (Fiedler, 1967), path-goal leadership (House, 1971), and behavioral approaches to leadership (Fleishman, Harris, \& Burtt, 1955). These theories have in common an underlying assumption that leaders tend to treat their followers in a similar manner. Additionally, these theories generally assume that followers respond to their leader in a similar manner. Leader-member exchange (LMX) theory breaks from this line of thinking and asserts that unique relationships develop between a leader and each individual follower (i.e., member).

LMX (Graen \& Cashman, 1975) has its roots in social exchange theory (Blau, 1964). Taking a systems perspective, Blau asserted that social exchange brought attention to the emergent properties of social interaction. Social exchange is defined as "voluntary actions of individuals that are motivated by the returns they are expected to bring and typically do in fact bring from others" (Blau, p. 91). The basic principle of social exchange theory is that giving something to another person, which that person values, obligates that person to the individual. In order to fulfill this obligation, the person who initially received benefits supplies something of value in return. This fundamental principle of social exchange theory has a long history in social relations theory (e.g., Gouldner, 1960; Homans, 1961) dating from Aristotle (The Nicomachean Ethics). Importantly, the nature of what is exchanged between the two individuals is unspecified. For example, if a supervisor provides an employee with advice on how to 
do his or her job better, the employee may provide the supervisor with extra effort or time when he or she needs it. It should also be noted that no specific agreement is made about the exchange at the time of the initial offering of benefits. In fact, one of the distinguishing features of social exchanges is that no specific time horizon is established for the return of benefits such as from the employee to the supervisor in the previous example (Blau, 1964).

Another unique feature of social exchange relationships is that while these relationships are developing, members in the social exchange relationship develop feelings of trust and loyalty for each other (Blau, 1964). Since one offers benefits to another without any explicit guarantee of reciprocation, trust becomes a fundamental attribute of the social exchange relationship, particularly in well-developed, highquality relationships.

Blau (1964) contrasted the diffuse and affective nature of social exchange relationships with the more precise and 'cool' nature of economic exchange relationships. Economic exchange relationships are characterized by specificity of what is exchanged. In the work place, one may hear an employee lament that a task "Isn't in my job description." This comment is indicative of the perception of the employee that he or she is in an economic exchange relationship with the organization. This employee is exchanging effort on specific tasks (i.e., the job description) for monetary compensation. Any departure from this implicit agreement may be interpreted as unfair and outside the bounds of the economic exchange relationship. Additionally, in an economic exchange relationship, no feelings of trust and loyalty develop between the members in the relationship. 
Extending the work of Blau (1964), Sahlins (1972) developed a taxonomy of exchange relationships based on a continuum of reciprocity (Figure 6). Three types of relationships (i.e., negative, balanced, and generalized), varied on three dimensions. The first dimension is equivalence of returns. Equivalence of returns refers to the extent to which individuals exchange resources that are highly comparable in kind or in value. The second dimension, immediacy of returns, refers to the time span within which a recipient of some resource reciprocates in order to discharge the obligation. This time span can range from virtually instantaneously (high immediacy) to very long term. The third dimension deals with the nature of the interest of the person providing a resource in the exchange relationship. Interest can be located anywhere on a continuum from complete self-interest to concern for the other person in the exchange relationship.

Using these three dimensions, Sahlins (1972) suggested that relationships could be located on a continuum of reciprocity. While Sahlins conceptualized reciprocity as a continuum, he identified three typical forms of reciprocity: negative, balanced, generalized. Different combinations of the three dimensions of reciprocity described above characterize the three forms of reciprocity. High equivalence of returns, high immediacy or returns, and a concern for oneself characterize negative reciprocity. These conditions are similar to an economic exchange relationship. Balanced reciprocity is characterized by high equivalence and immediacy of returns, and mutual interest. Although not a true social exchange relationship, balanced reciprocity does have the characteristic that one is interested in the outcomes and welfare of the other party. Generalized reciprocity is closest in nature to social 
exchange. Low equivalence and immediacy of returns and a concern for the other person characterize generalized reciprocity. Sparrowe and Liden (1997) noted that one important contribution of Sahlins' work was in describing the precise nature of the exchanges that take place between partners.

Utilizing the concepts developed by Blau (1964) and Sahlins (1972), Graen and Cashman (1975) applied social exchange theory to the workplace, and in particular to the development of relationships between supervisors and subordinates. In contrast to the predominant theories of leadership, Graen and Cashman argued that supervisors, due to constraints on time and resources, developed differential relationships with each of their subordinates. Consequently, it was critical to examine leadership at the dyad level. This new framework for examining leadership was called the vertical dyad linkage (VDL) model.

Empirical support for the claim that leaders (i.e., supervisors) develop differential relationships with members in their work unit is considerable (see Liden, Sparrowe, \& Wayne, 1997 for a review). Please note that while there is considerable debate on whether or not supervisors are de facto leaders (e.g., Yukl, 1989), I use the terms interchangeably as is consistent with the extant LMX research. In the first empirical investigation of the VDL model, Dansereau, Graen, and Haga (1975) found that $85 \%$ of the leaders in their study developed differential relationships with their subordinates. Subordinates generally fell into either an "in-group" or an "out-group." The measure of relationship quality in this study was the amount of negotiating latitude provided to the member by the leader. Negotiating latitude is defined as "the extent to which a superior is willing to negotiate requests from a member concerning 
role development" (Dansereau et al., 1975, p. 51). Relationships between the leader and in-group members reflected characteristics of social exchange relationships. Ingroup members were provided greater latitude in their jobs, and received more time and support from their leaders. Relationships between the leader and out-group members, in contrast, reflected characteristics of economic exchange relationships. It is important to note that this approach to leadership, one in which leaders treat members differentially, stands in contrast to most theories of leadership in which leader behavior is homogenous enough to be identified as a consistent style (Dansereau et al., 1975). For example, trait theories of leadership (e.g., Ghiselli, 1963; Stogdill, 1948) view leaders as having a given set of predispositions with which they treat all followers. In practice, researchers average responses of subordinates to classify a leader's style and hence, these theories are often referred to as average leadership style (ALS) theories. A criticism of ALS theories is that they assume that all members "who report to the same superior are sufficiently homogenous...that they can be considered a single entity: the 'work group"' (Dansereau et al., 1975, p. 47). In contrast, LMX theory treats each dyad independently. Some research suggests that LMX and ALS operate simultaneously and are complementary (Dansereau, Alutto, Markham, \& Dumas, 1982; Katzenberg \& Hom, 1981; Vecchio, 1982). For example, although it may be true that leaders develop differential relationships with members, the leader may have a general style of leadership that he or she employs with all members.

Early research on LMX indicated that in-group/out-group status was related to important outcomes such as satisfaction, turnover, performance, and promotions (e.g., 
Dansereau et al., 1975; Graen \& Cashman, 1975; Graen \& Ginsburgh, 1977). These promising results led to interest in more fully developing the theoretical mechanisms that drove LMX development (Liden et al., 1997).

\section{$\underline{\text { LMX Development }}$}

Several theorists have offered ideas and models of how the LMX relationship develops. Three of these approaches are described here. The first focuses on the development of LMX relationships within the role making paradigm (Dansereau, Graen, \& Haga, 1975). Secondly, Dienesch and Liden (1986) offer a process oriented model of LMX development. Third, a relationship based and multilevel approach to LMX development is offered by Graen and Uhl-Bien (1995).

Graen and colleagues (e.g., Dansereau, et al., 1975; Graen \& Cashman, 1975; Graen \& Scandura, 1987) used role theory (Katz \& Kahn, 1978) to describe the process of relationship building that occurs in a supervisor-subordinate dyad. The role emergence process consists of three distinct phases (Graen \& Scandura, 1987): role taking, role making, and role routinization. Both members of the dyad bring to the first phase, role taking, personal characteristics and experiences and begin their relationship in the context of the organization within which they work. Interactions in the role taking phase are initiated by the supervisor, who has the goal of discovering the "relevant talents and motivations of the member through iterative testing sequences" (Graen \& Scandura, 1987, p. 180). That is, a superior will ask the member for assistance on some task, the member will respond, and the superior will then evaluate the member's response and decide whether or not to initiate another role taking sequence. Importantly, the member responds to the superior's request in this 
phase because the requests are perceived as part of the job requirements. Therefore, exchanges in this phase fall under the rubric of economic exchanges (Blau, 1964).

In the second phase, role making, either the superior or the member may initiate the interaction sequence. Graen and Scandura (1987) asserted that, "Role making is built on the mutual contribution of valued resources" (p. 182). In essence, these researchers claimed that superior-member exchanges in the role making phase are social exchanges. Both members of the dyad contribute resources to the relationship and to work goals (e.g., successfully working on unstructured tasks) that are valued by the other member.

In the third phase, role routinization, the behaviors of the superior and member become interdependent. In this phase, either the member or the superior may initiate a role making sequence. Over time, those coordinated behaviors that are perceived to be successful become strengthened and those that are seen as ineffective are weakened. For example, if a member assists (of her own initiative) the superior in meeting an important deadline and the superior publicly thanks the member for her assistance and offers career advice, then the coupled behaviors of both the member and the superior are strengthened. In the course of role rountinization, a dyadic understanding emerges in which the superior and member develop a set of expectations of each other in terms of social exchanges.

Dienesch and Liden (1986) offered a process oriented model of LMX development, which is distinct from the role emergence approach. The following sequence of events represents the core of this model: initial interaction, leader delegation, member behavior and attribution, and leader attributions of member 
behavior. However, even before the initial interaction between a leader and a

member, Dienesch and Liden suggested that development of LMX may depend upon whether or not the relationship is 1) new but the member has some prior history with the organization that provides the context for the relationship or if the member is 2) new to the organization. Newcomers to an organization will likely require more information and support than incumbents (Bauer, Morrison, \& Callister, 1998) and leaders are likely resources for this information and support. As such, leaders may have more to offer newcomers, in contrast to incumbents, in terms of valuable developmental resources in the social exchange process and consequently LMX development.

The first step of actual LMX development is the initial interaction between the member and the leader. It is possible, although unlikely, that a leader will determine the extent of LMX between him/herself and a member based upon a single member characteristic (e.g., race, gender) or on very few member characteristics (Dienesch \& Liden, 1986; Graen, 1976). In this case, the remainder of the process model is less important.

The second step of the model involves leader delegation to the member. Because the leader-member relationship is in the early stages of development, Dienesch and Liden (1986) assume that the tasks that are delegated to the member fall within what the leader generally perceives to be the job of the member. Additionally, these theorists argue that tasks are delegated to test the member's contribution to the relationship, loyalty to the leader, and liking of the leader. 
In response to the leader's assignment, the member makes some attribution about the leader's request and behaves in some way (including potentially ignoring the leader's assignment). Diensesh and Liden (1986) emphasized that it is critical for researchers to consider more than the member's job performance in response to the leader's assignment. If it is true that leaders use delegation to assess member's loyalty and liking of themselves, then performance is only one dimension on which the leader will evaluate the member in terms of the social exchange relationship. The member will also make some attribution about the task(s) delegated to him or her by the leader. For example, the member may consider the equity or fairness of the social exchange relationship (e.g., "Am I getting back enough in terms of support, resources, etc. for the effort, loyalty, etc. I am giving the leader?"). How a member addresses these concerns should affect eventual LMX quality.

Lastly, the leader will make attributions about the member's behavior. Causal attributions are cognitive efforts to interpret the underlying reason for a person's behavior (Weiner, 1986). Dienesch and Liden (1986) reasserted the theoretical argument presented by Green and Mitchell (1979) regarding the effect of leader causal attributions of member behavior. In essence, leaders' internal attributions about member behavior (i.e., member behavior is due to internal, stable factors such as abiltiy) will have a greater impact on LMX quality (in either a positive or negative direction) than will external attributions (e.g., luck).

All these LMX theorists agree that LMX develops over time through a series of exchanges or "interacts" between a leader and a member (Dienesch \& Liden, 1986; Graen \& Scandura, 1987). Two empirical studies have longitudinally examined LMX 
development. Bauer and Green (1996) found that personality similarity (i.e., positive affectivity) was positively related to leaders' performance ratings of members early in the leader-member relationship. Secondly, good performance was related to increased delegation to the member by the leader. Lastly, good performance by the member and increased delegation by the leader were positively related to high quality LMX. Interestingly, over time, the relationship between personality similarity and LMX was overshadowed by the nature of the performance-delegation interacts between the leader and the member. That is, later in the LMX relationship, good performance and higher levels of delegation were more predictive of LMX quality than personality similarity.

Liden, Wayne, and Stilwell (1993) found that leader and member expectations of each other measured within the first five days of the life of the dyad predicted LMX six months later. Similarly, leader and member perceptions of similarity and liking assessed two weeks into the life of the dyad, predicted LMX at six months. In contrast to Bauer and Green (1996), Liden et al. did not find that performance, assessed at two weeks, predicted later LMX quality.

Graen and Uhl-Bien (1995) differentiated their work from the early work on LMX. Recall that one of the assumptions of LMX was that leaders had limited resources (e.g., time) and consequently could only develop high quality LMX relationships with a subset of members (i.e., the in-group). Based on empirical evidence that suggested that leaders could increase the number and quality of LMX relationships through training (Graen, Scandura, \& Graen, 1986; Scandura \& Graen, 1984), Graen and Uhl-Bien recommended that all members be offered an opportunity 
by the leader to develop high quality LMX relationships. This may not only lead to higher productivity, but also affect the perceived fairness of differential LMX relationships within a work group (Scandura, 1999). However, Green, Anderson, and Shivers (1996) found that training did not lead to increases in the number or quality of LMX relationships in a sample of library employees.

Based on the assumption that all members should be offered an opportunity to develop a high quality LMX relationship with their leader, Graen and Uhl-Bien (1995) developed the leadership making model. The leadership making model is comprised of three chronologically based phases (i.e., stranger, acquaintance, and maturity). In the stranger phase, the relationship is characterized by contractual exchanges. That is, leaders only give followers what they need to perform and followers only do what is required of their job. These low quality LMX relationships are based on "unidirectional downward influence, economic behavior exchange, formal roledefined relations, and loosely coupled goals" (p. 232).

The offer and acceptance of an improved working relationship marks the transition from the stranger phase to the acquaintance phase. Either the member or the leader may make the offer. In this phase, there are increased social exchanges (versus contractual exchanges) and increases in resource sharing, however, there still exists an equitable return of resources and the time span of reciprocity is limited. In essence, the acquaintance phase is a testing phase of the relationship. Through successive interacts, mutual trust, respect, and obligation are developed in the relationship and movement toward the final phase of the leadership making model is made. Interestingly, if a particular dyadic relationship does not progress to the final phase, it is theorized that 
the dyad will eventually fall back to the first stage. Therefore, this testing phase is critical to the long-term quality of the LMX relationship.

The final phase of the leadership making model is the maturity phase. In this phase, leaders and followers are partners. Leaders can depend on followers to provide them with assistance when it is needed and followers can depend on leaders to provide them with support and career investments. Importantly, the partnership is based on mutual influence both in terms of direction and magnitude. Additionally, the interests of members in high quality LMX relationships moves beyond their own self-interest to larger mutual interests. For example, there may be internalization of common goals, followers may provide leadership to their work group to enhance productivity, and followers may be good organizational citizens (Graen, 1990).

One early caution of LMX theory concerned the possible inequity that members with low LMX relationships may perceive. In order to examine this possible consequence of LMX, it is useful to view a particular LMX dyad as one in a system of interdependent dyads (Graen \& Scandura, 1987). That is, one way in which members may perceive inequity is through social comparison. While it is possible that some internal standard of fairness may be violated in a low LMX relationship or in comparison to a prior working relationship, the most salient social comparisons are likely to be made with other LMX relationships of a person's leader.

Taking a multi-level, systems approach to LMX allows researchers to examine the possible effects of differential LMX relationships on a work group. Additionally, it is possible to ask several key research questions including, How do members of higher-quality LMX relationships and lower-quality LMX relationships within the 
same work group get along? How do differentiated LMX relationships with the same work group affect task performance? How do they affect attitudes of work group members (Forret \& Turban, 1996)? How many high-quality relationships can be supported within a single work group? Is there one 'best' combination/proportion of LMXs within a work group (e.g., some combination of highs and lows, all highs, etc.)? How do equity issues influence perceptions of relationships among work unit members (Scandura, 1999)?

While there are considerable differences among these approaches to LMX formation (e.g., Dienesch \& Liden, 1986; Graen \& Scandura, 1987; Graen \& UhlBien, 1995), there are also some fundamental similarities. First, both leaders and members bring into the relationship personal characteristics and experiences that will affect LMX quality. Second, leaders and members engage in an exchange relationship that is generally initiated by the leader via some form of delegation. Third, through a series of interacts over time LMX quality gravitates toward either a higher quality LMX characterized by high trust; loyalty, liking, support, respect, and exchange of resources or a lower quality LMX characterized by low levels of these same attributes. The LMX Relationship as a System

Lendaris (1986) defined "A system as a) a unit with certain attributes perceived relative to its external environment, and b) a unit that has the quality that it internally contains subunits and those subunits operate together to manifest the perceived attributes of the unit" (p. 604). There is a conceptually strong link between the definition of a system and LMX. The LMX dyad can be thought of as the "unit" described in part "a" of the definition above. The external environment of the unit, in 
the definition of a system, depends on the focus of study. Of interest here, is a specific LMX dyad within a set of dyads for a given leader (i.e., a work group). Consequently, the external environment of the LMX dyad is the work group. In terms of part " $b$ " of the definition above, each LMX dyad is comprised of two individuals who interact to manifest the attributes of the relationship. In essence, LMX is an emergent property of the characteristics (e.g., personality, background) and behaviors (e.g., performance, job assignments) of the leader and the member.

Graen and Uhl-Bien (1995) discussed LMX theory from a multi-level, multidomain perspective. Graen and Uhl-Bien argued that there are three domains of leadership: the follower, the leader, and the relationship. Many studies of leadership focus on one of these domains, and leadership researchers have been encouraged to develop studies that take a multiple domain perspective (Klein, Dansereau, \& Hall, 1994; Rouseau, 1985). Within each domain, Graen and Uhl-Bien asserted that different levels of analysis can be utilized. For example, it is possible to examine the LMX relationship at the individual level (How does the member perceive the LMX relationship?), the dyad level (What are the characteristics of the dyadic relationship?), the work group (How does the collective of LMX relationships operate in the work group?), or even larger units.

The multi-level perspective reflects many of the concepts contained in the definition of a system offered by Lendaris (1986) (Table 1). Using the conceptualization of system, in the discussion above, LMX was characterized as an emergent property of the characteristics and behaviors of the member and leader. Moving to the level of the work group, the units that comprise the system are the 
dyads and the system is the work group. Group characteristics such as group climate and productivity are the emergent properties of the collective of dyads of one leader.

\section{LMX Development and Systems Archetypes}

Senge (1990) described a set of systems archetypes that may be used to describe certain core aspects of the LMX development process. First, LMX research has shown that LMX relationships develop quickly in a new dyad and stabilize (Bauer \& Green, 1996; Liden et al., 1993). The interaction of the leader and member begins the growth of the LMX relationship. In the early phases of a high quality LMX, the relationship develops quickly. That is, trust, loyalty, liking increase rapidly as a result of the interaction between the leader and the member. However, there are several limiting conditions that will eventually slow the growth of the relationship. For example, the leader is likely constrained in how much time and resources she or he can commit to an individual (Green et al., 1996). The member, on the other hand, is limited by his/her ability, his/her time to invest in the job, and resources to invest in the relationship with the leader. This situation of rapid, early growth followed by slower growth over time is similar to Senge's presentation of the limits to growth system archetype. While Senge offered the Limits to Growth archetype (Figure 7) as a potential problem, there is nothing inherently harmful to a stable high quality LMX.

A fundamental purpose of the utility of LMX reflects a tragedy of the commons archetype (Senge, 1990; Figure 8). In the "tragedy of the commons" archetype, a shared and limited resource is used based solely on the needs of the individuals who have access to the resource. Therefore, while it is beneficial for each individual to use as much of the resource has he or she can, this behavior on the part of 
all individuals using the resource will result in either diminishing returns or exhaustion of the resource. One can view a leader's time as the shared and limited resource and each member as an individual user of the resource. If a leader has several members and each member desires a high quality LMX relationship, then it is quite possible that the shared resource would be depleted. In Figure 8, for example if only one member desired a high quality LMX, then he or she would expect an increase of some unit " $\mathrm{x}$ " in LMX for each positive interaction with the leader. However, if there are several such members, then this same member may see an increase of something less than " $x$ " for each positive interaction with the leader. In the worst case scenario, the resource is depleted to such a degree that no member would benefit from positive interactions with the leader in terms of quality of LMX. One advantage the leader has in avoiding the tragedy of the commons is that he or she has the opportunity to manage the commons (i.e., his or her time). LMX theory asserts that this is precisely what is happening when a leader develops differential relationships with members. Again, taking this systems perspective allows for the exploration of some critical research questions. For example, is there a best way to manage the commons in terms of supervisor satisfaction and performance, member satisfaction and performance, and work group satisfaction and performance? Additionally, Senge suggested that ideally, participants would design the mechanisms that manage the commons. This is akin to Graen and Uhl-Bien's (1995) recommendation that leaders offer all members the opportunity to develop high quality LMXs and then let the members decide, via their actions, if they want to a high quality LMX with their leader. 
While the current research is not focused on the development of LMX, the utilization of Senge's (1990) system archetypes provides a foundation for exploring the relationships between LMX, organizational justice, trust, and organizational and individual outcomes. The concept of building a general systems model and then applying that general model to the supervisor-subordinate relationship will also be used.

The Antecedents of LMX

Over the past 25 years, an extensive literature has developed regarding the antecedents of LMX (Liden et al., 1993). The antecedents of LMX include member ability (e.g., Day \& Crain, 1992; Dockery \& Steiner, 1990), demographic similarity (e.g., Bauer \& Green, 1996; Green et al., 1996), personality similarity (e.g., Bauer \& Green, 1996; Phillips \& Bedeian, 1994), and liking (Dockery \& Steiner, 1990; Wayne \& Ferris, 1990; Wayne, Liden, Graf, \& Ferris, 1997). Of particular interest here is prior research conducted in areas of individual performance, relational demography, and personality. Additionally, contextual variables that may affect LMX relationships (e.g., work group composition, leader resources, span of control, etc.) are highlighted.

\section{Member Performance}

Early LMX researchers believed that member performance was critical to the development of LMX (Dansereau et al., 1975; Graen \& Scandura, 1987). Recall that leaders evaluate member's ability after successive role making episodes (or interacts) as the LMX relationship develops. There is mixed empirical support for the relationship between member performance and LMX (Liden et al., 1997). For example, Bauer and Green (1996) and Liden et al. (1993) found positive relationships 
between leader assessments of members' performance and LMX when the two variables were measured at the same time, but found no predictive relationship between member performance and subsequent assessments of LMX. However, in the Liden et al. study, supervisor performance ratings were less predictive of LMX than leader perceived similarity and leader liking of the member. Deluga and Perry (1994) reported a positive relationship between member performance and LMX in a crosssectional study. However, Wayne and Ferris (1990) did not find a relationship between LMX and subordinate performance in a field study. Given the range of findings regarding the relationship between subordinate performance and LMX, more research is needed in this area. The present study contributes to this existing body of literature.

\section{Relational Demography}

Graen and Cashman (1975) proposed that relational demography (the degree to which individuals in the leader-member dyad are similar on demographic characteristics such as gender, ethnicity, age) may contribute to the leader's ingroup/out-group decision. Bauer and Green (1996) suggested that member similarity is important to leaders as a means to reduce uncertainty or risk in the delegation process. That is, delegation of responsibilities is important to managers and delegation to subordinates involves risk. Delegating to subordinates who are similar to a leader may have the effect of reducing the perceived risk in the delegation process due to a higher level of trust associated with others who are similar (Mayer et al., 1995). In a sample of Junior Achievement groups, Duchon, Green, and Tabor (1986) found that class status (i.e., junior, senior) and gender predicted in-group/out-group status in a 
longitudinal design. In contrast, Bauer and Green found no relationship between gender similarity and LMX in a diverse sample of adult employees using a longitudinal design. However, Bauer and Green found an indirect relationship between personality similarity and LMX.

Personality Similarity

Bauer and Green (1996) found that positive affectivity similarity predicted leader delegation to members which was then related to LMX. Positive affectivity is defined as an individual's tendency to feel enthusiastic, active, and alert (Watson, Clark, \& Tellegen, 1988). Similarly, Deluga (1998) found an indirect relationship between conscientiousness and LMX. Conscientiousness refers to an individual's disposition to be dependable, responsible, and organized (Barrick \& Mount, 1991). Conscientiousness similarity was directly related to supervisor reports of subordinates' performance. Performance was then related to higher quality LMX.

In summary, the existing research on the relationship between demographic similarity and LMX is equivocal and in need of further examination. The relationship between personality similarity and LMX appears fairly robust. However, Deluga (1998) and Bauer and Green (1996) called for more research examining the relationship between personality and LMX. For example, other than Deluga's incorporation of conscientiousness, no research has been published examining the relationship LMX and the Big Five personality characteristics in terms of leadermember similarity (i.e., openness to experience, agreeableness, extraversion, emotional stability, conscientiousness). The inclusion of trust as a dispositional 
construct in the present research extends the research to date on the relationship between personality and LMX.

\section{Contextual Factors}

Dienesch and Liden (1986) suggested that contextual factors, beyond the LMX dyad, might influence LMX development and quality. Liden et al. (1997) and Green et al. (1996) expressed concern that only three LMX studies have considered contextual variables. As defined by Liden et al., and Green et al. context is similar to that defined by Lendaris (1986). That is, there are characteristics in the environment in which a focal system (LMX dyad) operates that affect its behavior. Green and colleagues $(1983,1996)$ found that both unit size (i.e., the number of employees in a work group) and subordinate workload were negatively related to LMX. Additionally, Green et al. (1996) found a positive relationship between organizational resources (e.g., net income) and LMX. Kinicki and Vecchio (1994) found that the average LMX of a work unit was positively related to time stress perceived by the leader of the unit. These researchers argued that subordinates rallied around their supervisor and thus influenced the quality of LMX relationships in the work unit. While the effect of various contextual factors on LMX had been reported in these studies, there is a need for further research in this area.

LMX theorists have alluded to the possible impact of trust on LMX quality (e.g., Bauer \& Green, 1996; Dienesch \& Liden, 1986; Liden et al., 1997). As defined previously, trust refers to the expectation that a person will act in expected ways without monitoring (Mayer et al., 1995). High quality LMX is associated with generalized reciprocity where there is low equivalence in terms of what is exchanged 
(e.g., a leader may provide career development advice and the member may provide the leader with increased work effort), low immediacy (e.g., there may be a long time delay between exchanges), and a concern for the other person in the relationship (Liden et al., 1997). Trust, therefore, is theorized to be positively related to LMX. In a high quality LMX one person is trusting (i.e., expects) the other in the dyad to engage in the exchange process without being prodded or monitored. However, no empirical research exists which explicitly tests this relationship. Regarding the relationships between trust and LMX, the following hypotheses are offered (Figure 9): Hypothesis 2a: Members' trust in the leader is positively related to members' perceptions of the quality of LMX.

Hypothesis. 2b: Leaders' trust in the member is positively related to leaders' perceptions of the quality of LMX.

Similar to the research methodology utilized to examine Hypothesis 1, Hypothesis 2a was examined in both a field study and a laboratory study. Hypothesis $2 \mathrm{~b}$ was examined in a field study where both leaders and members report on trust in each other and LMX from their respective perspectives.

\section{The Consequences of LMX}

The consequences of LMX have been more extensively studied than the antecedents of LMX. Prior research has found that LMX is related to a host of important individual and organizational outcomes. Prior research has shown that LMX is positively related to organizational commitment (e.g., Duchon et al., 1986; Green et al., 1996), organizational citizenship behavior (e.g., Anderson \& Williams, 1996; Setton, Bennett, \& Liden, 1996), satisfaction with supervision (e.g., Duchon et al., 
1986), general satisfaction with work (e.g., Liden \& Maslyn, 1998; Vecchio \&

Gobdel, 1984), supervisory ratings of job performance (e.g., Graen, Novak, \& Sommerkamp,1982; Liden \& Maslyn, 1998; Scandura \& Schriesheim, 1994), rate of promotions (e.g., Wakabayashi \& Graen, 1984; Wakabayashi, Graen, Graen, \& Graen, 1988), and creativity (Tierney, Farmer, \& Graen, 1999). Importantly, with the exception of Liden and Maslyn (1998) all of these studies utilized a unidimensional measure of LMX, mostly some version of the LMX-7 (Gerstner \& Day, 1997). This review will focus on five of these outcomes, which are included in the model examined here: organizational citizenship behavior, organizational commitment, general job satisfaction, intention to quit, and performance ratings.

Overall Job Satisfaction

In terms of overall job satisfaction, a meta-analysis based on 33 samples revealed that the corrected correlation coefficient between LMX and job satisfaction was .50 (Gerstner \& Day, 1996). While this effect size is substantial, the empirical research is not unanimous. For example, Vecchio and Gobdel (1984) reported that middle-group members were more satisfied than out-group members, but in-group members did not report significantly higher job satisfaction than middle-group members. Liden and Maslyn (1998) found that the LMX dimension of contribution was the only LMX dimension significantly related to satisfaction with work. $\underline{\text { Satisfaction with Supervision }}$

LMX has generally been found to be positively related to satisfaction with supervision (Dansereua et al., 1975; Green et al., 1996; Vecchio and Gobdel, 1984; Vecchio, Griffeth, \& Hom, 1986). For example, Vecchio and Gobdel, using a 
trichotomy index of LMX quality (i.e., in-group, middle-group, and out-group), found that in-group members were more satisfied with supervision than middle-group members and middle-group members were more satisfied that out-group members: Utilizing the LMX-MDM, Liden and Maslyn reported a significant relationship between three dimensions of LMX (affect, loyalty, and professional respect) and satisfaction with supervision. However, some researchers have not found a relationship between LMX and satisfaction with the leader (e.g,, Duchon et al., 1986; Liden \& Graen, 1980). While these exceptions exist, the relationship between LMX and satisfaction with supervision appears to be significant and positive. Gerstner and Day (1997) summarized the results of 27 samples using meta-analytic techniques and found a corrected correlation coefficient between LMX and satisfaction with supervision of .71 .

\section{$\underline{\text { Organizational Commitment }}$}

Organizational commitment refers to the degree to which an employee feels a sense of loyalty to the organization (Allen \& Meyer, 1990). Liden and Maslyn (1998) reported a significant positive relationship between the contribution and professional respect dimensions of LMX and organizational commitment. Settoon et al. (1996) found that all four dimensions of the LMX-MDM correlated with organizational commitment, however, using structural equation modeling including perceived organizational support in the model, LMX was not related to organizational commitment. Similarly, Wayne et al. (1997) found that perceived organizational support was related to affective commitment and LMX was not. Tierney and Bauer (1996) found that LMX was related to subsequent organizational commitment in a 
longitudinal field study. Therefore the research results on the relationship between LMX and organizational commitment are mixed.

\section{Performance}

In a cross-sectional field study, Duarte, Goodson, and Klich (1994) found that supervisory ratings of member performance were positively related to LMX in new leader-member relationships (i.e., short tenure). However, for established dyads, there was no relationship between LMX and performance ratings. Dunegan, Duchon, and Uhl-Bien (1992) found that certain task characteristics moderated the relationship between LMX and member performance. Specifically, these researchers found that when tasks were routine or when tasks were high in uncertainty and challenge there was a significant relationship between LMX and performance. Vecchio and Gobdel (1984) found a positive relationship between supervisor ratings of member performance, but no relationship between LMX and two indicators of objective job performance. All of these studies utilized a unidimensional measure of LMX. Utilizing the multidimensional LMX-MDM measure, which they developed, Liden and Maslyn (1998) reported a positive relationship between member performance and the loyalty and contribution dimensions of LMX. In contrast, no relationship was found between member performance and the affect and professional respect dimensions of LMX.

\section{Organizational Citizenship Behavior}

Organizational citizenship behavior (OCB) is defined as those useful behaviors that employees contribute to the organization that are neither required nor expected (Bateman \& Organ, 1983). Organ (1988) proposed five dimensions to OCB: altruism, conscientiousness, courtesy, sportsmanship, and civic virtue. These dimensions vary 
primarily on the type of behavior exhibited by an employee. In contrast, Williams and Anderson (1991) suggested that OCBs can be distinguished in terms of the target of the behavior exhibited by the employee. OCBs directed at the organizational in general (OCBO) are one type of OCB. The second type of OCB is those behaviors directed at an individual (OCBI). Williams and Anderson suggested that the OCBO and $\mathrm{OCBI}$ labels are similar to the conscientiousness and altruism dimensions respectively. Settoon et al. (1996) and Wayne et al. (1993), using structural modeling techniques found that LMX was positively related to OCB. In a longitudinal field study, Tierney and Bauer (1996) found that member reports of LMX predicted subsequent leader reports of member OCB. In general, the relationship between LMX and OCB appears to be robust.

Organizational Retaliatory Behaviors

Due to their relative newness in the organizational behavior literature, a short review of the literature on organizational retaliatory behaviors, one of the outcome variables of the present research, is presented next. As noted in the introduction, considerable media attention has been given to dramatic and terrible episodes of workplace violence (e.g., disgruntled employees killing co-workers). In a survey of 1,016 human resource professionals, the Society for Human Resource Management (1996) found that $48 \%$ of the respondents indicated that a violent incident had occurred at their workplace between 1994 and 1996. In a similar survey conducted in 1993 , only $33 \%$ of respondents reported that a violent incident had occurred between 1988 and 1993. However, statistics show a decline in workplace homicides in recent years (Smoyer \& Way, 2000). 
Additionally, these incidents are relatively rare and are very difficult to research. For example, according to the United States'Bureau of Justice Statistics, between 1992 and 1996 approximately 1.5 million incidents of workplace violence were reported annually (ranging from assault to homicide) in a workforce of over 140 million (Warchol, 1998). Some researchers have suggested that the range of behaviors individuals who believe they have been aggrieved engage in is varied and extensive (e.g., Bies \& Tripp, 1996; Robinson \& Bennett, 1995). Several researchers have argued that any perceived inequity in the workplace may lead an employee to engage in behavior that is harmful to those people in the organization that are perceived as responsible for the injustice (e.g., Aram \& Salipante, 1981; Bies, Tripp, \& Kramer, 1997; Wall \& Nolan, 1987). Homans (1961) argued that when a person feels unfairly treated by an entity more powerful (e.g., an organization or supervisor) than him/her, attempts to restore equity are more likely to be indirect than direct. Organizational retaliatory behavior (ORB) is generally conceptualized as a set of negative behaviors that employees engage in to punish an organization, its members, or both in response to some perceived injustice (Skarlicki \& Folger, 1997).

Robinson and Bennett (1995) provided the first attempt to classify an extensive set of deviant behaviors that mirror the concept of ORB. Employee deviance is defined as "voluntary behavior that violates significant organizational norms and in so doing threatens the well-being of an organization, its members, or both" (Robinson \& Bennett, 1995, p. 556). Based on responses from a variety of people (i.e., students, employees, and general citizens), these researchers developed a two dimensional typology of ORBs. Robinson and Bennett found that ORBs varied on the seriousness 
(i.e., serious and minor) of the behavior and the target (i.e., the organization or an individual) of the behavior. The finding that deviant behavior can be targeted at the organization or an individual is similar to Williams and Anderson's (1991) finding of OCBs directed at either the organization or an individual. Consequently, there are four general types of ORB. First, there are serious ORBs directed at the organization, termed "property deviance". These ORBs include sabotaging equipment and stealing from the company. Second, there are minor ORBs directed at the organization, called "production deviance". Behaviors in this category include leaving work early and intentionally working slow. Third, there are minor ORBs directed at individuals. This category includes gossiping about co-workers and showing favoritism. Lastly, there are behaviors that are serious and directed at an individual. These behaviors include sexual harassment and verbal abuse.

In continuing their research stream, Bennett and Robinson (2000) developed two scales to measure workplace deviance. One scale was designed to assess behavior that could harm the organization. A second scale was designed to tap behavior that could harm individuals in the organization. In support of the construct validity of these two scales, the authors generally found expected relationships between the two deviance scales and organizational justice, frustration, and organizational citizenship behaviors. However, the correlation between the two scales was high $(\underline{r}=.64)$.

\section{Precursors of ORB}

Skarlicki and Folger (1997) found that organizational justice was related to the incidence of ORB in a sample of manufacturing employees. Specifically, they found that distributive justice was negatively related to ORB only when both procedural and 
interactional justice were low. These researchers developed a 17-item behavioral observation scale using the critical incident technique (Flanagan, 1954) to measure ORB.

In a follow-up study using data reported in Skarlicki and Folger (1997), Skarlicki, Folger, and Tesluk (1999) found that negative affectivity and agreeableness (two personality variables) moderated the relationship between organizational justice perceptions and ORB. Specifically, employees high in negative affectivity or low in agreeableness were more likely to engage in ORB in the presence of perceived injustice.

In contrast to OCBs (i.e., discretionary behaviors that help an organization function), ORBs are discretionary behaviors that may have the effect of being harmful to an organization, its members, or both. ORBs represent a set of behaviors that workers may engage in to "right a wrong". As such, they warrant examination as a potential negative outcome of low quality LMX and low perceptions of organizational justice. To date, no research has been published that examines the relationship between LMX and ORBs.

\section{Expected Relationships between LMX and the Outcome Variables}

In Chapter Four of the present dissertation, it is hypothesized that distributive and procedural justice mediate the relationship between LMX and the outcome variables. The first step in examining this mediator effect is to determine if there are relationships between LMX and the outcome variables. Therefore, I expect to find the following relationships between LMX and the outcome variables.

LMX is positively related to members' overall job satisfaction. 
LMX is negatively related to members' intention to quit.

LMX is positively related to organizational commitment.

LMX is positively related to members' job performance.

LMX is positively related to members' organizational citizenship behavior directed at the organization.

LMX is positively related to members' organizational citizenship behavior directed at an individual.

LMX is negatively related to members' organizational retaliatory behaviors.

\section{LMX Summary}

While there is continuing debate on the precise nature of LMX (Gerstner \& Day, 1997), there is considerable evidence that LMX, an indicator of the quality of the relationship between a supervisor and a subordinate, is related to a host of important individual and organizational outcomes. However, some significant questions remain. For example, is a poor quality LMX related to a member's propensity to engage in behaviors harmful to the organization or organizational personnel? What is the role of trust, dispositional and person-specific, in LMX quality? Do members' perceptions of fair treatment affect LMX quality? One component of the leader-member relationship that has been heavily researched, but not in relation to the quality of LMX relationships specifically, is organizational justice. Similar to LMX, organizational justice has its theoretical roots in social exchange theory. 
Table 1

$\underline{\text { LMX dyad as a system in Lendaris' (1986) framework. }}$

\begin{tabular}{|c|c|c|c|}
\hline Perceptual Level & Suprasystem & System & Subsystem \\
\hline A & Department & & \\
\hline B & Workgroup & Workgroup & \\
\hline C & Dyad & Dyad & Dyad \\
\hline D & & Individual & Individual \\
\hline E & & & Individual \\
& & & Characteristics \\
\hline
\end{tabular}


Form of Reciprocity

$\begin{array}{lccc}\text { Dimension } & \text { Negative } & \text { Balanced } & \text { Generalized } \\ \text { Equivalence } & \text { High } & \text { High } & \text { Low } \\ \text { Immediacy } & \text { High } & \text { High } & \text { Low } \\ \text { Interest } & \text { Self-interest } & \text { Mutuality } & \text { Concern for Other }\end{array}$

Figure 6. Sahlins' (1972) Continuum of Reciprocity. 


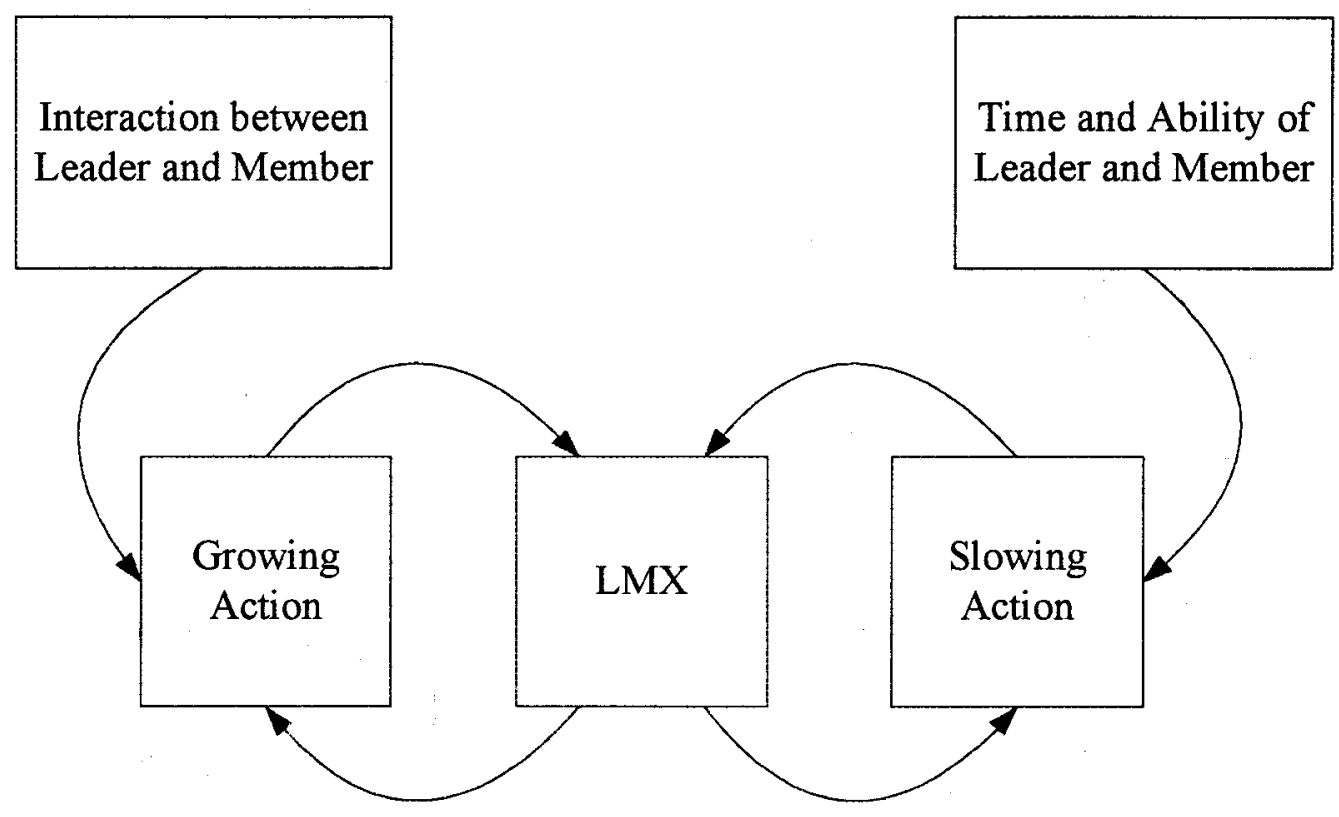

Figure 7. Limits to Growth Archetype within the context of leader-member exchange. 


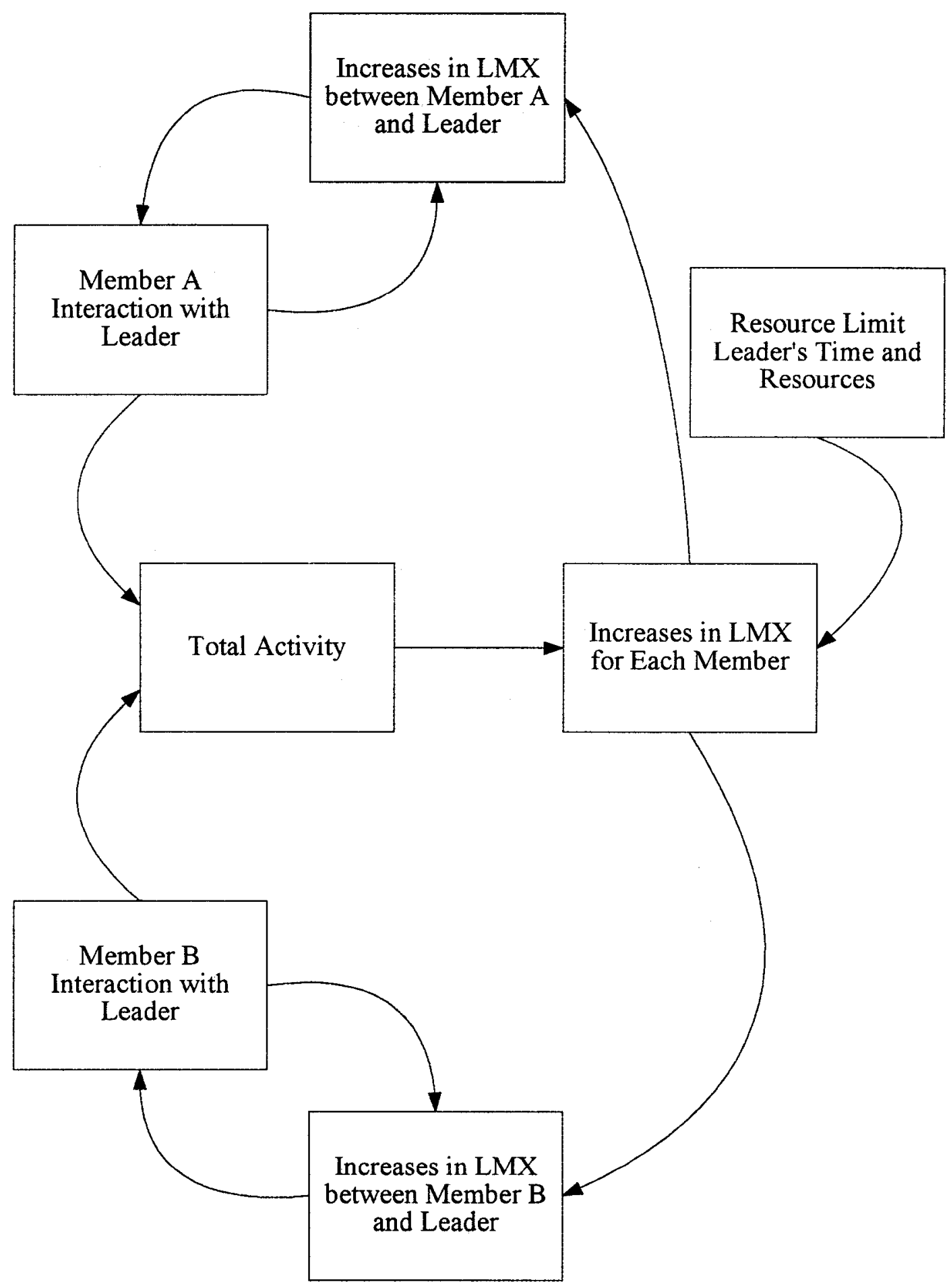

Figure 8. Tragedy of the Commons Archetype within the context of leadermember exchange. 


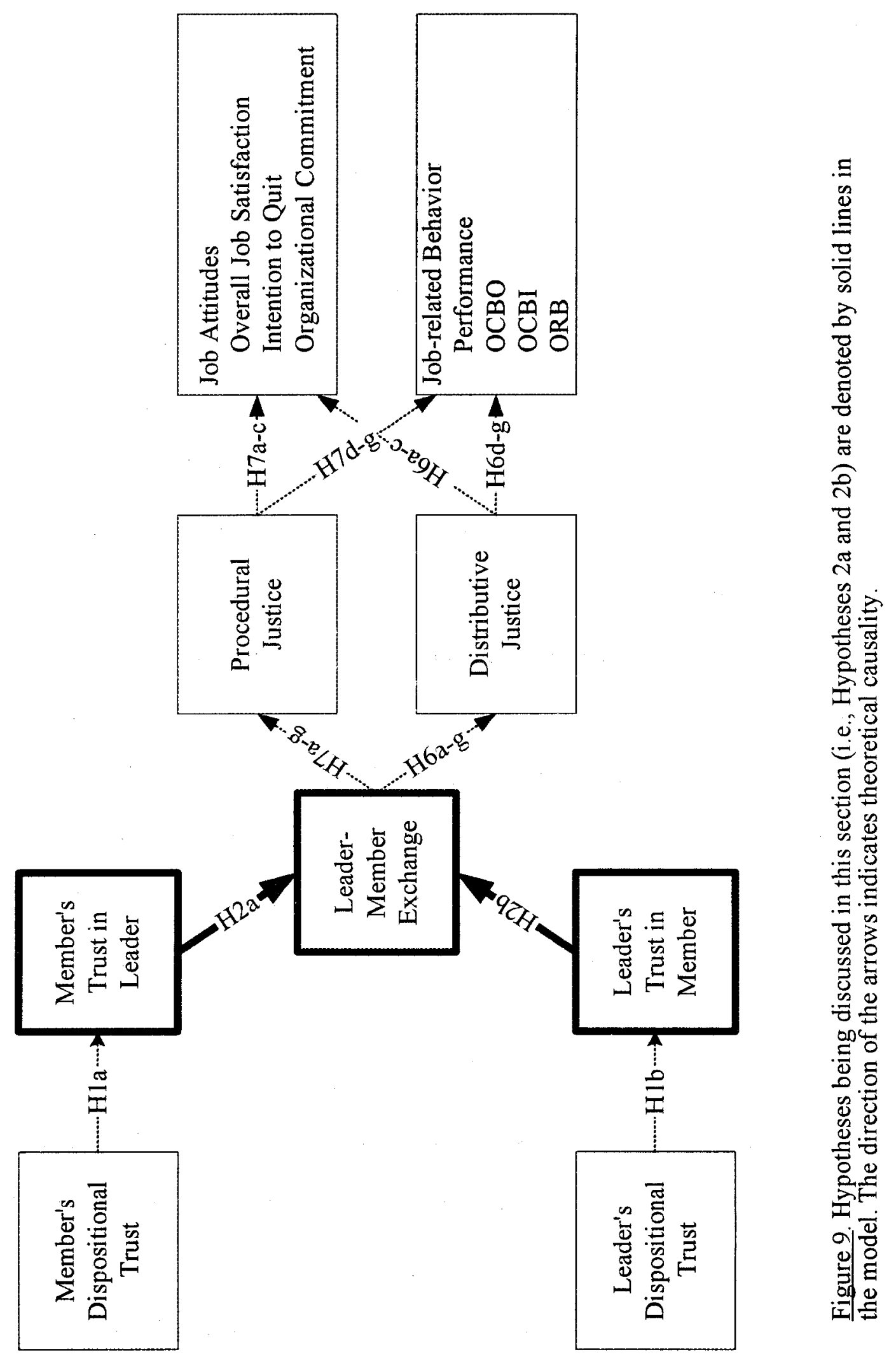


Chapter Four

\section{Organizational Justice}

Theories of organizational justice are based in the theory of inequity in social exchange (Adams, 1965). Adams theorized that employees continually evaluate the perceived fairness of the exchange of the relationship between their organizations and themselves. In order to evaluate the fairness of the relationship, a process of social comparison is utilized. For example, Employee A, in evaluating the fairness of his or her relationship with the organization will compare his or her ratio of inputs (e.g., job effort, organizational citizenship behaviors, time) to outcomes (e.g., pay, status) to the perceived ratio of inputs to outcomes of comparison others (e.g., co-workers of the same rank). It is also possible for Employee A to use some internal standard or set of expectations for the input/outcome ratio in determining the fairness of the relationship.

Kramer (1996) echoed the idea that employees continually and rather vigilantly monitor the fairness of the exchange relationship. Homans (1961) further argued that those in the lower power position (i.e., subordinate or member) are more concerned with the fairness of the relationship than those in the higher power position are.

In comparing one's input/outcome ratio to others' it is possible for either advantageous or disadvantageous inequity to exist. If an employee perceives that his outcomes are greater that his inputs (i.e., an advantageous ratio), the relationship is inequitable and the employee may feel guilty and work harder to restore equity (Adams, 1965; Mowday, 1996). In terms of the theoretical underpinning of LMX development, it can be argued that partners in high quality LMX relationships 
participate in an increasing cycle of inputs in order to avoid feelings of discomfort (e.g., guilt, indebtedness). Theoretical arguments (Adams, 1965; Homans, 1961) and empirical evidence (Lind \& Tyler, 1988; Thibaut \& Walker, 1975), however, suggested that the perception of advantageous inequity and subsequent feelings of guilt are not likely to occur. These results are found in relation to non-personal outcomes such as pay or status. Therefore, the focus of most organizational justice research has been on reactions to disadvantageous inequity.

Regardless of the type of the perceived inequity, Adams (1965) suggested that there were primarily two sets of actions one could take to alleviate perceived inequity. Adams termed one set of these responses altering. In essence, altering occurred when a person actually altered one or more terms in the equity equation. For example, actually changing one's inputs (e.g., putting in less effort, lowing productivity) or outputs (e.g., increasing pay or status) or changing the comparison other's inputs (e.g., making him or her work harder) or outputs (e.g., pay, benefits) may bring the equity equation into equilibrium.

Organizational citizenship behaviors (OCB) may be a set of behaviors that have the effect of reducing one's input and increasing the input of the comparison other. Organ (1990) defined OCBs as "those organizationally beneficial behaviors and gestures that can neither be enforced on the basis of formal role obligations nor elicited by contractual guarantee of recompense" (p. 44). When a member reduces OCBs from which the leader benefits (e.g., volunteering for special assignments, working overtime), this action reduces the member's input and may increase the leader's and/or coworkers' input. 
The second set of responses Adams (1965) suggested that people may use to resolve inequity involves cognitive distortion. That is, a person may change how they perceive their own inputs or outcomes or a comparison others' inputs or outcomes: For example, in the LMX context, one may initially perceive as unfair the treatment another member in the work group with a high quality LMX receives. One way to resolve the inequity would be to say to oneself, "But look at how often that other person stays late at work to help out the boss. I'm glad I don't have to do that." This response requires a cognitive change regarding the comparison other's inputs and has the effect of reducing the perceived inequity.

\section{The Psychological Contract}

A second approach to the broad issue of fairness in organizations is termed the psychological contract. The psychological contract refers to an individual's beliefs about the terms of the reciprocal exchange obligations between that person and another party (e.g., employer) (Rousseau, 1989). As such, the research in psychological contracts is also rooted in social exchange theory (Blau, 1964; Homans, 1961).

Utilizing MacNeil's (1985) typology of contracts, Robinson, Kraatz, and Rousseau (1994) defined two types of psychological contracts: transactional and relational. Transactional contracts are characterized as "monetizable" (e.g., wages, benefits) and generally have a finite and brief time horizon. Relational contracts, in

contrast, are more open-ended, less specific agreements between two parties. These two types of contracts mirror Blau's (1964) concepts of economic and social exchange relationships presented earlier. 
Organizational Justice

The predominant framework for exploring issues of faimess in the work place has been organizational justice (Greenberg, 1990a). Folger and Cropanzano (1998) posited that justice deals with how two or more actors relate to one another in exchange situations. The term "actors" is broadly defined to include individuals or other social units (e.g., work organization). Additionally, because something is exchanged, a resource of some sort is implied. Resources are again broadly defined and can be economic or socioemotional. There is literature developing on the antecedents and consequences of organizational justice (e.g., Aquino, 1995; Schaubroeck, May, \& Brown, 1994). While there are potential philosophical concerns with using the terms "fairness" and "justice" interchangeably (Folger \& Cropanzano), the terms are used interchangeably here, which is consistent with the industrial and organizational psychology literature (e.g., Folger \& Cropanzano).

The perceived faimess of an outcome (e.g., treatment by a supervisor, personnel selection decision, promotion) is theorized to be composed of two distinct constructs: procedural justice and distributive justice. Additionally, there is some debate about the existence of a third type of justice - interactional justice. Procedural justice deals with one's sense of whether or not the "methods, mechanisms, and processes" (Folger \& Cropanzano, 1998, p. 26) by which an outcome was determined were fair. For example, in the personnel selection context, were the selection processes used to hire new employees (e.g., written knowledge test, interview, personality test) fair? In the context of LMX, was the process by which leaders determined the allocation of resources fair (e.g., promotions, scheduling, performance appraisal 
ratings, pay raises)? A substantial amount of research has shown that procedural justice affects a number of individual and organizational outcomes. These empirical findings are reviewed later.

Folger and Cropanzano (1998) argued that one aspect of the social relationship between an employee and their supervisor or organization that significantly affects perceptions of procedural fairness is the notion of process control (Thibaut \& Walker, 1975) or voice (Folger, 1977). Thibaut and Walker distinguished between process control and decision control in outcome decision-making. In pay raise decisions, for example, a supervisor may have ultimate decision control in terms of the amount an individual receives (i.e., decision control). However, what kind of information the supervisor uses, how that information is gathered and from whom (i.e., everything that happens before the decision is made or process control) may include individual employees. The importance of providing employees with process control has been well documented (e.g., Folger \& Konvosky, 1989; Folger, Rosenfeld, Grove, \& Corkran, 1979; Lind \& Tyler, 1988). The fundamental finding in these studies is that when employees feel that the decision making process is fair, they are more tolerant "about the consequences of the process" (Folger \& Cropanzano, 1998, p. 32). One explanation for this finding is that if employees believe that the processes used to make decisions regarding outcomes that are important to them are fair, then over the long run, they should receive what they believe they deserve.

Distributive justice deals with whether or not the actual distribution of an outcome (e.g., being hired for a job, a pay raise) is perceived as fair. Folger and Cropanzano's explication of distributive justice is based strongly in Adam's (1964) 
equity theory. In the context of LMX, one may ask the question, do members who deserve to have high quality LMX relationships with the leader have them and those who do not deserve them not have high quality LMX relationships? There is less research on distributive justice than on procedural justice in the $\mathrm{I} / \mathrm{O}$ literature, however, some relationships between distributive justice and individual and organizational outcomes have been found. These findings are explored more fully later.

Bies (1987) argued that in addition to the distributive and procedural aspects of justice, the manner in which outcomes were communicated to organizational members was important. The term interactional justice "refers to social conduct with implications for other people's dignity" (Folger \& Cropanzano, 1998, p. 29). That is, there is something about how a message is communicated to an individual and the attributions the receiver makes regarding responsibility for the communicated outcome that influences the perceived fairness of the outcome. However, these researchers have subsequently changed their position (Tyler \& Bies, 1990). In fact, most researchers view interactional justice as a component of procedural justice (e.g., Cropanzano \& Greenberg, 1997).

Having reviewed the basic theoretical foundation of organizational justice and defined the core components of organizational justice (i.e., procedural and distributive), the antecedents and consequences of organizational justice are reviewed next. 
The antecedents of procedural and distributive justice are rather subjective. Folger and Cropanzano (1998) comment that "equity - like beauty - is in the eye of the beholder" (p. 3). As discussed earlier, organizational justice theory is based in equity theory and what is essential to judgments of fairness in the social exchange process is the perceptions of the individuals involved.

Tyler (1994) argued that procedural and distributive justice had unique antecedents based on the underlying motive for justice. The first motive reflects a resource based model of justice (e.g., Talyor \& Moghaddam, 1987; Walster, Walster, \& Berscheid, 1978). This model assumes that people act in ways "to maximize their own resource gains in interactions with others" (Tyler, 1994, p. 851). A second approach to the justice motive involves a relational model (e.g., Lind \& Tyler, 1988; Tyler \& Lind, 1992). This model asserts that what drives the justice motive is a concern about the social bonds between the individual and other people, groups, larger institutions, and group authorities. A fundamental assumption of the relational model is that people are predisposed to belong to social groups (Tyler, 1994).

In a sample of people from diverse work settings, Tyler (1994) tested the hypothesis that distributive and procedural justice had different antecedents. Using structural equation modeling, Tyler found that two resource variables, outcome level (i.e., satisfaction with the outcome they received) and expectancy violation (i.e., how discrepant their outcome was relative to their expected outcome), were related to distributive justice and not to procedural justice. He also found that four relational variables, process control (i.e., how much control an employee had in presenting 
information to their supervisor), neutrality of the supervisor, trust in the

supervisor's motives, and the degree to which the supervisor treated the employee with respect and politeness, were related to procedural justice. Interestingly, neutrality and trustworthiness also were related to distributive justice perceptions. Tyler concluded that while distributive and procedural justice have different antecedents, relational concerns dominated judgments regarding both distributive and procedural justice.

Two other models stipulating several other determinants of procedural justice tend to converge (i.e., Greenberg, 1986; Leventhal, 1980). Leventhal's taxonomy of justice was developed to apply to a wide array of settings. He suggested that procedural justice had six determinants. The degree to which a procedure was applied in the same manner across people and over time to the same person was termed consistency. The second determinant was called bias suppression. Bias suppression was defined in terms of the ability of the decision-maker to be a disinterested party and not be guided by prior beliefs. The third determinant was the degree to which accurate records of the inputs of people were recorded (i.e., accuracy of information). Fourth, if the procedure included some mechanism for correcting poor decisions (i.e., correctability) then perceptions of procedural justice would be enhanced. Fifth, procedural justice perceptions would be increased if the allocation process reflected the interests of those affected by the outcome decisions (i.e., representativeness). Lastly, the degree to which an allocation process is congruent with one's own standards of ethics would also increase perceptions of procedural justice. 
Greenberg (1986) developed a similar taxonomy within the context of

performance appraisal. Interestingly, his five determinants mapped onto Leventhal's constructs very closely with an emphasis on the accuracy of information determinant. Greenberg's five determinants were: soliciting and using input prior to evaluation; two-way communication during the appraisal discussion; ability to challenge the evaluation; rater familiarity with ratee's work; consistent application of performance standards.

Distributive justice judgments are based on one of three major rules (Gilliland, 1993; Leventhal, 1980; Lind \& Tyler, 1988): Equity, equality, and need. The equity rule is most frequently studied in the organizational behavior literature (Gilliland, 1993). The equity rule states that an individual's distributive justice judgments are based on a comparison of one's inputs to one's outcomes compared to some standard of fairness (Adams, 1965). For example, pay raises may be based on the relative contribution of employees to organizational priorities. The equality rule states that outcomes are distributed equally to all people (Leventhal, 1980). For example, the same pay raise is expected to be given to all employees. Leventhal suggested that the equality rule may be more salient in circumstances when group harmony is highly valued. The third distributive justice rule is based on individual need. That is, outcomes should be distributed in a way to meet the unique needs of each individual. Applying the pay raise example, it may be considered fair if employees with the most need (e.g., new family member, illness in the family) received the highest pay raises. Consistent with most organizational behavior research, the focus of this study is the equity rule. 
Consequences of Organizational Justice

Prior research shows that organizational justice is related to a number of important individual and organizational outcomes. Judgments of fairness are related to organizational commitment (e.g., Folger \& Konovsky, 1989; McFarland \& Sweeney, 1992), performance (e.g., Konovsky \& Cropanzano, 1991; Lind, Kanfer, \& Earley, 1990), OCB (e.g., Moorman, 1991; Niehoff \& Moorman, 1993; Organ \& Moorman, 1993), and job satisfaction (e.g., Konovsky \& Cropanzano, 1991; McFarland \& Sweeney, 1992).

Several studies have shown that issues of procedural justice (e.g., opportunities of employees to express their views) are strongly related to justice perceptions of performance appraisals in work settings (e.g., Dipboye \& de Pontbraind, 1981; Landy, Barnes, \& Murphy, 1978) regardless of the performance appraisal outcome. The finding that procedural justice correlates with personal and organizational outcomes regardless of the allocation of resources is frequently referred to as the fair process effect (e.g., van den Bos, Lind, Vermunt, \& Wilke, 1997). These researchers argued and found evidence in two studies that individuals may not have comparison information on which to base distributive justice perceptions because they only know their personal outcome, therefore, they rely on their understanding of the procedures by which outcomes are distributed (i.e., procedural justice).

As alluded to previously, several studies have examined the relative strength of the relationship between procedural justice and distributive justice to various organizational and individual outcomes. Lind and Tyler (1988), following logic offered by Leventhal (1980), suggested that procedural justice would have a stronger 
effect on attitudes about a group, institution, or leader than on attitudes about a specific outcome. For example, Sweeney and McFarlin (1993) in a field study of engineers found that distributive justice was related to individual-level perceptions of pay satisfaction (i.e., an attitude about a specific outcome) while procedural justice was related to organizational commitment (i.e., an attitude about the organization). Similarly, McFarlin and Sweeney (1992) found that distributive justice was more highly correlated with the personal outcomes of pay satisfaction and job satisfaction than procedural justice was. Lastly, in a field study, Folger and Konovsky (1989) asked employees to think about the most recent pay raise decision their supervisor made. These researchers found that perceptions of distributive justice were related to satisfaction with pay and procedural justice was related to organizational commitment and trust in their supervisor.

In reviewing the literature, Organ and Moorman (1993) argued that procedural and interactional justice are related to OCB while distributive justice is not. For example, Moorman (1991) found in a field study using structural equation modeling that there was a positive relationship between procedural justice and four of five dimensions of OCB. In contrast, distributive justice was not related to any dimension of OCB. Aquino (1995), however, found that both procedural justice and distributive justice (i.e., pay inequity) were related to two dimensions of OCB (i.e., compliance and altruism).

Given the robust findings to date, the following hypotheses are made regarding the relationship between organizational justice and the outcome variables of interest in 
the present research (Figure 10). These hypotheses were examined in both a field setting and a laboratory setting.

Hypothesis 3a: Distributive justice is positively related to members' job satisfaction. Hypothesis 3b: Distributive justice is negatively related to members' intention to quit. Hypothesis 3c: Distributive justice is positively related to members' organizational commitment.

Hypothesis 3d: Distributive justice is positively related to members' job performance. Hypothesis 3e: Distributive justice is positively related to members' organizational citizenship behavior directed at the organization.

Hypothesis 3f: Distributive justice is positively related to members' organizational citizenship behavior directed at an individual.

Hypothesis 3g: Distributive justice is negatively related to members' organizational retaliatory behavior directed at an individual.

Hypothesis 3h: Distributive justice is negatively related to members' organizational retaliatory behavior directed at the organization.

Hypothesis 4a: Procedural justice is positively related to members' job satisfaction. Hypothesis 4b: Procedural justice is negatively related to members' intention to quit. Hypothesis 4c: Procedural justice is positively related to members' organizational commitment.

Hypothesis 4d: Procedural justice is positively related to members' job performance. Hypothesis 4e: Procedural justice is positively related to members' organizational citizenship behavior directed at the organization. 
Hypothesis 4f: Procedural justice is positively related to members' organizational citizenship behavior directed at an individual.

Hypothesis 4g: Procedural justice is negatively related to members' organizational retaliatory behavior directed at an individual.

Hypothesis 4h: Procedural justice is negatively related to members' organizational retaliatory behavior directed at the organization.

The Interaction of Procedural and Distributive Justice

Although these direct relationships between organizational justice and outcomes are hypothesized to exist, the interaction between procedural justice and distributive justice must also be considered. There is considerable empirical evidence that suggests that when distributive and procedural justice are examined together, positive outcomes are most affected by procedural justice when distributive justice is low (Brockner \& Siegel, 1996; Colquitt, Conlon, Wesson, Porter, \& Ng, 2001; Figure 11). Additionally, there is some evidence that suggests distributive justice affects ORB when both procedural and interactional justice are low (Skarlicki \& Folger, 1997; Skarlicki, Folger, \& Tesluk, 1999).

McFarlin and Sweeney (1992) found that a procedural justice and distributive justice interaction predicted organizational outcomes (i.e., organizational commitment and subordinate's evaluation of the supervisor). Specifically, the combination of low procedural justice and low distributive justice were related to the lowest ratings of organizational outcomes.

Greenberg (1986) found no procedural justice effect when the referent outcome was positive (i.e., a positive performance appraisal). That is, only when the 
outcome was negative did procedural justice tactics enhance perceptions of distributive justice and satisfaction with the outcome. Lind and Tyler (1988) proposed that perhaps when the outcome is positive, there is a ceiling effect in terms of affective responses to the organization. However, these researchers correctly point out that the procedural justice effect occurs in those situations in which it is most needed, when employees may withhold useful behaviors (e.g., organizational citizenship behaviors) or participate in retaliatory behaviors harmful to the organization (e.g., Shapiro, Trevino, \& Victor, 1995; Skarlicki, Folger, \& Tesluk, 1999). In other words, in the absence of a fair process, a negative outcome is more likely to lead employees to withhold OCBs and engage in organizational retaliatory behaviors.

Bies, Martin, and Brockner (1993) in a field study of 147 workers who had been notified of their upcoming termination found that the perceived fairness of the layoff process was significantly related to OCB. In particular, the perceived adequacy of the explanation provided for the layoffs and the degree to which employees were treated with dignity and respect (i.e., interactional justice) predicted the perceptions of faimess of the process. The importance of explaining the reasons for a negative outcome was also demonstrated in a field experiment by Schaubroeck et al. (1994). An explanation of the fairness of a decision to freeze pay mitigated the relationship between the pay freeze and turnover intentions and procedural justice.

The research on organizational justice in the workplace suggests that as long as the procedures used in making organizational decisions are perceived as fair, then the perceived fairness of any one outcome is not as salient to employees. In other words, procedural justice moderates the effects of distributive justice. In reviewing the 
literature, Brockner and Wiesenfeld (1996) found this interaction effect in 45

studies. Specifically, three results emerged from their analysis of these studies. First, when distributive justice is low (or, low outcome favorability), then the relationship between procedural justice and individuals' reactions to the decision is particularly strong. Second, when procedural justice is low, then distributive justice is more likely to be positively related to individuals' reactions to the decision. Lastly, individuals are likely to react extremely negatively to a decision when both distributive justice and procedural justice are low.

Given the empirical support for the interaction shown in Figure 11, the following hypotheses are made (Figure 12): For participants who report low procedural justice there is a stronger positive relationship (vis-à-vis those who report high procedural justice) between distributive justice and overall job satisfaction (Hypothesis 5a), organizational commitment (Hypothesis 5c), member performance (Hypothesis 5d), organizational citizenship behavior directed at the organization (Hypothesis 5e), organizational citizenship behavior directed at an individual (Hypothesis 5f), and a stronger negative relationship to intention to quit (Hypothesis 5b), ORBI (Hypothesis 5g), and ORBO (Hypothesis 5h). These hypotheses were examined in both a field study and a laboratory study. Additionally, in the laboratory study, both distributive justice and procedural justice were manipulated so that it was possible to examine the potential causal effects of this interaction on the outcomes. This hypothesis explained in more detail in the introduction to Study One.

One of the contributions of the present study was that it examined both LMX and organizational justice together. The next set of hypotheses concern the mediating 
effect of organizational justice on the relationship between LMX and various

personal and organizational outcomes (Figure 13). Scandura (1999) argued that procedural and distributive justice mediate (i.e., account for a significant amount of variance in) the relationship between LMX and member performance and potentially a host of other individual and organizational outcomes. The hypothesized relationships between LMX, perceptions of organizational justice, and the various outcome variables are explicated next.

High perceptions of distributive justice indicate that a member accepts the distribution of resources and sees the distribution as fair. Therefore, regardless of the quality of LMX, the member perceives the employment exchange as fair and performance should not be affected. Again, the present model extended this logic to other individual and organizational outcomes. It is hypothesized that members' perceptions of distributive justice mediate the relationship between LMX and outcomes (Figure 14). That is, when both LMX and distributive justice are examined simultaneously, the relationship between LMX and employee attitudes and behaviors is substantially reduced or eliminated. This result would suggest that LMX operates through perceptions of distributive justice, rather than having a direct effect on employee attitudes and behaviors. The following hypotheses are offered. Distributive justice mediates the relationship between LMX and overall job satisfaction (Hypothesis 6a), intention to quit (Hypothesis 6b), organizational commitment (Hypothesis 6c), member performance (Hypothesis 6d), and organizational citizenship behavior directed at the organization (Hypothesis 6e) and at an individual (Hypothesis 6f), ORBI (Hypothesis 6g), and ORBO (Hypothesis 6h). 
Hypothesis 6 was examined before and after a manipulation of distributive justice in a laboratory setting and using cross-sectional data collected in a field setting. Scandura (1999) applied the same reasoning provided for the mediating effect of distributive justice to procedural justice. Therefore, the following hypotheses are offered. It is hypothesized that procedural justice perceptions mediate the relationship between LMX overall job satisfaction (Hypothesis 7a), intention to quit (Hypothesis 7b), organizational commitment (Hypothesis 7c), member performance (Hypothesis 7d), and organizational citizenship behavior directed at the organization (Hypothesis 7e) and at an individual (Hypothesis 7f), and organizational retaliatory behavior directed at an individual (Hypothesis $7 \mathrm{~g}$ ) and the organization (Hypothesis $7 \mathrm{~h}$ ). This set of hypotheses was also tested in laboratory and field settings. 


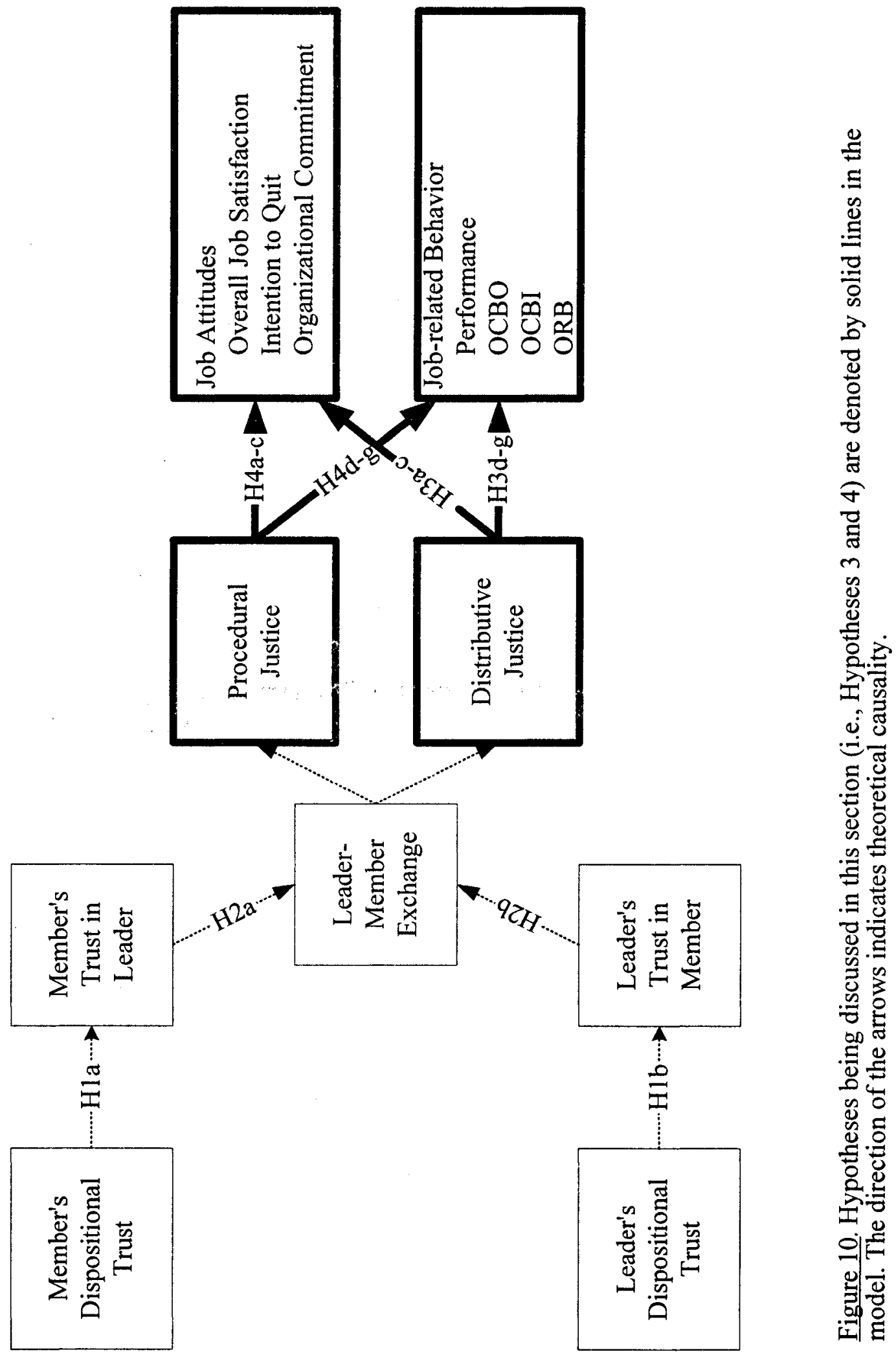




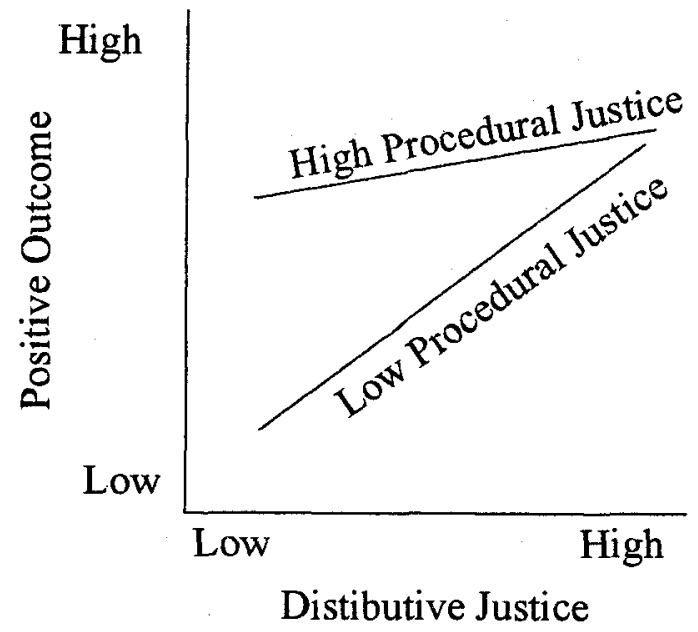

Figure 11. Common interaction found between procedural justice and distributive justice. 


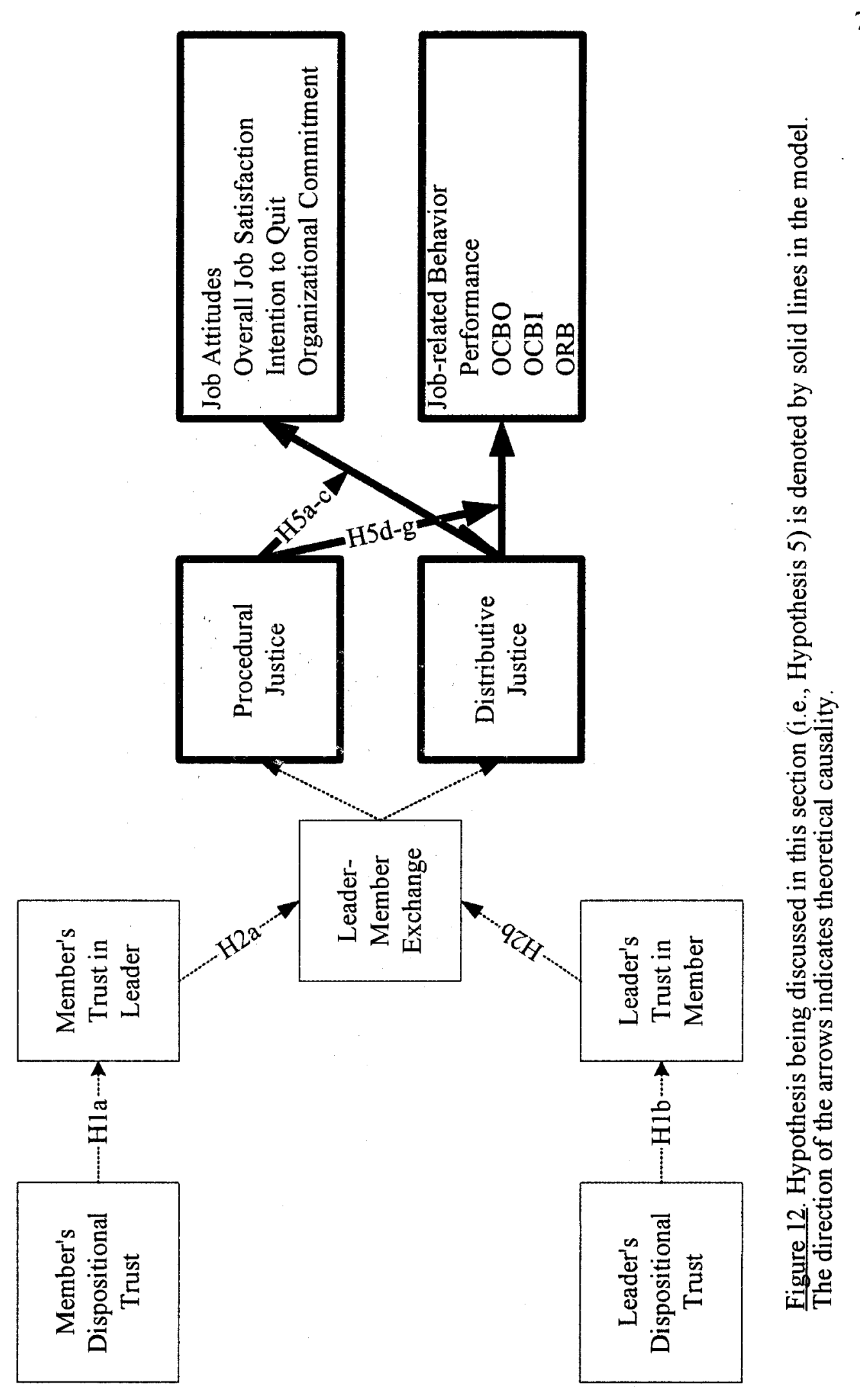




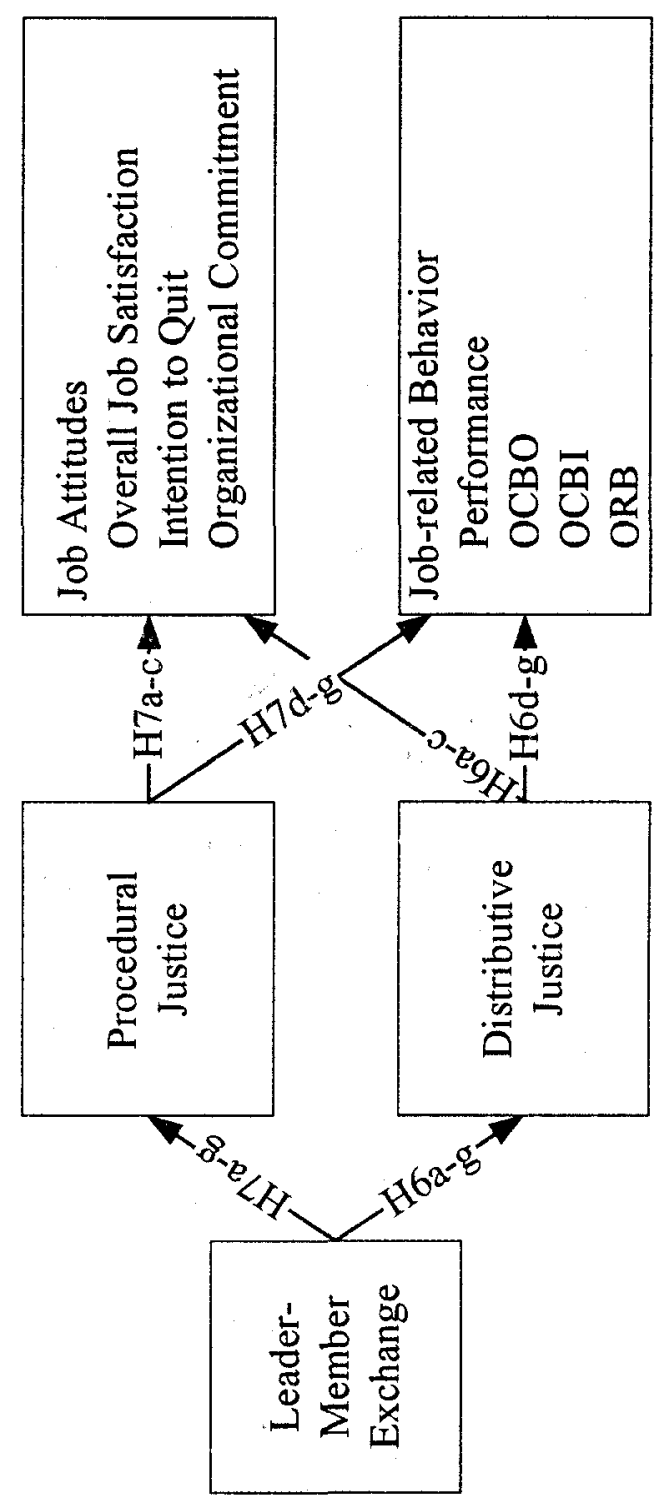

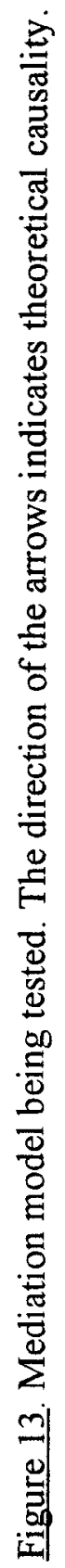



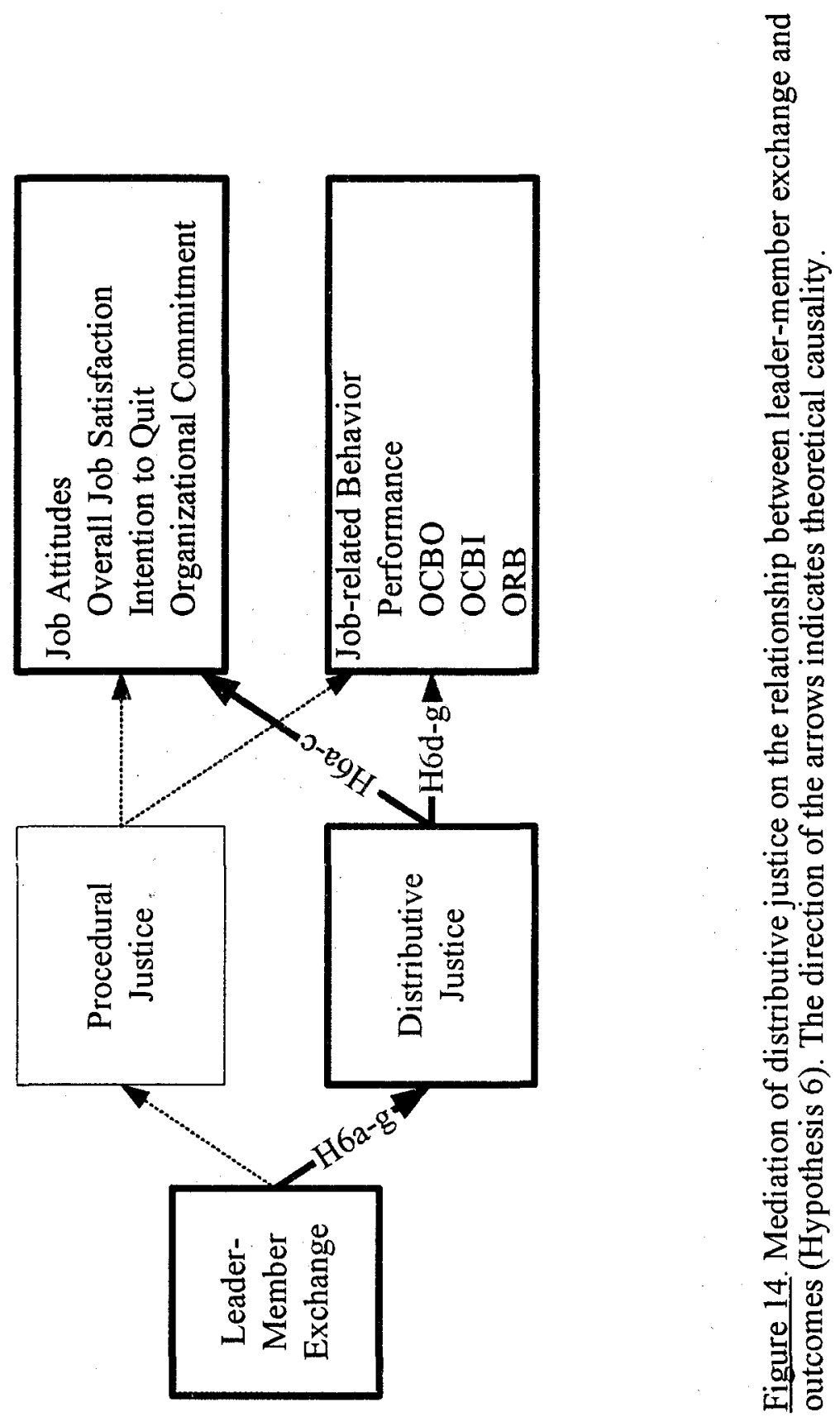

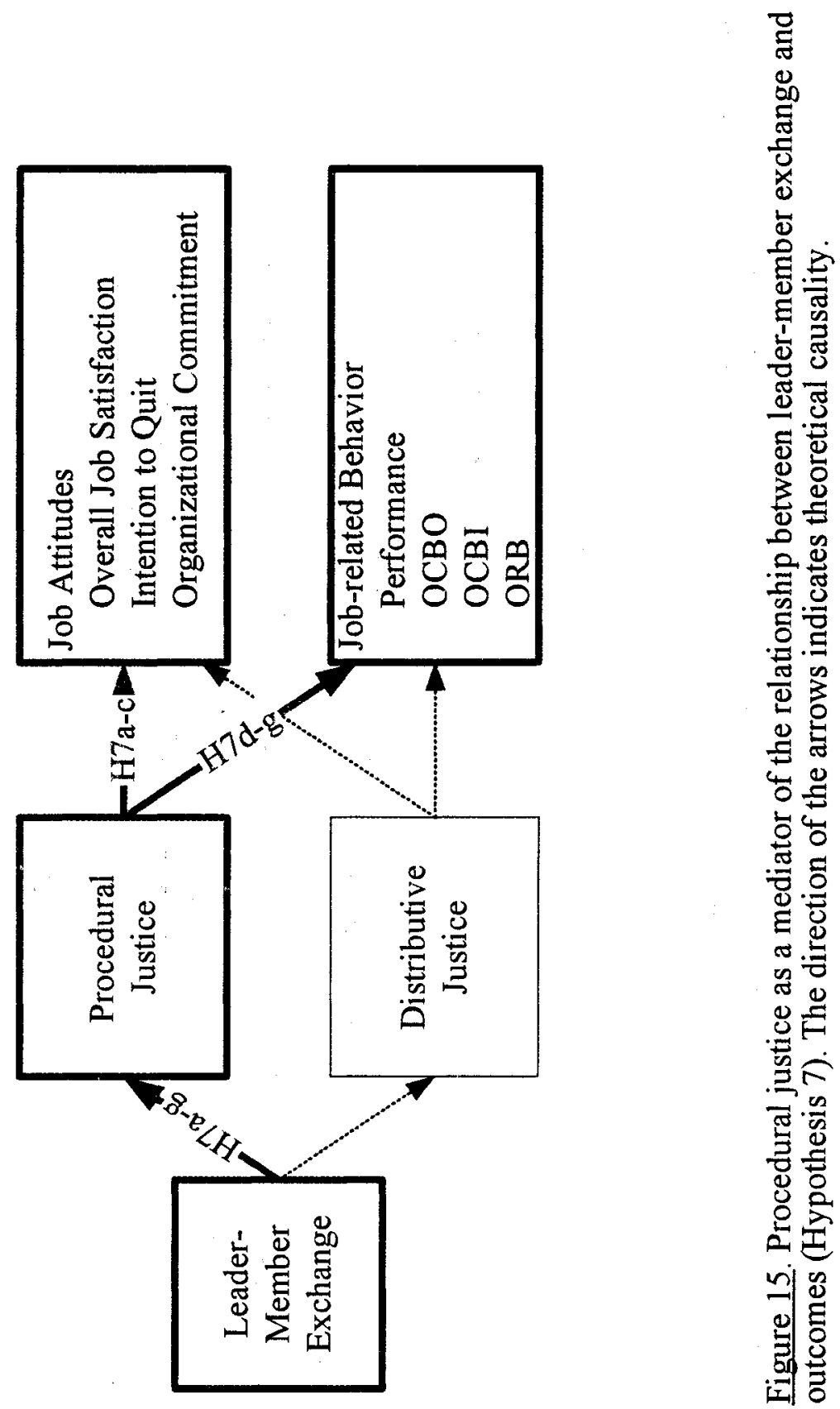


\section{Model Summary}

The purpose of the present research was to examine the relationships between trust, LMX, organizational justice and several outcome variables. Figure 2 shows the model that was examined in the present research. The rationale for each of the individual paths in the model has already been provided. Additionally, the formal hypotheses examined in the present research have been offered. However, a brief summary of the hypothesized paths in the model is provided next.

Hypothesis 1 predicts a positive relationship between dispositional trust and trust in a specific other. Hypothesis 2 predicts a positive relationship between trust and LMX.

Hypotheses 3 and 4 focus on the direct relationships between organizational justice and each of the outcome variables. Specifically, it is hypothesized that procedural and distributive justice is positively related to overall job satisfaction, organizational commitment, performance, OCBO, and OCBI. Additionally, it is hypothesized that procedural and distributive justice is negatively related to ORB and intentions to quit.

Hypothesis 5 examines the often-found interaction between procedural and distributive justice in relation to the outcome variables. Specifically, the positive relationship between distributive justice and overall job satisfaction, organizational commitment, performance, $\mathrm{OCBO}$, and $\mathrm{OCBI}$ are hypothesized to be stronger when procedural justice is low than when procedural justice is high. Similarly, the negative 
relationship between distributive justice and ORB and intention to quit is hypothesized to be stronger when procedural justice is low than when procedural justice is high.

Hypotheses 6 and 7 consider the mediating effect of organizational justice on the relationship between LMX and the outcome variables. Specifically, it is hypothesized that distributive (Hypothesis 6) and procedural (Hypothesis 7) justice mediate the relationship between LMX and the various outcome variables. In other words, the relationship between LMX and the outcome variables is reduced when perceptions of organizational justice are included in the regression models.

The present research empirically examined several relationships for the first time. These relationships are shown in Figure 16. First, while the relationship of dispositional trust and trust in a specific other has been studied, it has not been studied within the framework of LMX. Second, the relationship between trust in a specific other and LMX has not been examined directly. Third, the mediating effect of organizational justice on the relationship between LMX and the various outcomes has not been examined. Lastly, the relationship between LMX and organizational retaliatory behaviors was examined for the first time in this study. Although this direct relationship is not shown in Figure 16, it is an interesting and valuable contribution to the literature.

The model was examined in two studies. The first study utilized a student sample and included a manipulation of organizational justice. Additionally, Study One data utilized a pre-/post-manipulation methodology. The second was a field study 
wherein data were collected cross-sectionally from both managers and their subordinates. 


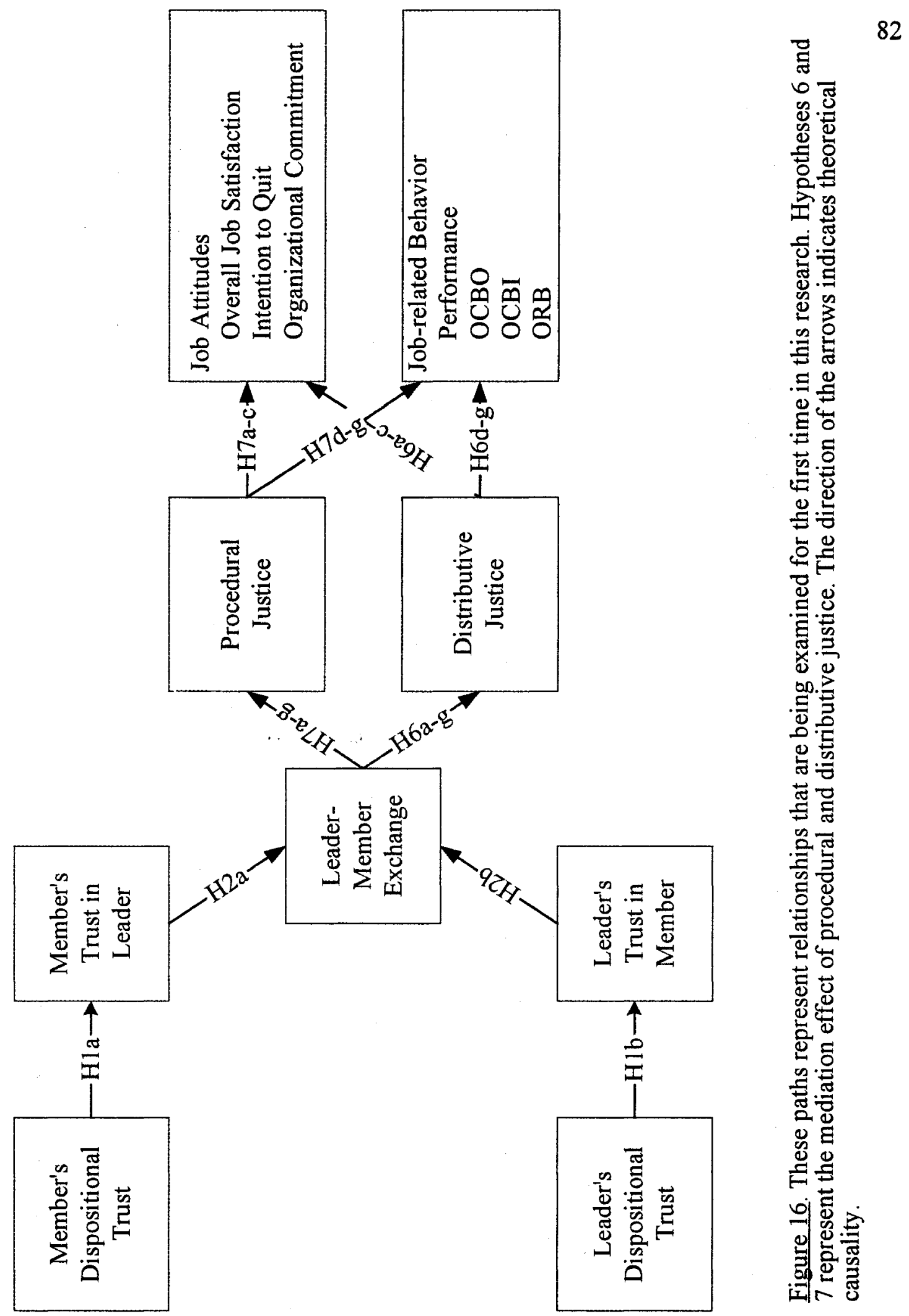




\section{Study One}

Introduction

The purpose of Study One was threefold. First, using four fictitious work scenarios, organizational justice was manipulated to examine its effects on the outcome variables. This type of manipulation in the field would be very difficult to realize and unethical. Second, a pre/post design was used to examine possible causal relationships between treatment of members via a paper manipulation and subsequent changes in the attitudinal and behavioral outcomes. Third, these relationships were examined within a specific human resource context (i.e., a bonus decision). This was in contrast to the general perceptions of organizational justice examined in Study Two. Additional Hypotheses for Study One

In addition to the hypotheses reviewed in Chapter Five, three more hypotheses were examined in Study One. Trust and LMX are theorized to develop over a series of interactions between the leader and the member. While the manipulation employed here was designed to examine the effects of organizational justice on the relationship between LMX and various outcomes, it was possible that this one episode, if perceived as egregious, would affect a member's trust in their leader and/or the quality of LMX relationship. Therefore the following two hypotheses are offered: Hypothesis 8a: Person-specific trust decreases from Time 1 (pre-manipulation) to Time 2 (post-manipulation) for participants in the low procedural justice and low distributive justice condition and only for participants in that condition. 
Hypothesis 8b: Similarly, LMX decreases from Time 1 to Time 2 for participants in

the low procedural justice and low distributive justice condition and only for participants in that condition.

Skarlicki and Folger (1997) found that distributive justice was related to ORBs only when procedural justice was low. Specifically, these researchers found that only in the case where both distributive and procedural justice were low, were perceptions of organizational justice related to increases in ORB. Because organizational justice was manipulated in Study One, it was possible to retest the Skarlicki and Folger findings and extend the logic of their research to other attitudes and behaviors included in the present research. Therefore, the following hypotheses are offered. Hypothesis 9: After exposure to the manipulation, for participants in the low distributive justice and low procedural justice condition, there is a positive relationship between LMX and overall job satisfaction (Hypothesis 9a), organizational commitment (Hypothesis 9c), member performance (Hypothesis 9d), organizational citizenship behavior directed at the organization (Hypothesis 9e), organizational citizenship behavior directed at an individual (Hypothesis $9 \mathrm{f}$ ) and negatively related to intention to quit (Hypothesis 9b), ORBI (Hypothesis 9g), and ORBO (Hypothesis 9h). Additionally, there is no relationship between LMX and the various outcome variables for participants in the other conditions.

\section{Method}

\section{Measures}

All the measures utilized had been developed in prior research. Additionally, a five-point Likert scale ranging from strongly disagree (1) to strongly agree (5) was 
used for all scales, except the ORB scale, which used a seven-point frequency scale. It is important to note that all of the scales used in this research rely on the perceptions of participants.

\section{Dispositional Trust}

Rotter's (1967) 25-item interpersonal trust survey was adapted to measure dispositional trust. The dimensionality of this scale has been the focus of some debate (e. g., Chun \& Campbell, 1975; Stack, 1978). Tedeshi and Wright (1975; 1980) using a variety of samples found that the interpersonal trust survey contained three factors. The first factor was named Political Trust (e.g., "This country has a dark future unless we can attract better people into politics."). In general, these are targets that an individual is unlikely to have direct contact with. The second factor, and more relevant to the present research deals with trust in social agents with which a person may have considerable contact (e.g., "Parents can usually be relied upon to keep their promises"). This factor was called Parental Trust. The third factor was termed Trust of Strangers. It taps cynicism more than trust (e.g., "Using the Honor System of not having a teacher present during exams would probably result in increased cheating"). The six items of the interpersonal trust scale that comprise the second factor were used to measure dispositional trust. Unfortunately, these researchers did not report reliability estimates for these three factors of the interpersonal trust scale.

\section{Trust in a Specific Other}

Butler's (1992) overall trust subscale was adapted to apply to both members and leaders. This 4-item scale was designed specifically to research trust in a specific other within the context of the workplace. A sample item is "I feel that my supervisor 
can be trusted." Butler reported an estimate of internal consistency of .97 and a testretest reliability of .91 for this 4-item scale.

$\underline{\mathrm{LMX}}$

The LMX-7 (Graen et al., 1982) grew out of the early work on negotiating latitiude by Graen and colleagues (Dansereau, 1975; Graen \& Cashman, 1975). The core item (Gerstner \& Day, 1997) of this seven-item scale is "I have a good working relationship with my supervisor." As is evident from the wording of this item, the LMX-7 measures LMX from the perspective of the member (subordinate).

Bauer and Green (1996) revised the LMX-7 based on changes made to the response scale made by Liden et al. (1993) and breaking one "double-barreled" item into two separate items, creating an eight item scale (LMX-8). The LMX-8 from the member's perspective (Bauer \& Green, 1996) was adapted to assess LMX from the leader's perspective. Bauer and Green reported an estimate of reliability of .94 .

Distributive Justice

Price and Mueller's (1986) five-item distributive justice scale was used. A sample item is "To what extent are you fairly rewarded considering the responsibilities that you have?" Estimates of internal consistency have ranged from .94 to .95 (Price \& Mueller, 1986).

\section{Procedural Justice}

An eight-item general procedural justice scale developed by Folger and Konovsky (1989) that reflects Leventhal, Karuza, and Fry's (1980) six procedural justice rules and Geenberg's (1986) procedural justice determinants was used. A sample item is "My company has procedures that ensure information for making 
decisions is accurate." Skarlicki and colleagues (Skarlicki used \& Folger, 1997;

Skarlicki, Folger, \& Tesluk, 1999) reported estimates of internal consistency for this scale of .88 .

\section{Organizational Citizenship Behavior}

The two-facet organizational citizenship behavior scale developed by Williams and Anderson (1991) was used to assess organizational citizenship behavior directed at the organization (6-items) and organizational citizenship behavior directed at individuals (7-items). A sample item from the organizational citizenship behavior directed at the organization (OCBO) scale is "Attendance at work is above the norm." A sample item from the organizational citizenship directed at individuals (OCBI) is "Assists supervisor with his/her work when not asked." Both leaders and members completed the two scales. Williams and Anderson report estimates of internal consistency of .88 for OCBI and .75 for OCBO.

\section{Member Performance}

Members provided a self-report of their in-role job performance using six positively worded items from the scale developed by Williams and Anderson (1991). A sample item from this scale is "Meets formal requirements of the job." These researchers reported an estimate of internal consistency of .91 .

\section{$\underline{\text { Job Satisfaction }}$}

Members reported levels of overall job satisfaction using a subscale from the Job Descriptive Index (Hackman \& Oldham, 1980). A sample item from the overall job satisfaction scale is "Generally speaking, I am very satisfied with this job." 
Intention to Quit

Members reported their intention to quit using a subscale from the Job Descriptive Index (Hackman \& Oldham, 1980). A sample item from this scale is "I intend to quit the job I currently have."

Organizational Retaliatory Behaviors

The 12-item organizational deviance and 7-item interpersonal deviance scales developed by Bennett and Robinson (2000) were used to measure organizational retaliatory behaviors. In contrast to the other scales used in this research, this scale used a 7-point Likert response format ranging from never (1) to daily (7). A sample item from the this scale is "Intentionally worked slower than I could have worked."

\section{Scale Development}

Although all scales had been developed in prior research, factor analyses indicated that each scale was unidimensional as expected, with the exception of the ORB scale. Scales were created by all variables, except for ORB, by taking the average of the responses to items in the scale. Therefore, variables had a range from one to five. The factor analysis of the ORB scale did not result in the expected twofactor solution. However, both ORBI and ORBO had reasonable estimates of internal consistency (i.e., .83 and .84 respectively). Therefore, both subscales were retained. Both ORB scales had a range of 1 to 7 .

\section{Procedure}

Pre-manipulation. Participants completed surveys before and after the manipulation. A summary of the survey administration process is in Table 2. Participants completed the following measures at Time One: disposition to trust, trust 
in their supervisor, LMX-8, procedural justice, distributive justice, overall job satisfaction, organizational commitment, $\mathrm{OCB}$, job performance, and $\mathrm{ORB}$. Participants also provided information on several demographic variables (e.g., age, gender, ethnicity, job tenure, tenure with their supervisor).

Experimental Manipulation. After completing the pre-manipulation survey, participants randomly received one of four scenarios in which organizational justice was manipulated (Table 3). In each scenario procedural and distributive justice was manipulated to be either high or low resulting in four distinct conditions (Table 4).

Post-manipulation. After reading the scenario, participants responded to a survey measuring the same constructs as at Time 1. Participants were asked to respond to the post-manipulation survey as if the situation they just read actually happened to them. Due to the manipulation, some changes were made to the measures from Time 1. These changes are described next.

Post-Manipulation Procedural Justice. Because the focus of Study One was a manipulation of procedural and distributive justice within the context of a bonus decision, scales developed by Colquitt (2001) were used to measure procedural and distributive justice at Time 2 . Each item was written to apply to a specific organizational process and outcome (e.g., a bonus decision). The procedural justice scale contained seven items. A sample item is "I have been able to express my views and feelings during the procedures used to determine bonuses".

Post-Manipulation Distributive Justice. The distributive justice scale contained four items. A sample item is "My bonus reflects the effort I have put into my work". 
Post-Manipulation Organizational Retaliatory Behavior. The instruction and response sets were changed for ORB to indicate how likely the respondent would be to engage in these behaviors in the next six months. While self-reports of likely future behavior are not as realistic as reports of actual behavior by others, there is some evidence that self-reports of the likelihood to engage in future behavior are reasonably accurate (Sheppard, Hartwick, \& Warshaw, 1988).

Post-Manipulation Organizational Citizenship Behavior. Similar changes to the instruction and response sets were made with OCB as were made with ORB. 


\section{Table 2}

Summary of Survey Administration for Study Two

\begin{tabular}{|l|c|c|}
\hline Construct & Pre-Manipulation & Post-Manipulation \\
\hline Dispositional Trust & $\mathrm{X}$ & $\mathrm{X}$ \\
\hline Person-Specific Trust & $\mathrm{X}$ & $\mathrm{X}$ \\
\hline LMX-8 & $\mathrm{X}$ & $\mathrm{X}$ \\
\hline Procedural Justice & $\mathrm{X}$ & $\mathrm{X}$ \\
\hline Distributive Justice & $\mathrm{X}$ & $\mathrm{X}$ \\
\hline Job Performance & $\mathrm{X}$ & $\mathrm{X}$ \\
\hline Overall Job Satisfaction & $\mathrm{X}$ & $\mathrm{X}$ \\
\hline Intention to Quit & $\mathrm{X}$ & $\mathrm{X}$ \\
\hline Organizational Commitment & $\mathrm{X}$ & $\mathrm{X}$ \\
\hline OCB & $\mathrm{X}$ & $\mathrm{X}$ \\
\hline ORB & $\mathrm{X}$ & $\mathrm{X}$ \\
\hline
\end{tabular}

Note. An " $X$ " indicates which constructs were measured before and after the manipulation. Procedural and distributive justice were manipulated with a fictitious scenario between the pre. and post-manipulation. 
Table 3

Text of Laboratory Study Manipulations

\section{High Procedural Justice, High Distributive Justice}

When reading the following scenario, assume that this situation happens to you in your current job. Also assume that the organization you work in determines bonuses for its employees once per year.

Your organization has an established policy regarding how bonuses are determined for employees. The amount of your bonus depends on your performance during the past year. You have performed exceptionally well this year.

In this organization, a committee of supervisors from your division meets annually to determine employee bonuses. Based on the decision of the committee, you will either receive a bonus equal to $25 \%$ of your base salary or no bonus at all.

In this organization, each subordinate is instructed to complete a copy of the evaluation form the bonus committee will be using to determine bonuses and turn the completed form to the bonus committee. The committee will consider this subordinate self-evaluation as another source of information when making the bonus determination.

As part of the bonus committee meeting, each subordinate is offered the opportunity to talk with the committee about his/her performance. The committee informs subordinates that if they want to appeal the bonus decision that they need to appeal the decision to the division manager in writing within one week.

You have just found out that you will be receiving a bonus equal to $25 \%$ of your base annual salary.

\section{High Procedural Justice, Low Distributive Justice}

When reading the following scenario, assume that this situation happens to you in your current job. Also assume that the organization you work in determines bonuses for its employees once per year.

Your organization has an established policy regarding how bonuses are determined for employees. The amount of your bonus depends on your performance during the past year. You have performed exceptionally well this year.

In this organization, a committee of supervisors from your division meets annually to determine employee bonuses. Based on the decision of the committee, you will either receive a bonus equal to $25 \%$ of your base salary or no bonus at all. 
In this organization, each subordinate is instructed to complete a copy of the evaluation form the bonus committee will be using to determine bonuses and turn the completed form to the bonus committee. The committee will consider this subordinate self-evaluation as another source of information when making the bonus determination.

As part of the committee meeting, each subordinate is offered the opportunity to talk with the committee about his/her performance. The committee informs subordinates that if they want to appeal the bonus decision that they need to appeal the decision to the division manager in writing within one week.

You have just heard that you will not receive any bonus this year.

\section{Low Procedural Justice, High Distributive Justice}

When reading the following scenario, assume that this situation happens to you in your current job. Also assume that the organization you work in determines bonuses for its employees once per year. The amount of your bonus depends on your performance during the past year. You have performed exceptionally well this year. You will either receive a bonus equal to $25 \%$ of your base salary or no bonus at all.

Your organization has no particular system established regarding how bonuses are determined for employees. It is unclear to employees how bonuses are determined for each individual employee. There is a sense among employees that bonuses are based on "who you know, not how you perform".

You have just heard that you will receive a bonus equal to $25 \%$ of your base annual salary.

\section{Low Procedural Justice, Low Distributive Justice}

When reading the following scenario, assume that this situation happens to you in your current job. Also assume that the organization you work in determines bonuses for its employees once per year. The amount of your bonus depends on your performance during the past year. You have performed exceptionally well this year. You will either receive a bonus equal to $25 \%$ of your base salary or no bonus at all.

Your organization has no particular system established regarding how bonuses are determined for employees. It is unclear to employees how bonuses are determined for each individual employee. There is a sense among employees that bonuses are based on "who you know, not how you perform".

You have just heard that you will not receive a bonus this year. 
Table 4

Conditions of the Organization Justice Manipulation in Study Two

\begin{tabular}{|c|c|c|}
\hline Condition Number & $\begin{array}{c}\text { Level of } \\
\text { Procedural Justice }\end{array}$ & $\begin{array}{c}\text { Level of } \\
\text { Distributive Justice }\end{array}$ \\
\hline 1 & High & High \\
\hline 2 & High & Low \\
\hline 3 & Low & High \\
\hline 4 & Low & Low \\
\hline
\end{tabular}


Chapter Seven

Results

Study One

\section{Participants}

A total of 223 currently employed students at a university located in the Northwest United States completed a set of surveys. Participation in the study was voluntary and anonymous. Most students received extra-credit in a course they were taking if they participated. This sample size achieved a power level of .80 , assuming medium effect sizes, to test Hypotheses 8 and 9 (the hypotheses requiring the most power). For those participants reporting demographic characteristics, $51.4 \%(\underline{\mathrm{n}}=114)$ were men, $73.6 \%(\underline{n}=162)$ were Caucasian and $13.2 \%(\underline{n}=29)$ were Asian, $90.6 \%(\underline{n}$ $=202$ ) were either junior or senior level at the university. The average age of participants was 25.39 years. Participants worked an average of 27.09 hours per week and had worked with their current supervisor for an average of 1.48 years.

Descriptive statistics and correlations between all variables in the permanipulation phase are included in Table 5. Descriptive statistics and scale reliabilities for the post-manipulation phase (collapsed across all four manipulation conditions) are reported in Table 6 . Tables 7 through 10 contain the correlations between all the postmanipulation variables for each condition respectively.

\section{The Role of Dispositional Trust}

It was hypothesized that dispositional trust would be related to trust in a specific other (Hypothesis 1). Dispositional trust was stable from the pre-manipulation to the post-manipulation survey (mean difference $=.06, \underline{t}=1.94, \underline{p}>.05$ ). However, 
there was no correlation between dispositional trust and trust in supervisor (Table 5), therefore, Hypothesis 1 was not supported.

The Relationship between Trust in Supervisor and LMX

The correlation between trust in supervisor and LMX was very strong $(r=.79$, $\mathrm{p}<.01)$ (Table 5). Additionally, after controlling for several background variables (e.g., age, gender, length of relationship, span of control of supervisor), trust in supervisor was strongly related to $\operatorname{LMX}\left(\Delta \mathrm{R}^{2}=.59, \underline{\mathrm{F}}=355.52, \mathrm{p}<.01\right)($ Table 11). Therefore, Hypothesis 2 was supported. Distributive Justice and the Outcome Variables

Hypothesis 3 was tested with correlation coefficients (Table 5). There was a significant, positive relationship between distributive justice and job satisfaction $(\underline{r}=$ $.56, \mathrm{p}<.01)$, organizational commitment $(\mathrm{r}=.56, \mathrm{p}<.01)$, in-role performance $(\mathrm{r}=$ $.17, \mathrm{p}<.01)$, and OCBI $(\mathrm{r}=.19, \mathrm{p}<.01)$. There was a significant negative relationship between distributive justice and intention to quit $(\underline{r}=-.46, \underline{p}<.01)$. Lastly, no relationship was found between distributive justice and OCBO, ORBO, or ORBI. These results provide mixed support for Hypothesis 3.

Procedural Justice and the Outcome Variables

Hypothesis 4 was also tested with correlation coefficients (Table 5). There was a significant positive relationship between procedural justice and job satisfaction $(\underline{r}=$ $.58, \underline{p}<.01)$, organizational commitment $(r=.70, \underline{p}<.01)$, and OCBI $(r=.19, \underline{p}<$ $.01)$. There was a significant negative relationship between procedural justice and intention to quit $(r=-.46, \underline{p}<.01)$. Lastly, no relationship was found between 
distributive justice and in-role performance, OCBO, ORBO, or ORBI. These results provide mixed support for Hypothesis 4.

The Interaction of Procedural and Distributive Justice with Pre-manipulation Data

To test Hypothesis 5, the interaction of procedural and distributive justice on the outcome variables, hierarchical regression was used. The first step in this process was to center the organizational justice variables by subtracting each individual value from the mean of the sample. Therefore, variables had a mean of zero. In the next step, procedural and distributive justice were entered into the equation predicting each outcome variable in turn. In the third step, the interaction term (i.e., procedural justice $\mathrm{x}$ distributive justice) was entered. If this third step was statistically significant, then two regression lines would be developed in order to examine the specific nature of the interaction. The interaction term was significant for OCBI (Table 12), OCBO (Table 13), and in-role performance (Table 14). The interaction term was not significant for job satisfaction, organizational commitment, intention to quit, ORBO, or ORBI.

To examine the nature of the significant interactions, two regression lines were drawn for OCBI, OCBO, and in-role performance (Figures 17 - 19). Next, predicted values for each of the outcome variables for each of the four conditions (high distributive/high procedural, high distributive/low procedural, low distributive/high procedural, low distributive/low procedural) were generated. High values for both distributive and procedural justice were defined as one standard deviation above the mean. Similarly, low values for the organizational justice variables were defined as one standard deviation below the mean. Then a regression line was generated using the unstandardized b-weights to predict the value of the outcome variable. Each of the 
control variable means was multiplied by its b-weight. Distributive justice,

procedural justice, and the interaction term (distributive justice multiplied by

procedural justice) were multiplied by the appropriate b-weight. Lastly, an error term was added to the equation. As an example, the regression line for high distributive justice/high procedural justice predicting in-role performance as the outcome variable is below.

$$
\begin{aligned}
& 4.56=(.003 * 24.61)+(-.003 * .51)+(.007 * 28.37)+(.02 * 1.65)+(.001 * 18.65)+(.09 * 1.04) \\
& +(.01 * .90)+(.16 * 1.01 * .90)+3.99
\end{aligned}
$$

The interaction effects depicted in Figures 17-19 do not reflect the hypothesized relationships. First, the slope of the high procedural justice lines is much more positive than what was expected. Second, the slope of the low procedural justice lines is flat if not negative, which is contrary to what was expected. Therefore, Hypothesis 5 was not supported.

Lind (2001) suggested that a more parsimonious and general relationship may exist between distributive and procedural justice, which better explains the overall results found here. This theoretical explanation will be elaborated on in the post hoc analyses section of Study One.

Building the Mediation Models

A series of regression models were run to test the hypothesized mediating effect of organizational justice. Hypothesis 6 predicted that distributive justice would mediate the relationship between LMX and the various outcome variables. Baron and Kenny (1986) recommend a three-step regression analysis to test mediation models. In the first step (Figure 20), the independent variable (i.e., LMX) is regressed on the 
dependent variable (i.e., outcome variables). If a significant relationship is found then step two regresses the independent variable (i.e., LMX) on the mediator variable (i.e., distributive justice; Figure 21). If this relationship is significant, then step three is employed. In step three (Figure 22), the mediator is entered into the regression equation first predicting the outcome variable. Then, the independent variable is entered into the regression equation. Full mediation exists if the relationship between the independent variable and dependent variable is non-significant. Partial mediation exists if the relation between the independent variable and the dependent variable is reduced in magnitude from step 1. An example of these three steps is provided in Table 15 for Hypothesis $6 a$.

This process was used for each of the outcome variables in turn for distributive justice and then for procedural justice.

\section{The Mediation Effect of Distributive Justice}

In the first step of the mediator analysis (Table 16), LMX was significantly related to pre-manipulation reports of job satisfaction $\left(\mathrm{R}^{2}=.35, \underline{\mathrm{p}}<.01\right)$, intention to quit $\left(\underline{\mathrm{R}^{2}}=.23, \underline{\mathrm{p}}<.01\right)$, organizational commitment $\left(\underline{\mathrm{R}^{2}}=.40, \underline{\mathrm{p}}<.01\right)$, in-role performance $\left(\underline{\mathrm{R}^{2}}=.07, \underline{\mathrm{p}}<.01\right)$, OCBI $\left(\underline{\mathrm{R}^{2}}=.10, \underline{\mathrm{p}}<.01\right)$, and OCBO $\left(\underline{\mathrm{R}}^{2}=.03, \underline{\mathrm{p}}<\right.$ .05). LMX was unrelated to either dimension of ORB or an ORB composite. In the second regression model (Table 17), LMX was positively related to distributive justice $\left(\underline{\mathrm{R}^{2}}=.30, \underline{\mathrm{p}}<.01\right)$.

In step three of the mediation analyses (Table 18), distributive justice was entered into the regression model first, followed by LMX. Table 19 shows the reduction in variance accounted for be LMX in the outcome variables before and after 
the inclusion of distributive justice. Distributive justice was unrelated to OCBO,

therefore no mediation could exist. There were substantial reductions in the amount of variance accounted for by LMX in job satisfaction, intention to quit, and organizational commitment after the inclusion of distributive justice. There were more modest reductions in the variance accounted for by LMX in performance and OCBI after the inclusion of distributive justice. These results provide partial support for Hypothesis 6.

\section{The Mediation Effect of Procedural Justice}

The first step of the mediator analysis for procedural justice was identical to that for distributive justice (Table 20). In the second regression model (Table 21), LMX was positively related to procedural justice $\left(\underline{\mathrm{R}^{2}}=.28, \underline{\mathrm{p}}<.01\right)$.

In step three of the mediation analyses (Table 22), procedural justice was entered into the regression model first, followed by LMX. Table 23 shows the reduction in variance accounted for be LMX in the outcome variables before and after the inclusion of procedural justice. Procedural justice was unrelated to performance and OCBO, therefore no mediation could exist. There were substantial reductions in the amount of variance accounted for by LMX in job satisfaction, intention to quit, and organizational commitment after the inclusion of procedural justice. There was a more modest reduction in the variance accounted for by LMX in OCBI after the inclusion of procedural justice. These results provide partial support for Hypothesis 7 . Testing the Overall Model with Pre-Manipulation Data

Structural equation modeling was used to test the accuracy of the entire model. The value to this approach is that while statistically significant results may be found as 
hypothesized, structural equation modeling allows for the testing of alternative models as well as deriving empirically driven modifications. Since the parameters of interest in the model are the relationships between the latent variables and prior research has provided evidence of the psychometric properties of the scales used to measure these latent variables, a single indicator model was used for most variables to test the full model. Using single indicators increases the subjects to degrees-offreedom ratio, which provides more power to examine the structural relationships in the model. For each variable, the path from the indicator to the latent variable (lambda) was set to the square root of the scale reliability. The error variance was set equal to the variance of the scale multiplied by one minus the reliability (Hayduk, 1987; Jörsekog \& Sörbom, 1989). This strategy to examine structural models in organizational behavior research is common (e.g., Bauer et al., 2001; Wayne et al., 1997).

Structural equation modeling also allowed a test of the idea that both distributive and procedural justice perceptions were influenced by an overall fairness judgment (Lind, 2001). Therefore, "overall fairness" is presented as a latent variable that influences both distributive and procedural justice perceptions. Theoretically, this approach indicates that perceptions of distributive and procedural justice lead to an overall sense of fairness for individuals. It is this overall fairness perception that becomes a heuristic that influences perceptions of attitudes and behaviors (Lind, 2001).

Figure 23 represents the full, hypothesized model. This model did not fit the data well (Table 24). However, modification indices for this model suggested that the 
path between dispositional trust and trust in leader be eliminated. This change also made theoretical sense since the average tenure of the relationship between members and leaders was over one year. In dyadic relationships of this length, it is likely that person specific information would be much more salient that one's disposition to trust others. This change did not result in a better fitting model (Table 24). Since it is more likely that in the presence of general injustice (i.e., no specific person is responsible for the injustice), individuals are more likely to withhold helpful behaviors from the organization rather than co-workers, and more likely to engage in behaviors harmful to a "faceless" organization than to co-workers, Model 4 eliminated both OCBO and ORBI. Additionally, overall fairness did not have a statistically significant relationship with either OCBO of ORBI Model 4 fit the data moderately well.

The next model (Model 5) tested added paths between outcome variables that have shown consistent relationships in prior research. Therefore, job satisfaction, intention to quit and organizational commitment were allowed to co-vary, and a path between performance and OCBI was added to the model (Figure 25). This model fit the data very well.

The last two models tested were based on the strong positive relationship between trust in supervisor and LMX. Rather than the hypothesized model in which trust in supervisor was related to LMX and then LMX was related to overall fairness, a direct path between trust in supervisor and overall fairness was added (Figure 24). This model did not fit the data well. The final model tested reflected the elimination of dispositional trust, OCBO, and ORBI from the hypothesized model. This final model also reflects the addition of paths between job satisfaction and intention to quit and 
performance and OCBI. While the fit indices indicated that this model was an improvement over Model 6, it still did not fit the data well.

The best fitting model in this series was Model 5 and is shown in Figure 25. The overall fit indices for this model met or exceeded the recommended minimum values to indicate a well fitting model except for the AGFI, which has a recommended minimum of .90 . This model suggests that both LMX and trust in supervisor contributed to perceptions of overall fairness. Overall fairness judgments impacted both perceptions of distributive and procedural justice. Overall fairness judgments were related to job satisfaction, intention to quit, organizational commitment, performance, OCBI, and ORBO in expected ways.

Manipulation Check of the Fictitious Bonus Scenario

Two one-way ANOVAs were run to check the scenario manipulation. To test the effect of procedural justice, the two experimental conditions in which procedural justice was high were coded 1 and the other two conditions were coded 0 . Postmanipulation reports of procedural justice showed that those in the high procedural justice conditions (mean $=3.36$ ) reported significantly higher procedural justice than those in the low procedural justice conditions (mean $=2.28)(\mathrm{F}=90.15, \mathrm{p}<.01)$.

The same process was followed to examine the effect of the manipulations on distributive justice. Results indicated that those in the high distributive justice conditions reported significantly higher distributive justice $($ mean $=3.64)$ than those in the low distributive justice conditions $($ mean $=1.96)(F=157.54, \underline{p}<.01)$. 
Effect of Organizational Justice on LMX

Two sets of four paired samples t-test were run to test Hypotheses $8 \mathrm{a}$ and $8 \mathrm{~b}$. If there was a significant decrease in trust in supervisor from Time 1 to Time 2 for participants in the low distributive justice and low procedural justice condition and only for participants in this condition, then Hypothesis 8 a would be supported. As hypothesized, there was a marked decrease in the reports of trust in supervisor for participants in the low distributive justice/low procedural justice condition (Table 25; mean difference $=1.27, \underline{\mathrm{t}}=7.65, \underline{\mathrm{p}}<.01)$. Also, as expected, there was no mean difference in pre- and post-manipulation reports of trust in supervisor for those in the high distributive justice/high procedural justice condition $(\mathrm{t}=-.79, \mathrm{p}>.05)$. Unexpectedly, there was also a statistically significant reduction in trust in supervisor for those in the low distributive justice/high procedural justice condition (mean difference $=.88, \underline{\mathrm{t}}=6.13, \mathrm{p}<.01)$ and those in the high distributive justice/low procedural justice condition (mean difference $=.37, \underline{\mathrm{t}}=2.76, \mathrm{p}<.01$ ). These results provide partial support for Hypothesis 8a.

Concerning Hypothesis 8b, if there was a significant decrease in LMX from Time 1 to Time 2 for participants in the low distributive justice and low procedural justice condition and only for participants in this condition, then Hypothesis $8 \mathrm{~b}$ would be supported. A hypothesized, the greatest mean difference was found for those in the low distributive justice/low procedural justice condition (Table 26). The mean difference for this group was 1.40 (Table $22 ; \mathrm{t}=9.70, \mathrm{p}<.01$ ). Results also supported the notion that participants in the high distributive justice/high procedural justice would not report lower levels of LMX after the manipulation $(t=-.41, \underline{p}>.05)$. 
However, for the other two experimental conditions, post-manipulation reports of LMX did decrease from pre-manipulation levels. The mean difference for those in the low distributive justice/high procedural justice condition was $.90(\mathrm{t}=6.28, \mathrm{p}<.01)$. For those in the high distributive justice/low procedural justice condition the mean difference was $.31(\mathrm{t}=3.28, \underline{\mathrm{p}}<.01)$. These results provide partial support for Hypothesis $8 \mathrm{~b}$.

Mediating Effect of Post-Manipulation Distributive Justice on LMX and Outcome Relationships

In the first step of the mediator analysis (Table 27), LMX was significantly related to post-manipulation reports of job satisfaction $\left(\underline{\mathrm{R}^{2}}=.36, \mathrm{p}<.01\right)$, intention to quit $\left(\underline{\mathrm{R}^{2}}=.09, \mathrm{p}<.01\right)$, organizational commitment $\left(\underline{\mathrm{R}^{2}}=.43, \mathrm{p}<.01\right)$, in-role performance $\left(\underline{\mathrm{R}^{2}}=.17, \underline{\mathrm{p}}<.01\right), \mathrm{OCBI}\left(\underline{\mathrm{R}^{2}}=.11, \underline{\mathrm{p}}<.01\right), \mathrm{OCBO}\left(\underline{\mathrm{R}^{2}}=.12, \underline{\mathrm{p}}<.01\right)$, and ORBI $\left(\underline{\mathrm{R}^{2}}=.02, \underline{\mathrm{p}}<.05\right)$, and ORBO $\left(\underline{\mathrm{R}^{2}}=.08, \underline{\mathrm{p}}<.01\right)$. In the second regression model (Table 28), LMX was positively related to distributive justice $\left(\underline{\mathrm{R}^{2}}=.39, \mathrm{p}<\right.$ $.01)$.

In step three of the mediation analyses (Table 29), distributive justice was unrelated to ORBI, therefore mediation was not possible. There were substantial reductions in variance accounted for by LMX in job satisfaction, intention to quit, organizational commitment, performance, OCBI, OCBO, and ORBO (Table 30). These results provided partial support for Hypothesis 6 . 
Mediating Effect of Post-Manipulation Procedural Justice on LMX and Outcome

\section{Relationships}

The first step of mediation for procedural justice was the same as for distributive justice (Table 31). In the second regression model (Table 32), LMX was positively related to procedural justice $\left(\underline{\mathrm{R}^{2}}=.34, \underline{\mathrm{p}}<.01\right)$.

In step three of the mediation analyses (Table 33), procedural justice was unrelated to ORBI, therefore mediation was not possible. There were substantial reductions in variance accounted for by LMX in job satisfaction, intention to quit, organizational commitment, performance, OCBI, and OCBO (Table 34). There was a more modest reduction in the amount of variance accounted for by LMX in ORBO. These results provide partial support for Hypothesis 7.

\section{Post Hoc Analyses}

Dispositional Trust. It is theorized that over time information about the ability, integrity, and benevolence of one's supervisor would dominate the formation of perceptions of trust versus one's tendency to trust others. Therefore, a correlation coefficient was calculated between dispositional trust and trust in supervisor for those participants who had less than one year of tenure with their supervisor $(\underline{n}=83)$. While of a greater magnitude than the correlation for the entire sample, the coefficient was not significant $(\mathrm{r}=.14, \mathrm{p}>.05)$. Therefore, Hypothesis 1 was not supported. It is possible that the low reliability of the measure of dispositional trust $(\alpha=.61)$ contributed to this result. 
Trust in Supervisor and LMX. Although the relationship between trust in supervisor and LMX was hypothesized to exist in the pre-manipulation data, the high correlation between the two constructs calls into question the distinction between the two. As noted in the literature review, some theorists have implied that trust is one of several factors of LMX (Liden \& Maslyn, 1998). Therefore, a factor analysis was run with items from both the LMX-8 and trust in supervisor measures. Using oblique rotation, the best solution was a two-factor solution. The first factor accounted for $58.38 \%$ of the variance in the items and contained 10 items including 6 of the 8 items in the original LMX scale and all 4 items in the trust in supervisor scale. The items of this factor (Supervisory Relationship) had an estimated reliability of .92. The second factor accounted for $8.67 \%$ of the variance in the items and contained 2 items from the LMX scale. The two items of the second factor (Standing with Supervisor) had an estimated reliability of .89 . One item from this factor was "I know where I stand with my supervisor." Since the first factor best captured the conceptual content of the LMX and trust in supervisor scales, this factor was further explored.

Supervisory relationship was related to distributive justice $(\underline{\mathrm{r}}=.50, \mathrm{p}<.001)$, procedural justice $(\mathrm{r}=.50, \mathrm{p}<.001)$, organizational commitment $(\mathrm{r}=.61, \mathrm{p}<.001)$, job satisfaction $(\underline{r}=.57, \underline{p}<.001)$, intention to quit $(r=-.50, \underline{p}<.001)$, in-role performance $(\underline{r}=.26, \underline{p}<.01)$, OCBI $(\underline{r}=.30, \underline{p}<.001)$, OCBO $(\underline{r}=.17, \underline{p}<.05), a$ modified measure of ORB directed at an individual $(\mathrm{r}=-.11, \mathrm{p}<.05$ two-tailed) (the modified measure of ORBI is discussed in the next section).

For the post-manipulation data the factor analysis of the trust in supervisor and LMX scales resulted in a single factor solution. This 12-item factor accounted for 
$71.87 \%$ of the variance in the items and had an estimated reliability of .96 . This variable, post supervisory relationship, was related positively to post-manipulation perceptions of distributive justice $(\underline{r}=.62, \underline{p}<.001)$, procedural justice $(\underline{r}=.59, \underline{p}<$ $.001)$, organizational commitment $(\underline{r}=.66, \underline{p}<.001)$, job satisfaction $(\underline{r}=.61, \underline{p}<$ $.001)$, in-role performance $(r=.40, p<.001)$, OCBI $(r=.34, p<.001)$, OCBO $(r=$ $.35, \mathrm{p}<.001)$. Post supervisory relationship was also negatively related to intention to quit $(\mathrm{r}=-.32, \underline{\mathrm{p}}<.001)$, and modified measures of ORBI $(\underline{\mathrm{r}}=-.17, \underline{\mathrm{p}}<.05)$ and ORBO $(\underline{r}=-.29, \underline{p}<.01)$.

The factor analytic results suggested that participants were unable to make a distinction between LMX and trust in supervisor as measured here. Additionally, the new combined measure (supervisory relationship) was related in expected ways to distributive justice, procedural justice, and all but one of the outcome variables (i.e., pre-manipulation ORBO).

Organizational Retaliatory Behavior. As noted in the results section, when all items in the ORB scale were initially factor analyzed, the two expected dimensions did not appear as hypothesized. Therefore, the 18 items in the ORB scale were factor analyzed using a principal components method with oblique rotation. The initial factor analyses resulted in 3 items cross-loading. After eliminating these items, for the premanipulation data a four-factor solution accounted for $61.86 \%$ of the variance in the items. The first factor consisted of five items $(\alpha=.80)$ and reflected a time wasted dimension ( $(\mathrm{ORB}-\mathrm{time})$. One item from this factor was "Tried to look busy while wasting time." The second factor consisted of five items $(\alpha=81)$ and reflected ORB 
directed at individuals ( rumors about coworkers." The third factor consisted of four items $(\alpha=.81)$ and reflected a severe ORB dimension (ORB-severe). One item for this factor was "On purpose, damaged equipment or work processes." The last factor consisted of the single item asking about drug and alcohol use.

ORBI-mod was related to pre-supervisory relationship $(\underline{r}=-.11, \underline{p}<.05$ twotailed). No relationships were found between the three new subscales and distributive justice or procedural justice. However, both ORBI-mod $(\underline{r}=-.15, \underline{p}<.05)$ and ORBtime $(\mathrm{r}=-.18, \underline{\mathrm{p}}<.01)$ were negatively related to organizational commitment.

For the post-manipulation data, three factors best represented the data. The initial factor analysis resulted in six items that cross-loaded. After eliminating these items, a two-factor solution accounted for $66.66 \%$ of the variance in the items. The first factor contained 7 items $(\alpha=.92)$ that reflected ORBO (post-ORBO-mod). One item from this factor was "Called in sick when not ill." The second factor contained four items $(\alpha=.89)$ that reflected the ORBI (post-ORBI-mod).

The post- ORBI scale was negatively related to post-manipulation perceptions of trust in supervisor $(\mathrm{r}=-.18, \mathrm{p}<.05), \operatorname{LMX}(\mathrm{r}=-.15, \mathrm{p}<.05)$, supervisory relationship (i.e., combined trust in supervisor and LMX measure) $(r=-.17, \underline{p}<.05)$, distributive justice $(\underline{r}=-.12, \underline{\mathrm{p}}<.05)$, job satisfaction $(\underline{\mathrm{r}}=-.20, \underline{\mathrm{p}}<.05)$, and organizational commitment $(\mathrm{r}=-.15, \mathrm{p}<.05)$. The modified ORBI scale was also positively related to intentions to quit $(\mathrm{r}=.20, \mathrm{p}<.05)$. 
The post-manipulation modified ORBO scale was negatively related to

trust in supervisor $(\mathrm{r}=-.23, \mathrm{p}<.05), \operatorname{LMX}(\mathrm{r}=-.30, \mathrm{p}<.001)$, supervisory

relationship (i.e., combined trust in supervisor and LMX measure) $(r=-.29, \mathrm{p}<.001)$,

distributive justice $(\underline{r}=-.22, \underline{p}<.05)$, job satisfaction $(\underline{r}=-.30, \underline{p}<.001)$, and

organizational commitment $(\underline{r}=-.31, \underline{p}<.001)$. The modified ORBO scale was also

positively related to intentions to quit $(\mathrm{r}=.26, \mathrm{p}<.05)$.

The results of the pre- and post-manipulation reports of ORB, as measured with the modified scales, showed mixed results in terms of the relationship between ORB and supervisory relationship, distributive justice, and procedural justice. Although the primary interest in ORB was at it related to trust, LMX, and organizational justice, both modified ORB subscales showed some expected relationships with the positive outcome variables.

The General Fairness Heuristic. Lind (2001) suggested that members of organizations encounter a "fundamental social dilemma" throughout their workdays. Employees must decide on a continual basis how to spend their time. How much time does one spend contributing to the larger goals of the organization (e.g., helping out a colleague, putting extra hours) at the potential expense of one's personal interests and identity (e.g., doing only one's own work, spending time with family). Lind asserted that to resolve this dilemma, employees rely on general perceptions of fairness as a decision heuristic. That is, if one believes that he or she is treated fairly, then one is more likely to act in ways that further organizational goals even at the expense of one's personal interests. To the extent that one believes that he or she has been treated unfairly, one is less likely to engage in behaviors that will further organizational goals 
and may even engage in behaviors that harm the organization. Importantly, these general fairness judgments also affect workplace attitudes.

No support was originally found for the interaction between distributive and procedural justice on the outcome variables. Lind (2001) argued that while the interaction between distributive justice and procedural justice is frequently found, it is not always found. Brockner and Weisenfeld (1994) found the interaction in 20 field studies, however this represents only a portion of studies that examined distributive and procedural justice. For example, in a meta-analysis, Colquitt et al. (2001) found 95 studies that included some conceptualization of both procedural and distributive justice. Additionally, Colquitt et al. found an uncorrected population correlation between distributive justice and procedural justice of .56 in these studies. Unfortunately, Colquitt et al. did not test for the interaction effect in their metaanalysis. Given the non-universality of the interaction effect and the strong correlation of distributive and procedural justice, Lind suggested that perhaps a better, more parsimonious theoretical explanation that may account for more of the observed findings is that distributive and procedural justice have unique and reciprocal effects on overall fairness judgments. While not abandoning the idea that distributive and procedural justice interact to influence outcomes, recently Brockner (2002) agreed with Lind's suggestion that the interaction explanation may be too general. Support for this explanation was found in the analysis of the full model in Study One. It was found that both procedural justice and distributive justice were influenced by the latent variable "Overall Fairness". 
Additionally, it is possible to test for the presence of the effect of an overall

fairness judgment utilizing the post-manipulation data. If an overall fairness judgment was operating, it would be expected that when both distributive and procedural justice were high this would be associated with the highest levels of the positive outcome variables (e.g., job satisfaction, organizational commitment) and the lowest levels of the negative outcomes (i.e., intention to quit, ORB) relative to the other conditions. Additionally, it would be expected that when either distributive or procedural justice was low that this would be related to lower perceptions of the positive outcome variables and higher levels of the negative outcome variables. Lastly, the condition in which both distributive and procedural justice were low would be associated with the lowest levels of the positive outcomes and the highest levels of the negative outcomes. An examination of the post-manipulation means of the outcome variables shows that the expected pattern is evident (Table 6). To test mean differences, a series of one-way ANOVAs were run with Tukey's HSD post hoc comparisons. Tables 35 contains the results of these analyses.

The expected mean difference pattern was generally supported. Participants in the high distributive justice/high procedural justice condition generally reported significantly higher levels of the positive outcome variables relative to those in the other three conditions. There were no statistically significant mean differences on the outcome variables between participants who were in one of the two conditions were only distributive or procedural justice was low. Lastly, participants in the low distributive justice/low procedural justice condition generally reported significantly lower levels of the positive outcome variables and higher levels of the negative 
outcomes than those in the other three conditions This pattern of results suggests that when either procedural justice or distributive justice is adversely affected, that there is an adverse effect on positive outcomes. The results provide overall support for the effect of a general fairness heuristic.

A series of 2 (procedural and distributive justice) $\times 2$ (high and low) ANOVAs were run to further examine the general fairness heuristic. If there were main effects for distributive and procedural justice and no interaction effects, this would provide support for the general fairness heuristic. Results of these ANOVAs indicated that there were main effects for procedural justice on trust in supervisor (mean square $=$ $22.68, \underline{F}=21.21, \underline{p}<.001)$, organizational commitment (mean square $=13.07, \underline{F}=$ $15.56, \mathrm{p}<.001$ ), job satisfaction (mean square $=12.17, \underline{\mathrm{F}}=16.42, \underline{\mathrm{p}}<.001$ ), intention to quit (mean square $=3.99, \underline{\mathrm{F}}=3.88, \underline{\mathrm{p}}<.05$ ), and job performance (mean square $=$ $2.58, \underline{F}=4.94, \underline{p}<.05)$. There were main effects for distributive justice on trust in supervisor $($ mean square $=28.87, \underline{\mathrm{F}}=26.89, \underline{\mathrm{p}}<.001$ ), organizational commitment $($ mean square $=20.93, \underline{\mathrm{F}}=24.91, \underline{\mathrm{p}}<.001)$, job satisfaction $($ mean square $=16.46, \underline{\mathrm{F}}=$ $22.22, \underline{\mathrm{p}}<.001$ ), intention to quit (mean square $=4.61, \underline{\mathrm{F}}=4.48, \underline{\mathrm{p}}<.05$ ), job performance $($ mean square $=11.57, \underline{F}=22.16, \underline{p}<.001)$, OCBI $($ mean square $=6.95$, $\underline{F}=13.02, \underline{p}<.001)$, OCBO (mean square $=13.14, \underline{F}=27.98, \underline{p}<.001)$, ORBI $($ mean square $=6.72, \underline{F}=8.26, \underline{p}<.001)$, and $\mathrm{ORBO}($ mean square $=7.90, \underline{\mathrm{F}}=13.36, \underline{\mathrm{p}}<$ .001). No interaction effects were found. Therefore, there is support for the general fairness heuristic.

Modified Full-Model Analyses. Based on the factor analytic results and the subsequent changes in the measures for trust in supervisor, LMX, and ORB a series of 
models was run. In this series of models, dispositional trust was not included. Second, supervisory relationship (i.e., combined trust in supervisor and LMX measure) replaced both LMX and trust in supervisor from the original model (Figure 26). Lastly, the three subscales of the modified ORB measure were included. As with the previous model analyses, a single indicator model was utilized. This initial model is depicted in Figure 26.

The full model did not fit the data well (Table 36). Model 3 reflected the elimination of paths from the model that were statistically non-significant. Model 3 was a moderately good fit to the data (Table 36). In Model 4, paths were added between the outcome variables that have been found in previous research. Specifically, job satisfaction, intention to quit and organizational commitment were allowed to covary, and paths were added between performance and OCBI, and ORBI modified and ORB time wasted. This model fit the data very well (Table 36). Model 4 is depicted in Figure 27.

Since dispositional trust was related to some of the outcome variables, perhaps it was the case in this data that dispositional trust did not operate as predicted, but could still be an important variable in the model. Therefore, a model was run where dispositional trust was directly related to all outcomes (Model 5). Non-significant paths were eliminated from Model 5 (i.e., paths between dispositional trust and job satisfaction, intention to quit, and organizational commitment) to create Model 6. Although Model 6 is not a well-fitting model, the paths between dispositional trust and all of the behavioral outcomes were significant. Specifically, dispositional trust was 
negatively related to performance, $\mathrm{ORCBI}$, and $\mathrm{OCBO}$, and positively related to ORBI and ORBO.

Overall, many of the hypothesized relationships were found in the laboratory study. Four of these findings contribute new knowledge to the literature. First, LMX and trust in supervisor were strongly related. Second, perceptions of organizational justice partially mediated relationships between LMX and attitudinal variables. Third, evidence was found the existence of a general fairness judgment. Lastly, in post hoc analyses supervisory relationship was related to organizational retaliatory behaviors. The major exception was the finding that there was not a relationship between dispositional trust and trust in supervisor even when considering only those participants with relatively short tenure (i.e., less than one year) with their supervisors. While examining these relationships in a laboratory setting provided a unique opportunity to manipulate perceptions of organizational justice and study the relationships of interest across a diverse sample of jobs, additional information could be gathered by collecting data in a field setting. Collecting data in a professional, field setting with full-time employees allowed for testing the hypothesized model where the consequences of LMX and organizational justice were real. 


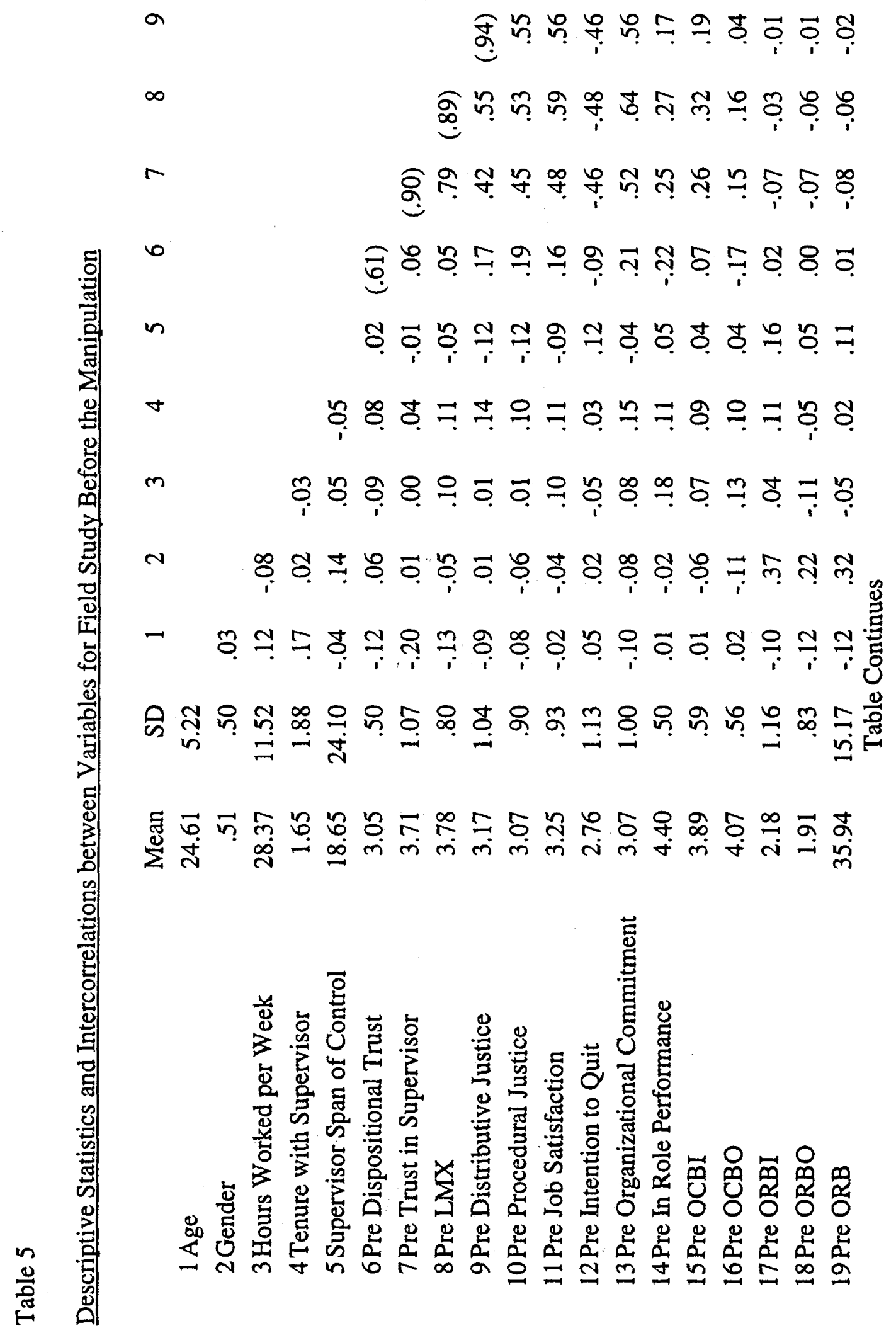



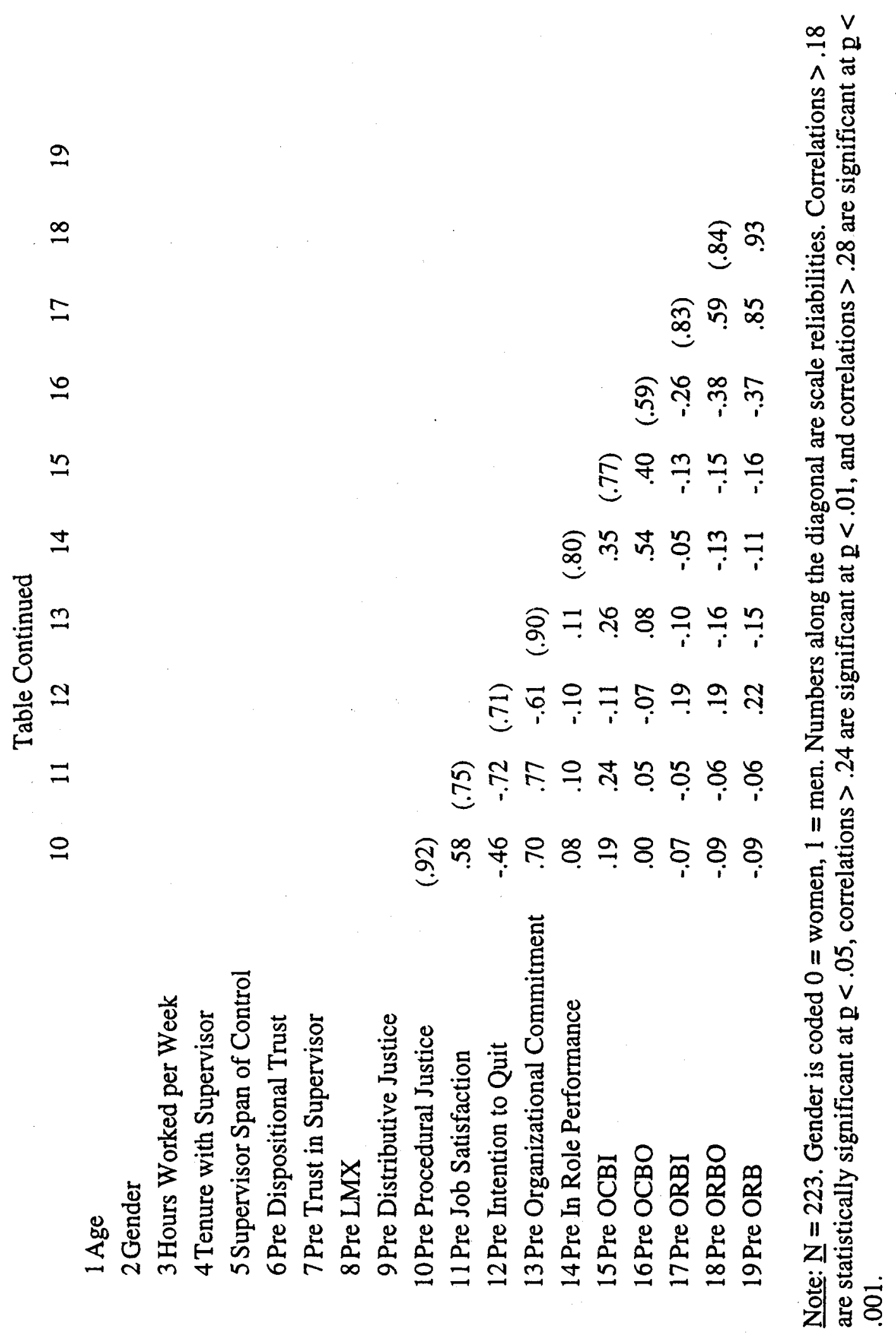


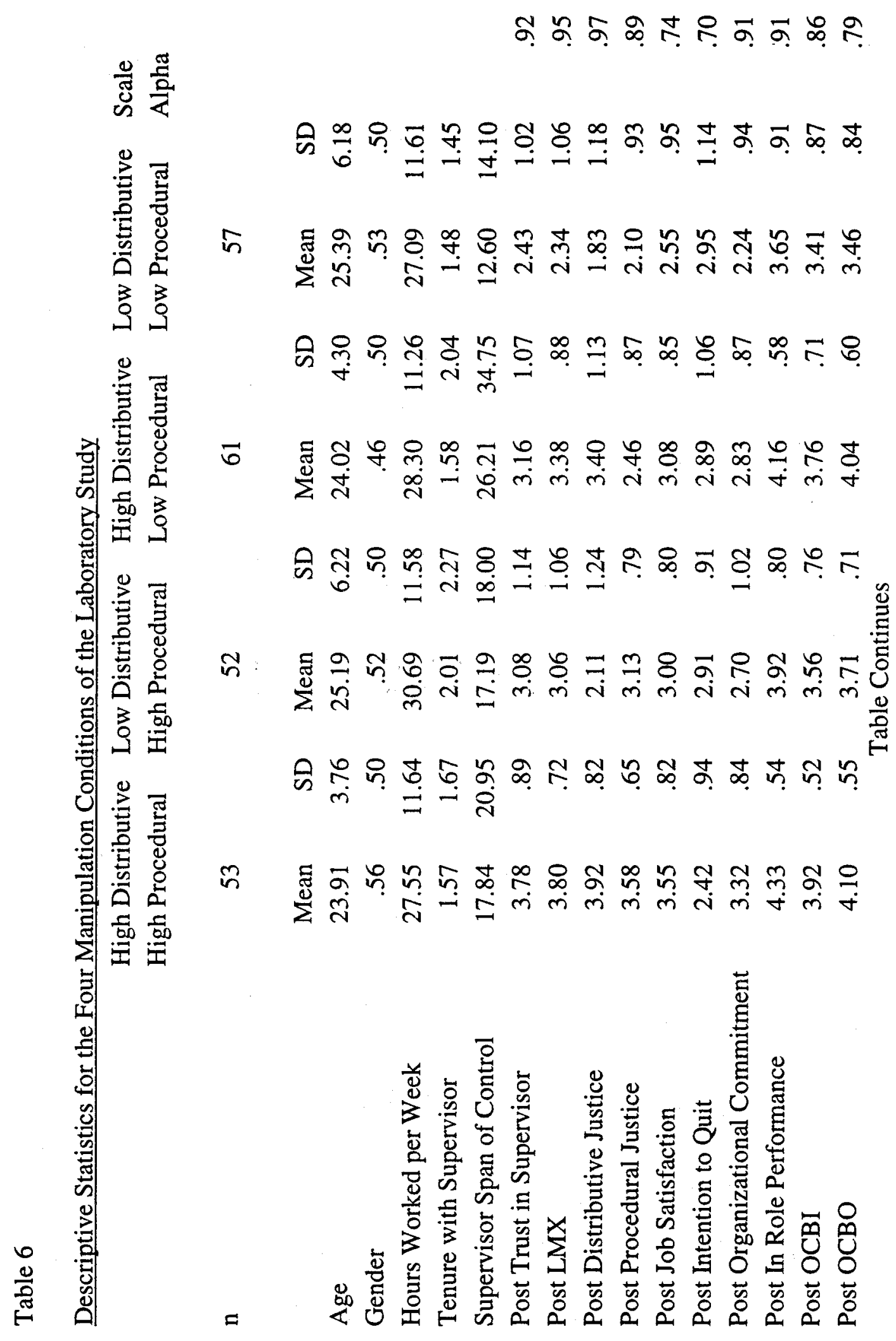




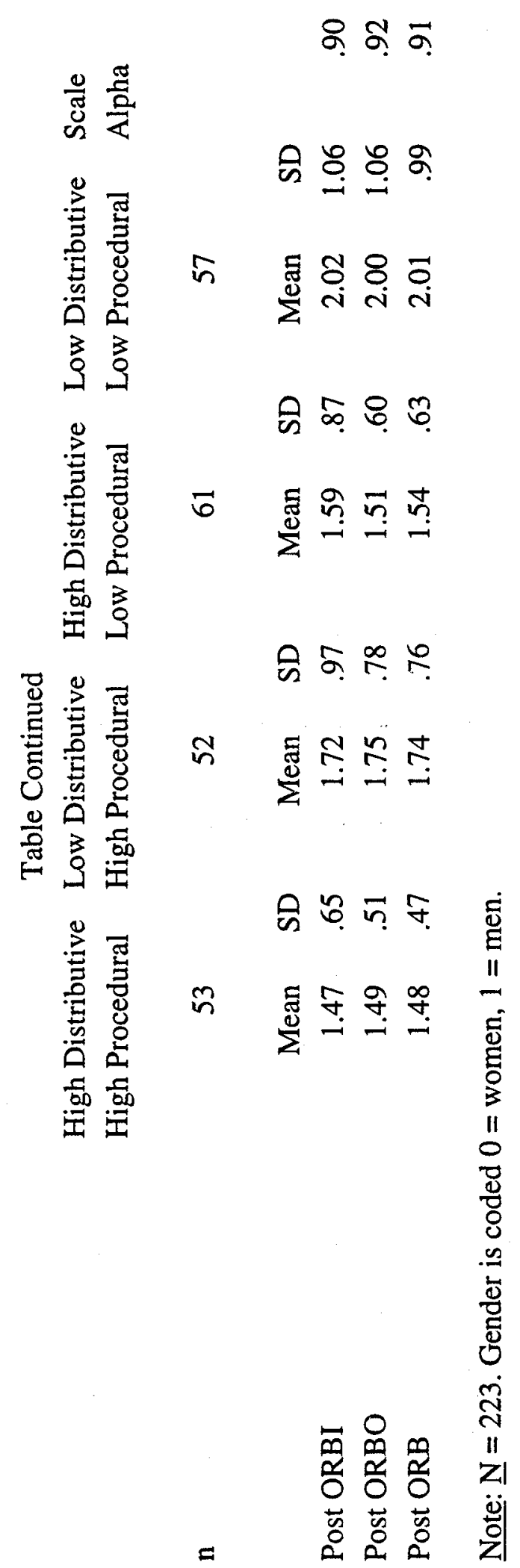




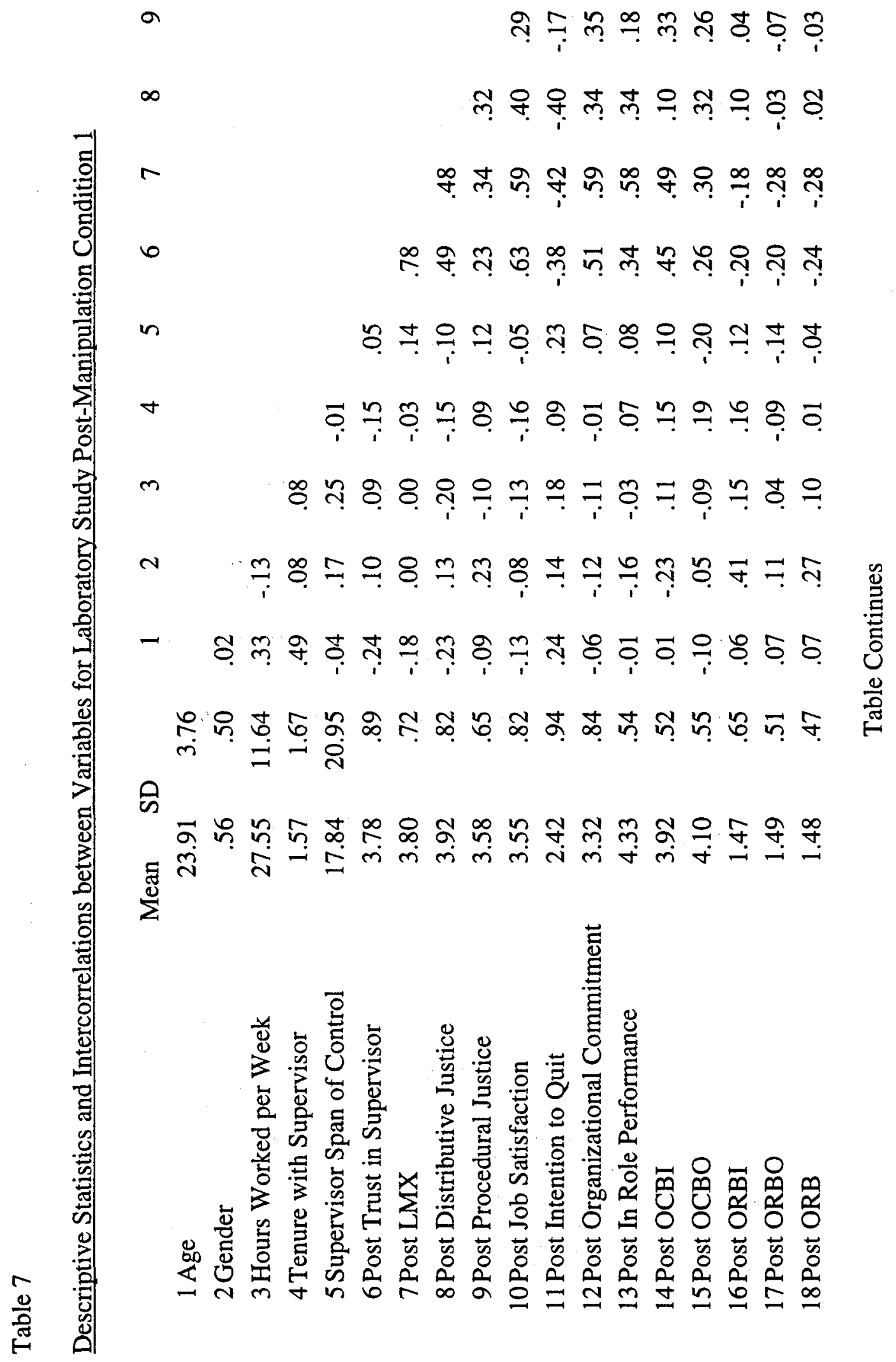




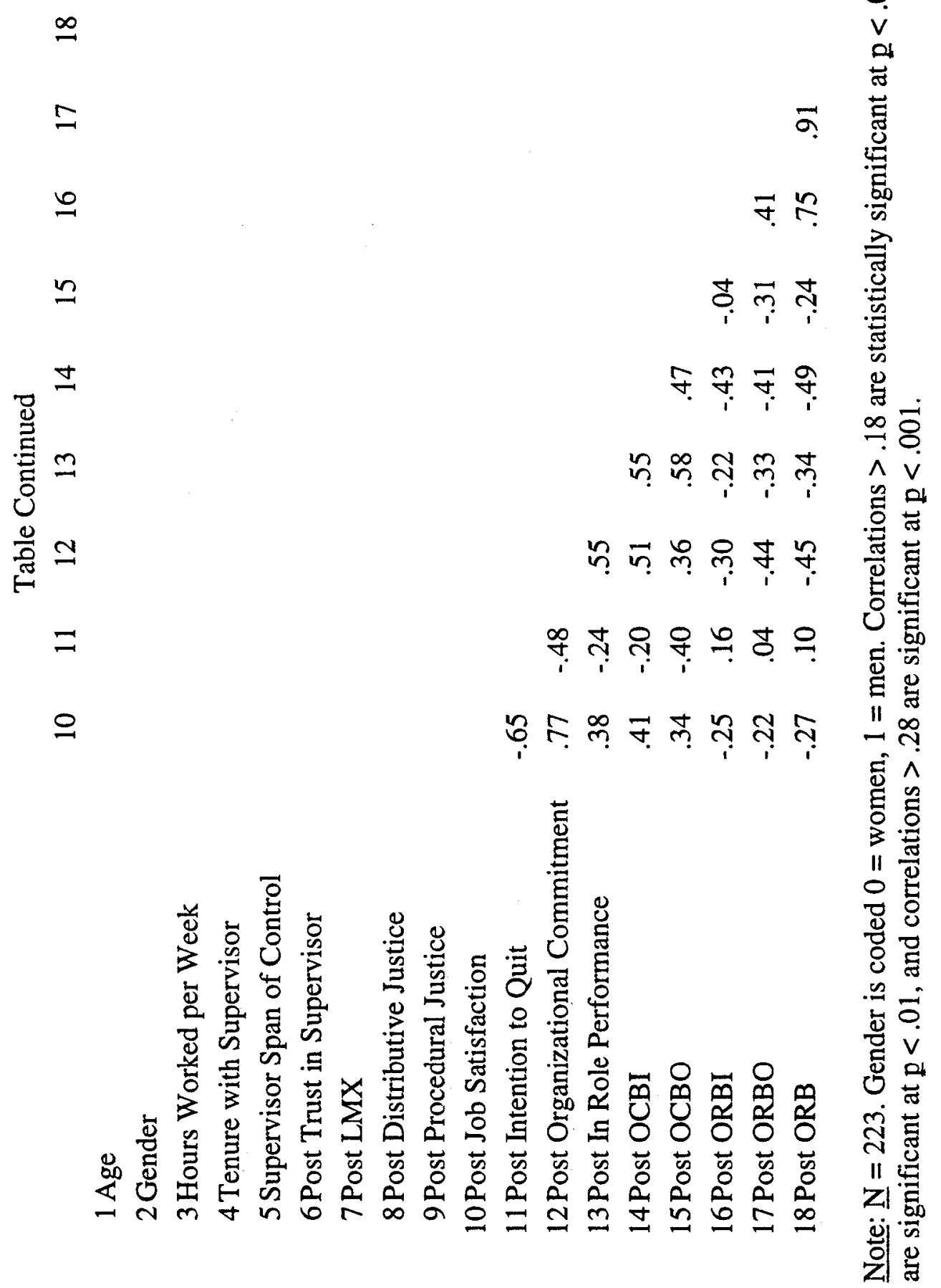


$a$

$\infty$

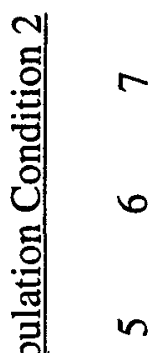

$\forall$

$n$

$N$

- กิ

은 균

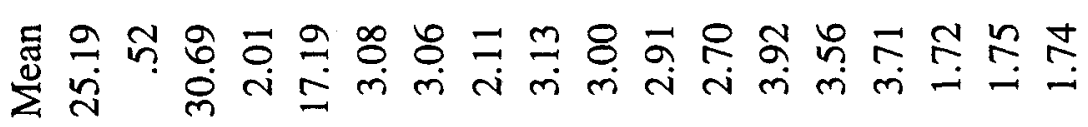

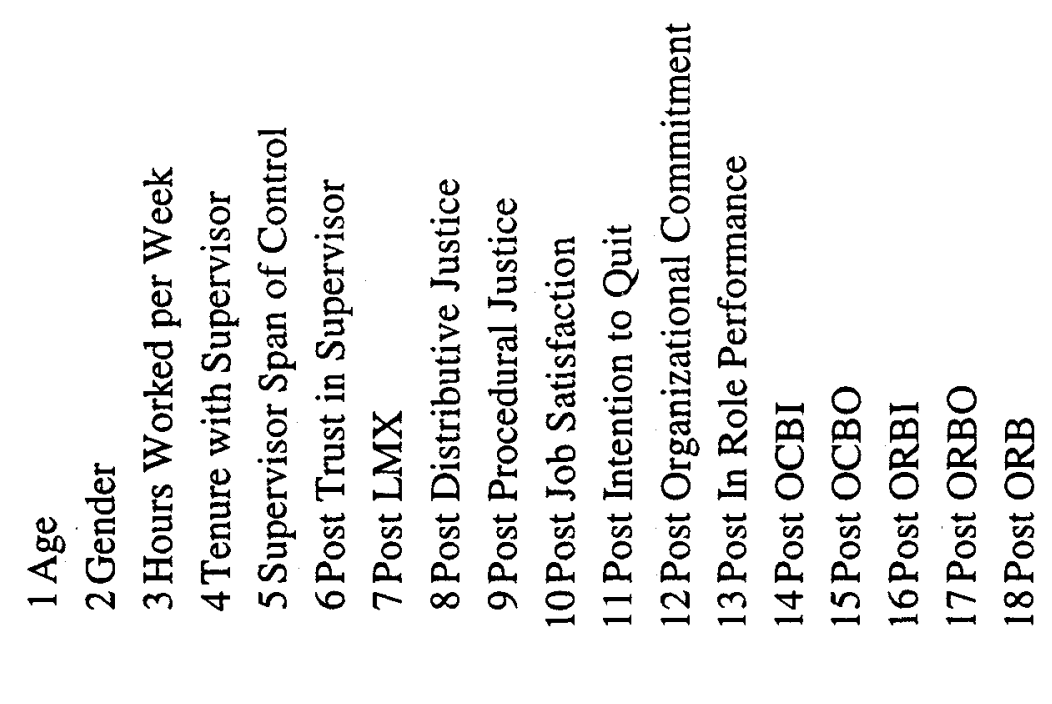




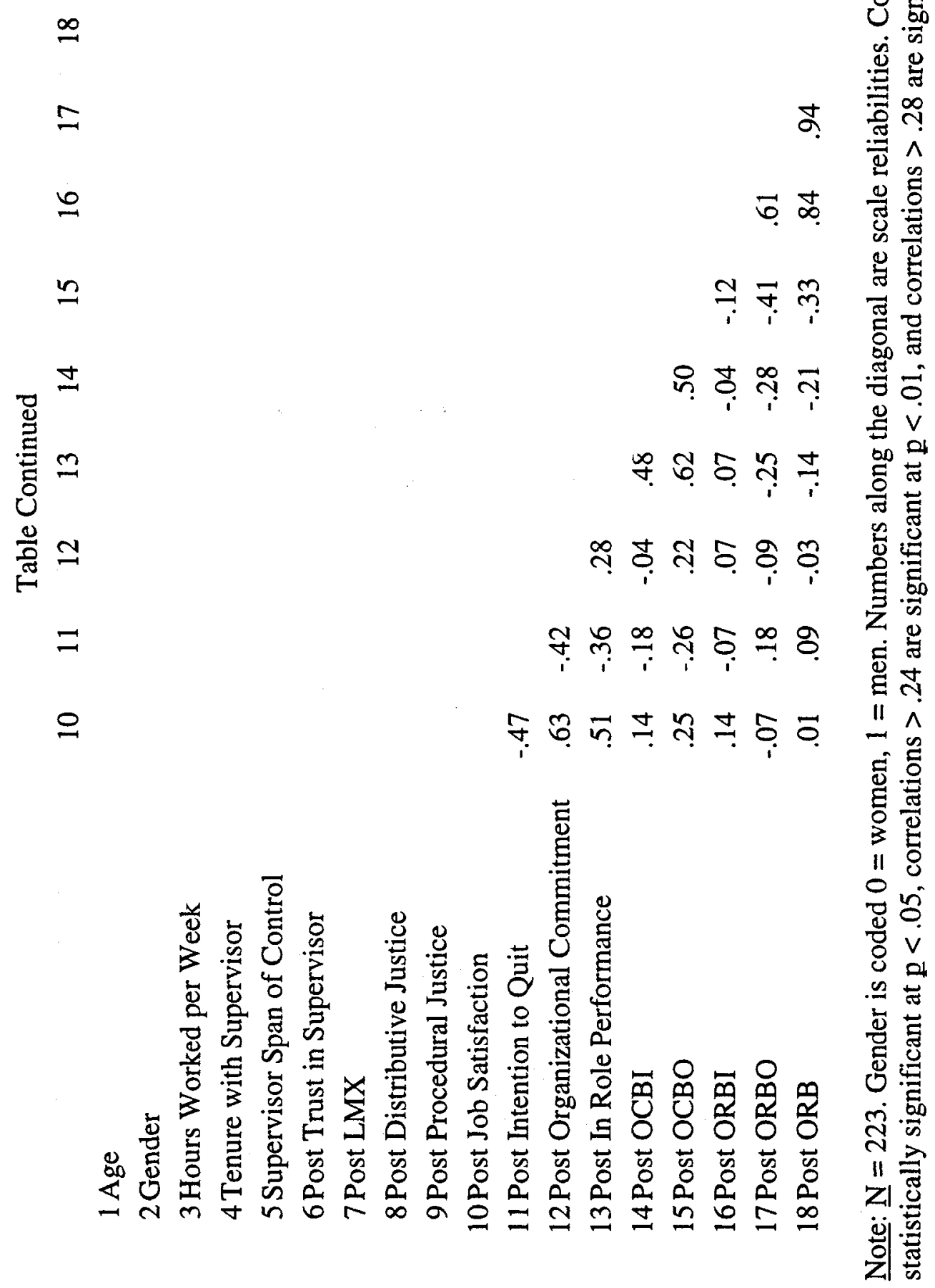




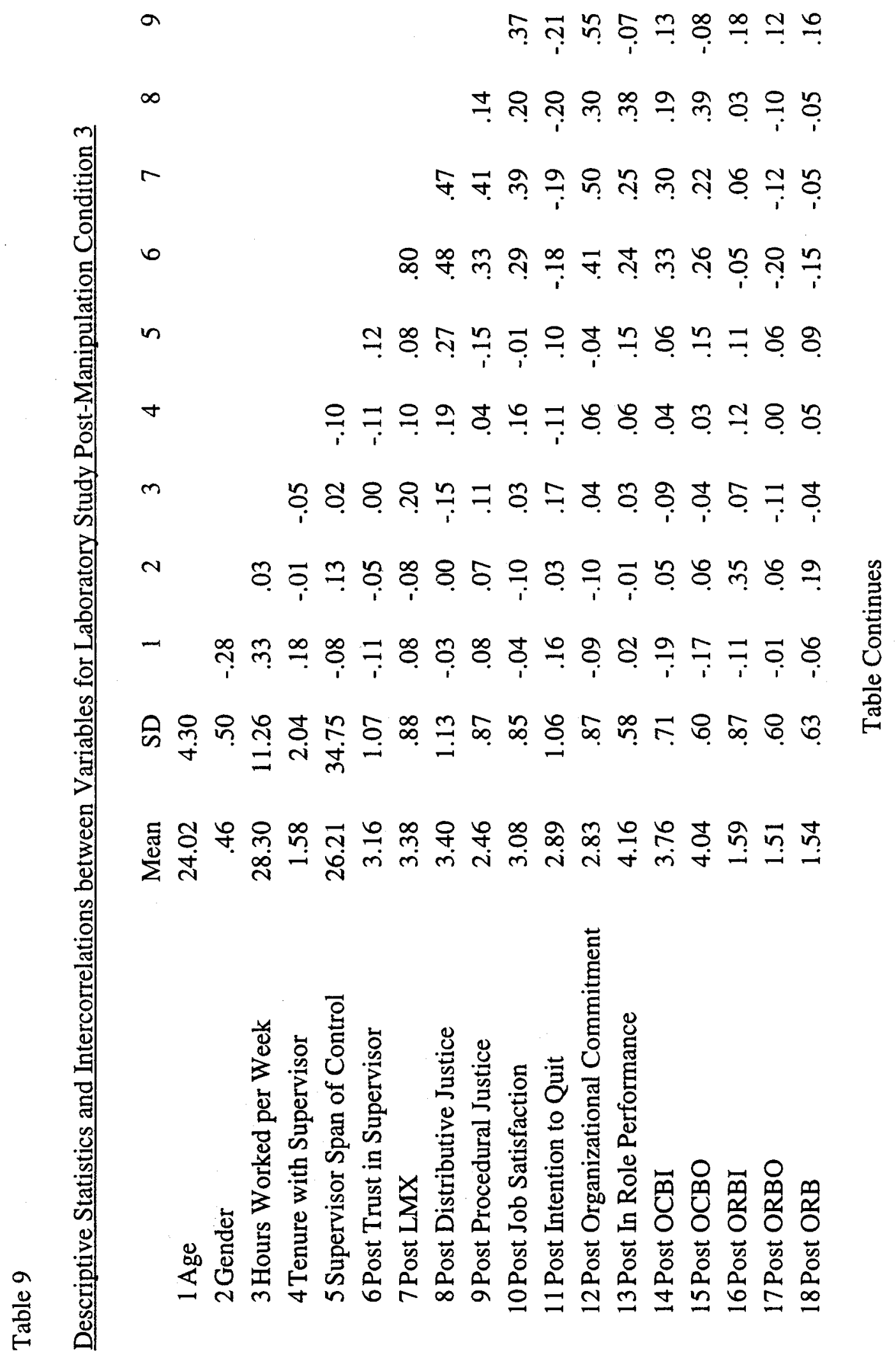




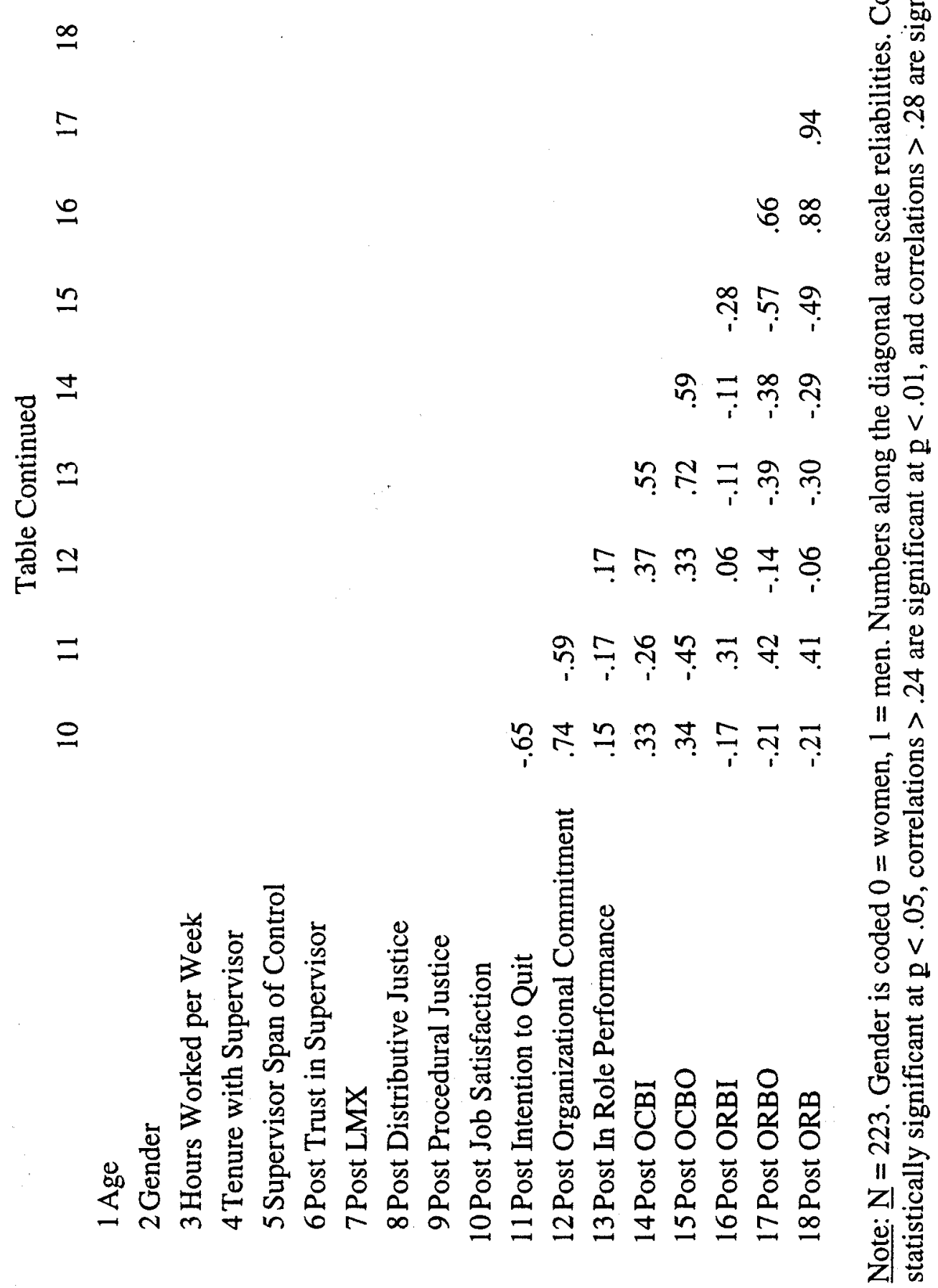




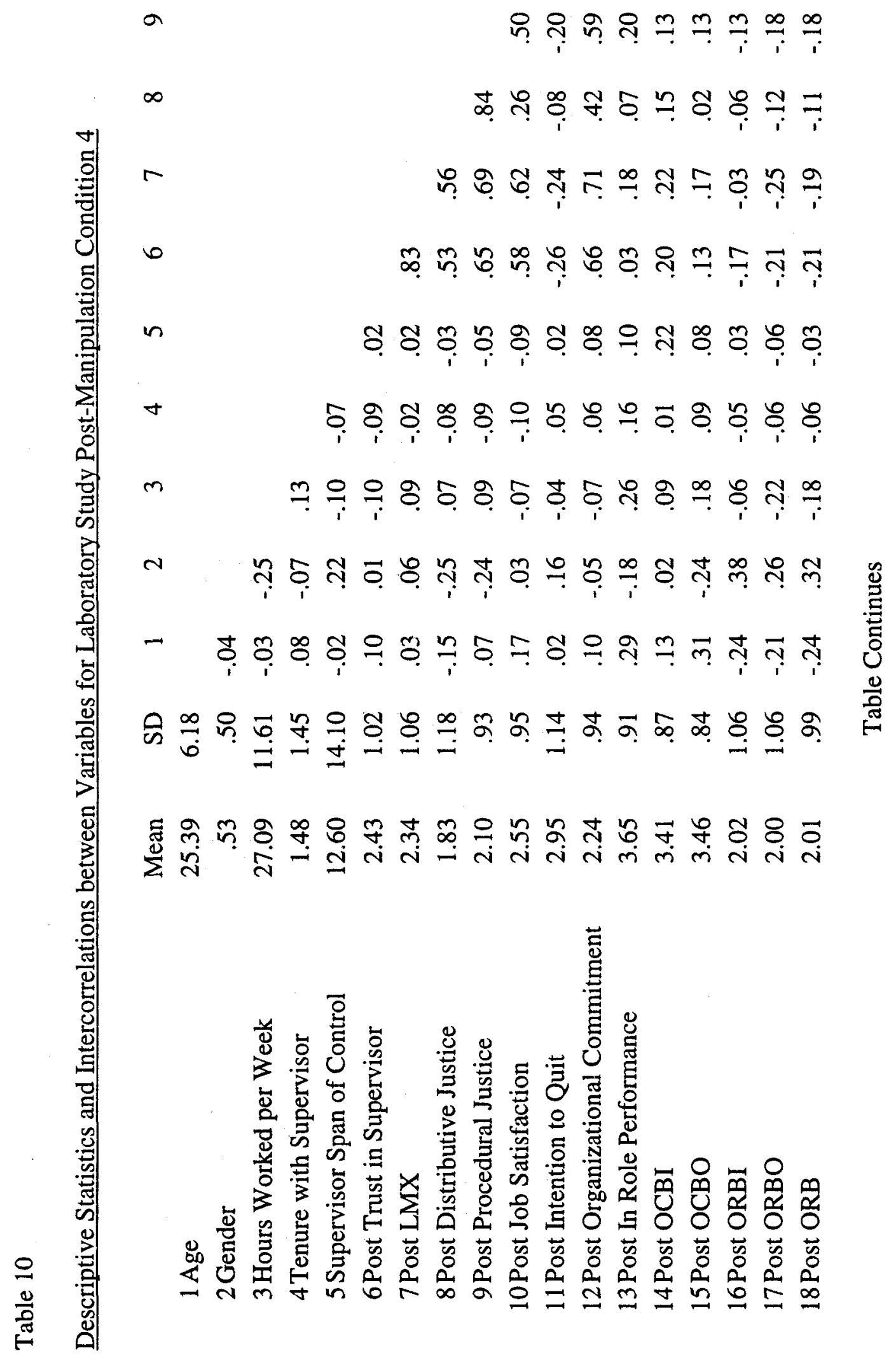




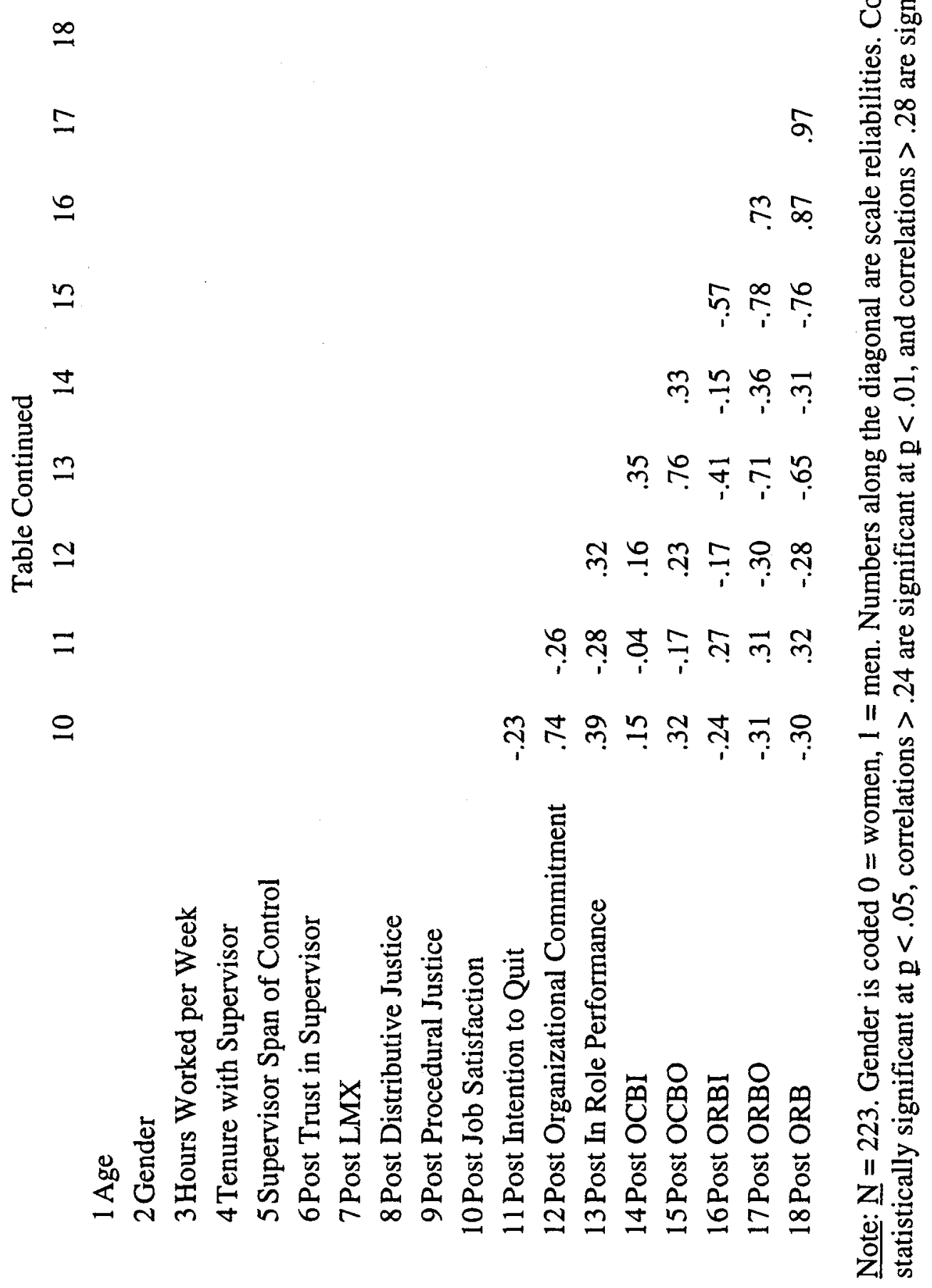


Table 11

The Relationship between Trust in Supervisor and LMX with Control Variables

\begin{tabular}{|c|c|c|c|c|}
\hline & B & $\mathrm{R}^{2}$ & $\Delta \mathrm{R}^{2}$ & $\mathrm{~F}$ \\
\hline Step 1 & & .06 & & $2.51^{*}$ \\
\hline Age & -.14 & & & \\
\hline Gender & .08 & & & \\
\hline Hours Worked & -.03 & & & \\
\hline Tenure with Organization & .19 & & & \\
\hline Tenure with Supervisor & .12 & & & \\
\hline $\begin{array}{l}\text { Span of Control of } \\
\text { Supervisor }\end{array}$ & -.05 & & & \\
\hline
\end{tabular}

Step 2

Trust in Supervisor

$.65 \quad .59 \quad 355.52 * *$

Note: $\underline{N}=223$. Gender is coded Male $=1$, Female $=0$. Beta weights are from the final equation.

$*^{*} \mathrm{p}<.05$.

$* * \mathrm{p}<.01$. 
Table 12

The Interaction of Distributive and Procedural Justice on OCBI

\begin{tabular}{llrrrr} 
& & $\mathrm{B}$ & $\mathrm{R}^{2}$ & $\Delta \mathrm{R}^{2}$ & $\mathrm{~F}$ \\
\hline Step 1 & & & .02 & & .890 \\
& Age & .05 & & & \\
& Gender & -.04 & & & \\
& Hours Worked & .05 & & & \\
& Tenure with Supervisor & .06 & & & \\
& Span of Control of & .07 & & & \\
& Supervisor & & & & \\
& & & & & \\
Step 2 & Organizational Justice & & .06 & .04 & \\
& Distributive Justice & $-.77^{* *}$ & & & \\
& Procedural Justice & $-.65^{* *}$ & & & \\
& & & & & \\
Step 3 & Interaction & $1.47^{* *}$ & .13 & .08 & $18.83^{* *}$ \\
& DJ x PJ & & & & \\
\hline
\end{tabular}

Note: $\underline{N}=223$. Gender is coded Male $=1$, Female $=0$. Beta weights are from the final equation.

$* * \mathrm{p}<.01$. 
Table 13

The Interaction of Distributive and Procedural Justice on OCBO

\begin{tabular}{|c|c|c|c|c|c|}
\hline \multirow{2}{*}{ Step 1} & & B & \multirow{2}{*}{$\frac{\mathrm{R}^{2}}{.04}$} & $\Delta \mathrm{R}^{2}$ & $\mathrm{~F}$ \\
\hline & & & & & .08 \\
\hline & Age & .02 & & & \\
\hline & Gender & -.10 & & & \\
\hline & Hours Worked & .12 & & & \\
\hline & Tenure with Supervisor & .10 & & & \\
\hline & Span of Control of & .05 & & & \\
\hline & Supervisor & & & & \\
\hline Step 2 & Organizational Justice & & .05 & .01 & .34 \\
\hline & Distributive Justice & $-.51 * *$ & & & \\
\hline & Procedural Justice & $-.53 * *$ & & & \\
\hline Step 3 & $\begin{array}{l}\text { Interaction } \\
\text { DJ x PJ }\end{array}$ & $.96^{* *}$ & .08 & .03 & $7.58 * *$ \\
\hline
\end{tabular}

Note: $\underline{\mathrm{N}}=223$. Gender is coded Male $=1$, Female $=0$. Beta weights are from the final equation.

$* * \mathrm{p}<.01$. 
Table 14

The Interaction of Distributive and Procedural Justice on In-Role Performance

\begin{tabular}{llrrrr} 
& & B & \multicolumn{1}{c}{$\mathrm{R}^{2}$} & \multicolumn{1}{c}{$\Delta \mathrm{R}^{2}$} & \multicolumn{1}{c}{$\mathrm{F}$} \\
\hline Step 1 & & & .05 & & 2.09 \\
& Age & .03 & & & \\
& Gender & -.00 & & & \\
& Hours Worked & $.16^{*}$ & & & \\
& Tenure with Supervisor & .09 & & & \\
& Span of Control of & .06 & & & \\
& Supervisor & & & & \\
Step 2 & Organizational Justice & & .08 & .03 & $3.61^{*}$ \\
& Distributive Justice & $-.81^{* *}$ & & & \\
& Procedural Justice & $-.87^{* *}$ & & & \\
Step 3 & Interaction & $1.67^{* *}$ & .18 & .10 & $25.45^{* *}$ \\
& DJ x PJ & & & & \\
\hline
\end{tabular}

Note: $\underline{\mathrm{N}}=223$. Gender is coded Male $=1$, Female $=0$. Beta weights are from the final equation.

$* \mathrm{p}<.05$.

$* * \mathrm{p}<.01$ 
Table 15

Steps Testing for the Mediation of the Relationship between LMX and Overall Job

Satisfaction by Distributive Justice (Hypothesis 6a)

\begin{tabular}{|c|c|c|c|}
\hline $\begin{array}{c}\text { Mediator Model } \\
\text { Analysis Step }\end{array}$ & $\begin{array}{c}\text { Independent } \\
\text { Variable } \\
\text { (LMX) }\end{array}$ & $\begin{array}{c}\text { Mediator Variable } \\
\text { (Distributive } \\
\text { Justice) }\end{array}$ & $\begin{array}{c}\text { Dependent } \\
\text { Variable } \\
\text { (Overall Job } \\
\text { Satisfaction) }\end{array}$ \\
\hline 1 & $\mathrm{X}$ (significant) & $\mathrm{X}$ \\
\hline 2 & $\mathrm{X}$ (significant) & $\mathrm{X}$ & $\mathrm{X}$ \\
\hline 3 & $\mathrm{X}$ (non-significant) & $\mathrm{X}$ (significant) & \\
\hline
\end{tabular}

Note: An " $\mathrm{X}$ " in the box indicates which variables are in the regression model for a particular step in the mediation analysis. In step two, the mediator variable serves as the dependent variable in the regression model. Full mediation exists if the hypothesized significant relationships are found. 


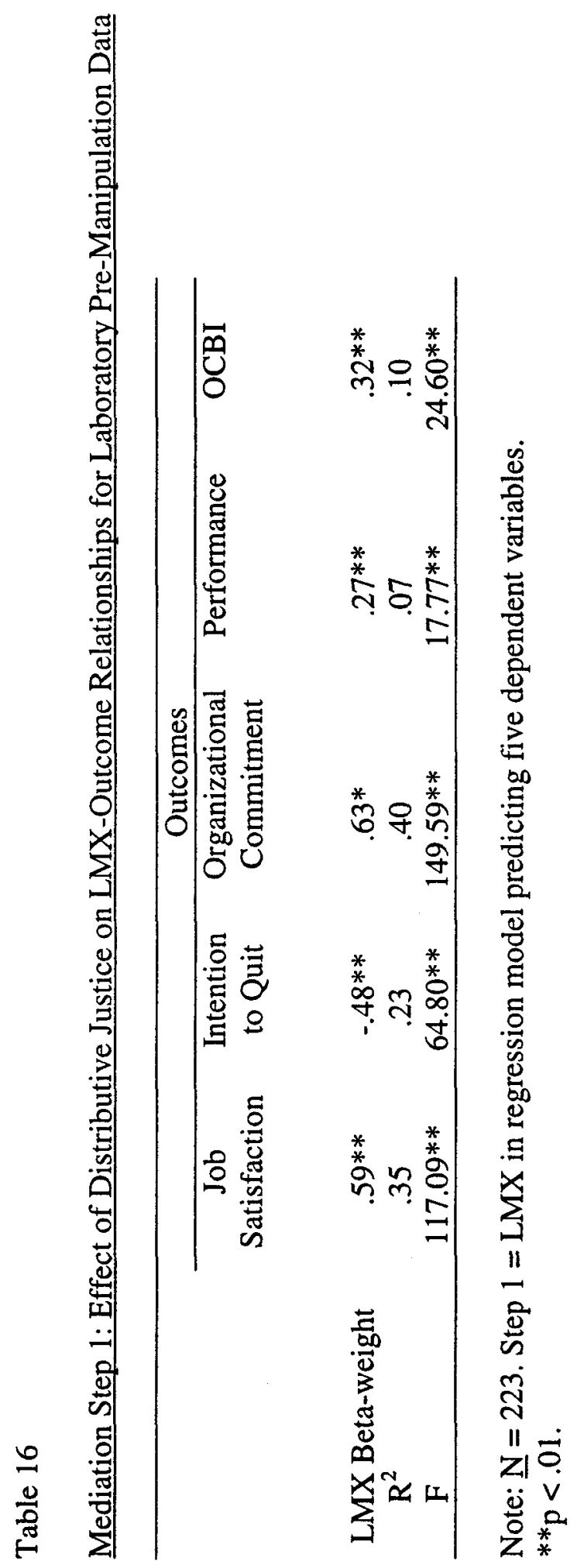




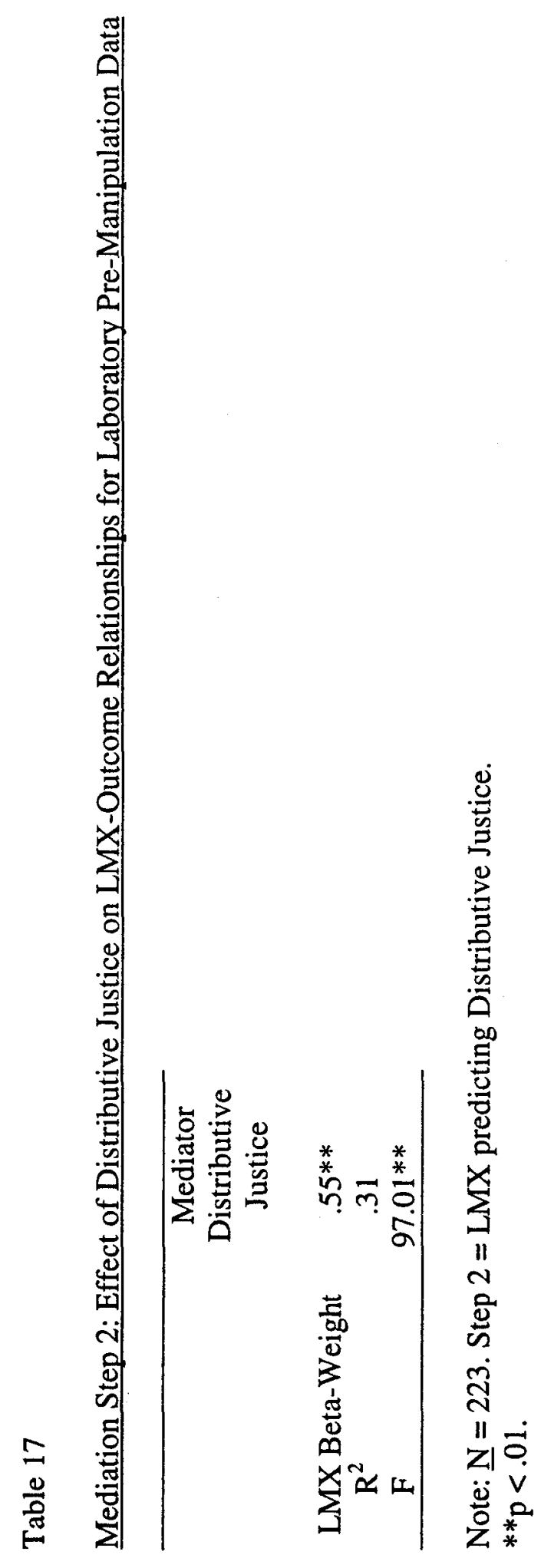




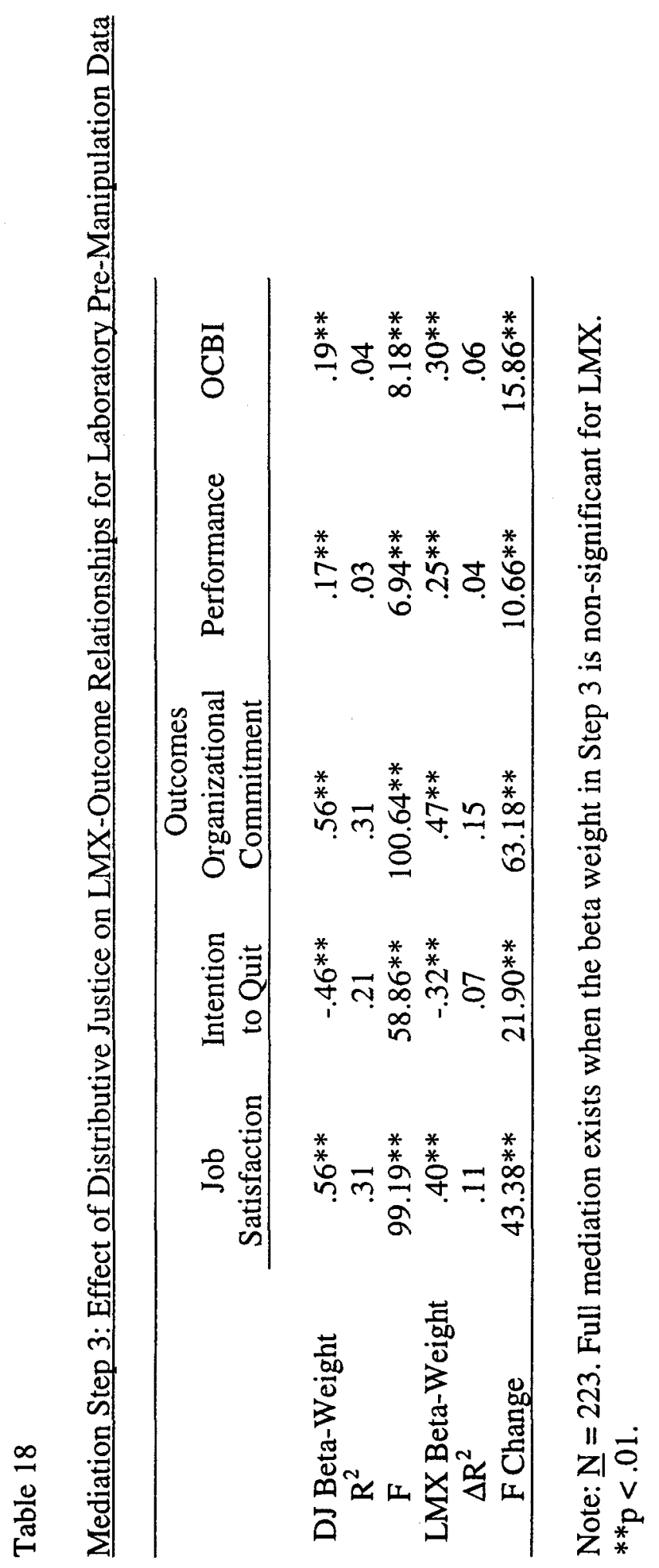


Table 19

Reduction in Variance Accounted by Distributive Justice on LMX-Outcome Relationships

\begin{tabular}{llll}
\hline & $\begin{array}{l}\text { Percentage of } \\
\text { Variance Accounted } \\
\text { for by LMX } \\
\text { Initially }\end{array}$ & $\begin{array}{l}\text { Percentage of } \\
\text { Variance Accounted } \\
\text { for by LMX After } \\
\text { Inclusion of } \\
\text { Distributive Justice } \\
\text { in Mediation Model }\end{array}$ & $\begin{array}{l}\text { Percentage } \\
\text { Decrease of } \\
\text { Variance } \\
\text { Accounted for in } \\
\text { Outcome } \\
\text { Variable After } \\
\text { Inclusion of } \\
\text { Mediator }\end{array}$ \\
\cline { 2 - 4 } & & & Med Satisfaction \\
$\begin{array}{llll}\text { Intention to Quit } \\
\text { Organizational }\end{array}$ & 35 & 11 & 69 \\
Commitment & 23 & 7 & 69 \\
Performance & 7 & 15 & 62 \\
OCBI & 10 & 4 & 43 \\
\hline
\end{tabular}

Note. $\underline{N}=223$. 


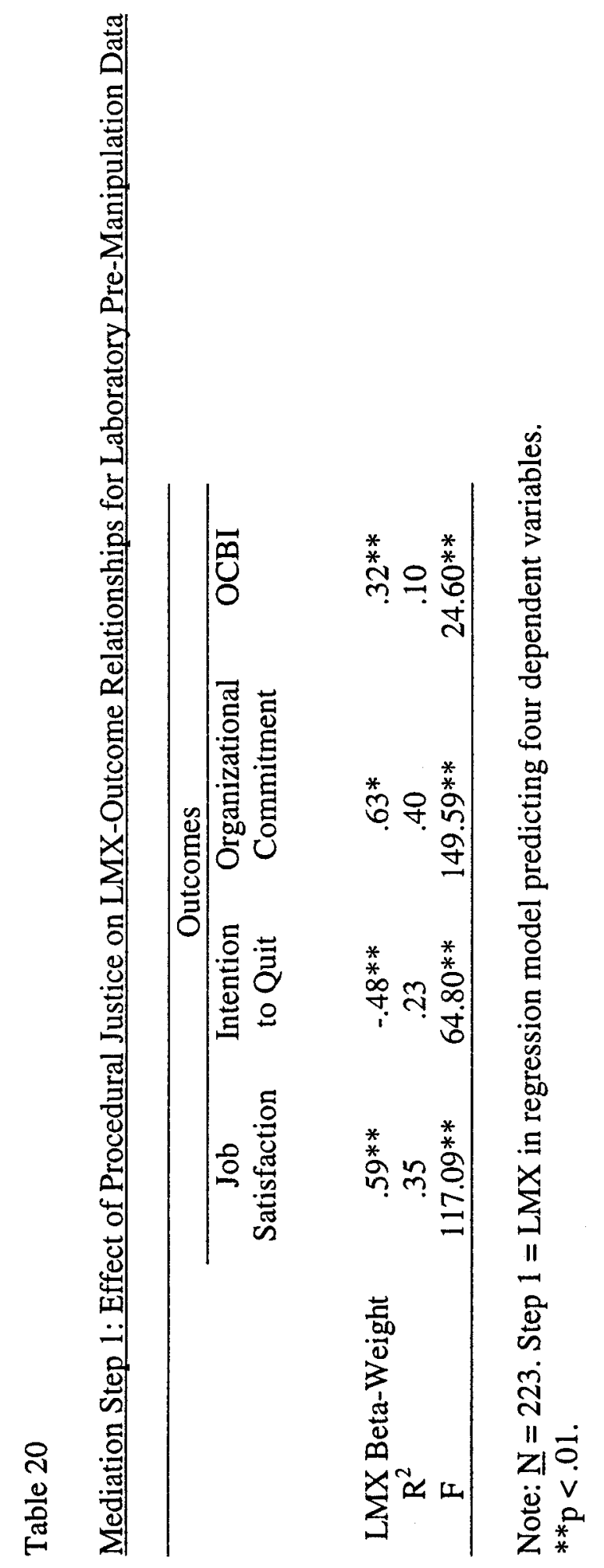




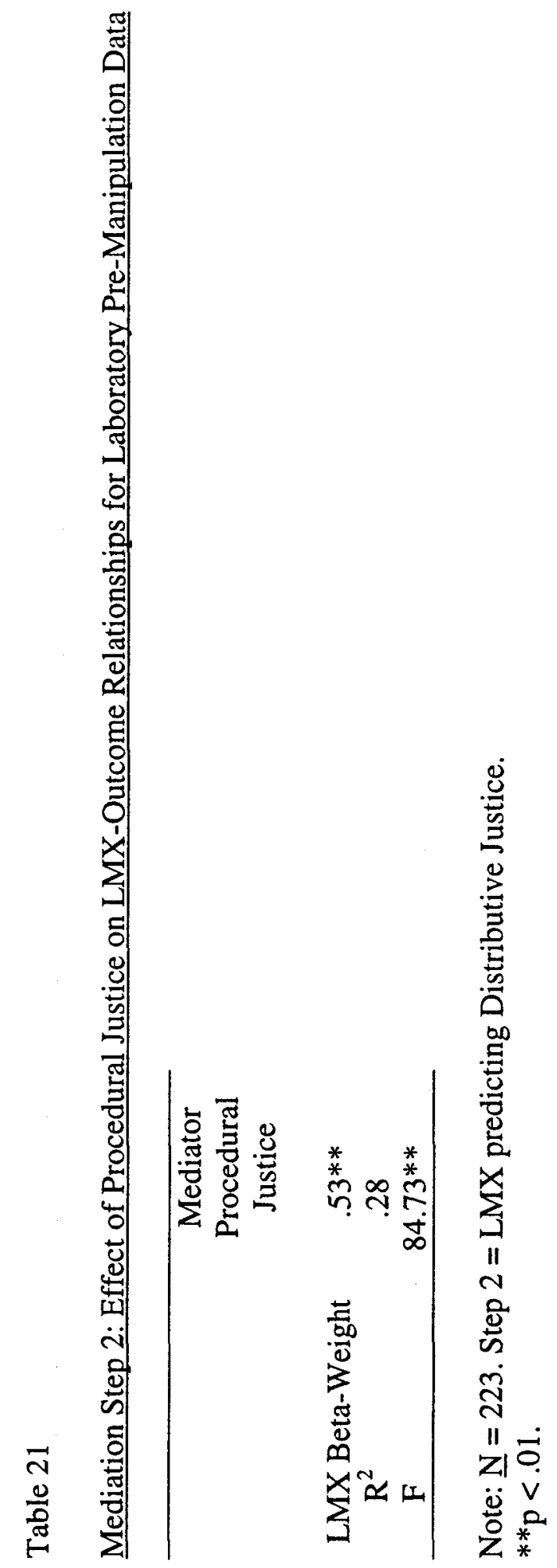




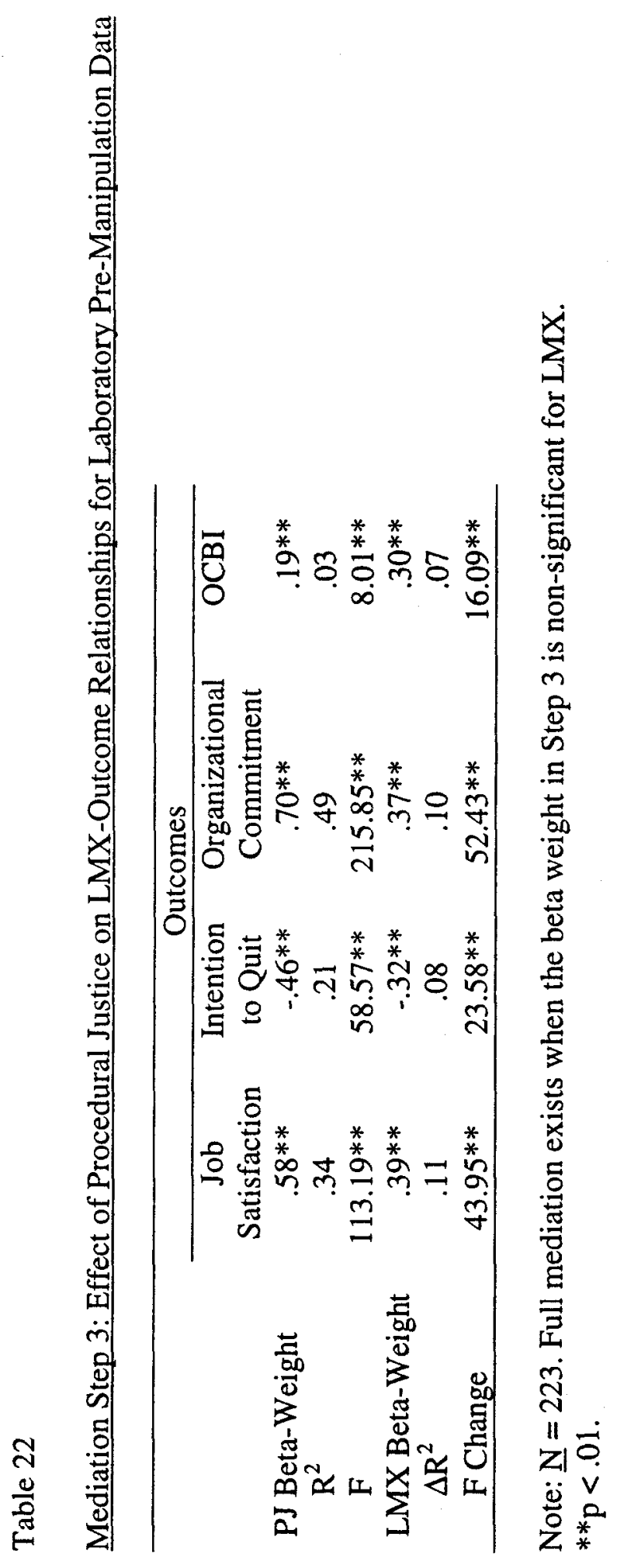


Table 23

Reduction in Variance Accounted by Procedural Justice on LMX-Outcome Relationships

\begin{tabular}{llll}
\hline & $\begin{array}{l}\text { Percentage of } \\
\text { Variance Accounted } \\
\text { for by LMX } \\
\text { Initially }\end{array}$ & $\begin{array}{l}\text { Percentage of } \\
\text { Variance Accounted } \\
\text { for by LMX After } \\
\text { Inclusion of } \\
\text { Procedural Justice } \\
\text { in Mediation Model }\end{array}$ & $\begin{array}{l}\text { Percentage } \\
\text { Decrease of } \\
\text { Variance } \\
\text { Accounted for in } \\
\text { Outcome } \\
\text { Variable After } \\
\text { Inclusion of } \\
\text { Mediator }\end{array}$ \\
$\begin{array}{llll}\text { Job Satisfaction } \\
\text { Intention to Quit }\end{array}$ & 35 & 11 & 69 \\
Organizational & 40 & 8 & 65 \\
Commitment & & 10 & 75 \\
OCBI & 10 & 7 & 30 \\
\hline
\end{tabular}

Note. $. \underline{N}=223$. 


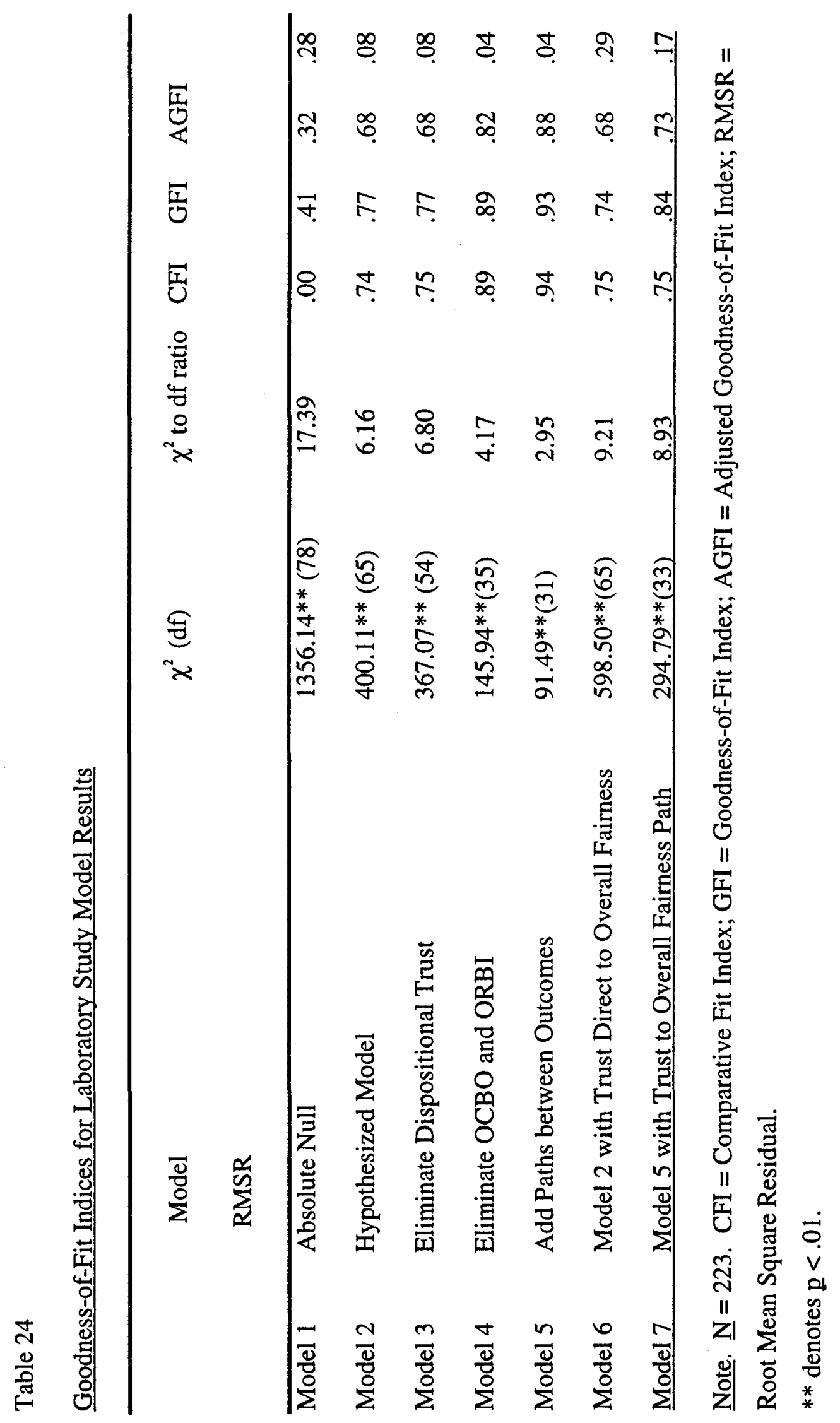


Table 25

$\underline{\text { Pre- Post-Manipulation Mean Differences of Trust in Supervisor }}$

\begin{tabular}{lccccc}
\hline Experimental Condition & $\mathrm{n}$ & $\begin{array}{c}\text { Pre-Manipulation } \\
\text { Mean }\end{array}$ & $\begin{array}{c}\text { Post-Manipulation } \\
\text { Mean }\end{array}$ & $\begin{array}{c}\text { t-test } \\
\text { Value }\end{array}$ \\
\cline { 2 - 6 } & 53 & 3.69 & 3.77 & -.79 \\
$\begin{array}{l}\text { High Distributive/High } \\
\text { Procedural }\end{array}$ & 52 & 3.96 & 3.08 & $6.13^{* *}$ \\
$\begin{array}{l}\text { Low Distributive/High } \\
\begin{array}{l}\text { Procedural } \\
\text { High Distributive/Low }\end{array}\end{array}$ & 61 & 3.54 & 3.16 & $2.76^{* *}$ \\
$\begin{array}{l}\text { Procedural } \\
\text { Low Distributive/Low }\end{array}$ & 57 & 3.69 & 2.42 & $7.65^{* *}$ \\
Procedural & & & & \\
\hline
\end{tabular}

Note. $\underline{N}=223$.

$* * p<.01$. 
Table 26

Pre- Post-Manipulation Mean Differences in LMX

\begin{tabular}{lcccc}
\hline Experimental Condition & $\mathrm{n}$ & $\begin{array}{c}\text { Pre-Manipulation } \\
\text { Mean }\end{array}$ & $\begin{array}{c}\text { Post-Manipulation } \\
\text { Mean }\end{array}$ & $\begin{array}{c}\text { t-test } \\
\text { Value }\end{array}$ \\
\cline { 2 - 5 } $\begin{array}{l}\text { High Distributive/High } \\
\begin{array}{l}\text { Procedural } \\
\text { Low Distributive/High }\end{array}\end{array}$ & 53.75 & 3.95 & 3.79 & -.41 \\
$\begin{array}{l}\text { Procedural } \\
\text { High Distributive/Low }\end{array}$ & 61 & 3.69 & 3.06 & $6.28^{* *}$ \\
$\begin{array}{l}\text { Procedural } \\
\text { Low Distributive/Low }\end{array}$ & 57 & 3.73 & 3.38 & $3.28^{* *}$ \\
Procedural & & 2.33 & $9.70^{* *}$ \\
\hline
\end{tabular}

Note. $\underline{N}=223$.

$* * \mathrm{p}<.01$. 


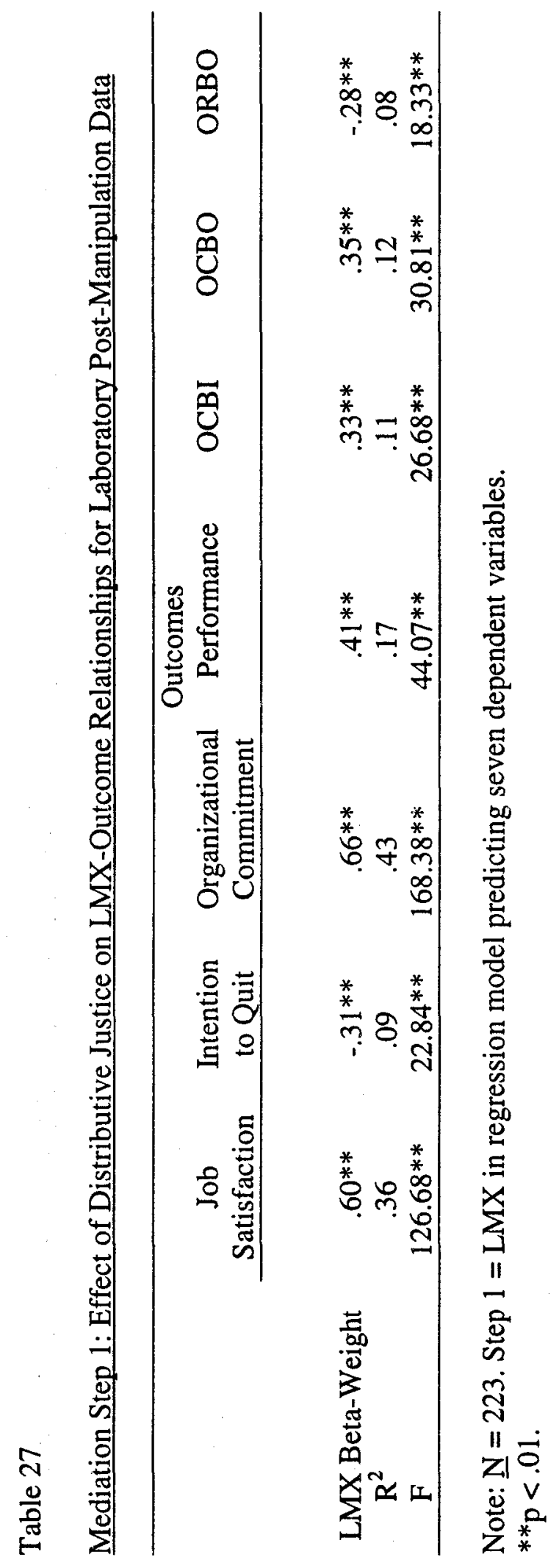




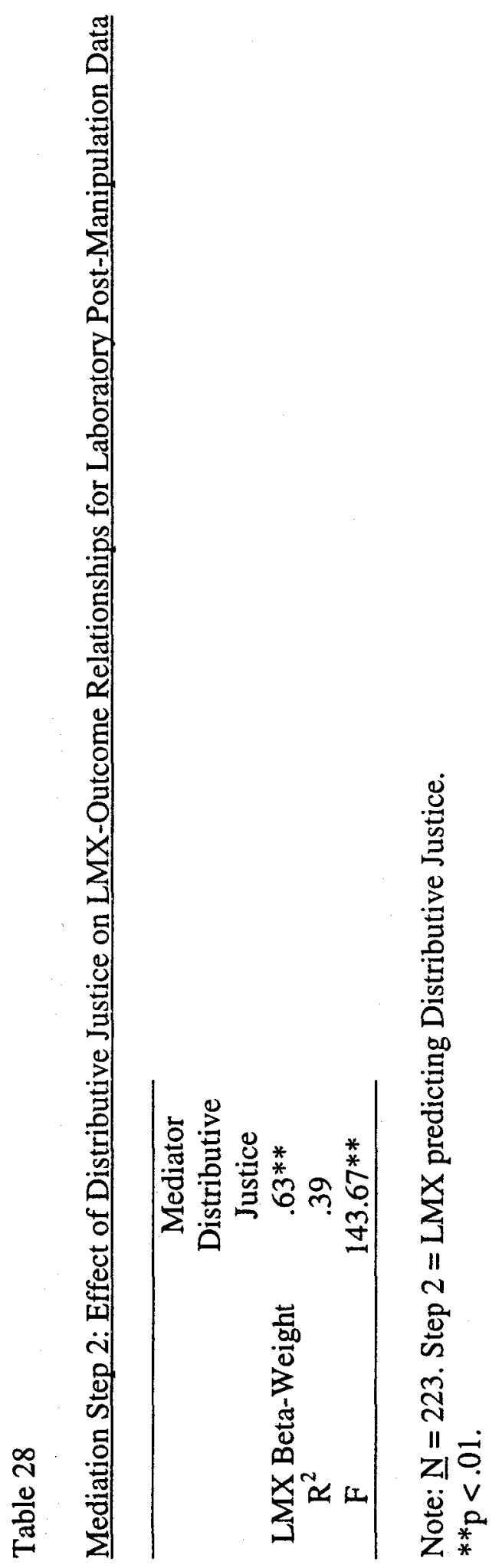




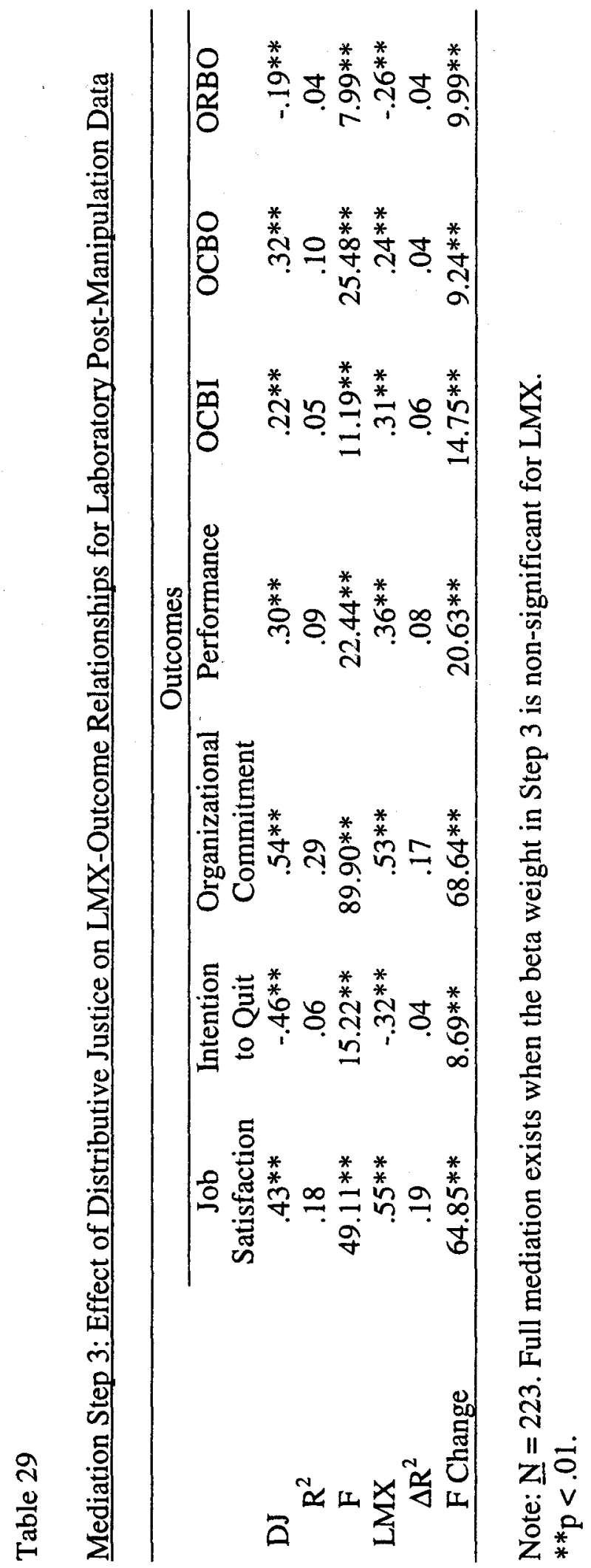


Table 30

Reduction in Variance Accounted by Post-Manipulation Distributive Justice on LMXOutcome Relationships

\begin{tabular}{llll}
\hline & $\begin{array}{l}\text { Percentage of } \\
\text { Variance Accounted } \\
\text { for by LMX } \\
\text { Initially }\end{array}$ & $\begin{array}{l}\text { Percentage of } \\
\text { Variance Accounted } \\
\text { for by LMX After } \\
\text { Inclusion of } \\
\text { Distributive Justice } \\
\text { in Mediation Model }\end{array}$ & $\begin{array}{l}\text { Percentage } \\
\text { Decrease of } \\
\text { Variance } \\
\text { Accounted for in } \\
\text { Outcome } \\
\text { Variable After } \\
\text { Inclusion of } \\
\text { Mediator }\end{array}$ \\
\hline $\begin{array}{l}\text { Job Satisfaction } \\
\text { Intention to Quit }\end{array}$ & 36 & & 47 \\
Organizational & 43 & 19 & 55 \\
Commitment & 9 & 4 & 60 \\
Performance & 17 & 17 & 53 \\
OCBI & 11 & 8 & 45 \\
OCBO & 12 & 6 & 67 \\
ORBO & 8 & 4 & 50 \\
\hline
\end{tabular}

Note. $\underline{N}=223$. 


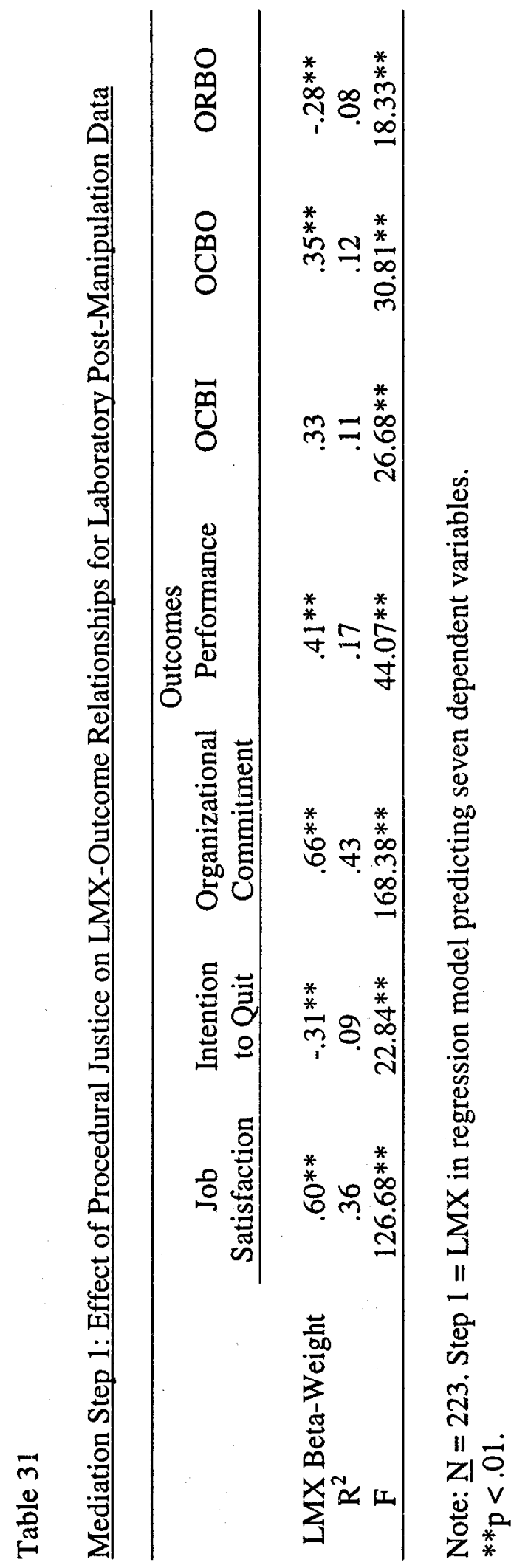




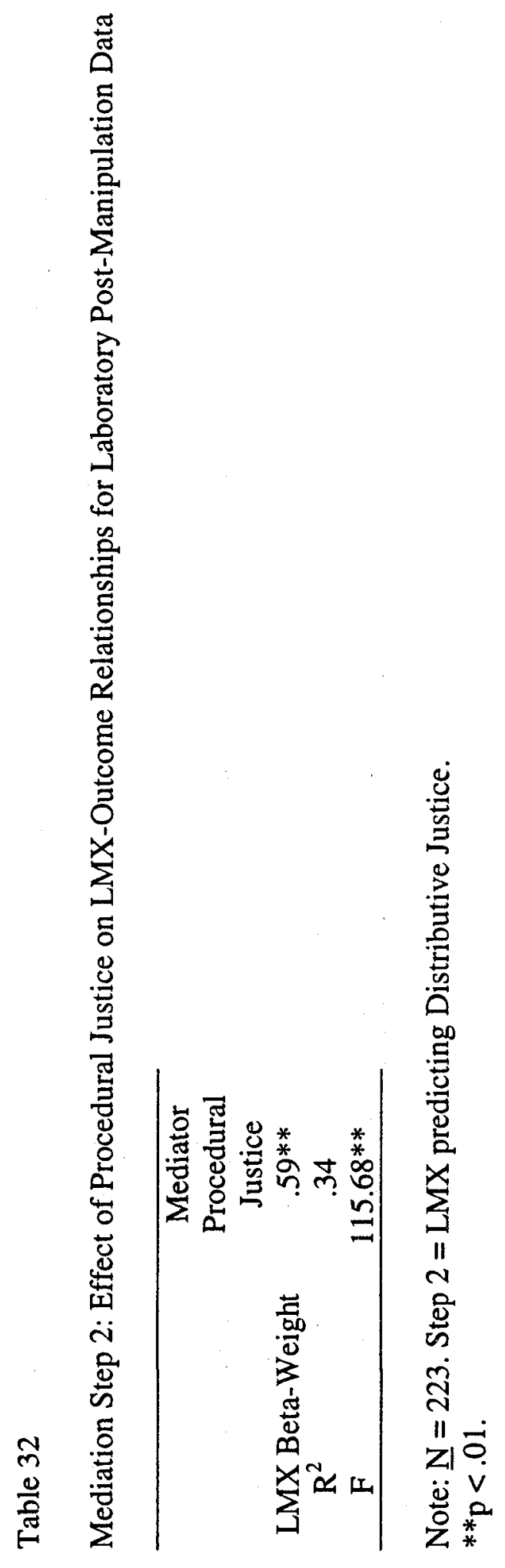




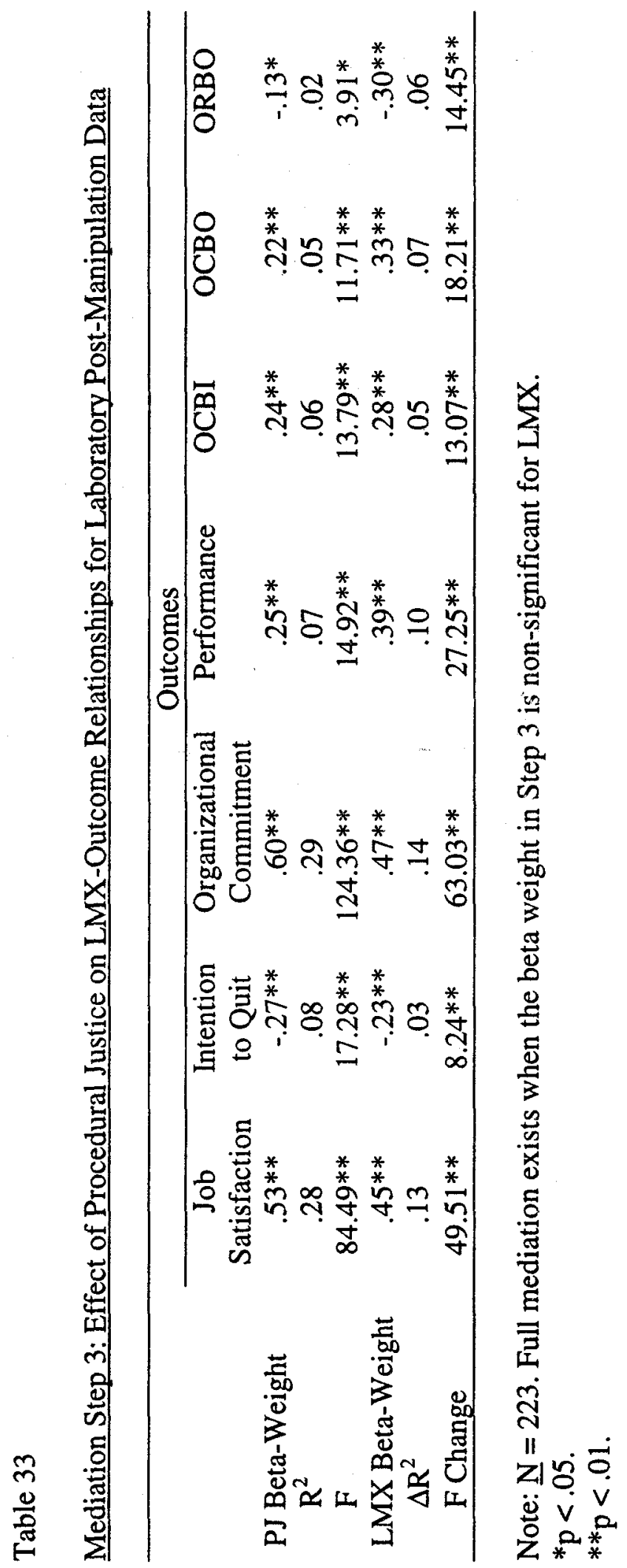


Table 34

Reduction in Variance Accounted by Post-Manipulation Procedural Justice on LMXOutcome Relationships

\begin{tabular}{|c|c|c|c|}
\hline & $\begin{array}{l}\text { Percentage of } \\
\text { Variance Accounted } \\
\text { for by LMX } \\
\text { Initially }\end{array}$ & $\begin{array}{l}\text { Percentage of } \\
\text { Variance Accounted } \\
\text { for by LMX After } \\
\text { Inclusion of } \\
\text { Procedural Justice } \\
\text { in Mediation Model }\end{array}$ & $\begin{array}{l}\text { Percentage } \\
\text { Decrease of } \\
\text { Variance } \\
\text { Accounted for in } \\
\text { Outcome } \\
\text { Variable After } \\
\text { Inclusion of } \\
\text { Mediator }\end{array}$ \\
\hline Job Satisfaction & 36 & 13 & 64 \\
\hline Intention to Quit & 9 & 3 & 67 \\
\hline $\begin{array}{l}\text { Organizational } \\
\text { Commitment }\end{array}$ & 43 & 14 & 67 \\
\hline Performance & 17 & 10 & 43 \\
\hline OCBI & 11 & 5 & 54 \\
\hline OCBO & 12 & 7 & 42 \\
\hline ORBO & 8 & 6 & 25 \\
\hline
\end{tabular}

Note. $\underline{\mathrm{N}}=223$. 


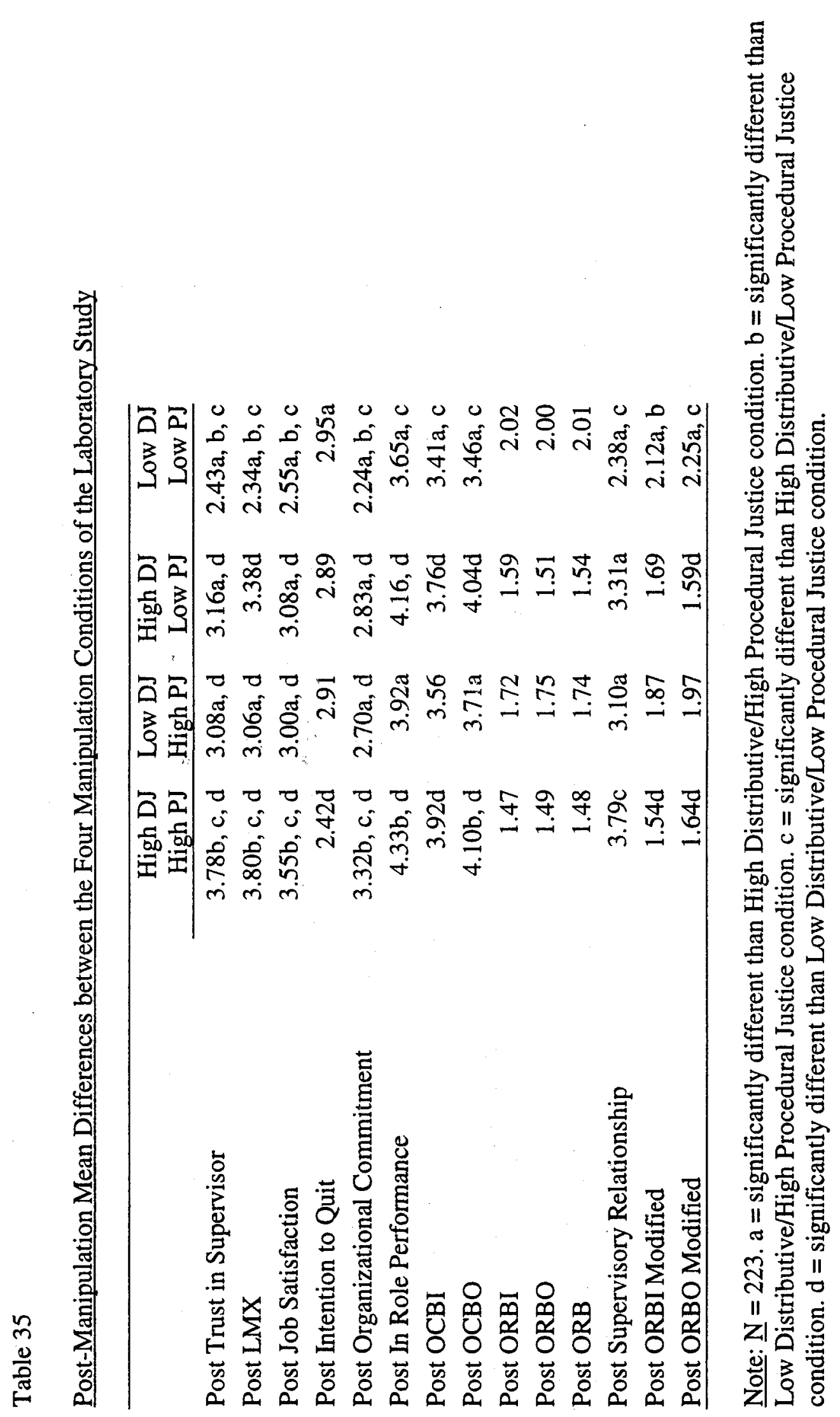




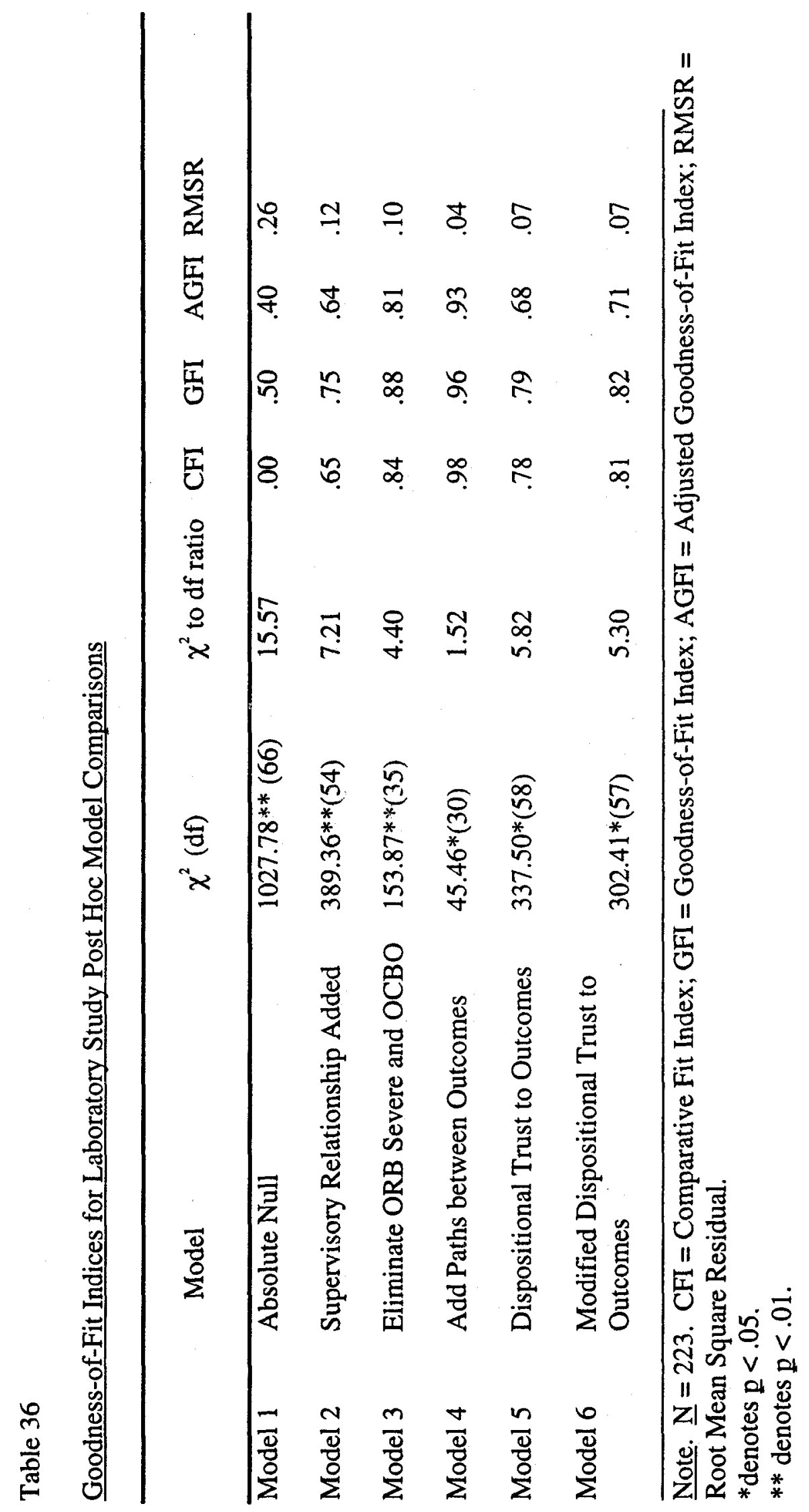




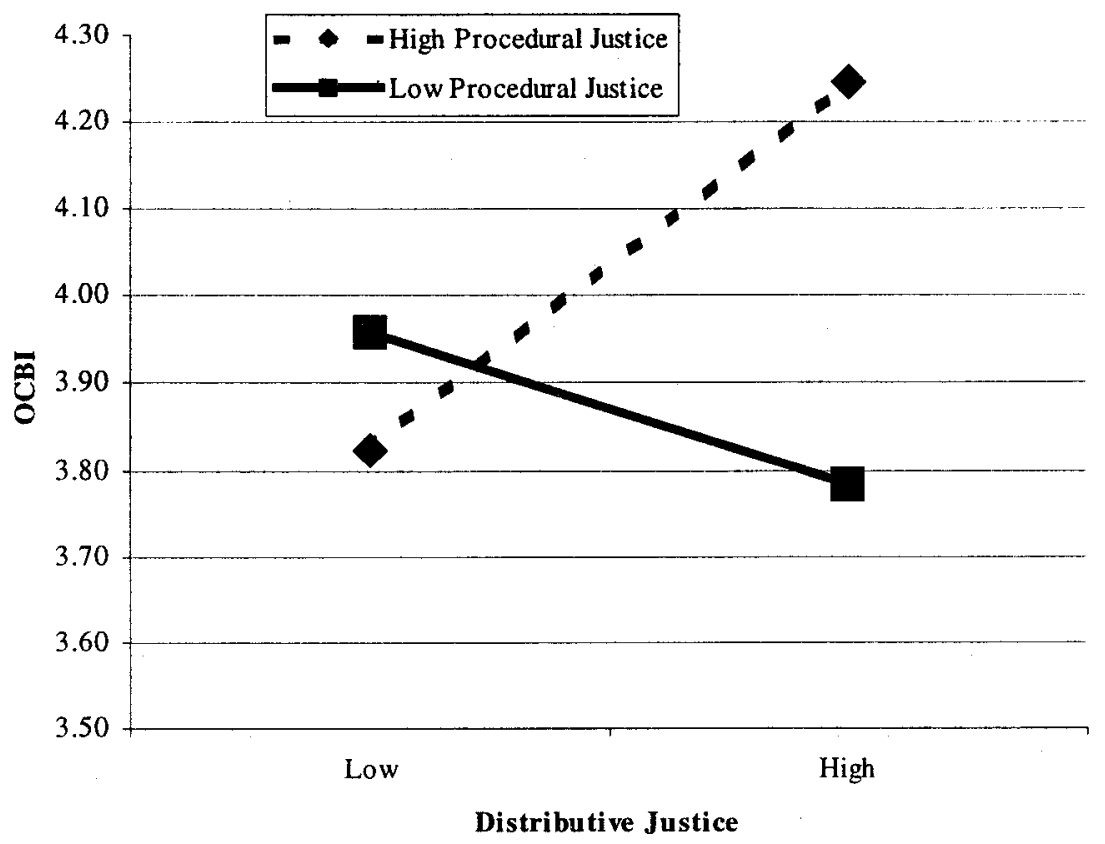

Figure 17. Distributive justice by procedural justice interaction effect on OCBI. 


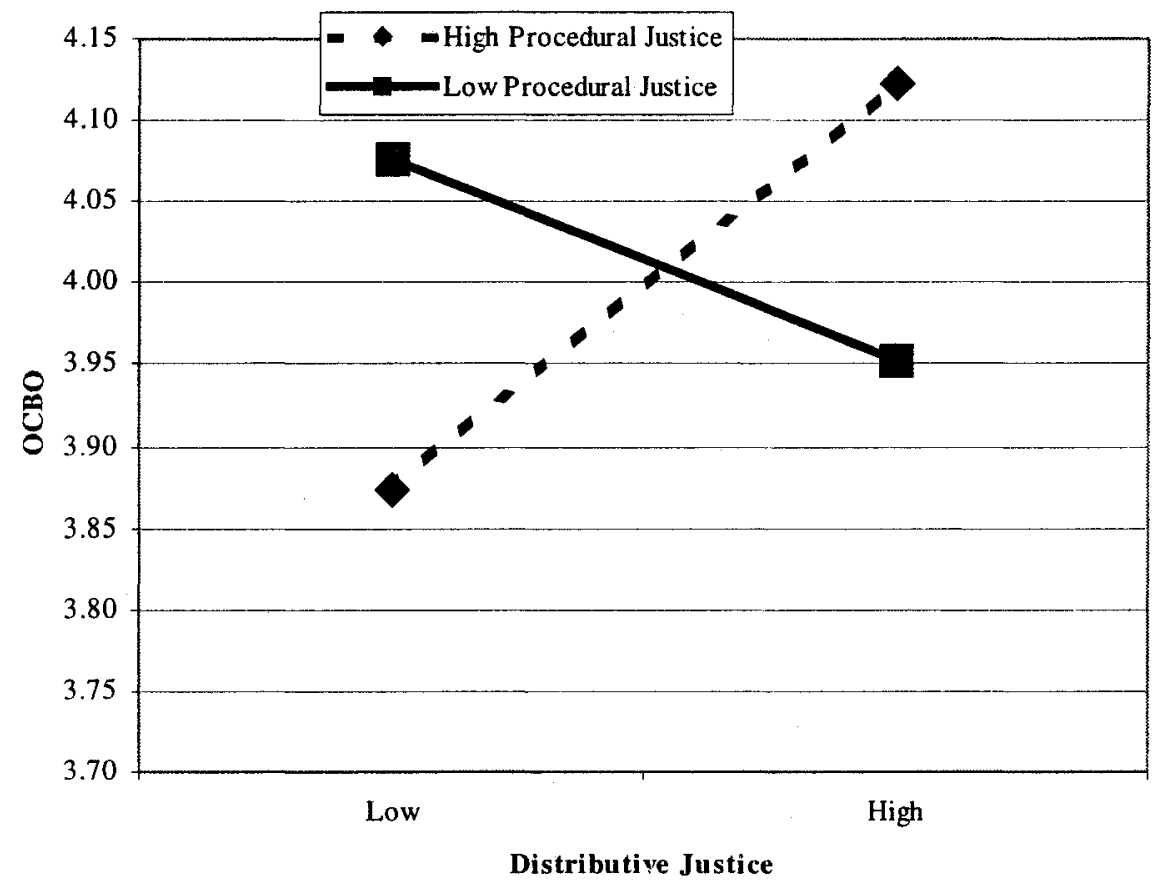

Figure 18. Laboratory Study: Distributive Justice by Procedural Justice Interaction Effect on OCBO 


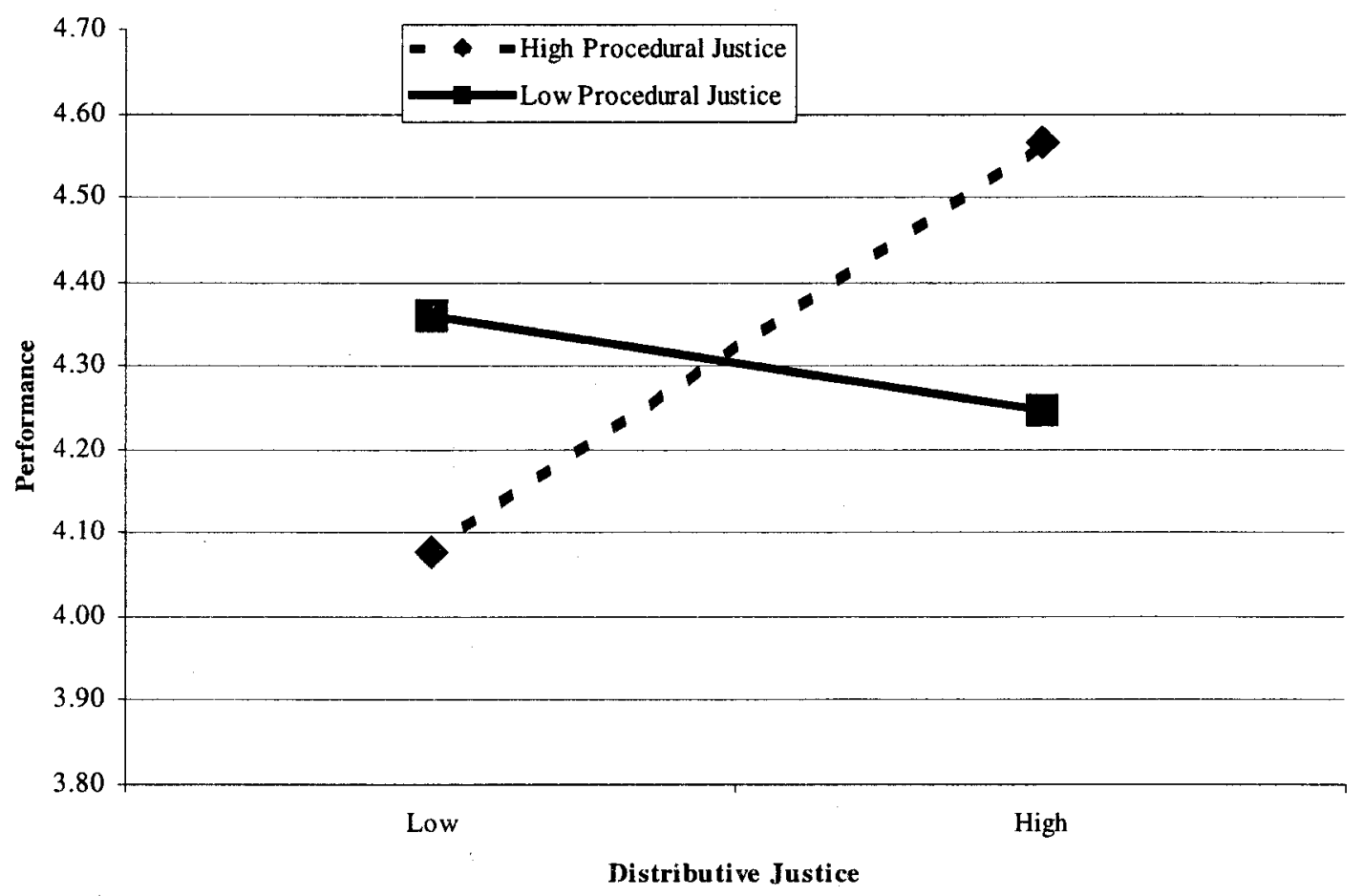

Figure 19. Laboratory Study: Distributive Justice by Procedural Justice Interaction Effect on In-role Performance 


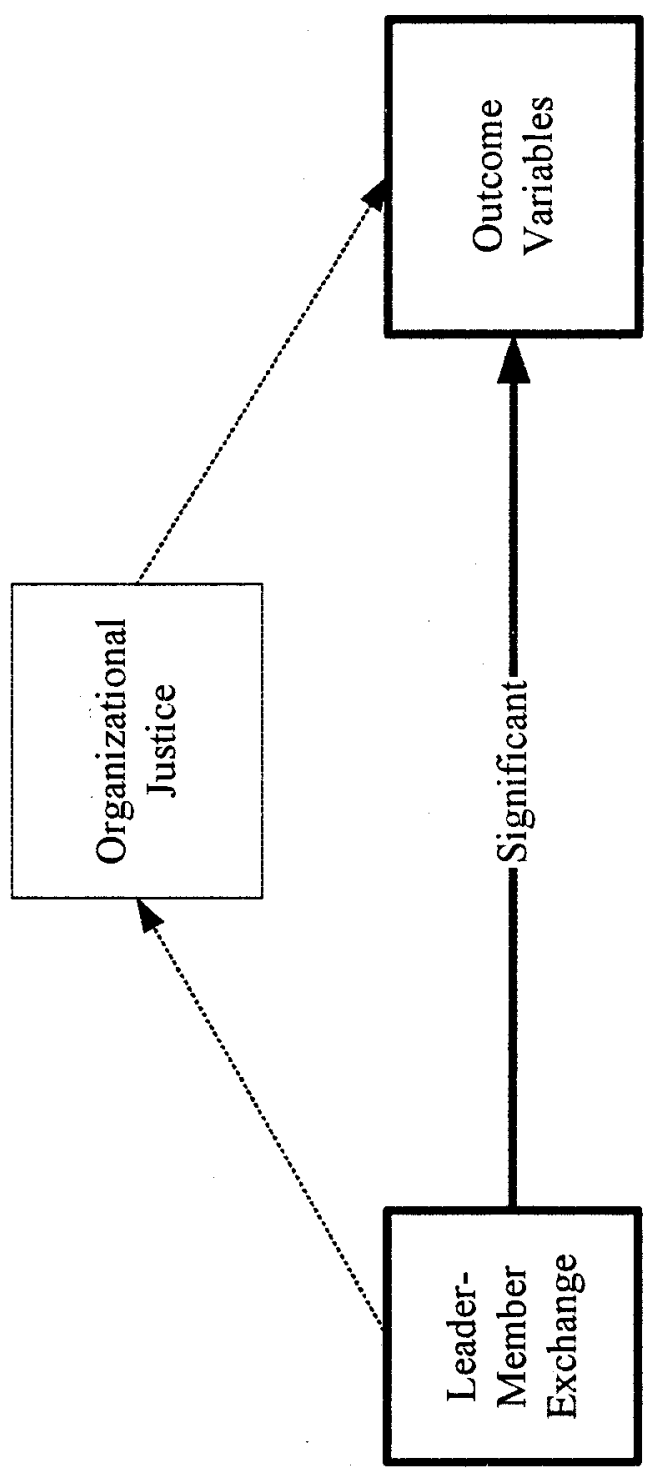

号 


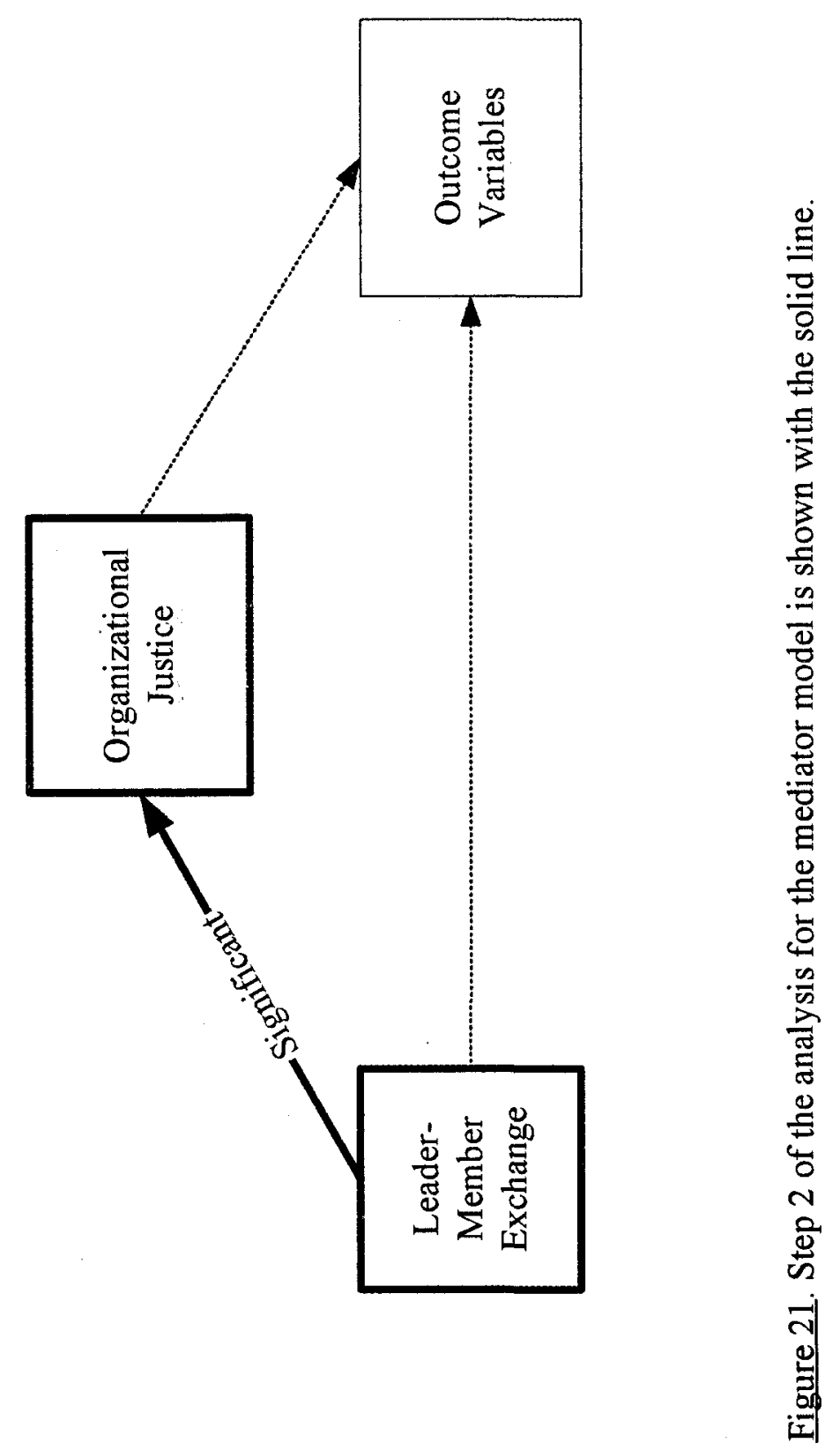




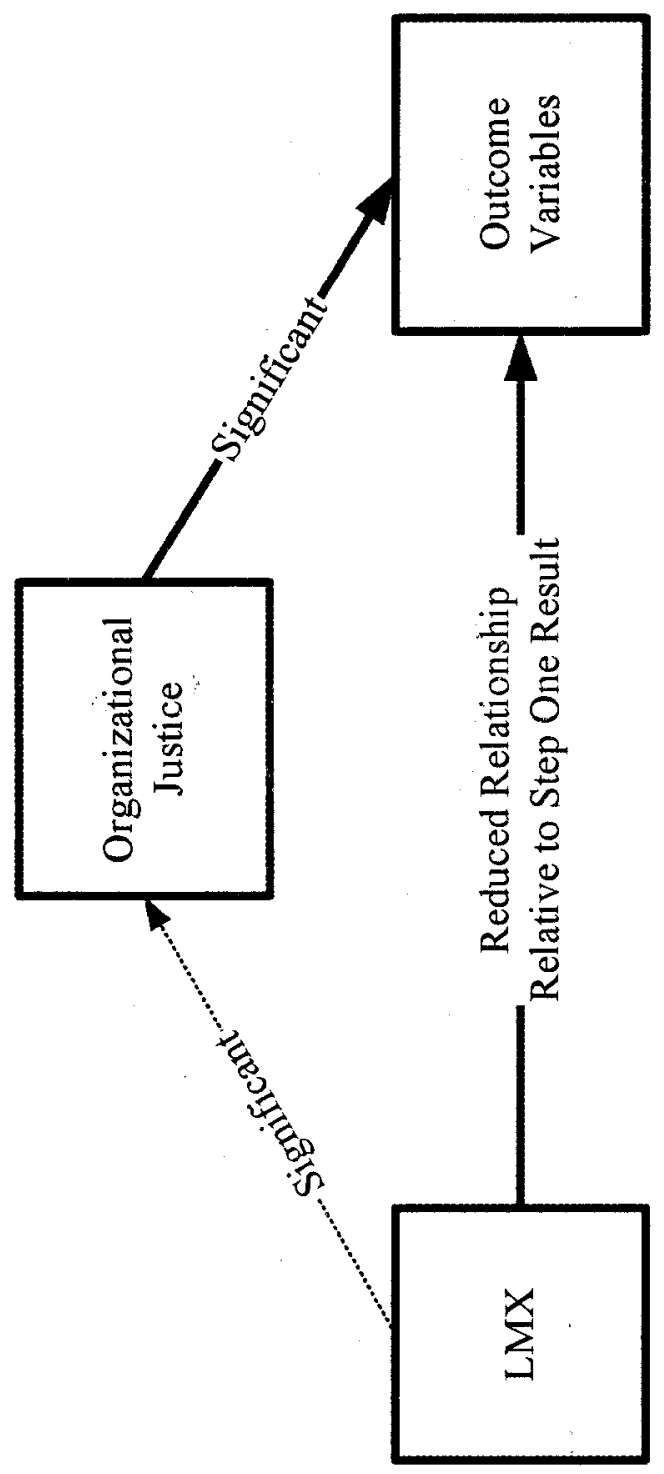

焉 


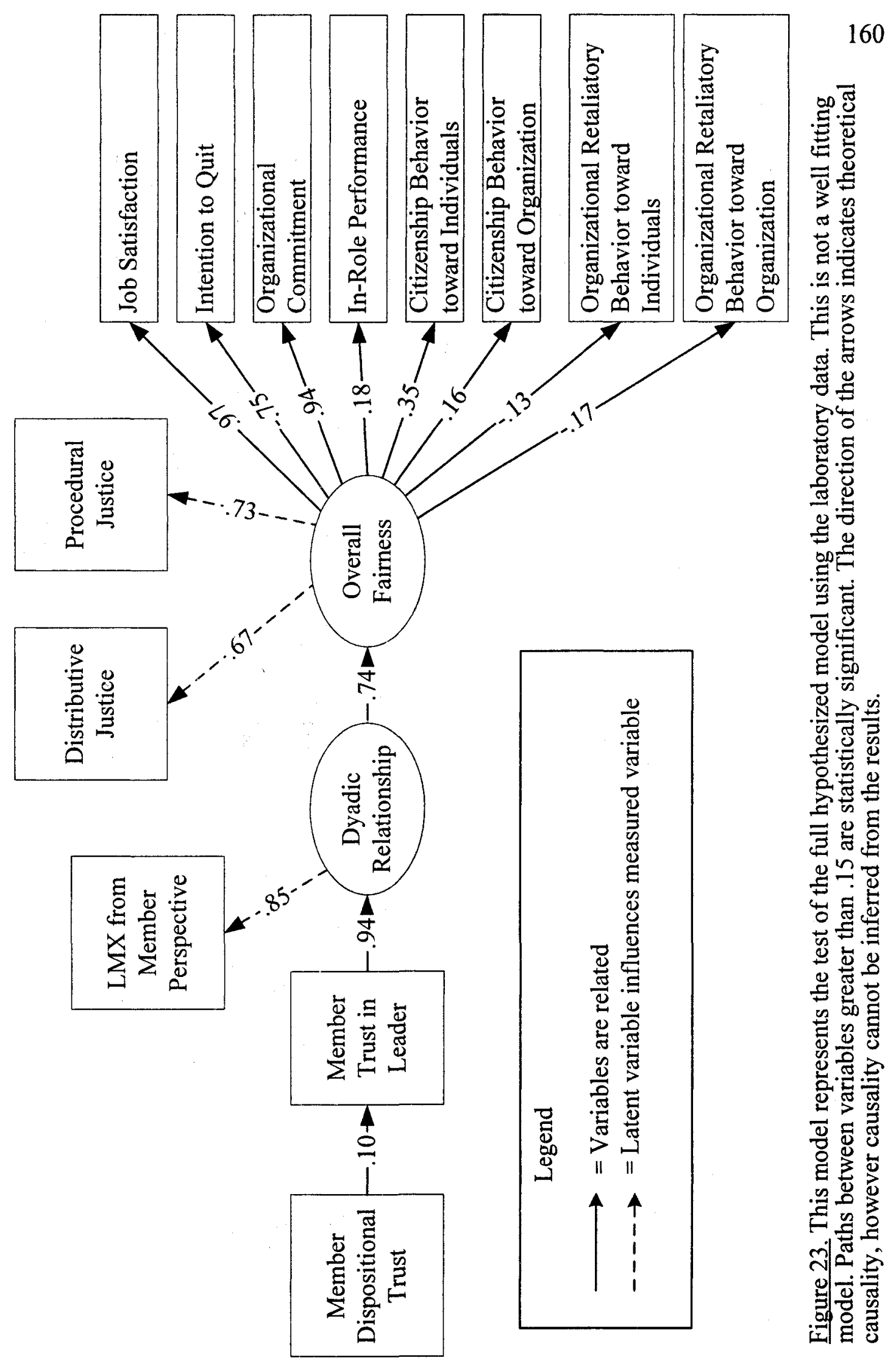




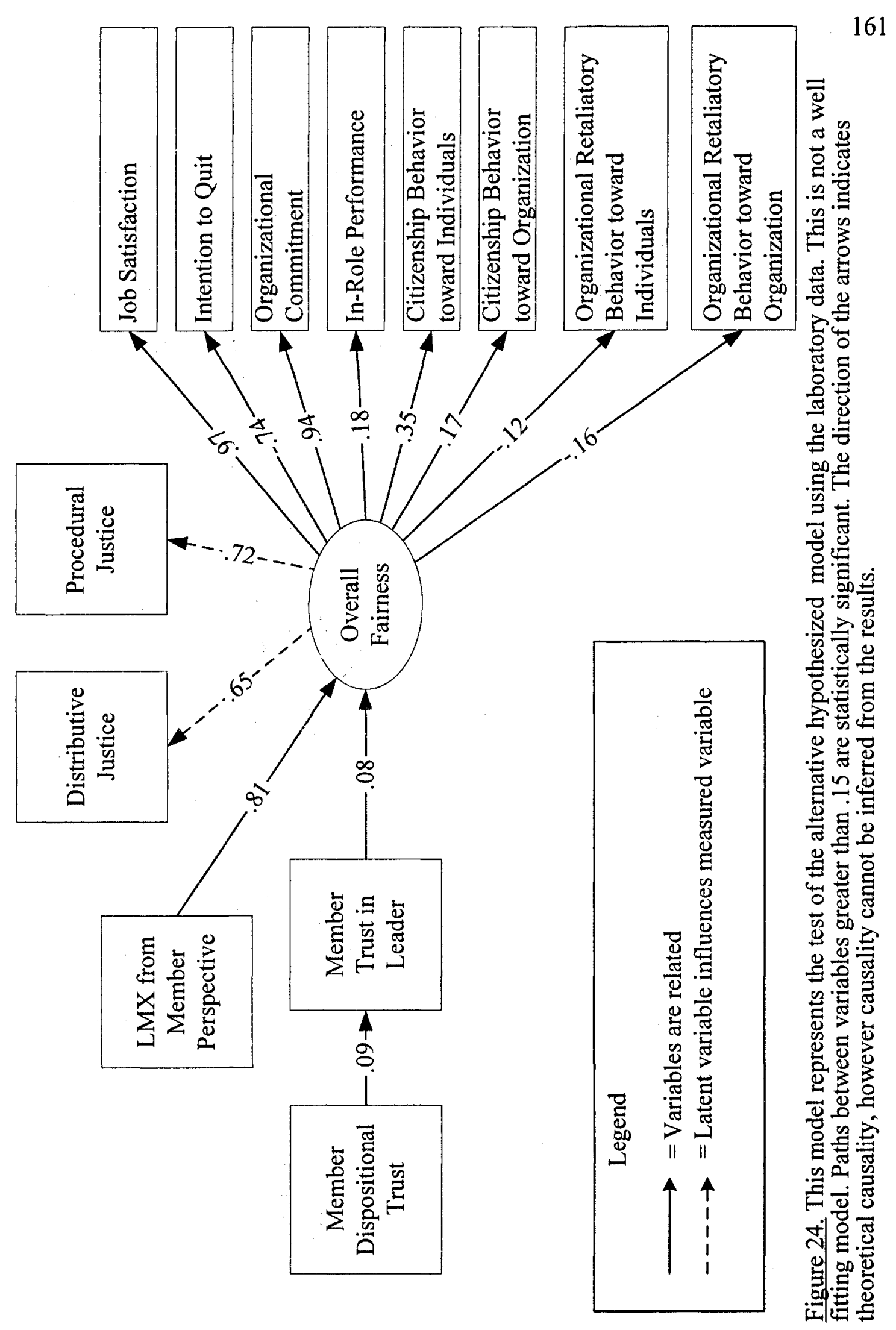




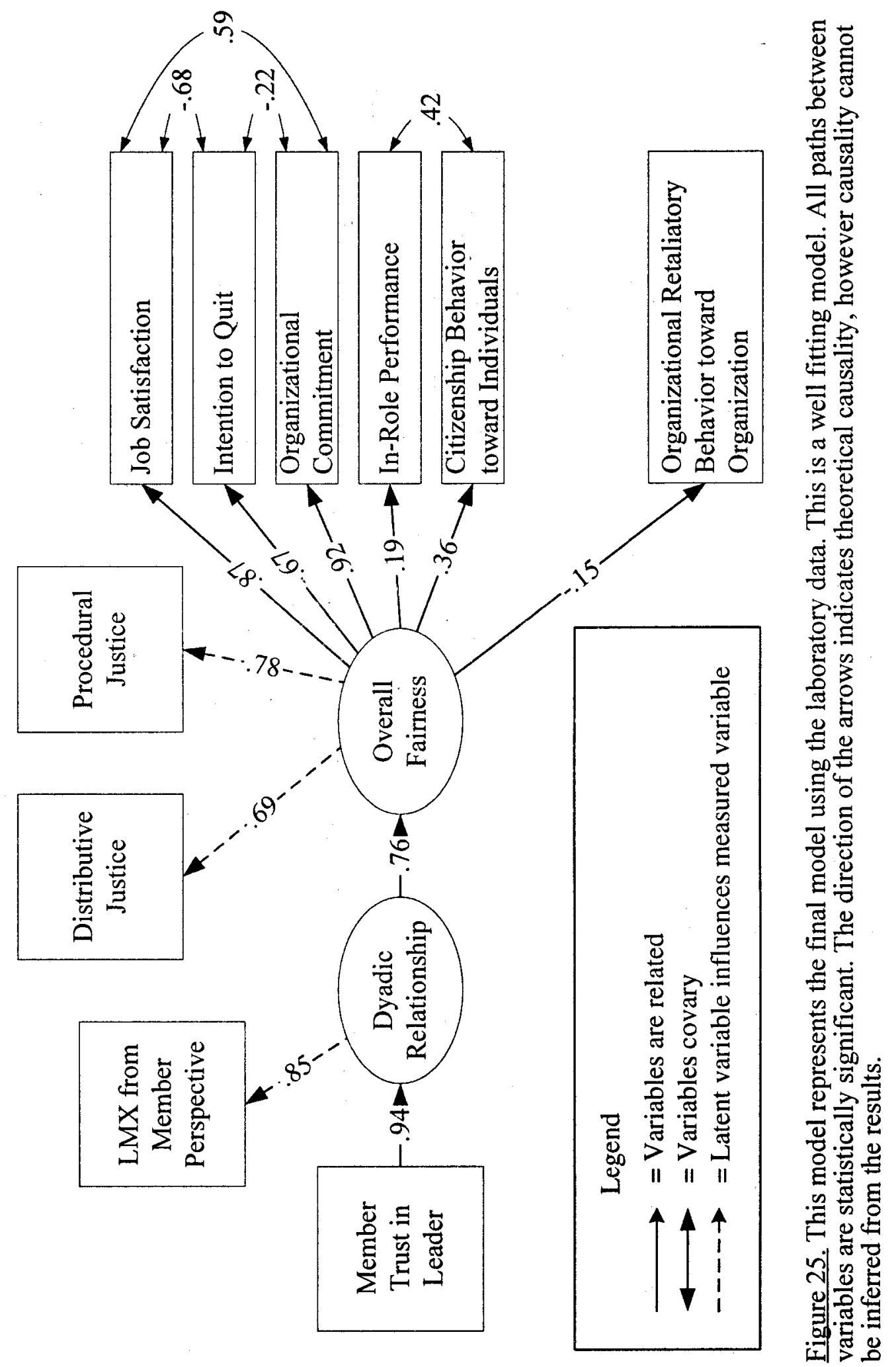




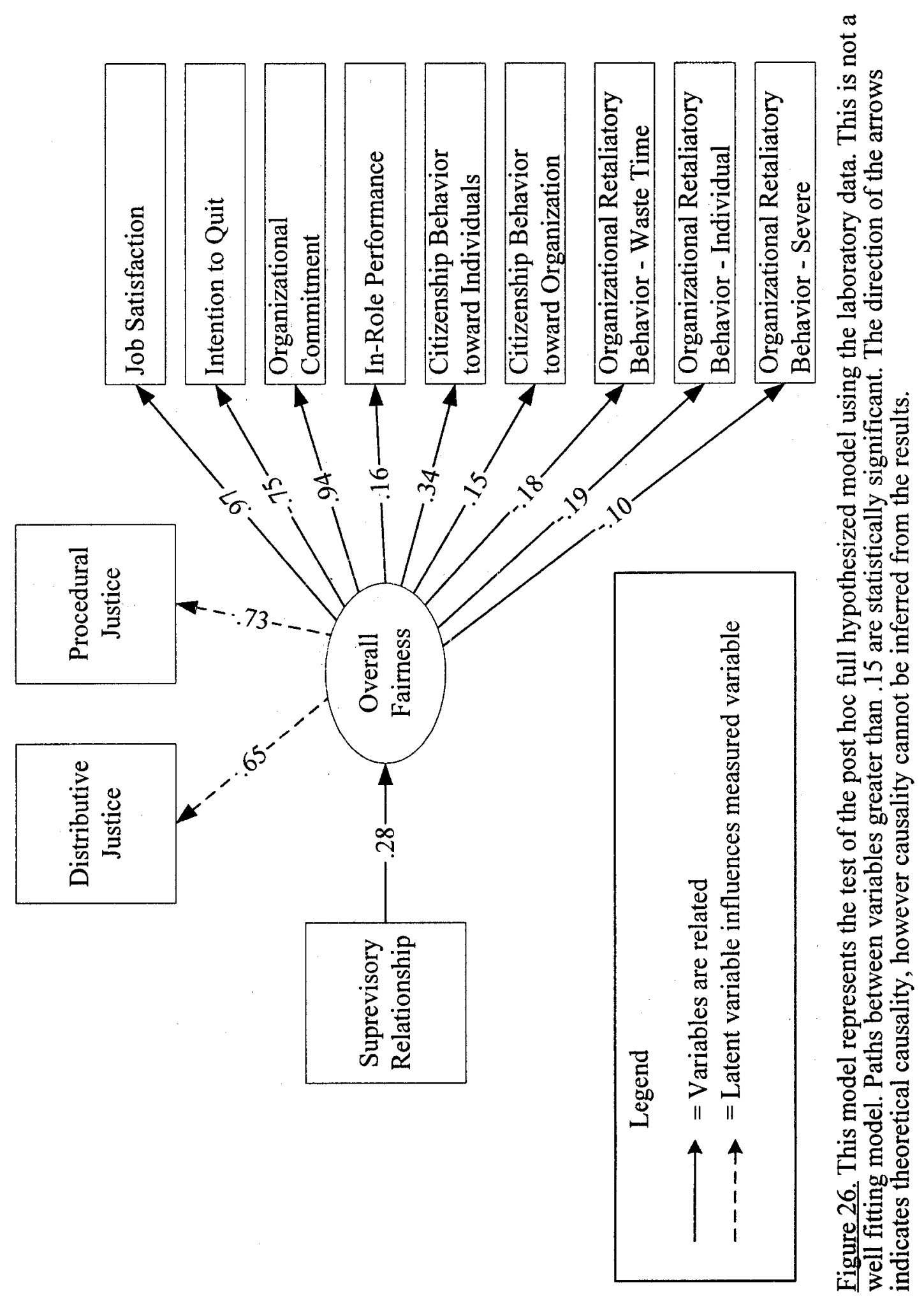




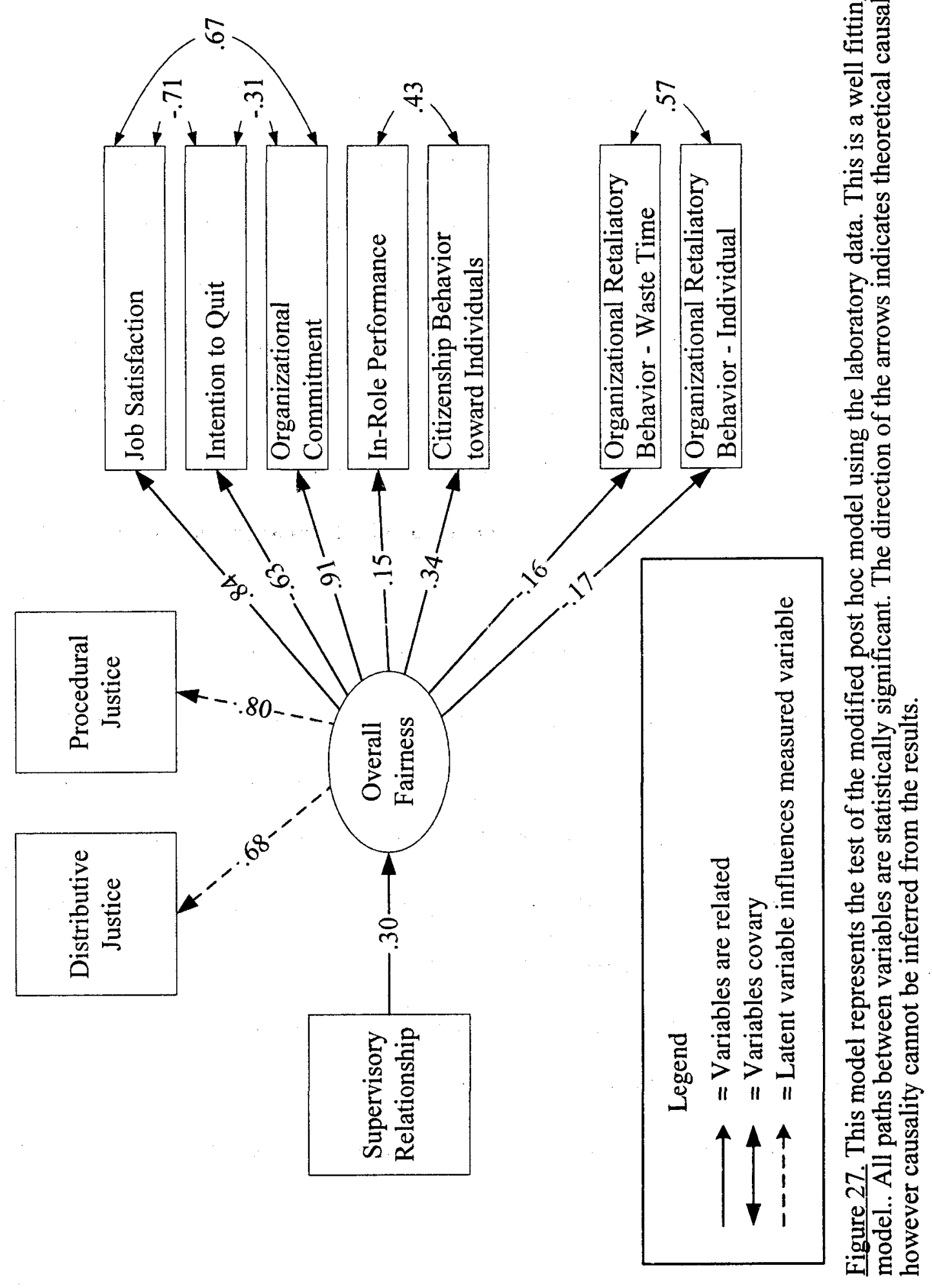




\section{Chapter Eight \\ Method \\ Study Two}

The purpose of Study Two was to examine the hypothesized relationships between the variables of interest described in Chapter Five and to test the full model. Data were collected in a field setting, which provides a useful foundation from which to discuss the practical implications of the findings. Additionally, data were collected from two sources, thereby mitigating the possibility that significant findings were due solely to common method variance. Collecting data from both members of the LMX dyad also allowed for the examination of the idea that LMX is an emergent property of the interaction between the leader and the member.

\section{Measures}

Similar demographic data were collected from participants in the field study as were collected in the laboratory study (e.g., age, gender, education, ethnicity, tenure with the organization, and tenure with current manager).

The measures for trust in supervisor, LMX, distributive justice, procedural justice, job satisfaction, intention to quit, organizational commitment, in-role performance, OCBI, and OCBO used at Time 1 in Study One were completed by subordinates. Dispositional trust and ORB were measured differently in the field study. Additionally, measures of LMX and ORB were modified for supervisors who were reporting their perceptions for each subordinate. These modifications are discussed next.

\section{Span of Control}


The number of employees that report to each supervisor was gathered from organizational records. This data was used as a control variable.

\section{Dispositional Trust}

MacDonald, Kessel, and Fuller (1972) developed a measure of interpersonal trust as an alternative to Rotter's Interpersonal Trust Scale (1967). This 10-item scale was developed with undergraduate students and correlated .56 with the Rotter scale. Lagace and Rhoads (1988) using a sample of employed adults determined that the MacDonald et al. scale contained two factors (i.e., trust and suspicion) of four items each. This scale showed adequate internal consistency ( $\alpha$ between .73 and .84 ) in the populations studied. This in contrast to the lack of published information on the internal consistency the Rotter Interpersonal Trust Scale. In the field study, both Rotter's (1967) trust in social agents factor and MacDonald et al.'s (1972) trust factor were used.

\section{$\underline{\mathrm{LMX}}$}

In addition to collecting perceptions of LMX from members, LMX perceptions were also measured from the leader's perspective. Liden, Wayne, and Stilwell (1993) revised the LMX-7 to measure LMX from the leader's perspective. Liden and colleagues reported alpha coefficients ranging from .75 to .81 for this measure. Similar adaptations were applied to the LMX-8 to assess LMX from the leader's perspective. A sample item of the LMX scale from the leader/supervisor's perspective (SLMX) is "This subordinate understands my job problems and needs."

\section{Organizational Retaliatory Behaviors}


The 12-item organizational deviance and 7-item interpersonal deviance scales developed by Bennett and Robinson (2000) and the 16-item ORB scale developed by Skarlicki and Folger (1997) were combined to measure organizational retaliatory behaviors. To the resulting 18 -item scale, another item was added because it was determined that it may capture an ORB unique to a high tech, professional environment. That item was "Spent too much time surfing the web instead of working." In contrast to the other scales used in this research, this scale used a 7-point Likert response format ranging from never (1) to daily (7). A sample item from the this scale is "Intentionally worked slower than I could have worked." Supervisors responded to the same set of items for each of their subordinates, however their scale included a "Do Not Know" option.

\section{Procedure}

Data were collected from both subordinates and their supervisors using a crosssectional design. A summary of the data collection process is in Table 37.

Participation in the research was voluntary and participant confidentiality was assured.

Subordinates were provided a packet of information that contained a cover letter (Appendix A), a survey for them to complete (Appendix B), and a return envelope (stamped and addressed to the researcher).

Subordinates completed a survey assessing their disposition to trust, trust in their supervisor, $\mathrm{LMX}$, overall job satisfaction, $\mathrm{OCB}$, job performance, intention to quit, and ORB. Additionally, demographic information was provided by subordinates (e.g., age, gender, ethnicity, job tenure, tenure with supervisor). 
Supervisors received a packet of information that contained a cover letter (Appendix C), instruction sheet on how to complete the set of surveys (Appendix D), and a set of surveys (i.e., one survey identical to the one subordinates completed, and one survey for each of their subordinates). Supervisors completed a survey for each of their subordinates (Appendix E). This survey included items assessing trust in each subordinate, LMX assessed from the supervisor's perspective (SLMX), the job performance of each subordinate, OCB of each subordinate, and ORB of each subordinate. Supervisors also provided demographic information (e.g., age, gender, ethnicity, job tenure, tenure with this subordinate). 
Table 37

Summary of Survey Plan for Study Two (Field Study)

\begin{tabular}{|l|c|c|}
\hline Construct & Subordinate & Supervisor \\
\hline Dispositional Trust & $\mathrm{X}$ & $\mathrm{X}$ \\
\hline Person-Specific Trust & $\mathrm{X}$ & $\mathrm{X}$ \\
\hline LMX-8 & $\mathrm{X}$ & $\mathrm{X}$ \\
\hline Procedural Justice & $\mathrm{X}$ & \\
\hline Distributive Justice & $\mathrm{X}$ & \\
\hline Job Performance & $\mathrm{X}$ & $\mathrm{X}$ \\
\hline Overall Job Satisfaction & $\mathrm{X}$ & \\
\hline Intention to Quit & $\mathrm{X}$ & \\
\hline Organizational Commitment & $\mathrm{X}$ & \\
\hline OCB & $\mathrm{X}$ & $\mathrm{X}$ \\
\hline ORB & $\mathrm{X}$ & $\mathrm{X}$ \\
\hline
\end{tabular}

Note. An " $\mathrm{X}$ " indicates which constructs were measured for each member of the dyad. 
Chapter Nine

Results

Study Two

\section{$\underline{\text { Participants }}$}

One-hundred and thirteen out of $143(79.0 \%)$ employees in one work unit of a high tech organization completed a survey on work time. Of the total of 113,19 were supervisors. Of those reporting on the demographic variables, $78.4 \%(\underline{n}=87)$ were men, 96.3\% ( $\underline{n}=107)$ had earned at least a bachelor's degree, and $58.7 \%(\underline{n}=61)$ were Caucasian and $35.6 \%(\underline{n}=37)$ were Asian. The average age of the participants was 36.83 years. Participants had worked for the organization an average of 8.57 years and worked with their current supervisor an average of 1.48 years. Participants worked an average of 46.88 hours per week. Due to missing data, there were a total of 103 dyads with matched surveys (i.e., both the subordinate and their supervisor completed surveys). A power analysis revealed (Table 38) that this sample size provided a power level of .80 , assuming medium effect sizes to test hypotheses one through four (Cohen, 1988). While there are no accepted methods of determining power for complex models (i.e., testing the entire hypothesized model) using structural equation modeling, the sample size is less than the ideal of 10 observations per variable in the model.

$\underline{\text { Scale Scores }}$

As in Study One, factor analyses were conducted to verify the dimensionality of the measures. These analyses resulted in the expected unidimensionality of all the scales except for the ORB scale. Based on the factor analytic results, no distinct 
factors were found. Therefore all items in the ORB scale were collapsed into one scale. This is similar to the strategy used by Lee and Allen (2002) for the Bennet and Robinson (2000) ORB scale. Scale scores were computed for each variable by calculating the mean of the set of items used for each scale. Therefore, all scales have a minimum value of 1 and a maximum value of 5 . The exception to this procedure was the organizational retaliatory behavior scale. For this scale, the responses to each of the 19 items were summed. This results in a scale range of 19 to 133 for subordinates' self-reports. Since supervisors' reports of ORB could include a "Do Not Know" response, these responses were treated as missing data. Therefore, it is possible for a supervisor report of member ORB to be one (i.e., 18 "Do Not Know" responses and 1 “Never" response). The high score remained 133 for supervisor reports of member ORB.

Descriptive statistics for all of the variables examined in Study Two are contained in Table 39 for measures from the subordinates' perspective and Table 40 for measures from the managers' perspective. Table 41 contains correlations for matched subordinate-supervisor dyads.

\section{The Role of Dispositional Trust}

Two scales measuring dispositional trust were included in Study Two.

Estimates of internal consistency indicated that the Rotter (1967) trust in social agents factor had a reliability of .63 and the MacDonald et al. (1972) trust factor had a reliability of .78 . Since internal consistency for the MacDonald scale was better, this scale was used for all analyses concerning dispositional trust. 
Based on the lack of a statistically significant correlation between subordinate's dispositional trust and subordinate's trust in their supervisor $(\mathrm{r}=.12, \mathrm{p}>.05)$ (Table 39) and between supervisor's dispositional trust and supervisor's trust in the subordinate $(\mathrm{r}=.07, \mathrm{p}>.05)$ (Table 40), Hypothesis 1 was not supported. Trust in a Specific Other and LMX

The correlation between trust in a specific other and LMX, from both the subordinate's $(\underline{r}=.73, \underline{\mathrm{p}}<.01)$ and supervisor's $(\underline{\mathrm{r}}=.67, \underline{\mathrm{p}}<.01)$ perspectives, was very strong. Additionally, after controlling for several background variables (e.g., age, gender, length of relationship, span of control of supervisor), trust in a specific other was strongly related to LMX for subordinates $\left(\Delta \mathrm{R}^{2}=.47, \underline{\mathrm{F}}=99.01, \mathrm{p}<.01\right)$ (Table 42) and supervisors $\left(\Delta \mathrm{R}^{2}=.43, \underline{\mathrm{F}}=79.67, \mathrm{p}<.01\right)$ (Table 43). Therefore, Hypothesis 2 was supported.

Distributive Justice and the Outcome Variables Using Self-Report Data

Hypothesis 3 was tested with correlation coefficients (Table 39). Subordinate reports of distributive justice were positively related to job satisfaction $(\mathrm{r}=.36, \mathrm{p}<$ $.01)$ and negatively related to intentions to quit $(\underline{r}=-.29, \underline{p}<.01)$. Distributive justice was unrelated to organizational commitment, in-role performance, OCBI, OCBO, or ORB. Therefore, Hypothesis 3 was partially supported.

Distributive Justice and the Behavioral Outcome Variables Using Supervisory Reports

Similar to the self-report data, distributive justice as reported by subordinates was not related to supervisor reports of in-role performance, OCBI, OCBO, or ORB (Table 41). 
Procedural Justice and the Outcome Variables Using Self-Report Data

Hypothesis 4 was also tested with correlation coefficients (Table 39).

Subordinates' perceptions of procedural justice were related to organizational commitment $(\underline{r}=.50, \underline{p}<.01)$, job satisfaction $(\underline{r}=.40, \underline{p}<.01)$, intention to quit $(\underline{r}=-$ $.31, \mathrm{p}<.01)$, and OCBO $(\underline{\mathrm{r}}=.26, \mathrm{p}<.01)$. Procedural justice was unrelated to in-role performance, OCBI, and ORB. Therefore, Hypothesis 4 was partially supported. Procedural Justice and the Behavioral Outcome Variables Using Supervisory Reports

Procedural justice as reported by subordinates was not related to supervisor reports of in-role performance, OCBI, OCBO, or ORB (Table 41).

The Interaction of Procedural and Distributive Justice and Outcomes

To test Hypothesis 5, the interaction of procedural and distributive justice on the outcome variables, hierarchical regression was used. In step one of the regression equation, a set of control variables was entered in the regression model (e.g., age, gender, tenure with the organization). In step two, procedural and distributive justice were entered into the equation predicting each outcome variable in turn. In the third step, the interaction term (i.e., procedural justice $\mathrm{x}$ distributive justice) was entered. If this third step was statistically significant, then two regression lines would be developed in order to examine the specific nature of the interaction. Utilizing the selfreport data from the 113 direct reports, the interaction term was not significant for any of the outcome variables in Study Two. Additionally, the interaction term was not significant when using supervisor reports of in-role performance, OCBI, OCBO, or ORB as the dependent variable. Therefore, Hypothesis 5 was not supported. 
Building the Mediation Models

The same process (Baron \& Kenney, 1986) that was used to test the mediation hypotheses in Study One was used in Study Two. A series of three regression models were run to test the hypothesized mediating effect of organizational justice. This process was used for each of the outcome variables first with distributive justice, then with procedural justice.

The Mediating Effect of Distributive Justice Using Self-report Data

In the first step of the mediator analysis for distributive justice (Table 44), LMX was significantly related to subordinate reports of job satisfaction $\left(\underline{R^{2}}=.39, \underline{p}<\right.$ $.01)$, intention to quit $\left(\underline{\mathrm{R}^{2}}=.13, \underline{\mathrm{p}}<.01\right)$, in-role performance $\left(\underline{\mathrm{R}^{2}}=.06, \underline{\mathrm{p}}<.05\right)$, organizational commitment $\left(\underline{\mathrm{R}^{2}}=.17, \underline{\mathrm{p}}<.01\right), \mathrm{OCBO}\left(\underline{\mathrm{R}^{2}}=.10, \underline{\mathrm{p}}<.01\right)$, and ORB $\left(\underline{\mathrm{R}^{2}}=.04, \mathrm{p}<.05\right)$. Because $\mathrm{LMX}$ was unrelated to OCBI, this variable was dropped from further analysis. In the second regression model (Table 45), LMX was positively related to distributive justice $\left(\Delta \underline{\mathrm{R}^{2}}=.13, \underline{\mathrm{p}}<.01\right)$.

The last step in the mediation analyses indicated that distributive justice was unrelated to organizational commitment, performance, OCBO, and ORB. Therefore, no mediation by distributive justice of the relationship between LMX and these outcome variables was possible. The inclusion of distributive justice in the model did result in reductions in the relationship between LMX and job satisfaction (Hypothesis 6a) and intention to quit (Hypothesis 6b) (Table 46). Table 47 shows that degree of the mediation. Hypothesis 6 was partially supported.

The Mediating Effect of Distributive Justice Using Supervisor Reports of Behavior 
In the first step of the mediator analysis for subordinate perceptions of

distributive justice, subordinate reports of LMX were significantly related to supervisor reports of in-role performance $\left(\underline{\mathrm{R}^{2}}=.18\right), \mathrm{OCBI}\left(\underline{\mathrm{R}^{2}}=.06\right), \mathrm{OCBO}\left(\underline{\mathrm{R}^{2}}=\right.$ $.14)$, and ORB $\left(\mathrm{R}^{2}=.13\right)$. In the second regression model, LMX was positively related to distributive justice $\left(\mathrm{R}^{2}=.13, \underline{\mathrm{p}}<.01\right)$. In the third step of the mediator analyses, subordinate reports of distributive justice were unrelated to supervisor reports of the outcome variables. Therefore, for supervisor reports of the behavioral outcome variables, Hypothesis 6 was not supported.

The Mediation Effect of Procedural Justice Using Self-report Data

The same process used to evaluate the mediation effect of distributive justice was used for procedural justice serving as the mediator (Hypothesis 7). The first step in the mediator analysis was the same as for distributive justice (Table 48). Therefore, OCBI was dropped from further analysis. In the second step of the mediator analysis (Table 49), LMX was significantly related to procedural justice $\left(\underline{\mathrm{R}^{2}}=.09, \underline{\mathrm{p}}<.01\right)$. In the third set of regression analyses, procedural justice was unrelated to performance and $\mathrm{ORB}$, therefore no mediation could exist and these variables were dropped from further analysis. Partial mediation was found between LMX and job satisfaction (Hypothesis 7a), intention to quit (Hypothesis 7b), organizational commitment (Hypothesis 7c), and OCBO (Hypothesis 7e) (Table 50). The magnitude of the reduction in variance accounted for was fairly substantial for these four outcomes (Table 51), therefore Hypothesis 7 was partially supported. 
The Mediating Effect of Procedural Justice Using Supervisor Reports of Behavior

In the first step of the mediator analysis for procedural justice using supervisor reports of the outcomes as the dependent variables was the same as for distributive justice. Subordinate perceptions of LMX were significantly related to supervisor reports of in-role performance, OCBI, OCBO, and ORB. In the second regression model, LMX was positively related to procedural justice $\left(\underline{\mathrm{R}^{2}}=.09, \underline{\mathrm{p}}<.01\right)$. Contrary to Hypothesis 7 , the last step in the mediation analyses indicated that subordinate reports of procedural justice were unrelated to supervisor reports of any of the behavioral outcome variable. Therefore Hypothesis 7 was not supported when using supervisor reports of subordinate behavior.

\section{Testing the Entire Model}

Testing the overall model was done in a manner similar to that done in the laboratory study. Additionally, since data were gathered from both supervisors and their subordinates structural equation modeling also allowed for testing the quality of the dyadic relationship between supervisor and subordinate as an emergent property of the perceptions of both parties. Figure 28 shows "quality of dyadic relationship" as a latent variable (i.e., an oval) related to leader perceptions of trust of the member and member perceptions of trust of the leader. Importantly, quality of the dyadic relationship as a latent variable influences both member perceptions of LMX and leader perceptions of LMX.

Figure 28 shows the relationships between variables in the full, hypothesized model. This model did not fit the data well (Table 52). Similar to the laboratory study, the length of the dyadic relationship between supervisors and subordinates averaged 
over one year. Therefore, it was likely that the relationship between dispositional trust and trust in a specific other would be less salient to study participants than the actual behavior and attitude of the other party in the dyad. Additionally, the results of the structural equation analysis for the hypothesized model indicated that these paths were not statistically significant. For these reasons, both subordinate dispositional trust and supervisor dispositional trust were eliminated from the model. Also similar to the laboratory study, the path between overall fairness and OCBI was not statistically significant. Since both distributive and procedural justice items were directed at organizational fairness, it is unlikely that overall fairness would have a substantial effect on OCBI. Therefore, this path was also eliminated from the model. The elimination of these variables did not result in improving the overall fit indices (Model 3; Table 52). Additionally, in Model 3, job satisfaction and intention to quit were allowed to co-vary. All paths in this revised model were statistically significant (Figure 29). Since this model made the most theoretical sense and all paths were statistically significant, although the fit indices were less than optimal, this model was retained as the most acceptable. It is likely that with a larger sample size, the fit indices would reach commonly accepted criteria to indicate a well fitting model. Additional model analyses are presented in the post hoc section, which follows, after modifications were made to some of the construct scales. 
$\underline{\text { Post Hoc Analyses }}$

Post hoc analyses, similar to those conducted in the laboratory study, were conducted with the field study data.

Dispositional Trust. Member reports of dispositional trust were related to member reports of trust in supervisor for the subsample of members $(\underline{n}=41)$ who had been reporting to their supervisor for less than one year $(\underline{r}=.27, \underline{p}<.05$ two-tailed $)$. This result provides support for the idea that individuals rely on general tendencies to trust other people early in the dyadic relationship.

Supervisor reports of dispositional trust were not related to supervisor perceptions of trust in their subordinates $(\underline{r}=.09, \underline{p}>.05)$ who had been supervising direct reports for less than a year $(\underline{n}=54)$. This result could be due to two factors. First, the amount of variance of in the dispositional trust variable was limited because these reports came from 18 supervisors. Secondly, due to the fact that supervisors in this organization are the hiring authority, it is likely that supervisors had a significant amount of information regarding each subordinate upon hiring. This would mitigate any potential effect of dispositional trust on trust in a specific subordinate.

Trust in Supervisor and LMX. As was the case in the laboratory study, there was a very high correlation between trust in supervisor and LMX. A factor analysis was run with items from both the LMX-8 and trust in supervisor measures. Using oblique rotation, the best solution was a two-factor solution. The first factor accounted for $60.62 \%$ of the variance in the items and contained 6 items including 2 of the 8 items in the original LMX scale and all 4 items in the trust in supervisor scale. The items of this factor (Supervisory Relationship) had an estimated reliability of .90 . The 
second factor accounted for $14.41 \%$ of the variance in the items and contained 2 items for the LMX scale. The two items of the second factor (Standing with Supervisor) had an estimated reliability of .87 . The other four items either failed to load on any factor or cross-loaded on both factors. Therefore, these items were eliminated. Since the first factor best captured the conceptual content of the LMX and trust in supervisor scales, this factor was included in further analyses.

Supervisory relationship was positively related to distributive justice $(\underline{r}=.34, \underline{p}$ $<.05)$, procedural justice $(\underline{r}=.27, \underline{p}<.05)$, organizational commitment $(\underline{r}=.40, \underline{p}<$ $.05)$, job satisfaction $(\underline{r}=.46, \underline{p}<.05)$, intention to quit $(\underline{r}=-.39, \underline{p}<.05)$, OCBO $(\underline{r}=$ $.33, \mathrm{p}<.05)$, and a modified measure of ORB directed at an individual $(\underline{\mathrm{r}}=-.40, \underline{\mathrm{p}}<$ .05) (the modified measure of ORBI is discussed in the next section). Supervisory relationship was unrelated to in-role performance, OCBI, and ORB-time wasted. Trust in Subordinate and LMX for the Supervisor's Perspective. A factor analysis was run with items from both the LMX-8 from the supervisor's perspective (SLMX) and trust in subordinate measures. Using oblique rotation, a two-factor solution resulted in the retention of 10 of the 12 original items. The first factor accounted for $56.47 \%$ of the variance in the items and contained 7 items including 3 of the 8 items in the original SLMX scale and all 4 items in the trust in subordinate scale. The items of this factor (Subordinate Relationship) had an estimated reliability of .90 . The second factor accounted for $16.78 \%$ of the variance in the items and contained 3 items for the SLMX scale. The three items of the second factor (Standing with Subordinate) had an estimated reliability of .87 . However, the reliability could be raised to .94 with the elimination of one item. The other two items either failed to load 
on any factor or cross-loaded on both factors. Therefore, these items were eliminated. Since the first factor best captured the conceptual content of the SLMX and trust in subordinate scales, this factor was included in further analyses.

Subordinate relationship was positively related to in-role performance $(\underline{r}=.76$, $\underline{\mathrm{p}}<.05), \mathrm{OCBI}(\underline{\mathrm{r}}=.56, \underline{\mathrm{p}}<.05), \mathrm{OCBO}(\underline{\mathrm{r}}=.68, \underline{\mathrm{p}}<.05)$, and negatively related to a modified measure of ORB directed at an individual $(\mathrm{r}=-.18, \underline{\mathrm{p}}<.05)$ (the modified measure of ORBI is discussed in the next section) and a modified measure of ORBO ( $\underline{r}$ $=-.38, \mathrm{p}<.05)$

Organizational Retaliatory Behavior from Subordinate Perspective. One item in the ORB scale failed to have any variance (i.e., all participants responded "never" to the item), therefore this item was eliminated from further analyses. An initial set of factor analyses were run using the principal components method with oblique rotation. This approach did not result in any theoretically sound solution. However, when a two-factor solution was forced on the items, an interpretable two-factor solution was found.

The first factor accounted for $27.69 \%$ of the variance in the items and contained 7 items reflecting a modified ORBI construct (RBI-mod). This scale had an estimated reliability of .72 . The second factor accounted for $14.01 \%$ of the variance in the items and contained 5 items. The three items of the second factor reflected a modified ORBO factor with an emphasis of wasting time (ORBO-mod). This scale had an estimated reliability of .64 .

The ORBI-mod scale was negatively related to supervisory relationship (i.e., combined trust in supervisor and LMX measure $)(\mathrm{r}=-.40, \underline{\mathrm{p}}<.05)$, procedural justice 
$(\underline{r}=-.20, \underline{p}<.05)$, job satisfaction $(r=-.24, \underline{p}<.05)$, organizational commitment $(\underline{r}$ $=-.22, \mathrm{p}<.05)$, and OCBO $(\mathrm{r}=-.26, \mathrm{p}<.05)$. The ORBI-mod scale was also positively related to intention to quit $(\underline{r}=.33, \underline{p}<.05)$.

The ORBO-mod scale was negatively related to performance $(r=-.21, \underline{p}<.05)$ and OCBO $(\underline{r}=-.50, \underline{p}<.05)$. The ORBO-mod scale was also positively related to intention to quit $(\underline{r}=.17, \underline{p}<.05$, two-tailed $)$.

Supervisor Reports of Subordinate Organizational Retaliatory Behavior. Three items in the ORB scale failed to have any variance as reported by supervisors (i.e., all participants responded "never" or "don't know" to the item), therefore these items were eliminated from further analyses. As was the case with subordinate's self-reports of $\mathrm{ORB}$, a forced two-factor solution resulted in an interpretable solution.

The first factor accounted for $30.07 \%$ of the variance in the items and contained 6 items reflecting a modified ORBI construct (SORBI-mod). This scale had an estimated reliability of .80 . The second factor accounted for $22.15 \%$ of the variance in the items and contained 6 items. The items of the second factor reflected a modified

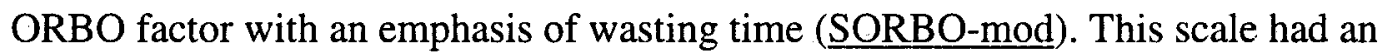
estimated reliability of 70 .

The SORBI-mod scale was negatively related to subordinate relationship (i.e., combined trust in subordinate and SLMX measure $)(\mathrm{r}=-.18, \mathrm{p}<.05)$, and supervisors' reports of subordinates' performance $(\underline{r}=-.18, \underline{\mathrm{p}}<.05)$ and $\mathrm{OCBO}(\underline{\mathrm{r}}=-$ $.27, \mathrm{p}<.05)$.

The SORBO-mod scale was negatively related to subordinate relationship (i.e., combined trust in subordinate and SLMX measure $)(\mathrm{r}=-.38, \mathrm{p}<.05)$, and 
supervisors' reports of subordinates' performance $(\underline{r}=-.43, \underline{p}<.05)$ and OCBO $(\underline{r}$ $=-.60, \underline{\mathrm{p}}<.05)$. Neither SORBI-mod nor SORBO-mod were related to supervisor reports of subordinates OCBI.

Full Model Analyses. As in the laboratory study, after the post hoc factor analyses, changes in the trust in supervisor/subordinate, LMX, SLMX, and ORB scales were made. The first model tested (Figure 30) did not include dispositional trust from either the supervisors' and subordinates' perspectives. Additionally, supervisory relationship (i.e., trust in supervisory and LMX combined) and subordinate relationship (i.e., trust in subordinate and SLMX combined) were included. This model fit the data moderately well (Table 53). Model 3 eliminated the relationship that was not statistically significant (i.e., path from overall fairness to OCBI). Additionally, paths between outcome variables that made theoretical sense were added (i.e., between job satisfaction and intention to quit; between ORBI-mod and ORBO-mod). This model fit the data moderately well, although all paths were statistically significant (Figure 31).

Because the overall fit indices indicated that Model 3 fit the data less than desired despite substantial path coefficients and only subordinate behavioral data were collected from supervisors, two additional sub-models were run utilizing subordinate self-perceptions. One model (Model 4; Table 53) contained only attitudinal outcomes from Model 3 (Figure 30). The path coefficients remained of similar magnitude to Model 3, however the overall fit indices improved dramatically. The second submodel (Model 5; Table 53) contained only the behavioral outcomes from Model 3 (Figure 31). Again, the path coefficients remained of similar magnitude to those in 
Model 3. There were only marginal improvements in the overall fit indices for

Model 5 over Model 3 (Table 53).

A second set of models was run with supervisor reports of subordinates' behaviors serving as the outcome variables. Due to the strong relationship between quality of dyadic relationship and the outcomes and the low relationship between subordinates' perceptions of overall fairness and supervisory perceptions of subordinates' behaviors, the initial model (Figure 32) failed to result in a stable solution. It seems unlikely that subordinate perceptions of organizational justice would be related to supervisory reports of subordinate behavior. Therefore, another model was run with direct paths from quality of relationship to the outcome variables (Figure 33). The results of this model showed that quality of the dyadic relationship as a latent variable influenced both supervisory relationship and subordinate relationship. Additionally, quality of dyadic relationship was strongly related to all of the subordinate behavioral variables as reported by supervisors. This model fit the data well (Model 3; Table 54).

Similar to the laboratory study, dispositional trust was directly related to some of the outcome variables. Therefore, a model was run with direct paths between subordinate dispositional trust and subordinate reports of the outcome variables (Model 6; Table 53). This model was not a well-fitting model. Maximum likelihood estimates indicated that only the paths between dispositional trust and organizational commitment and OCBO were statistically significant. After all non-significant paths were eliminated, the model was still not well-fitting (Model 7; Table 53). However, dispositional trust was positively related to organizational commitment and OCBO. 
Importantly, in the best fitting models from both the supervisor and subordinate perspectives both supervisory relationship and subordinate relationship were influenced by the latent variable Dyadic Relationship Quality.

A summary of the results for each formal hypothesis from both the laboratory and field studies is in Table 55. 
Table 38

Power Analysis for Study Two (Field Study)

\begin{tabular}{|c|c|c|c|}
\hline Hypothesis & Significance Test & $\begin{array}{c}\text { Medium } \\
\text { Effect Size }\end{array}$ & $\begin{array}{c}\text { Sample Size } \\
\text { Required }\end{array}$ \\
\hline 1 & $\begin{array}{l}\text { Correlation } \\
\text { Coefficient }\end{array}$ & .30 & 85 \\
\hline 2 & $\begin{array}{l}\text { Correlation } \\
\text { Coefficient }\end{array}$ & .30 & 85 \\
\hline 3 & $\begin{array}{l}\text { Correlation } \\
\text { Coefficient }\end{array}$ & .30 & 85 \\
\hline 4 & $\begin{array}{l}\text { Correlation } \\
\text { Coefficient } \\
\end{array}$ & .30 & 85 \\
\hline 5 & $\begin{array}{l}\text { Hierarchical } \\
\text { Regression }\end{array}$ & .15 & 76 \\
\hline 6 & $\begin{array}{l}\text { Hierarchical } \\
\text { Regression }\end{array}$ & .15 & 67 \\
\hline 7 & $\begin{array}{l}\text { Hierarchical } \\
\text { Regression }\end{array}$ & .15 & 67 \\
\hline $\begin{array}{l}\text { Test of } \\
\text { Entire } \\
\text { Model }\end{array}$ & $\begin{array}{l}\text { Path } \\
\text { Analysis/Structural } \\
\text { Equation Modeling }\end{array}$ & & 200 \\
\hline
\end{tabular}

Note. Minimum sample size requirements assuming medium effect sizes and power equals .80 (Cohen, 1992). 


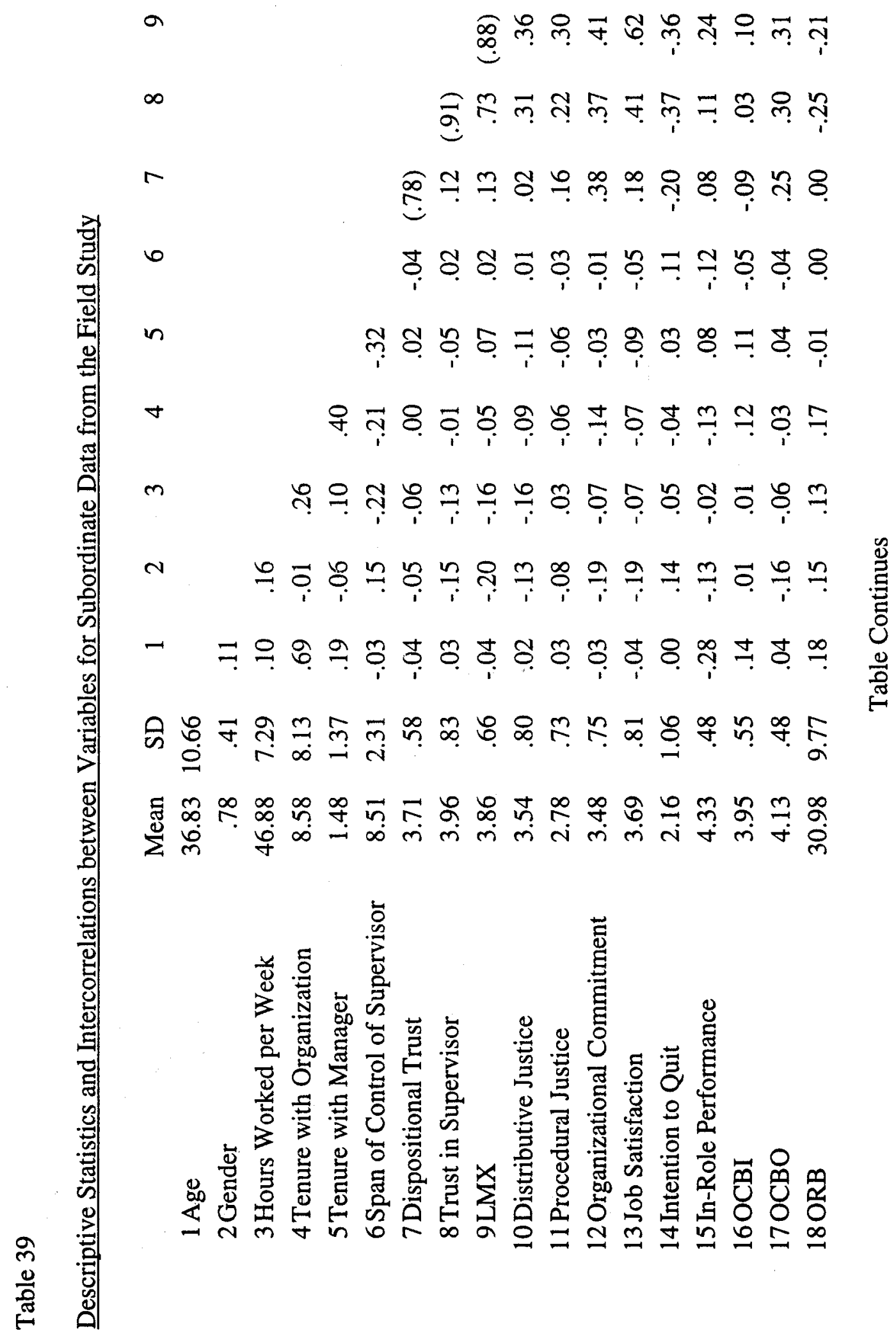



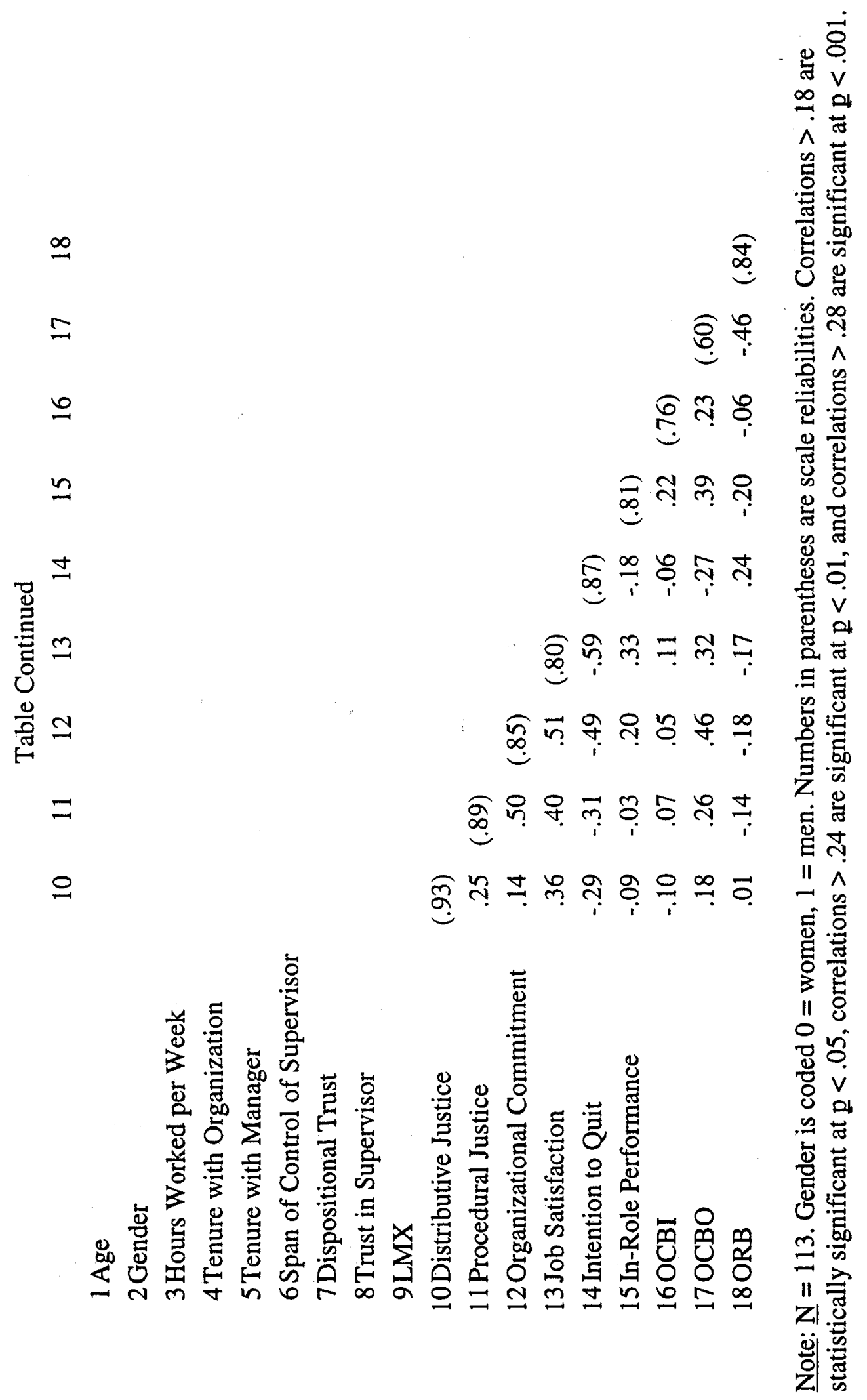


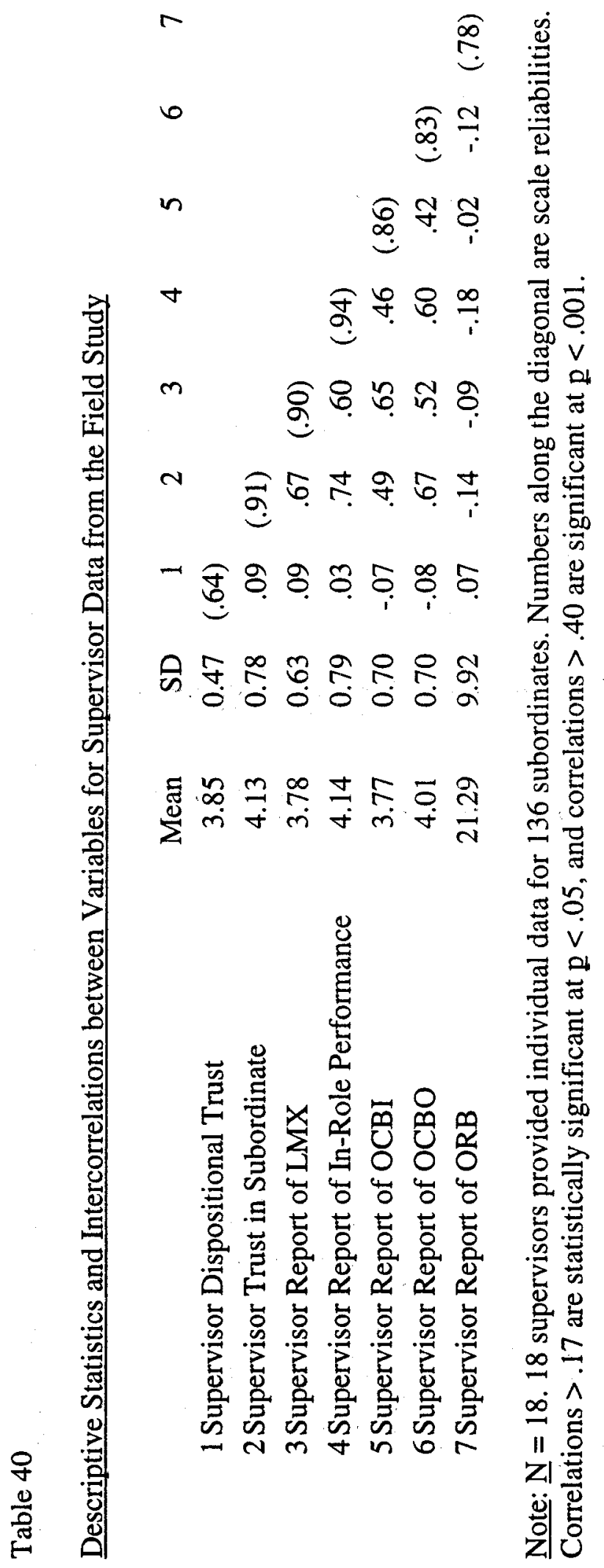




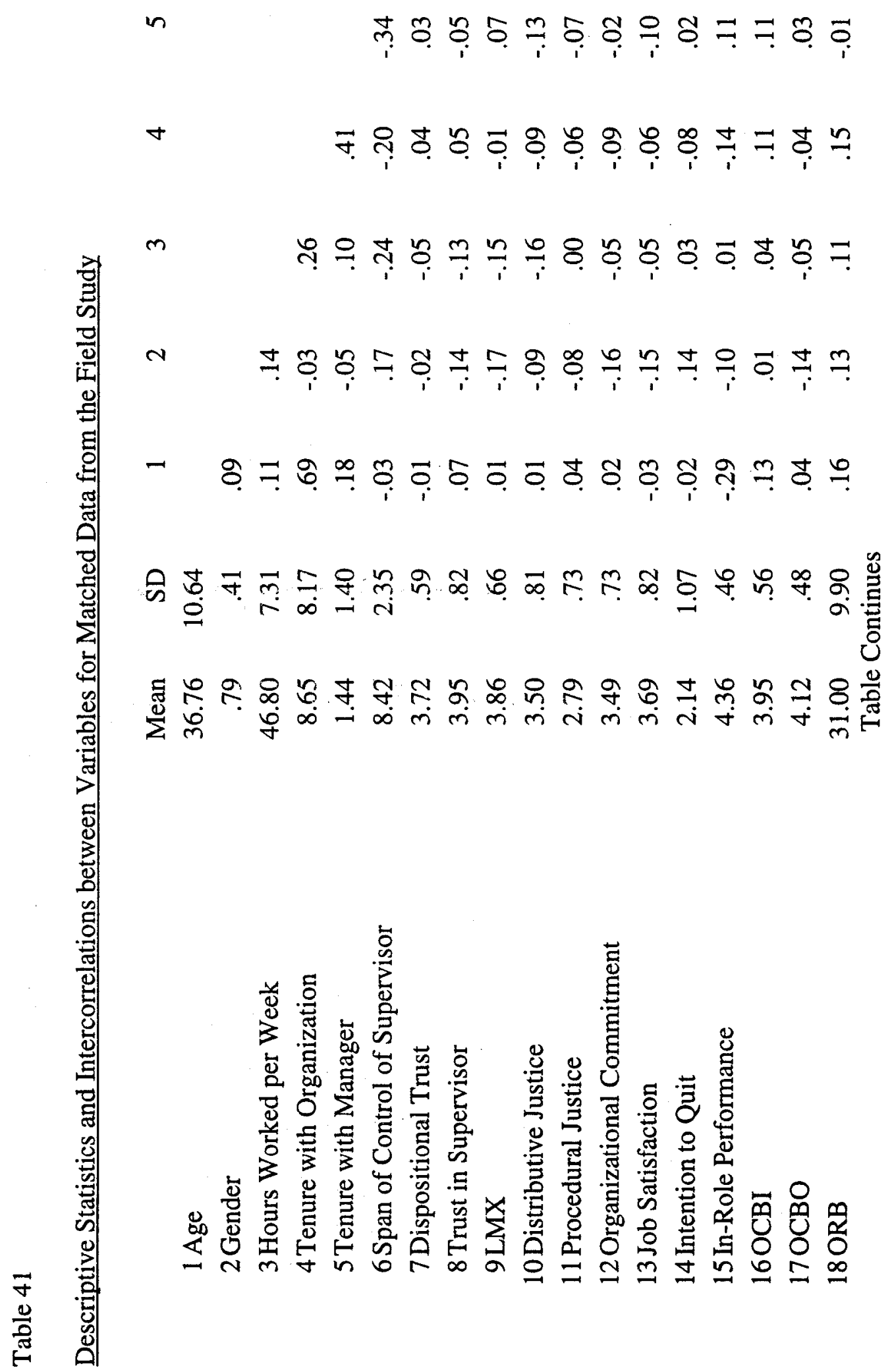




$$
\begin{aligned}
& n \text { 이 우ㅇㅝㅠ }
\end{aligned}
$$

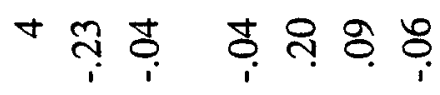

$$
\begin{aligned}
& \text { m } 0_{i}^{\infty} \stackrel{\circ}{\circ} \div 8 \\
& \text { ง } \\
& \text { - 궁 느응 }
\end{aligned}
$$

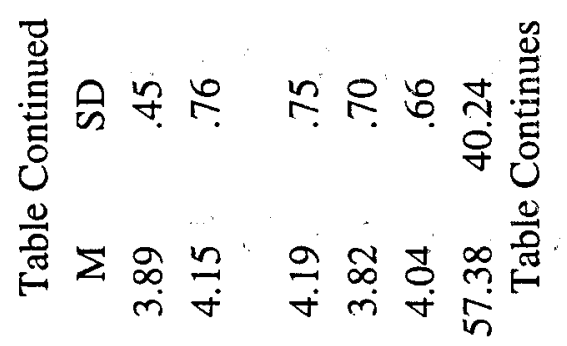

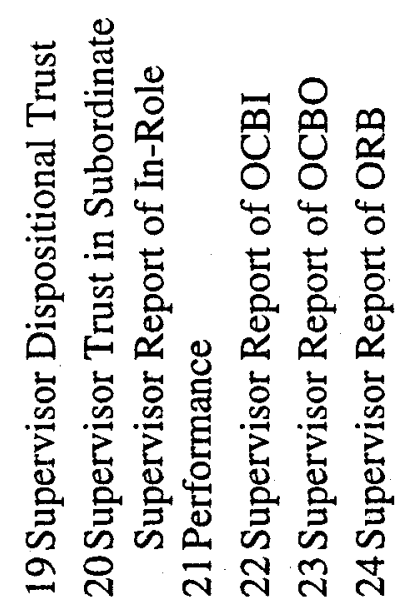




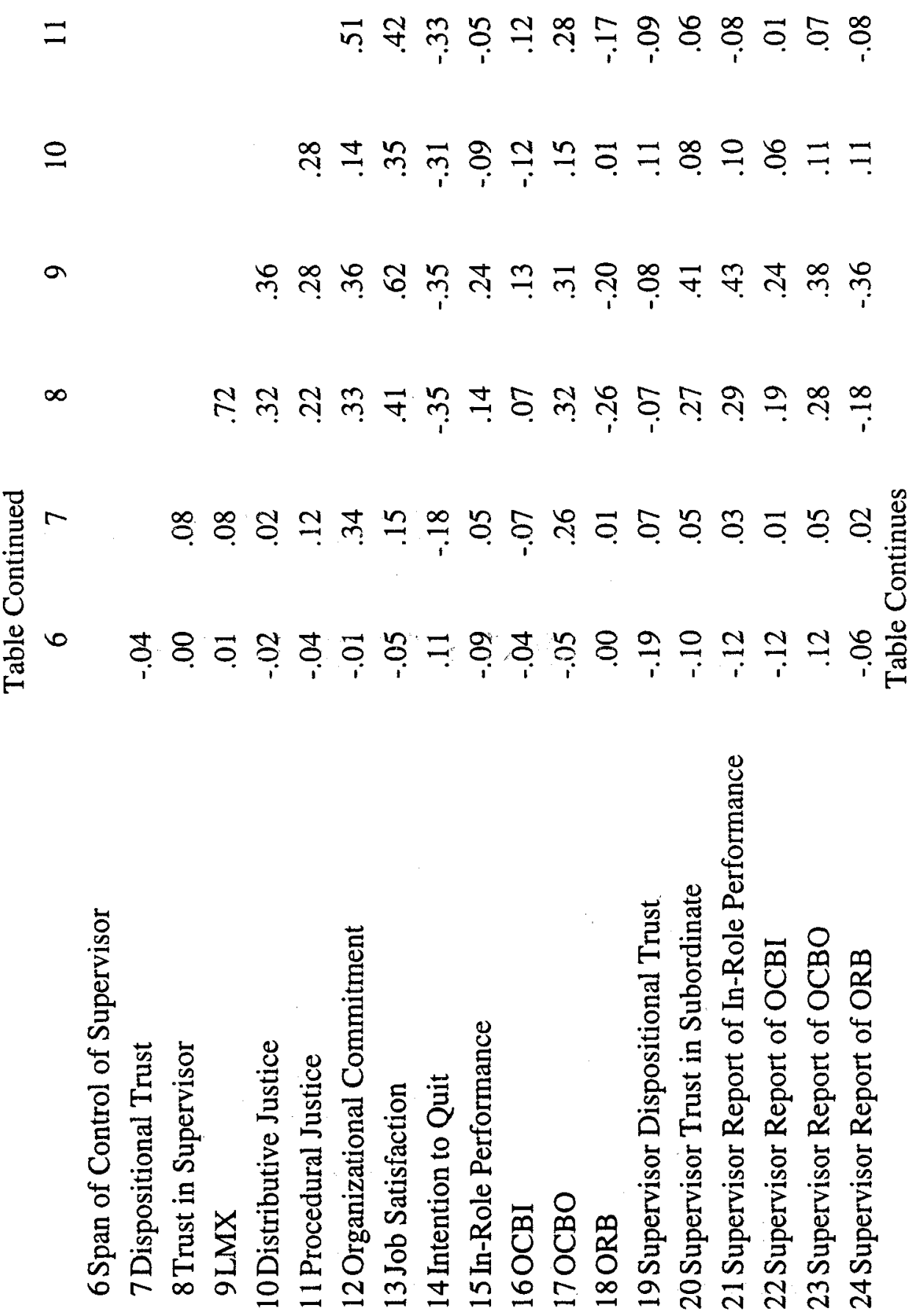




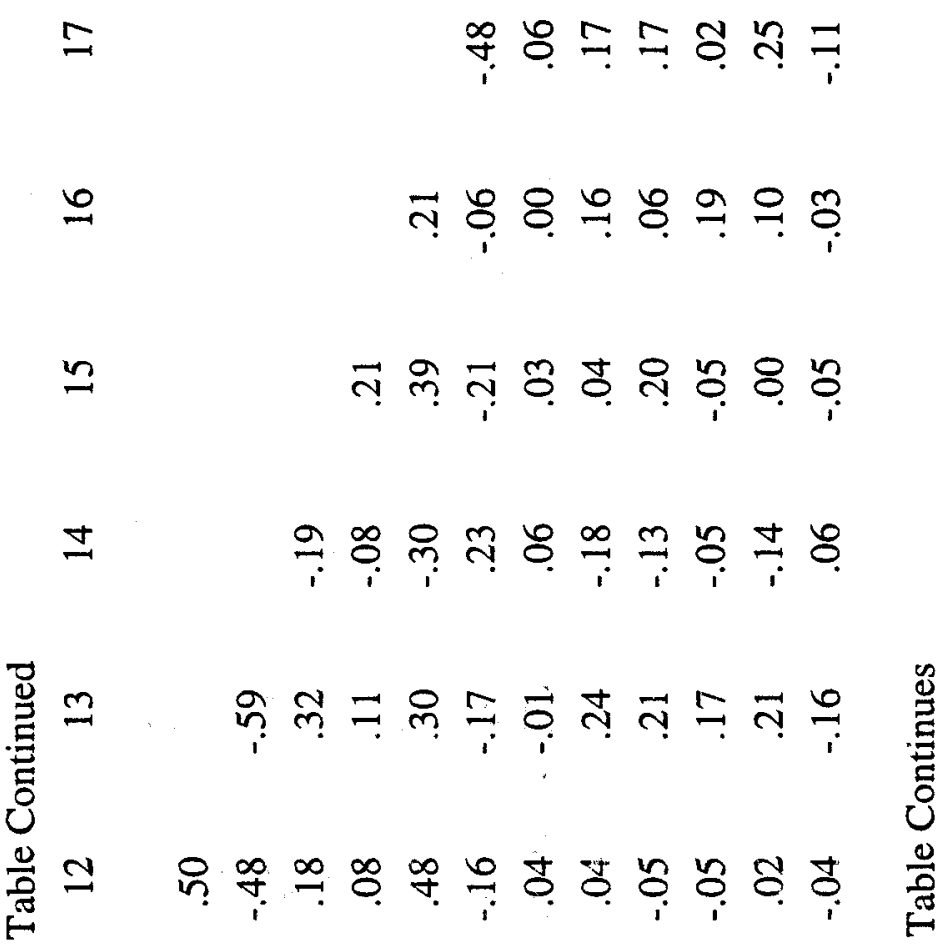

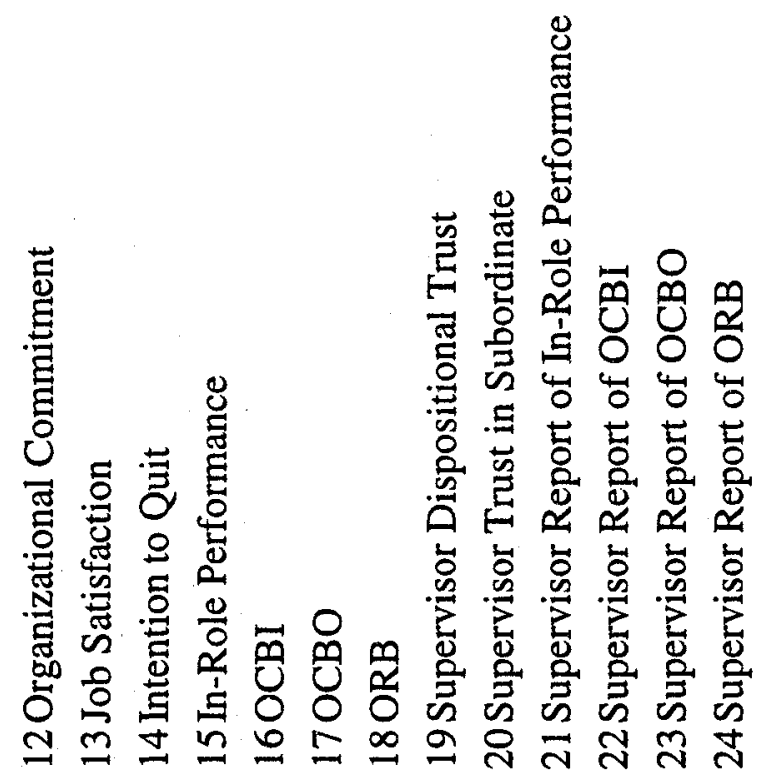




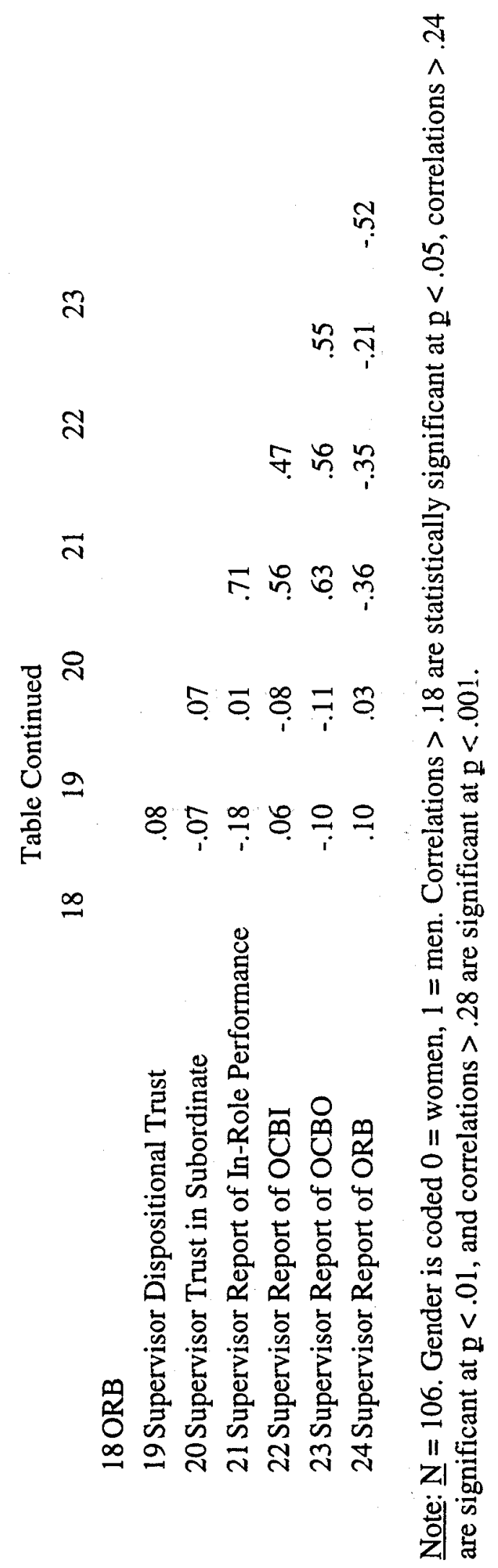


Table 42

The Relationship between Trust in Supervisor and LMX with Control Variables

\begin{tabular}{llllll} 
& & $\mathrm{B}$ & $\mathrm{R}^{2}$ & $\Delta \mathrm{R}^{2}$ & $\mathrm{~F}$ \\
\hline Step 1 & & .07 & & 1.25 \\
& Age & .00 & & \\
Gender & -.09 & & & \\
Hours Worked & -.05 & & & \\
& Tenure with Organization & -.08 & & & \\
& Tenure with Supervisor & .15 & & & \\
& Span of Control of & .05 & & & \\
& Supervisor & & &
\end{tabular}

\begin{tabular}{llllll} 
Step 2 & & .55 & .47 & $99.01^{* *}$ \\
& Trust in Supervisor & $.70^{* *}$ & & & \\
\hline
\end{tabular}

Note: $\underline{N}=113$. Gender is coded Male $=1$, Female $=0$. Beta weights are from the final equation.

$* * p<.01$. 
Table 43

The Relationship between Trust in Subordinate and LMX with Control Variables

\begin{tabular}{llrrrr} 
& & $\mathrm{B}$ & $\mathrm{R}^{2}$ & $\Delta \mathrm{R}^{2}$ & $\mathrm{~F}$ \\
\hline Step 1 & & .09 & & 1.44 \\
& Age & -.14 & & & \\
& Gender & .08 & & & \\
& Hours Worked & -.03 & & & \\
& Tenure with Organization & .19 & & & \\
& Tenure with Supervisor & .12 & & & \\
& Span of Control of & -.05 & & & \\
& Supervisor & & & &
\end{tabular}

\begin{tabular}{rlllll} 
Step 2 & & & & & \\
& Trust in Supervisor & $.67 * *$ & & .43 & $79.67^{* *}$ \\
\hline
\end{tabular}

Note: $\underline{N}=106$. Gender is coded Male $=1$, Female $=0$. Beta weights are from the final equation.

$* * \mathrm{p}<.01$. 
Table 44

Mediation Step 1: Effect of Distributive Justice on LMX-Outcome Relationships for Field Study Self-Report Data

\begin{tabular}{ccc}
\hline & \multicolumn{2}{c}{ Outcomes } \\
\cline { 2 - 3 } & \multicolumn{2}{c}{ Job } \\
Satisfaction & $\begin{array}{c}\text { Intention } \\
\text { to Quit }\end{array}$ \\
& & \\
LMX Beta-Weight & $.62^{* *}$ & $-.36^{* *}$ \\
$\mathrm{R}^{2}$ & .39 & .13 \\
$\mathrm{~F}$ & $71.04^{* *}$ & $16.67^{* *}$ \\
\hline
\end{tabular}

Note: $\underline{\mathrm{N}}=113$. Step $1=\mathrm{LMX}$ in regression model predicting two dependent variables. $* * \mathrm{p}<.01$. 
Table 45

Mediation Step 2: Effect of Distributive Justice on LMX-Outcome Relationships for Field Study Self-Report Data

\begin{tabular}{cc}
\hline & $\begin{array}{c}\text { Mediator } \\
\text { Distributive } \\
\text { Justice }\end{array}$ \\
$\mathrm{LMX}$ & $.36^{* *}$ \\
$\mathrm{R}^{2}$ & .13 \\
$\mathrm{~F}$ & $9.21^{* *}$ \\
\hline
\end{tabular}

Note: $\underline{N}=113$. Step $2=$ LMX predicting Distributive Justice.

$* * \mathrm{p}<.01$. 
Table 46

Mediation Step 3: Effect of Distributive Justice on LMX-Outcome Relationships for Field Study Self-Report Data

\begin{tabular}{ccc}
\hline & \multicolumn{2}{c}{ Outcomes } \\
\cline { 2 - 3 } & Job & Intention \\
& Satisfaction & to Quit \\
$\mathrm{DJ}$ & $.36^{* *}$ & $-.29^{* *}$ \\
$\mathrm{R}^{2}$ & .13 & .08 \\
$\mathrm{~F}$ & $16.86^{* *}$ & $10.02^{* *}$ \\
$\mathrm{LMX}$ & $.57^{* *}$ & $-.29^{* *}$ \\
$\Delta \mathrm{R}^{2}$ & .28 & .08 \\
$\mathrm{~F}$ Change & $52.54^{* *}$ & $10.27^{* *}$ \\
\hline
\end{tabular}

Note: $\underline{\mathrm{N}}=113$. Full mediation exists when the beta weight in Step 3 is non-significant for LMX.

$* * \mathrm{p}<.01$. 
Table 47

Reduction in Variance Accounted by Distributive Justice on Field Study LMXOutcome Relationships

\begin{tabular}{llll}
\hline & $\begin{array}{l}\text { Percentage of } \\
\text { Variance Accounted } \\
\text { for by LMX } \\
\text { Initially }\end{array}$ & $\begin{array}{l}\text { Percentage of } \\
\text { Variance Accounted } \\
\text { for by LMX After } \\
\text { Inclusion of } \\
\text { Distributive Justice } \\
\text { in Mediation Model }\end{array}$ & $\begin{array}{l}\text { Percentage } \\
\text { Decrease of } \\
\text { Variance Accounted } \\
\text { for in Outcome } \\
\text { Variable After } \\
\text { Inclusion of } \\
\text { Mediator }\end{array}$ \\
\cline { 2 - 4 } & & 28 & 28 \\
Job Satisfaction & 39 & 8 & 38 \\
\hline Intention to Quit & 13 & & \\
\hline
\end{tabular}

$\underline{\text { Note }} . \underline{N}=113$. 
Table 48

Mediation Step 1: Effect of Procedural Justice on LMX-Outcome Relationships for Field Study Self-Report Data

\begin{tabular}{lcccc}
\hline & \multicolumn{4}{c}{ Outcomes } \\
& $\begin{array}{c}\text { Job } \\
\text { Satisfaction }\end{array}$ & $\begin{array}{c}\text { Intention } \\
\text { to Quit }\end{array}$ & $\begin{array}{c}\text { Organizational } \\
\text { Commitment }\end{array}$ & OCBO \\
\cline { 2 - 5 } & & & & \\
LMX Beta-Weight & $.62^{* *}$ & $-.36^{* *}$ & $.41^{*}$ & $.31 * *$ \\
$\mathrm{R}^{2}$ & .39 & .13 & .17 & .10 \\
$\mathrm{~F}$ & $71.04^{* *}$ & $16.67^{* *}$ & $22.20^{* *}$ & $11.77^{* *}$ \\
\hline
\end{tabular}

Note: $\underline{N}=113$. Step $1=\mathrm{LMX}$ in regression model predicting four dependent variables.

$* \mathrm{p}<.05$.

$* * \mathrm{p}<.01$. 
Table 49

Mediation Step 2: Effect of Procedural Justice on LMX-Outcome Relationships for Field Study Self-Report Data

\begin{tabular}{cc}
\hline & $\begin{array}{c}\text { Procedural } \\
\text { Justice }\end{array}$ \\
LMX & $.30^{* *}$ \\
$\mathrm{R}^{2}$ & .09 \\
$\mathrm{~F}$ & $11.01^{* *}$ \\
\hline
\end{tabular}

Note: $\underline{N}=113$. Step $2=$ LMX predicting Procedural Justice.

$* * \mathrm{p}<.01$. 
Table 50

Mediation Step 3: Effect of Procedural Justice on LMX-Outcome Relationships for Field Study Self-Report Data

\begin{tabular}{ccccc}
\hline & \multicolumn{4}{c}{ Outcomes } \\
\cline { 2 - 5 } & Job & Intention & Organizational & OCBO \\
& Satisfaction & to Quit & Commitment & \\
PJ & $.40^{* *}$ & $-.31^{* *}$ & $.50^{* *}$ & $.26^{* *}$ \\
$\mathrm{R}^{2}$ & .16 & .10 & .25 & .07 \\
$\mathrm{~F}$ & $21.47^{* *}$ & $12.05^{* *}$ & $37.17^{* *}$ & $7.98^{* *}$ \\
$\mathrm{LMX}$ & $.55^{* *}$ & $-.29^{* *}$ & $.28^{* *}$ & $.25^{* *}$ \\
$\Delta \mathrm{R}^{2}$ & .28 & .08 & .07 & .06 \\
$\mathrm{~F}$ Change & $54.89^{* *}$ & $10.18^{* *}$ & $11.89^{* *}$ & $7.44^{* *}$ \\
\hline
\end{tabular}

Note: $\underline{\mathrm{N}}=113$. Full mediation exists when the beta weight in is non-significant for LMX.

$* * \mathrm{p}<.01$ 


\section{Table 51}

Reduction in Variance Accounted by Procedural Justice on Field Study LMXOutcome Relationships

\begin{tabular}{llll}
\hline & $\begin{array}{l}\text { Percentage of } \\
\text { Variance Accounted } \\
\text { for by LMX } \\
\text { Initially }\end{array}$ & $\begin{array}{l}\text { Percentage of } \\
\text { Variance Accounted } \\
\text { for by LMX After } \\
\text { Inclusion of } \\
\text { Procedural Justice } \\
\text { in Mediation Model }\end{array}$ & $\begin{array}{l}\text { Percentage } \\
\text { Decrease of } \\
\text { Variance } \\
\text { Accounted for in } \\
\text { Outcome } \\
\text { Variable After } \\
\text { Inclusion of } \\
\text { Mediator }\end{array}$ \\
$\begin{array}{llll}\text { Job Satisfaction } \\
\text { Intention to Quit }\end{array}$ & 39 & 28 & 28 \\
$\begin{array}{l}\text { Organizational } \\
\text { Commitment }\end{array}$ & 13 & 8 & 38 \\
OCBO & 10 & 7 & 59 \\
\hline
\end{tabular}

Note. $\underline{N}=113$. 


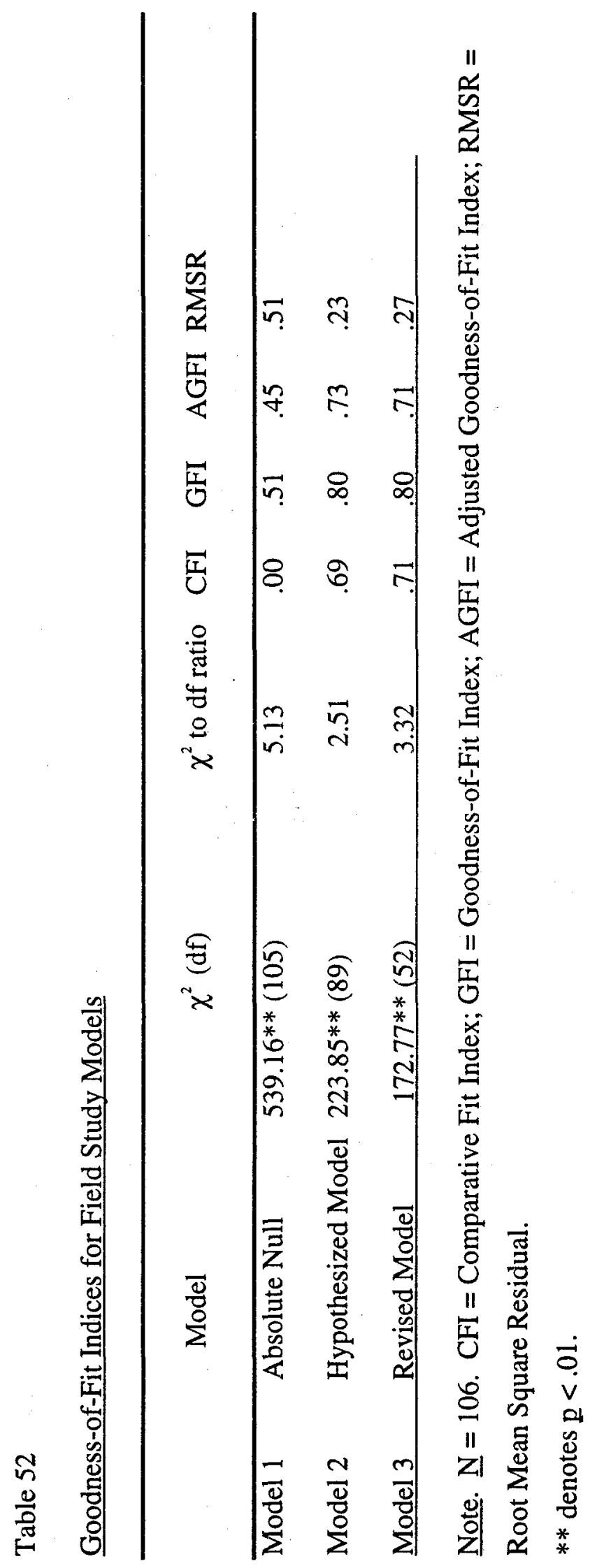




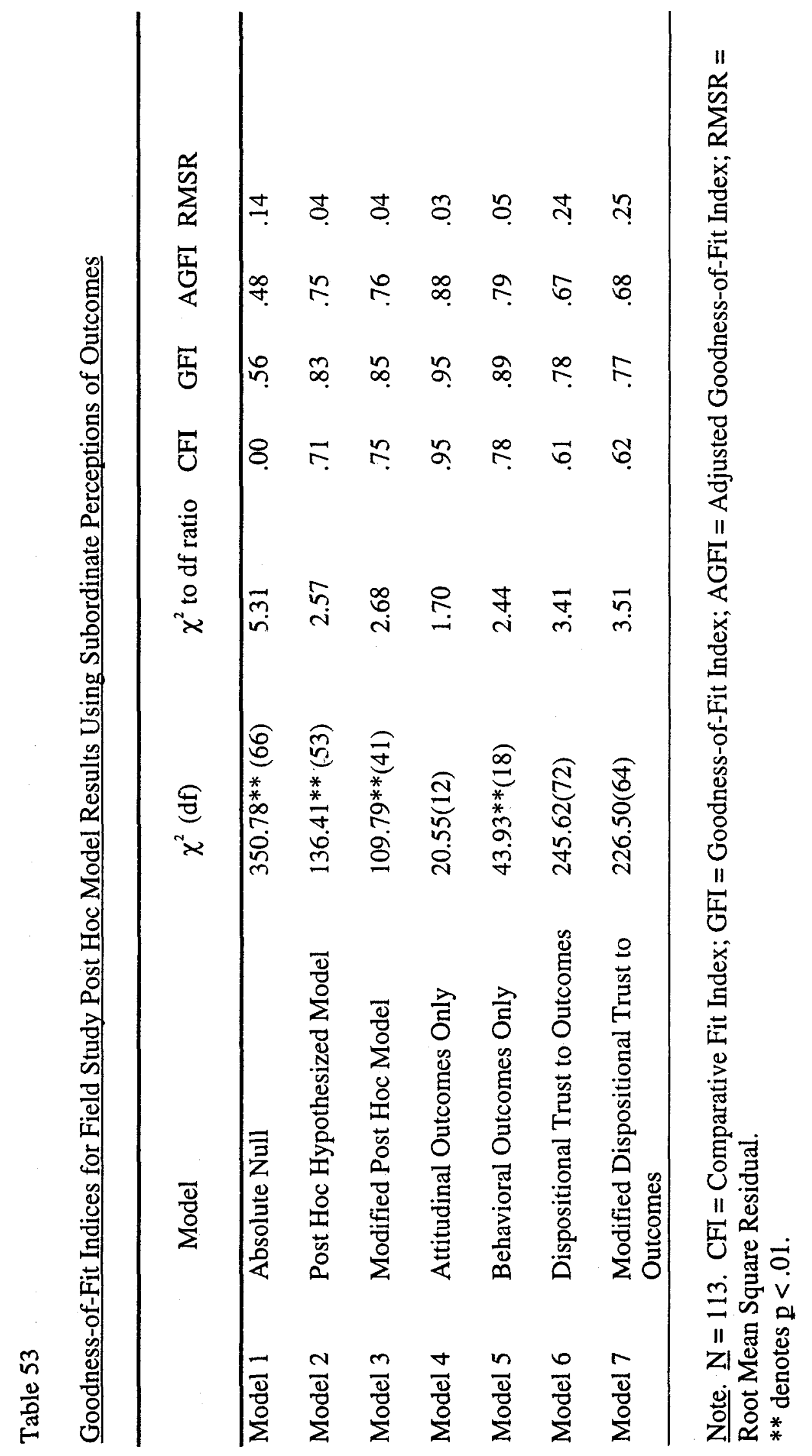




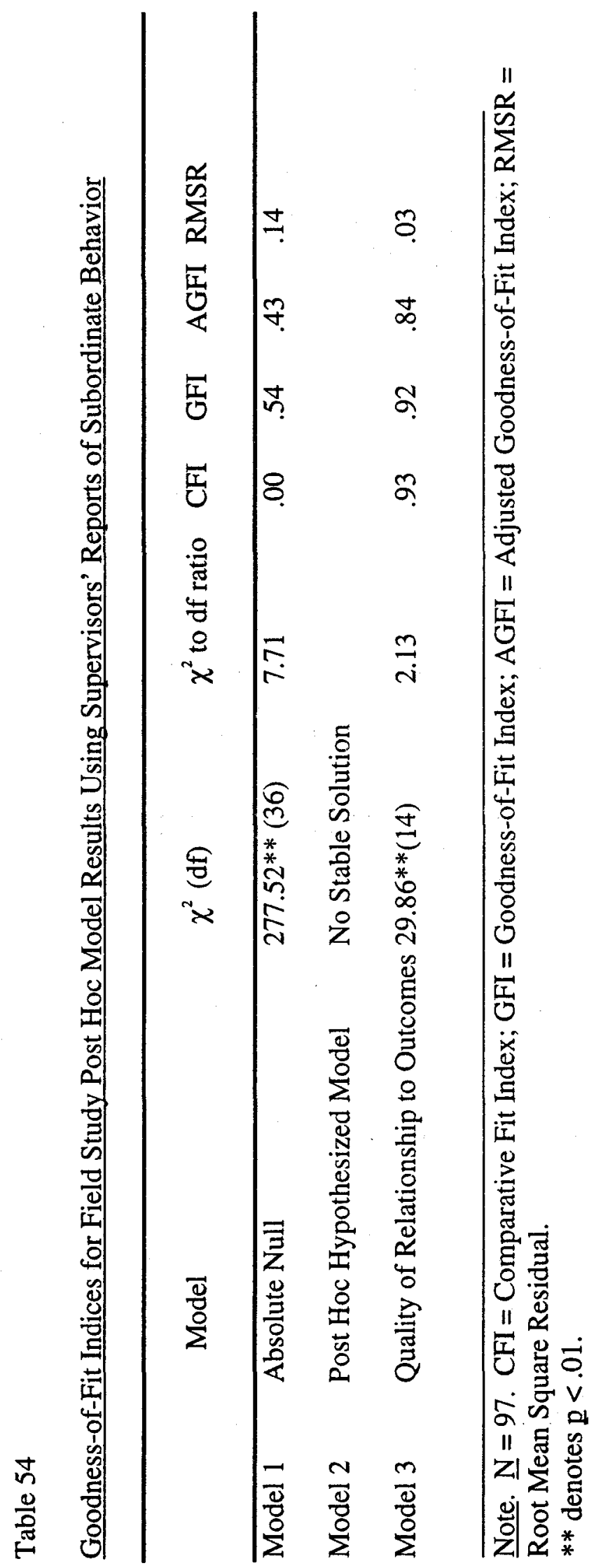


Table 55

Summary of Findings

\begin{tabular}{|c|c|c|c|c|}
\hline Hypothesis & $\begin{array}{c}\text { Pre- } \\
\text { Manipulation } \\
\text { Laboratory } \\
\text { Study } \\
\end{array}$ & $\begin{array}{c}\text { Post- } \\
\text { Manipulation } \\
\text { Laboratory } \\
\text { Study } \\
\end{array}$ & $\begin{array}{c}\text { Field Study } \\
\text { Subordinate } \\
\text { Reports }\end{array}$ & $\begin{array}{c}\text { Field } \\
\text { Study } \\
\text { Manager } \\
\text { Reports }\end{array}$ \\
\hline $\begin{array}{l}\text { 1a) Member's } \\
\text { dispositional } \\
\text { trust related to } \\
\text { member's trust } \\
\text { in leader. }\end{array}$ & NS & NA & NS & NA \\
\hline $\begin{array}{l}\text { 1b) Leader's } \\
\text { dispositional } \\
\text { trust related to } \\
\text { leader's trust in } \\
\text { member. }\end{array}$ & NA & NA & $\mathrm{NA}$ & NS \\
\hline $\begin{array}{l}\text { 2a) Member's } \\
\text { trust in leader } \\
\text { related to } \\
\text { member's } \\
\text { report of LMX. }\end{array}$ & Supported & Supported & Supported & NA \\
\hline $\begin{array}{l}2 \mathrm{~b}) \text { Leader's } \\
\text { trust in member } \\
\text { related to } \\
\text { leader's report } \\
\text { of LMX. }\end{array}$ & NA & NA & NA & Supported \\
\hline $\begin{array}{l}\text { 3a) Distributive } \\
\text { justice related } \\
\text { to job } \\
\text { satisfaction }\end{array}$ & Supported & Supported & Supported & NA \\
\hline $\begin{array}{l}\text { 3b) Distributive } \\
\text { justice related } \\
\text { to intention to } \\
\text { quit }\end{array}$ & Supported & Supported & Supported & NA \\
\hline $\begin{array}{l}\text { 3c) Distributive } \\
\text { justice related } \\
\text { to } \\
\text { organizational } \\
\text { commitment }\end{array}$ & Supported & Supported & NS & $\mathrm{NA}$ \\
\hline
\end{tabular}




\begin{tabular}{|c|c|c|c|c|}
\hline $\begin{array}{l}\text { 3d) Distributive } \\
\text { justice related } \\
\text { to in-role } \\
\text { performance }\end{array}$ & Supported & Supported & NS & NS \\
\hline $\begin{array}{l}\text { 3e) Distributive } \\
\text { justice related } \\
\text { to OCBI }\end{array}$ & Supported & Supported & NS & NS \\
\hline $\begin{array}{l}\text { 3f) Distributive } \\
\text { justice related } \\
\text { to OCBO }\end{array}$ & NS & Supported & NS & NS \\
\hline $\begin{array}{l}\text { 3g) Distributive } \\
\text { justice related } \\
\text { to ORBI }\end{array}$ & NS & NS & NS & NS \\
\hline $\begin{array}{l}\text { 3g) Distributive } \\
\text { justice related } \\
\text { to ORBO }\end{array}$ & NS & Supported & NS & NS \\
\hline $\begin{array}{l}\text { 4a) Procedural } \\
\text { justice related } \\
\text { to job } \\
\text { satisfaction }\end{array}$ & Supported & Supported & Supported & NA \\
\hline $\begin{array}{l}\text { 4b) Procedural } \\
\text { justice related } \\
\text { to intention to } \\
\text { quit }\end{array}$ & Supported & Supported & Supported & NA \\
\hline $\begin{array}{l}\text { 4c) Procedural } \\
\text { justice related } \\
\text { to } \\
\text { organizational } \\
\text { commitment }\end{array}$ & Supported & Supported & Supported & NA \\
\hline $\begin{array}{l}\text { 4d) Procedural } \\
\text { justice related } \\
\text { to in-role } \\
\text { performance }\end{array}$ & NS & Supported & NS & NS \\
\hline $\begin{array}{l}\text { 4e) Procedural } \\
\text { justice related } \\
\text { to OCBI }\end{array}$ & Supported & Supported & NS & NS \\
\hline $\begin{array}{l}\text { 4f) Procedural } \\
\text { justice related } \\
\text { to OCBO }\end{array}$ & NS & Supported & Supported & NS \\
\hline $\begin{array}{l}4 \mathrm{~g}) \text { Procedural } \\
\text { justice related } \\
\text { to ORBI }\end{array}$ & NS & NS & NS & NS \\
\hline
\end{tabular}




\begin{tabular}{|l|l|l|l|l|}
\hline $\begin{array}{l}\text { 4h) Procedural } \\
\text { justice related } \\
\text { to ORBO }\end{array}$ & NS & Supported & NS & NS \\
\hline $\begin{array}{l}\text { 5a) Procedural } \\
\text { justice by } \\
\text { distributive } \\
\text { interaction } \\
\text { effect on job } \\
\text { satisfaction }\end{array}$ & NS & NA & NS & NA \\
\hline $\begin{array}{l}\text { 5b) Procedural } \\
\text { justice by } \\
\text { distributive } \\
\text { interaction } \\
\text { effect on } \\
\text { intention to quit }\end{array}$ & NS & NA & NS & NA \\
\hline $\begin{array}{l}\text { 5c) Procedural } \\
\text { justice by } \\
\text { distributive } \\
\text { interaction } \\
\text { effect on } \\
\text { organizational } \\
\text { commitment }\end{array}$ & NS & NA & NS & NA \\
\hline $\begin{array}{l}\text { 5d) Procedural } \\
\text { justice by } \\
\text { distributive } \\
\text { interaction } \\
\text { effect on in-role } \\
\text { performance }\end{array}$ & NS & NA & NS & NS \\
\hline $\begin{array}{l}\text { 5e) Procedural } \\
\text { justice by } \\
\text { distributive } \\
\text { interaction } \\
\text { effect on OCBI }\end{array}$ & NS & NA & NS & NS \\
\hline $\begin{array}{l}\text { 5f) Procedural } \\
\text { justice by } \\
\text { distributive } \\
\text { interaction } \\
\text { effect on } \\
\text { OCBO }\end{array}$ & NS & NA & NS & NS \\
\hline $\begin{array}{l}\text { justice by } \\
\text { distributive } \\
\text { interaction } \\
\text { effect on ORBI }\end{array}$ & NS & NA & NS & \\
\hline
\end{tabular}




\begin{tabular}{|l|l|l|l|l|}
\hline $\begin{array}{l}\text { 5h) Procedural } \\
\text { justice by } \\
\text { distributive } \\
\text { interaction } \\
\text { effect on } \\
\text { ORBO }\end{array}$ & NS & NA & NS \\
\hline $\begin{array}{l}\text { 6a) Mediation } \\
\text { effect of } \\
\text { distributive } \\
\text { justice on job } \\
\text { satisfaction }\end{array}$ & Partial & Partial & Partial & NA \\
\hline $\begin{array}{l}\text { 6b) Mediation } \\
\text { effect of } \\
\text { distributive } \\
\text { justice on } \\
\text { intention to quit }\end{array}$ & Partial & Partial & Partial & NA \\
\hline $\begin{array}{l}\text { 6c) Mediation } \\
\text { effect of } \\
\text { distributive } \\
\text { justice on } \\
\text { organizational } \\
\text { commitment }\end{array}$ & Partial & Partial & NS & NA \\
\hline $\begin{array}{l}\text { 6d) Mediation } \\
\text { effect of } \\
\text { distributive } \\
\text { justice on in- } \\
\text { role } \\
\text { performance }\end{array}$ & Partial & Partial & NS & NS \\
\hline $\begin{array}{l}\text { 6e) Mediation } \\
\text { effect of } \\
\text { distributive } \\
\text { justice on OCBI }\end{array}$ & Partial & Partial & NS & NS \\
\hline $\begin{array}{l}\text { 6f) Mediation } \\
\text { effect of } \\
\text { distributive } \\
\text { justice OCBO }\end{array}$ & NS & Partial & NS & \\
\hline $\begin{array}{l}\text { 6g) Mediation } \\
\text { effect of } \\
\text { distributive } \\
\text { justice ORBI }\end{array}$ & NS & & NS \\
\hline $\begin{array}{l}\text { 6h) Mediation } \\
\text { distributive } \\
\text { justice ORBO }\end{array}$ & NS & Partial & NS & \\
\hline
\end{tabular}




\begin{tabular}{|c|c|c|c|c|}
\hline $\begin{array}{l}\text { 7a) Mediation } \\
\text { effect of } \\
\text { procedural } \\
\text { justice on job } \\
\text { satisfaction }\end{array}$ & Partial & Partial & Partial & NA \\
\hline $\begin{array}{l}\text { 7b) Mediation } \\
\text { effect of } \\
\text { procedural } \\
\text { justice on } \\
\text { intention to quit }\end{array}$ & Partial & Partial & Partial & NA \\
\hline $\begin{array}{l}\text { 7c) Mediation } \\
\text { effect of } \\
\text { procedural } \\
\text { justice on } \\
\text { organizational } \\
\text { commitment }\end{array}$ & Partial & Partial & Partial & NA \\
\hline $\begin{array}{l}\text { 7d) Mediation } \\
\text { effect of } \\
\text { procedural } \\
\text { justice on in- } \\
\text { role } \\
\text { performance }\end{array}$ & NS & Partial & NS & NS \\
\hline $\begin{array}{l}\text { 7e) Mediation } \\
\text { effect of } \\
\text { procedural } \\
\text { justice on OCBI }\end{array}$ & Partial & Partial & NS & NS \\
\hline $\begin{array}{l}\text { 7f) Mediation } \\
\text { effect of } \\
\text { procedural } \\
\text { justice OCBO }\end{array}$ & NS & Partial & Partial & NS \\
\hline $\begin{array}{l}7 \mathrm{~g}) \text { Mediation } \\
\text { effect of } \\
\text { procedural } \\
\text { justice ORBI }\end{array}$ & NS & NS & NS & NS \\
\hline $\begin{array}{l}\text { 7h) Mediation } \\
\text { effect of } \\
\text { procedural } \\
\text { justice ORBO }\end{array}$ & NS & Partial & NS & NS \\
\hline
\end{tabular}




\begin{tabular}{|c|c|c|c|c|}
\hline $\begin{array}{l}8 \text { a) Trust in } \\
\text { manager } \\
\text { decreases from } \\
\text { Time } 1 \text { to Time } \\
2 \text { for only } \\
\text { participants in } \\
\text { the low } \\
\text { distributive/low } \\
\text { procedural } \\
\text { justice } \\
\text { condition. }\end{array}$ & NA & Partial & $\mathrm{NA}$ & NA \\
\hline $\begin{array}{l}\text { 8b) LMX } \\
\text { decreases from } \\
\text { Time } 1 \text { to Time } \\
2 \text { for only } \\
\text { participants in } \\
\text { the low } \\
\text { distributive/low } \\
\text { procedural } \\
\text { justice } \\
\text { condition. }\end{array}$ & NA & Partial & NA & NA \\
\hline
\end{tabular}

Note. $\mathrm{NS}=$ not supported; NA $=$ not analyzed. 


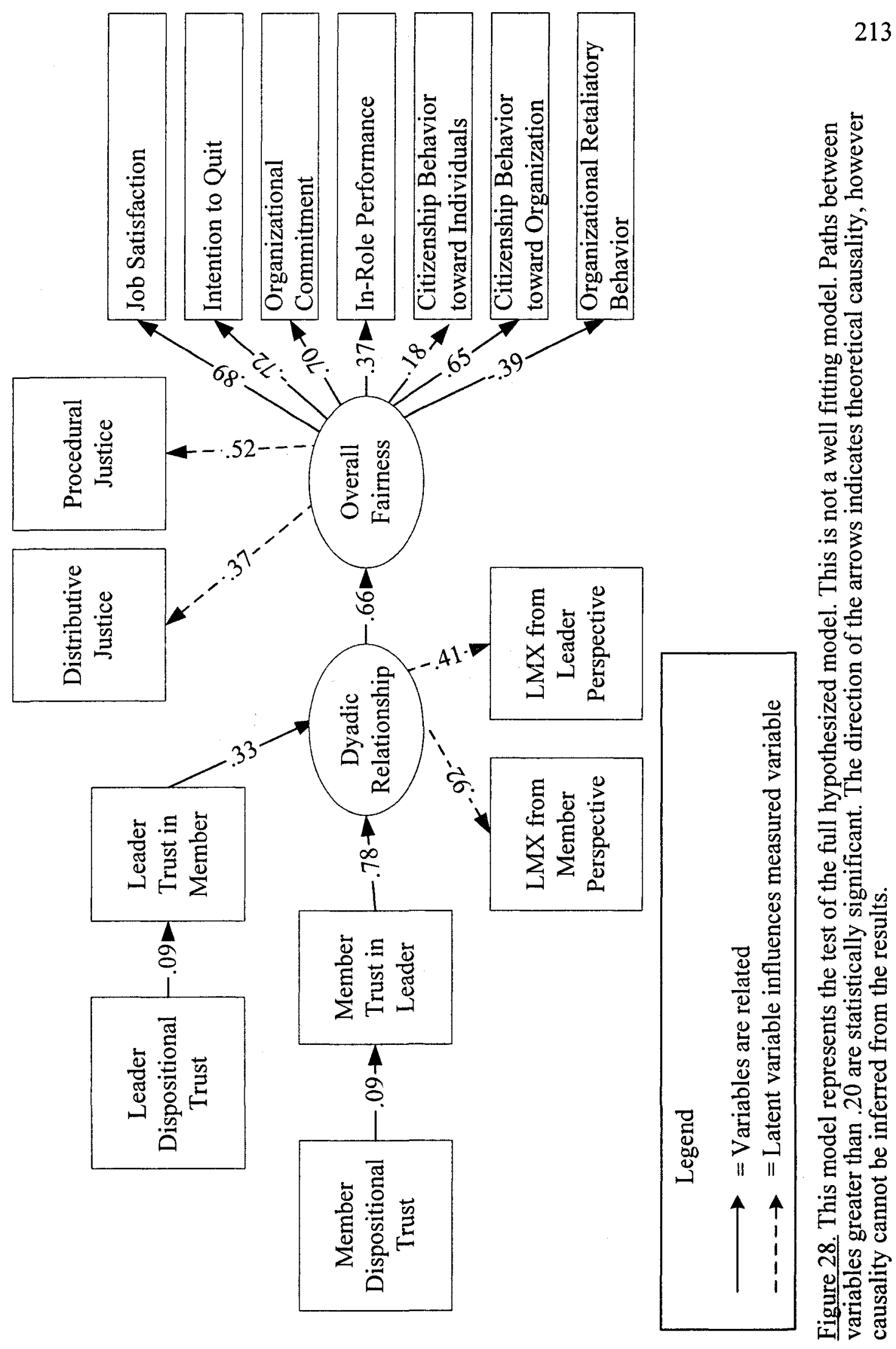




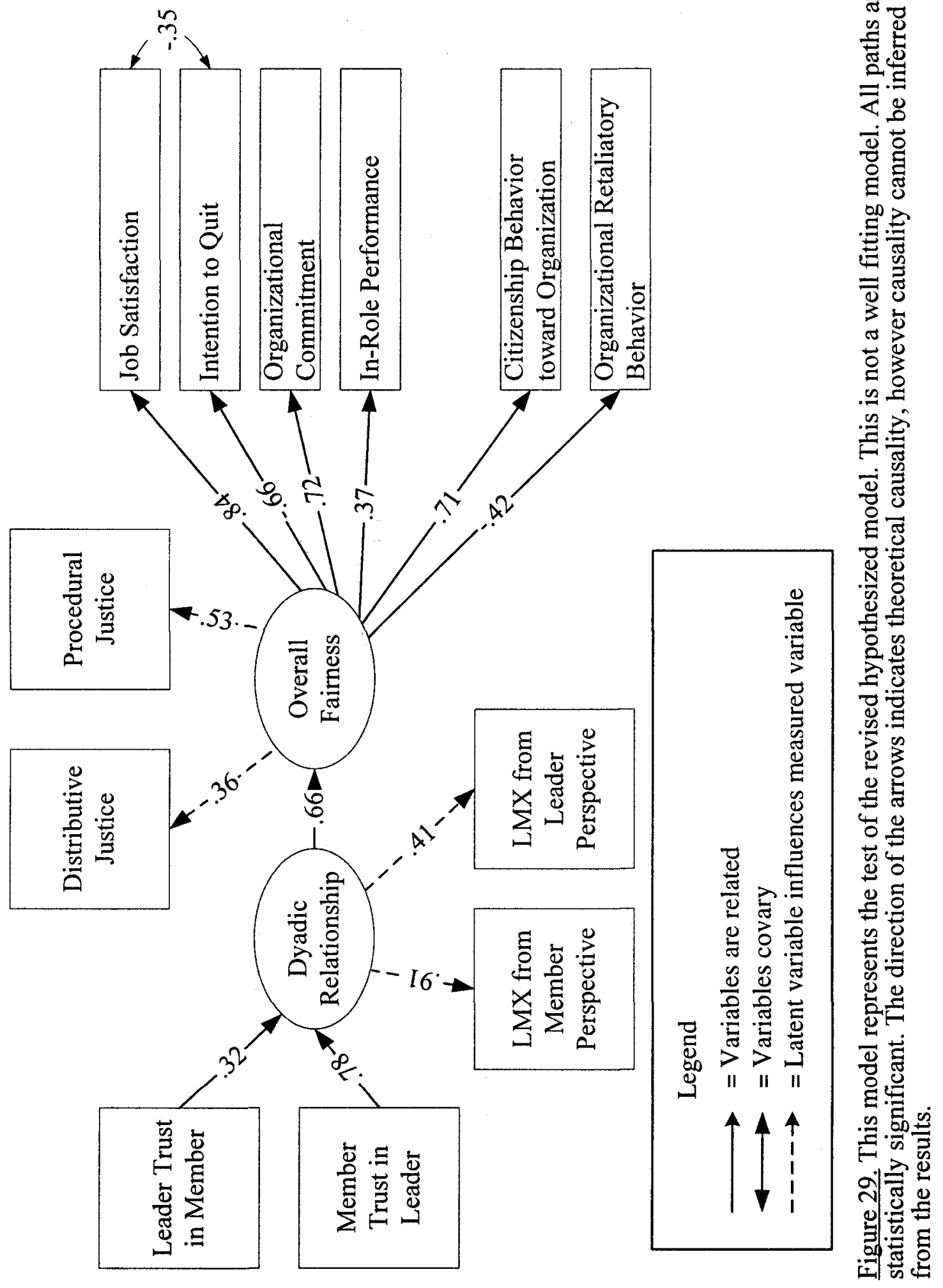




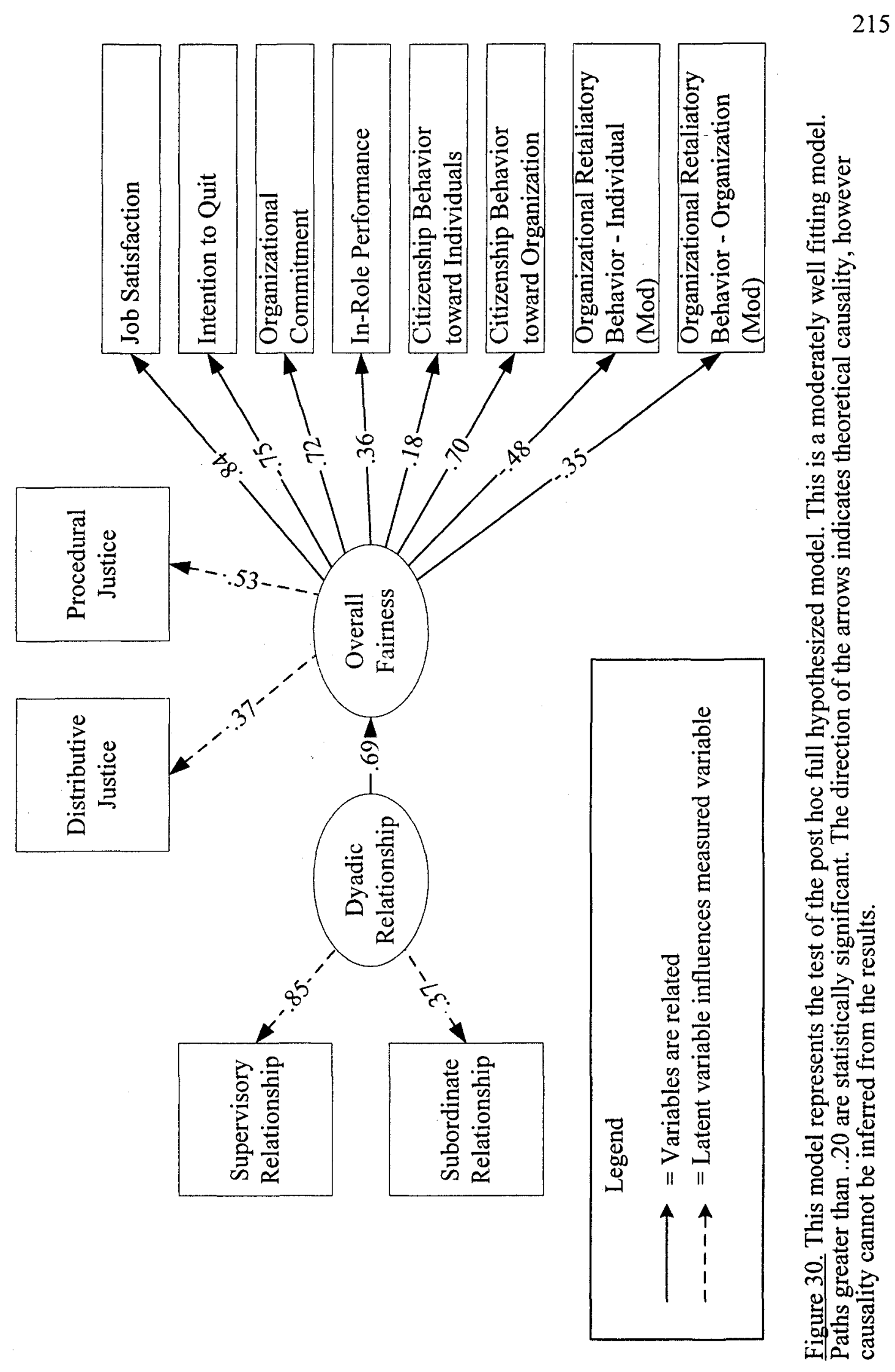




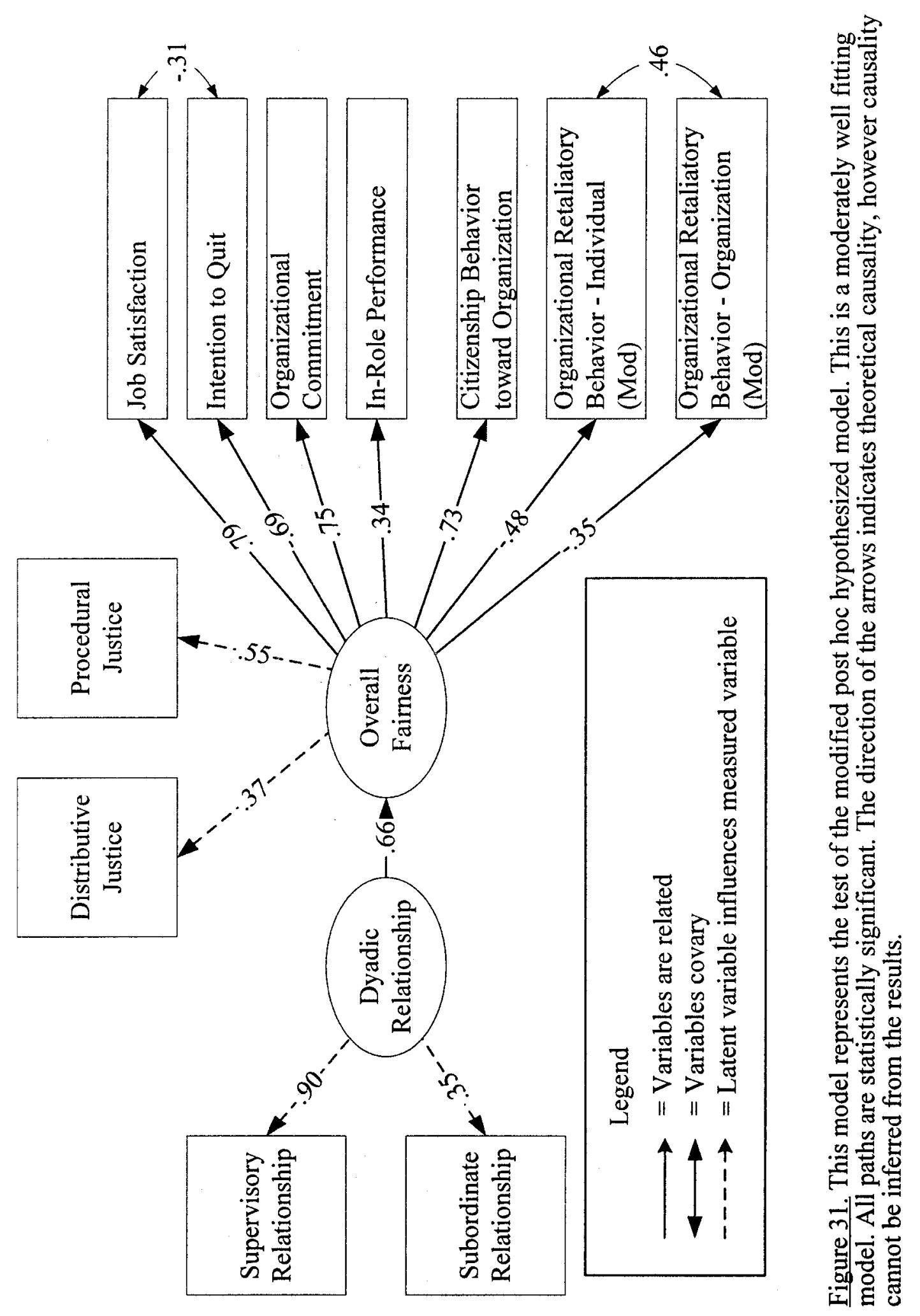




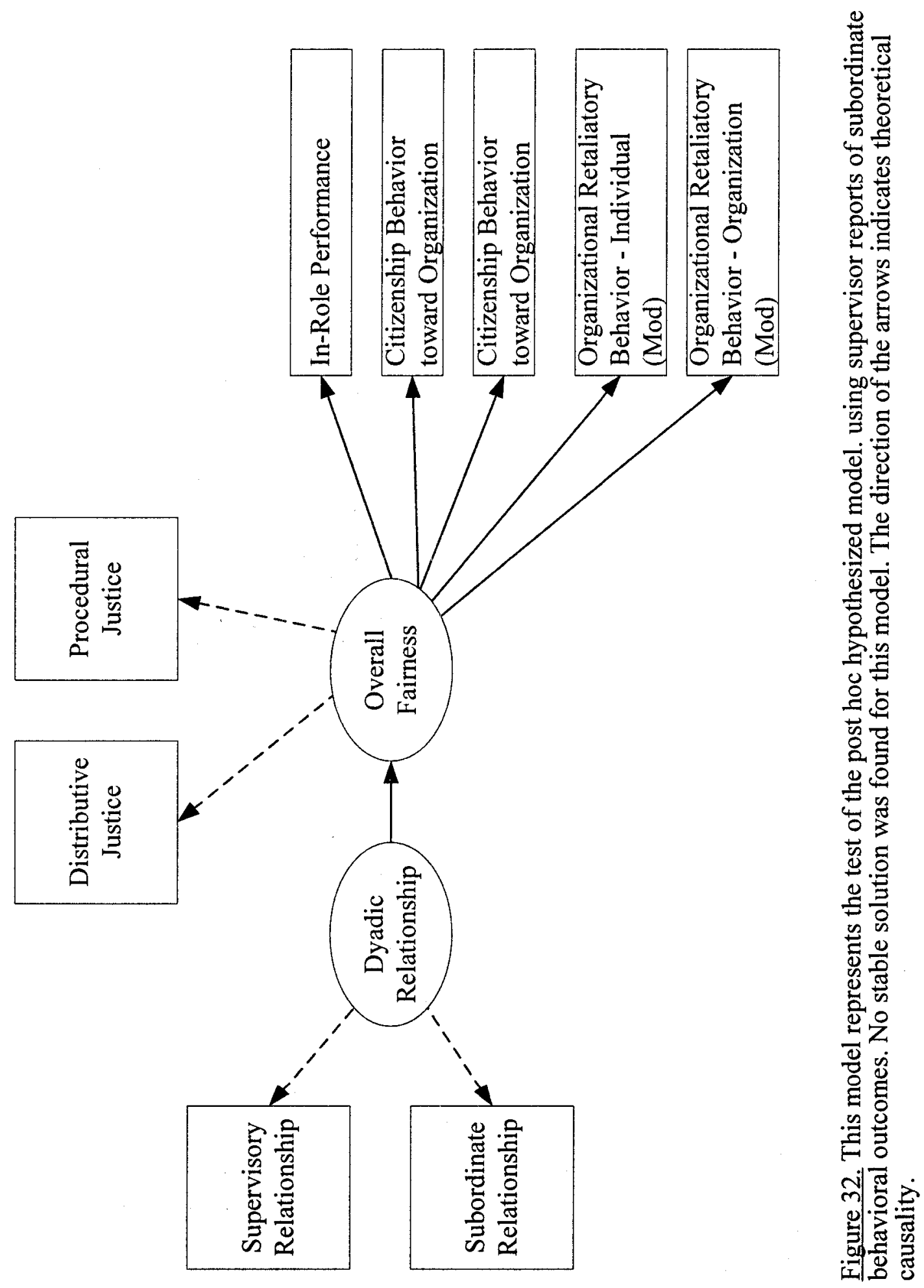



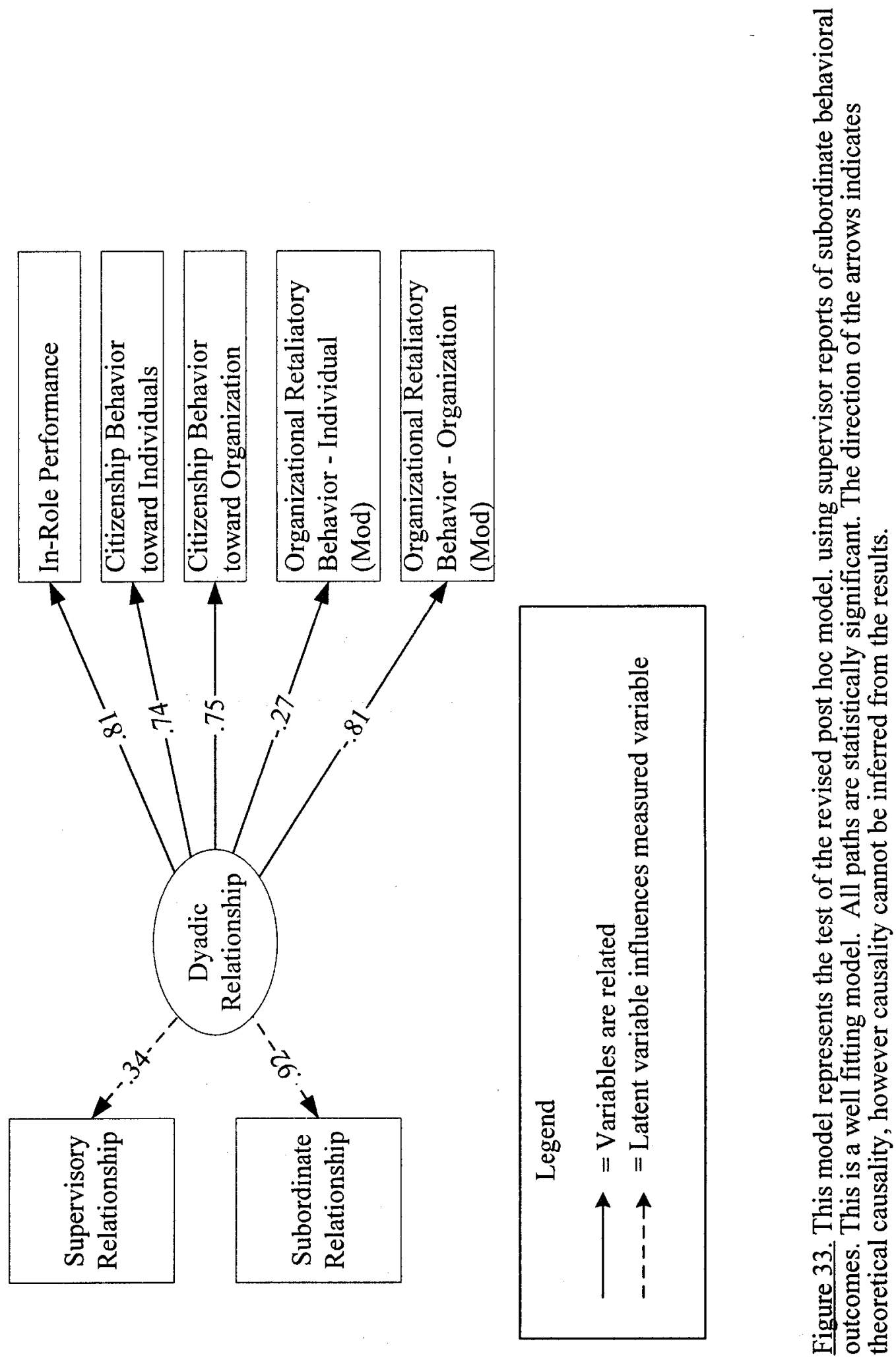


\section{Discussion}

The research presented in this dissertation tested a model (both its components and the entire model) of the relationships between trust, LMX, organizational justice and their role in explaining variance in employee attitudinal and behavioral outcomes. The model was tested with a student, laboratory sample and a field sample. This section examines each of the hypotheses tested, first for the laboratory study, and second for the field study. Lastly, theoretical and practical implications of the findings are presented.

\section{Laboratory Study}

The laboratory study permitted inferences regarding the generalizability of the relationships of interest by examining those relationships with participants who had a broad range of jobs. Additionally, it was possible in the laboratory study to manipulate organizational justice to examine the potential effects of organizational justice on trust in supervisor, LMX, and the outcome variables.

The Role of Dispositional Trust. Contrary to what was expected, no relationship was found between participants' tendency to trust other people and trust in their supervisor. It is likely that members had enough information about the trustworthiness (e.g., benevolence, reliability) of their supervisors that one's general tendency to trust was not salient. Although the mean length of the relationship between a supervisor and subordinate was just over one year, this length of time is long enough for members of the dyad to establish perceptions of trust based on actual interaction rather than on relying on general tendencies to trust others. Additionally, 
the measure of dispositional trust used in this study had less than desirable

reliability, which made finding any potential relationship between the constructs more difficult. It is also possible that the measure of dispositional trust is outdated or measures an inappropriate disposition. The measure utilized was developed in the 1960 's and it is possible that the nature of trust in the United States has changed since then. It is also possible that rather than assessing a general disposition to trust strangers, it would be more appropriate to assess employees' disposition to trust others in the workplace.

Results of post hoc analyses using structural equation modeling, showed that dispositional trust was negatively related to performance, OCBI, and OCBO, and positively related to ORBI and ORBO. For this sample, one's tendency to trust is negatively related to positive behavioral outcomes and positively related to negative outcomes. It is possible that being cautious in the workplace in terms of trusting others is associated with good performance because employees engage in these behaviors when trust has been earned. These results provide some direction for future research.

Trust in Supervisor and LMX. There was a strong relationship between trust in supervisor and LMX. What is important in the laboratory study is that this relationship held for a wide variety of people in different kinds of jobs.

The magnitude of the relationship between LMX and trust in a specific other raised concerns about the ability of employees to distinguish between the two constructs. While trust and LMX are theorized to be two distinct constructs, the two constructs share some theoretical underpinnings, as noted in the literature review. For example, there is a considerable degree of congruence between the characteristics of 
trust defined by Butler (1991) and the four dimensions of LMX (i.e., affect, loyalty, contribution, professional respect) identified by Liden and Maslyn (1998). The constructs of loyalty, competence, and support appear in both sets of dimensions. Trust and LMX are both variables that assess the nature of interpersonal relationships. It is possible that the high correlation between the two variables indicates that trust is a necessary, but not sufficient condition for high LMX. Alternatively, perhaps trust is a fifth dimension of LMX. Additional research exploring these two constructs simultaneously will be useful in determining if trust and LMX are distinct constructs.

Post hoc factor analyses indicated the participants in the laboratory study were unable to distinguish between trust in supervisor and LMX. The best factor analytic solution (e.g., significant factor loadings, no cross-loading items) consisted of one major factor that was composed of items from both the LMX-8 and trust in supervisor scales. Future research is necessary that more fully explores the constructs of LMX and trust in supervision. For example, it would be useful to administer a multidimensional measure of LMX (Liden \& Maslyn, 1998) and a multidimensional measure of trust (Butler, 1991) simultaneously. This would permit a more comprehensive examination of the two constructs.

It is my opinion that trust eventually will be found to be a component of a multidimensional conceptualization of LMX. There are two primary reasons for this conclusion. First, the theoretical similarities discussed earlier between the two operational definitions of LMX and trust point to the notion that trust may be a component of LMX. Second, the theoretical contribution of this paper in positing that LMX and trust are systemic emergent properties of the interaction between the a 
supervisor and subordinate leads to the potential that trust is a component of LMX, since they emerge in a similar fashion.

Distributive Justice and the Outcome Variables. Hypothesized relationships were found between distributive justice and job satisfaction, organizational commitment, in-role performance, OCBI, and intention to quit. Perceptions of distributive justice had strong relationships to attitudes (i.e., job satisfaction, organizational commitment, intention to quit) that are important to the individual and the organization. While relationships were found between distributive justice and two of the behavioral outcomes (i.e., OCBI and in-role performance), these relationships were substantially weaker than those for the attitudinal constructs. Additionally, no relationship was found between distributive justice and three of the behavioral variables (i.e., OCBO, ORBO, ORBI). For this sample, it appeared that perceptions of distributive justice are more salient to attitude formation than actual behavior.

Procedural Justice and the Outcome Variables. Similar to the findings for distributive justice, procedural justice was strongly related to the three attitude variables (i.e., job satisfaction, organizational commitment, and intention to quit). Additionally, it was related to one behavioral variable, OCBI.

The Distributive Justice by Procedural Justice Interaction. The interaction between distributive and procedural justice was significant for in-role performance, OCBI, and OCBO. However, contrary to the hypothesized nature of the interaction, high procedural justice did not mitigate the effects of low distributive justice. In fact, while the highest levels of the outcome variables were reported by those participants who also reported high procedural justice/high distributive justice (as expected), the 
lowest levels of the outcome variables were reported by those who also reported high procedural justice/low distributive justice (unexpected result). The general fairness heuristic (Lind, 2002) is one possible explanation for this finding. This idea is more fully developed in the section on theoretical implications later.

The Mediation of Distributive Justice on LMX-Outcome Relationships. Distributive justice partially mediated the relationship between LMX and self-reports of job satisfaction, intention to quit, organizational commitment, in-role performance, and organizational commitment. The mediation effect was strongest for the three attitudinal variables. This means that part of the relationship between LMX and these attitudinal outcome variables operated through perceptions of distributive justice. Since full mediation was not found, it can be concluded that both LMX and distributive justice are related to job satisfaction, intention to quit, and organizational commitment. More modest effects of mediation by distributive justice on the relationship between LMX and OCBI and job performance were also found.

The Mediation of Procedural Justice on LMX-Outcome Relationships. A similar pattern of results was found for the mediating effect of procedural justice on LMX-outcome relationships. There were substantial reductions in the relationship between LMX and the attitudinal outcomes (i.e., job satisfaction, intention to quit, and organizational justice) when procedural justice was modeled as a mediator variable. Procedural justice had a more modest mediating effect on the relationship between LMX and OCBI. The implication of these findings is that both LMX and procedural justice are related to the job satisfaction, intention to quit, organizational commitment, and OCBI. 
The Full Model. Although the hypothesized model did not fit the data well, a well fitting model was found with the elimination of three paths and the addition of one path reflecting a statistically significant relationship between in-role performance and OCBI (two outcome variables). Trust in leader and LMX were related to the overall quality of the dyadic relationship between leaders and members. The quality of this relationship was related to overall fairness. Both distributive and procedural justice were related to overall fairness with procedural justice being a stronger contributor to overall fairness than distributive justice.

Perceptions of overall fairness were related to job satisfaction, intention to quit, organizational commitment, in-role performance, OCBI, and ORB. Results indicated that model fit could not be improved with the addition of any direct paths between trust in leader or LMX to the outcome variables. This suggests that there may not be unique effects of LMX or trust in leader beyond what can be explained by overall fairness.

Post hoc analyses of the pre-manipulation data from the laboratory study resulted in substantially the same conclusions. The data driven post hoc model showed that supervisory relationship (i.e., a combined measure of LMX and trust in supervisor) was related to overall fairness. Importantly, overall fairness, as a latent variable, influenced perceptions of both procedural and distributive justice. This finding supports Lind's (2001) notion of a fairness heuristic. Overall fairness was then related to job satisfaction, intention to quit, organizational commitment, in-role performance, OCBI, and modified measures of ORBI and ORB-time wasted (i.e., a subset of the original ORBO items). 
The Impact of Organizational Justice on Trust and LMX. The results of

this study indicated that the process and outcome of one significant event (i.e., bonus decision) impacted established perceptions of LMX and trust. When participants were exposed to a situation in which distributive justice and procedural justice were high, LMX and trust in supervisor increased from base levels. However when participants were exposed to a situation when either distributive or procedural justice were low, reports of LMX and trust in supervisor decreased from base levels. This effect was most profound when both distributive justice and procedural justice were low. While the event considered here was fictitious, it does illustrate the possible impact of a single significant event on established perceptions of LMX and trust. This result is also supported by current theorizing about the effect of employees' exposure to events that lead to fairness judgments. Lind (2001) posited that employees, over time, develop a fairness heuristic. This judgment is refined with each subsequent fairness judgment. The refined heuristic, in turn, has effects on employee attitudes and behaviors. Practitioners need to be aware of the possible negative effects on LMX of situations in which there are low perceptions of either distributive or procedural justice, and especially when both are low.

\section{Mediating Effect of Manipulated Distributive Justice on LMX-Outcome}

Relationships. After being exposed to the fictitious bonus scenario in which both distributive and procedural justice were manipulated, results indicated that distributive justice partially mediated the relationship between LMX and job satisfaction, intention to quit, organizational commitment, performance, OCBI, OCBO, and ORBO. It may be concluded that in the immediate aftermath of an important organizational event that 
affects employees' perceptions of distributive justice that the positive effects of LMX are reduced because LMX operates through distributive justice.

\section{Mediating Effect of Manipulated Procedural Justice on LMX-Outcome}

Relationships. Post-manipulation reports of procedural justice partially mediated the relationship between LMX and job satisfaction, intention to quit, organizational commitment, performance, OCBI, OCBO, and ORBO. Again, the results indicated that at least some of the effects of LMX on several outcome variables operated through perceptions of procedural justice.

Organizational Retaliatory Behaviors. This is one of a growing number of studies that has included potentially harmful organizational behaviors as an outcome variable. In the pre-manipulation data for the laboratory study, there were no relationships found between trust in supervisor, LMX, distributive justice, or procedural justice with ORBI, ORBO, or a composite ORB measure using the established instrument for assessing ORB. However, pre-manipulation perceptions of quality of relationship with their supervisor (i.e., combined trust and LMX measure) were weakly and negatively related to a modified measure of ORBI. One would expect to find that if an employee has a positive interpersonal relationship with their supervisor, that they would be less likely to engage in ORBI. Interestingly, the combined trust in supervisor/LMX measure was unrelated to ORBO. Therefore, it appears, based on the pre-manipulation laboratory data, that employees are not likely to retaliate against the organization when the source of their dissatisfaction is the interpersonal relationship that they have with their supervisor. 
Additionally, in the post hoc analyses of the full model, overall fairness

(i.e., the latent variable that influenced both distributive and procedural justice) was related to both ORBI and time wasting behaviors (i.e., a subset of the original ORBO items). These results indicate that when employees feel that the organization is unfair, that they are more likely to engage in a wide range of potentially harmful behaviors on the job.

Post-manipulation reports of trust in supervisor, LMX, quality of supervisory relationship (i.e., combined measure of trust in supervisor and LMX), and distributive justice were related to post-manipulation estimates of the likelihood of employees to engage in ORBI and ORBO, using modified measures. While the laboratory study dealt with a fictitious scenario, it is interesting to note that immediately after a bonus decision, employees who were adversely affected reported that they were more likely to engage in behaviors that may harm the organization and co-workers. Of course, while employees may want to engage in these behaviors as indicated by the increased likelihood that they would, actual behavior will be affected by other strong forces in the work setting (e.g., other employment opportunities, promotion opportunities, likelihood of adverse consequences if caught, nature of on-going relationships in the workplace). These forces would likely constrain any actual organizational retaliatory behavior.

Overall, the laboratory study made several contributions to existing knowledge. First, trust in supervisor was a strong correlate of LMX. Post hoc analyses indicated the participants were unable to distinguish between these two constructs. Second, perceptions of distributive and procedural justice partially mediated the 
relationship between LMX and attitudinal outcomes. Third, there was evidence of an overall fairness judgment that influenced perceptions of both procedural and distributive justice. This overall fairness judgment was related to several of the outcomes examined here, especially the attitudinal outcomes. Importantly, the pattern of means for the four manipulated conditions in the laboratory study also support the idea that employees are more sensitive to unfairness than fairness (Gilliland \& Chan, 2000). That is, the greatest disparity in means occurred with participants who are in the low distributive justice/low procedural justice condition. Lastly, in post hoc analyses, supervisory relationship was negatively related to organizational retaliatory behaviors. This indicates that not only are there potential positive outcomes of high quality working relationships between supervisors and subordinates, but potentially negative outcomes for employees' co-workers and the organization if there are low quality relationships between subordinates and supervisors.

\section{Field Study}

In the field study, the same set of relationships examined in the laboratory study was examined within the context of a specific organization. Additionally, data were collected from both the supervisor and subordinate in the LMX dyad.

Dispositional Trust. As was the case in the laboratory study, no relationship was found between subordinates' tendency to trust other people and trust in their supervisor. Additionally, no relationship was found between supervisors' tendency to trust other people and their trust in individual subordinates. It is likely that members of each dyad have enough information about the trustworthiness (e.g., benevolence, reliability) of the other member that one's general tendency to trust is not salient. 
Post hoc analyses support this notion. For subordinates who had less than one year of tenure with their supervisor, there was a statistically significant relationship between dispositional trust and trust in supervisor. This same relationship, however was not found for supervisors' reports of dispositional trust and trust in a specific subordinate. It is likely that supervisors have significantly more information regarding newly hired subordinates than subordinates have on their new supervisors. For example, in this organization, supervisors are the hiring authority and have access to information about applicants' prior work history, background, and information gathered through reference checks. Therefore, dispositional trust is unlikely to be an important determinant of trust in a specific subordinate.

It is also interesting to note the only variable, for all participants in this study, that was related to dispositional trust was organizational commitment. While this relationship is not of specific interest to the hypotheses of this study, this relationship does provide some support for the notion that dispositional trust influences workplace attitudes when there is less known about the trustee (i.e., the organization). Post hoc full-model analyses also show that subordinate dispositional was positively related to organizational commitment and OCBO. These direct relationships between dispositional trust and outcome variables indicates that one's tendency to trust others may be related to other important outcomes and these relationship should be explored. Additionally, it would be interesting to examine if the tendency to trust influences the rate of development of trust in workplace relationships. At the very beginning of a dyadic workplace relationship, it is likely that very little is known about the trustworthiness of the other party in the dyad. Dispositional trust may affect the 
development of LMX in the absence of information about the other party in the dyad. For example, if both the leader and the member are high in dispositional trust, then that condition may accelerate the development of a high quality LMX, relative to the condition where both parties are low in dispositional trust (or even dispositionally distrustful).

Another potential effect of dispositional trust may be its effects on attitudinal and behavioral reactions when trust is violated. For example, if you are generally trusting of others, when trust is violated do you have a more extreme adverse reaction or are your reactions muted because you want to trust others. It seems plausible that those who are high in dispositional trust may be more tolerate of minor instances of injustice up to point. When that breaking point is reached, it is possible that these same high dispositional trust people may have very strong adverse reactions to a breach of trust.

Trust and LMX. The expected relationship between trust in a specific other and LMX was found from both the supervisor and subordinate perspectives. While the methodology employed does not allow for the direct inference of causality, it makes theoretical sense that trust would lead to high quality LMX. For example, it is unlikely that an employee would report an effective working relationship with a supervisor without first trusting the supervisor.

LMX, in turn, was related to several of the attitudinal and behavioral outcomes examined here. Assuming that in the work setting, the supervisor is the member of the dyad who will drive the development of the working relationship, supervisors can engage in certain behaviors to develop trust with subordinates. These include doing 
what they say they are going to do (integrity); show a genuine concern for the welfare of subordinates (benevolence); and demonstrate professional competence (ability).

As was the case in the laboratory study, post hoc factor analytic results indicated that neither subordinates nor supervisors were able to distinguish between trust a specific other and LMX. For both groups, the best factor analytic solution consisted of a single major factor that contained items from both the trust in supervisor/subordinate and LMX/SLMX measures. For subordinates, perceptions of the quality of supervisory relationship were related to distributive justice, procedural justice, organizational commitment, job satisfaction, intention to quit, $\mathrm{OCBO}$, and ORBI. For supervisors, perceptions of subordinate relationship were related to in-role performance, OCBI, OCBO, ORBI, and ORBO. In this organization, perceptions of the quality of working relationships were related to both employee attitudes and behaviors. The implication is that organizations need to be aware that there are both positive outcomes of quality subordinate-supervisor relationships and negative consequences for poor subordinate-supervisor relationships.

LMX-SLMX Agreement. Although not a focus of the present research, it is interesting to note that there was less agreement among supervisors and subordinates in their respective assessments of the dyadic relationship. The correlation between LMX and SLMX was .26. However, as mentioned previously, this research conceptualizes the leader-member exchange relationship as an emergent property of the interaction between the two parties. This approach to LMX may help to explain the often-observed low correlation between supervisor and subordinate reports of LMX. 
Viewing LMX as an emergent property of the interaction between a

supervisor and subordinate addresses two of the major concerns of LMX theory to date (Gerstner \& Day, 1997; Liden et al., 1997). First, conceptualizing LMX as an emergent property of the relationship between the supervisor and subordinate would allow for the two parties to have discrepant views on the quality of LMX which is often found and lamented in the literature (e.g., Gerstner \& Day, 1997; Maslyn \& UhlBien, 2001). If LMX is an emergent property of the interaction of a supervisor and subordinate, each member of the dyad could have a different subjective evaluation of the quality of LMX as it is currently measured. One would expect to find that there would be greater agreement among members of the dyad as the quality of the relationship solidified (either in a positive direction or a negative direction).

Conceptualizing LMX as an emergent property of the on-going and dynamic dyadic relationship also better explains the various research methodologies that have been used to study this phenomenon. For example, Liden et al. (1997) argued for "putting the exchange back in leader-member exchange" (p. 75). In other words, a considerable amount of attention has been paid to the correlates of LMX and not much attention to the actual psychological processes involved in what creates LMX. This emphasis on the correlates of LMX has led to some confusion regarding the antecedents and consequences of LMX (e.g., Gerstner \& Day, 1997; Liden et al., 1997). For example, some researchers have used subordinate performance as an outcome variable and some have used subordinate performance as an antecedent of LMX. Viewing LMX as an emergent property of the interaction between a supervisor and subordinate allows for both approaches and findings to be theoretically relevant. 
Additionally, and perhaps more importantly, LMX has generally been measured only from the subordinate's perspective (Maslyn \& Uhl-Bien, 2002) using the LMX-7 (Gerstner \& Day, 1997). When LMX has been measured from the supervisor's perspective, it has sometimes been measured by asking the supervisor to hypothesize what the subordinate's perception is and sometimes by assuming that the leader and member have the same resources to exchange. These approaches fail to capture the idea that LMX is an emergent property. These approaches have also contributed to the confusion of the antecedents and consequences of LMX, as just noted.

It is likely that due to the very nature of the structure of work organizations that supervisors and subordinates have different resources to exchange. This is not to say that there is not a considerable degree of overlap in terms of resources available to both supervisors and subordinates (e.g., caring for the other, professional respect, inrole job performance, filling-in for the other member of the dyad). However, some of these resources are more likely to be available to one member of the dyad. For example, it is more likely that a subordinate will fill-in for his or her supervisor than a supervisor is to fill-in for any one subordinate. Other resources will be available to only one member of the dyad. For example, delegation of work activities and promotion opportunities are the purview of supervisors in organizations.

Distributive Justice. Distributive justice was positively related to job satisfaction and negatively related to intentions to quit. The finding of the relationship between distributive justice and intentions to quit may be particularly important to organizations where personnel, as opposed to products or processes, is the organization's competitive advantage. 
Interestingly, distributive justice was not related to any of the behavioral variables nor organizational commitment. It is possible that in a professional environment with high performance expectations, one's belief about the fairness of the rewards you receive will not affect your behavior on the job. It is also true that in this organization, rewards (e.g., pay, benefits) are fairly high for individuals, and this would minimize any potential relationships between distributive justice and behavior.

Procedural Justice. Procedural justice was positively related to job satisfaction, organizational commitment and $\mathrm{OCBO}$, and negatively related to intention to quit. One of the major factors driving the relationship between procedural justice and these outcome variables was the context in which the participants were working. The organization had recently been through a significant reduction in force. The participants in this study, even though some were second-level managers, did not have any influence in that process. Consequently, it is possible that this lack of expected or desired input into such a significant personnel decision served as the primary referent for perceptions of procedural justice. This explanation was verified in a dialog with senior managers in the organization where data were collected. The mean for procedural justice was 2.78 on a 5 -point scale. This mean was the lowest for any variable in the study.

What is evident from the relationships found here is that the manner in which an organization handles a reduction in force may have significant implications for the attitudes of employees and even organizational citizenship behaviors directed at the organization. Perhaps most important among these relationships from an organizational standpoint are the relationships between procedural justice and 
organizational commitment and intention to quit. In an industry where talent can be difficult to find and expensive to develop, one does not want employees feeling badly about the organization and potentially speaking poorly about the organization to others who may be potential employees. One certainly does not want to lose high performing employees (in theory, only the lowest performing employees were laid off) because they believe that the organization did not handle the reduction in force fairly. The Interaction of Procedural and Distributive Justice. The hypothesized interaction of procedural and distributive justice in relation to the outcome variables was not supported. It is possible the specific context of the field study affected the expected interaction. Procedural justice appeared to drive the relationship between organizational justice and the outcome variables (this relationship is discussed in more detail in the subsection where the full model is examined), where there was a relationship. Examining the correlation matrix, procedural justice has a higher correlation with all the outcome variables than distributive justice does. In this situation, since the most recent significant reward (i.e., keeping one's job) was obtained by all participants, what mattered most to employees was the process by which the outcome was determined (i.e., procedural justice). Additionally, it is possible that a better conceptualization of the relationship between procedural and distributive justice is the overall fairness judgment. This idea will be discussed later. The Mediating Effect of Distributive Justice. This research also adds to the extant literature that considers LMX and organizational justice variables simultaneously (e.g., Masterson et al., 2000). Distributive justice partially mediated the relationship between LMX and subordinate self-reports of job satisfaction and 
intention to quit. These findings contribute to the literature, as no other published research to date has examined this relationship. It is interesting to note that although both organizational justice and LMX share social exchange theory as a foundation and there were significant relationships between distributive justice and LMX, since only partial mediation was found, the two likely have different antecedents and distinct influences on the outcome variables considered in the present research. This is particularly true for LMX to behavioral outcome relationships.

The Mediating Effect of Procedural Justice. Partial support was found for the hypothesis that procedural justice would mediate the relationship between LMX and the outcome variables. Procedural justice partially mediated the relationship between LMX and subordinate self-reports of job satisfaction, intention to quit, organizational commitment, and OCBO. The most dramatic mediation was with organizational commitment. Again, the context within which these data were collected may have influenced these results. It is likely that employees responded to the procedural justice items with the recent reduction in force in mind although the items were general in nature. This in turn may have affected the results of the mediation analyses.

The Full Model. As described in the results section, after eliminating dispositional trust and OCBI from the hypothesized model, a moderately well-fitting model was found. These results indicate that the quality of the dyadic relationship between a leader and a member is influenced by both parties' perception of trust in the other and both parties' reports of LMX. One of the unique contributions to the literature of this research was the way in which the latent variables in this model were developed. As discussed in the literature review, the quality of the dyadic relationship 
between a supervisor and subordinate is theorized to be an emergent property of the interaction between the two members of the dyad. Prior research, in the rare occasions when perceptions from both parties were assessed, simply examined these reports separately or developed some indicator of agreement between the two perspectives (e.g., difference score). The model developed here allowed for the examination of the perceptions that contribute to the latent (not directly measured), emergent variable of quality of the dyadic relationship. As expected, both indicators of this latent variable contributed to the quality of the dyadic relationship.

The nature of this dyadic relationship was then related to perceptions of overall fairness. Importantly, both distributive and procedural justice were influenced by this overall sense of fairness latent variable. Again, overall fairness is theorized to be an emergent property of both distributive and procedural justice. This approach stands in contrast to prior research wherein the two constructs were examined in an additive fashion or in a multiplicative fashion. Interestingly, this approach has been recently presented by Lind (2001) as an innovative way to conceptualize overall fairness judgments. Lind asserted that these overall fairness judgments then influence employee attitudes and behaviors. The model developed here reflects this approach to fairness. The results of the structural equation modeling analysis support this approach.

In this field sample, procedural justice was a stronger determinant of overall fairness than was distributive justice. As discussed earlier, this result could be explained by recent the reduction in force employees had experienced. While the 
employees taking part in this study had all survived the reduction in force, as a group, they reported relatively low perceptions of procedural justice.

In the full model, perceptions of overall fairness were related to job satisfaction, intention to quit, organizational commitment, in-role performance, and OCBO. While partial support for the mediation hypotheses described was found, the results of the overall model did not indicate that a better fitting model could be found by adding paths directly from LMX, trust, or the overall quality of the dyadic relationship to any outcome variable. This indicates that perhaps there were no unique effects of these variables on the outcomes when fairness and quality of the dyadic relationship were considered together. Therefore, it is recommended that both constructs be included in future research.

Organizational Retaliatory Behaviors. Subordinate perceptions of trust in their supervisor and LMX were negatively related to self-reports of a global measure of ORB. Supervisors' perceptions of trust in their subordinates was also related to a global measure of supervisor reports of subordinates engaging in ORB.

Post hoc analyses of the original ORB scale resulted in two subscales. Organizational retaliatory behaviors directed at individuals were negatively related to subordinate perceptions of quality of the supervisory relationship (i.e., a combined trust in supervisor/LMX measure) and procedural justice. The subscale tapping organizational retaliatory behaviors directed at the organization was unrelated to quality of the supervisory relationship, distributive justice, and procedural justice.

Based on post hoc scale analyses of reports by supervisors of the frequency of subordinate engagement in organizational retaliatory behaviors, two subscales were 
derived. Supervisor reports of subordinates engaging in ORB directed at individuals were related to supervisor perceptions of the quality of their relationship with subordinates (i.e., a combined trust in subordinate and SLMX measure). Similarly, Supervisor reports of subordinates engaging in ORB directed at the organization were related to supervisor perceptions of the quality of their relationship with subordinates.

From both the supervisor and subordinate data, it can be concluded that the quality of the working relationship an employee has with his or her supervisor is related to the frequency with which that employee engages in harmful organizational activities. So, poor supervisor-subordinate relationships not only result in a decrease in the positive outcomes (e.g., performance, job satisfaction), but also result in an increase in negative behaviors.

Although it is impossible to infer the direction of causality from the crosssectional field study, the lab study results indicated that a single, significant event that manipulated organizational justice perceptions, increased the likelihood of employees engaging in harmful organizational behaviors and decreased established perceptions of LMX and trust in supervision. Therefore, it is appears at least plausible that in this organization that had recently undergone a reduction in force that justice perceptions of the reduction in force may have adversely affected LMX and trust in supervisor which in turn increased the incidence of organizational retaliatory behavior as measured by self-reports from subordinates and reports by supervisors.

Limitations. As with any research, there are limitations to consider in Study two. First, the data were collected during a short period of time, which does not allow 
for the inference of causality. Additionally, the data were collected from a single organization within a unique context (just after a reduction in force). Although this allows for discussion of the dynamics of LMX and organizational justice in a turbulent environment, the results may not be generalizable to organizations in other contexts. However, this sample does provide a realistic assessment of the attitudes and behaviors of employees who have established dyadic relationships; function in a professional environment; and are coping with real upset in the organization. Theoretical Implications

There are four key theoretical implications of this research. First, one's disposition to trust may be a useful construct to include in future research. Although no support was found for the hypothesized relationship between dispositional trust and trust in a specific other, the relationship makes theoretical sense. Additionally, while the relationship between dispositional trust and person specific trust is appears in most conceptualizations of trust development, very few published studies have reported on this relationship. It is possible that the relative lack of published work is due to nonsignificant findings on the part of other researchers. However, it is likely that for this relationship to be found, research needs to be conducted at two specific points in time. First, it is possible that one's tendency to trust (from both the member's and leader's perspective) may influence the rate at which a dyadic relationship develops. For example, it is known that one of the factors that contributes to the development of LMX is delegation. A manager who generally does not trust employees is unlikely to delegate easily and will likely increase the criticality of assignments in small increments. Second, it is possible that employees who have a tendency to trust will 
tolerate minor injustices. However, when an injustice is severe, it is possible that these employees would react with the most attitudinal and behavioral change. Therefore, it is recommended that further theoretical development of the role of dispositional trust be done and that this construct be included in research where it is theoretically sound.

One emerging area in which dispositional trust may be critical to the development of person specific interpersonal trust and task performance is in the area of "virtual teams". Virtual teams are groups of individuals who work on a common project from disparate geographical locations (Lipnack \& Stamps, 1997). The communication process of these teams is generally computer mediated (e.g. through electronic mail, bulletin boards, chat rooms). Both business organizations and educational institutions are increasingly using virtual teams. The value to organizations of virtual teams is that there is a tremendous cost savings in terms of travel. Additionally, virtual teams allow for asynchronous work on a specific project. Members of virtual teams do not have access to the richness of face-to-face interactions (e.g., non-verbal communication cues) and therefore may rely more on their general tendency to trust others than on information about a specific other in order to develop perceptions of trust in team members. Jarvenpaa, Knoll, and Leider (1998) found that dispositional trust was related to trust in one's team and task performance in newly formed virtual teams. Therefore, the emerging area of virtual teams may be a excellent context in which to further examine the effects of dispositional trust on not only trust development in specific others but other attitudes 
(e.g., satisfaction with team, commitment to team) and behaviors (performance, OCB, ORB).

The second theoretical implication concerns the nature of LMX as a construct. In both the field study and the laboratory study, there was a very strong correlation between trust from the member's perspective and LMX as reported by the member. Some researchers have found that LMX is a multidimensional construct (e.g., Liden \& Maslyn, 1998) others have found that trust is a multidimensional construct (e.g., Butler, 1991). However, it is possible the two constructs are indistinguishable to employees given the current manner in which the constructs are measured.

As measured currently, both constructs serve as an emergent property of the relationship between a leader and a member. LMX theory and research would benefit by a serious effort to examine the nature of what is exchanged between leaders and members (e.g., Liden et al., 1997). For example, in the present research it was assumed that leaders and members exchange parallel resources (e.g., helping behavior, defending behavior). However, it is likely that members and leaders have different resources to exchange. For example, members may use as "currency" in the exchange relationship extra effort (e.g., extrarole behavior), moral support for a leader, loyalty to the leaders, etc. Leaders on the other hand, may use as currency positive performance appraisals, autonomy, desirable assignments, etc. Through this exchange process, it is likely that quality of the dyadic relationship (i.e., LMX as currently measured) could accurately be measured as an emergent property.

Third, support was not found for the mediation effect of organizational justice in the field study and only partial mediation was found for some constructs in the 
laboratory study. From a theoretical perspective, this means that the relationships

between LMX and the outcome variables examined here did not operate through organization justice. This is good news for LMX researchers, since it appears that the relationships found between LMX and outcomes is not accounted for by perceptions of organizational justice.

While LMX may not operate through organizational justice, it is not clear that LMX had unique relationships with the outcome variables studied here. The fourth theoretical implication comes from an examination of the full model results. In both the field study and the laboratory study, after the elimination of dispositional trust, the basic hypothesized model is supported. What is interesting about the final models in both studies is not just support for the hypothesized paths, but the lack of evidence of the inclusion of additional direct paths between LMX and the outcomes. This suggests that perhaps there are no unique effects of LMX on outcome variables once the relationship between LMX and organizational justice is considered. Since this is the first study to include this set of variables together, more research is needed to examine these relationships.

Practical Implications

There are also important implications of this research for practitioners. First, trust is very closely related to the quality of the working relationship between leaders and members. Therefore, the development of trust is important if one wants to have a high quality working relationship with members (from the leader's perspective). So, the question becomes how does one develop trust? Answers to this question may be found in Mayer et al.'s (1995) model of trust. The three characteristics of a trustee 
important to trust development are ability, benevolence, and integrity. Therefore, anything a leader (or member) can do to increase these factors in the eyes of the other member of the dyad would increase trust.

Secondly, in both the field study and the laboratory study, distributive and procedural justice contributed to an overall sense of fairness. Overall fairness was then related to several of the attitudes and behaviors examined. Interestingly, in both studies procedural justice was a larger determinant of overall fairness than distributive justice. For practitioners, this means that it is critical to ensure that decision-making processes in the organization are perceived as fair. It is not enough to ensure the faimess of the eventual distribution of resources.

Third, both LMX and fairness perceptions are important to the outcomes desirable for employees and the organization. Depending on the size of the organization, it is possible that individual leaders (i.e., supervisors) may have significantly more control over the quality of the working relationships they have with members versus distributive and procedural justice. However, managers need to be aware that perceptions of fairness for decision-making processes they may not have control over may affect employee attitudes and behaviors. This is not to say that no matter what a manager does that fairness perceptions determine employee attitudes and behaviors. Actually, quite the opposite is true. Based on the results of the full model, the quality of the dyadic relationship is at least as important to determining overall fairness as are procedural distributive justice.

Although not all hypotheses were supported, this research contributes to literature in several significant ways. First, this research examines a set of variables 
that share a common theoretical basis in social exchange theory (i.e., trust, LMX, organizational justice) for the first time. Second, the conceptualization of the quality of the dyadic relationship between supervisor and subordinate as being an emergent property of the perceptions and actions of both parties is also unique and better reflects the theoretical underpinnings of LMX than prior research. Third, overall fairness was modeled in a way that is consistent with new theory about how general fairness judgments are formed (Lind, 2001). Fourth, the effects of fairness on established perceptions of trust in supervisor and LMX were examined.

Overall, this research provides some insight into the role of trust, LMX, and organizational justice on employee attitudes and behaviors. The results of this research have practical implications for leaders in organizations that have been discussed above. While it is important that research continue in this area, the results provide some direction for future theorizing about trust, LMX, and fairness as well as directions for future research. 
References

Adams, J. S. (1965). Inequity in social exchange. In L. Berkowitz (Ed.), Advances in experimental and social psychology (Vol. 2., pp. 267-299). New York: Academic Press.

Alexander, S., \& Ruderman, M. (1987). The role of procedural and distributive justice in organizational behaviors. Social Justice Research, 1, 177-198.

Allen, N. J., \& Meyer, J. P. (1990). Organizational socialization tactics: A longitudinal analysis of links to newcomers' commitment and role orientation. Academy of Management Journal, 33, 847-858.

Anderson, S. E., \& Williams, L. J. (1996). Interpersonal, job, and individual factors related to helping processes at work. Journal of Applied Psychology, 81, 282296

Aquino, K. (1995). Relationships among pay inequity, perceptions of procedural justice, and organizational citizenship. Employee Responsibilities and Rights Journal, 8, 21-33.

Aram, J. D., \& Salipante, P. F. (1981). An evaluation of organizational due process in the resolution of employee/employer conflict. Academy of Management Review, 6, 197-204.

Baron, R. M., \& Kenny, D. A. (1986). The moderator-mediator variable distinction in social psychological research: Conceptual, strategic, and statistical considerations. Journal of Personality and Social Psychology, 51, 1173-1182.

Barrick, M. R., \& Mount, M. K. (1991). The big five personality dimensions and job performance: A meta-analysis. Personnel Psychology, 44, 1-26. 
Bass, B. M., \& Avolio, B. J. (1993). Transformational leadership: A response to critiques. In M. M. Chemers \& R. Ayman (Eds.). Leadership theory and research: Perspectives and directions (pp. 49-80). San Diego: Academic Press.

Bateman, T. S., \& Organ, D. (1983). Job satisfaction and the good soldier: The relationship between affect and employee citizenship. Academy of Management Journal, 26, 587-595.

Bauer, T. N., \& Green, S. G. (1996). Development of leader-member exchange: A longitudinal test. Academy of Management Journal, 39, 1538-1567.

Bauer, T. N., Morrison, E. W., \& Callister, R. R. (1998). Organizational socialization: A review and directions for future research. Research in Personnel and Human Resources Management, 16, 149-214.

Bauer, T. N., Truxillo, D. M., Sanchez, R. J., Craig, J. M., Ferrara, P., \& Campion, M. A. (2001). Applicant reactions to selection: Development of the personnel selection procedural justice scale. Personnel Psychology, 54, 387-419.

Bennett, R. J., \& Robinson, S. L. (2000). Development of a measure of workplace deviance. Journal of Applied Psychology, 85, 349-360.

Bies, R. J. (1987). The predicament of injustice: The management of moral outrage. In L. L. Cummings \& B. M. Staw (Eds.), Research in organizational behavior (Vol. 9, pp. 289-319). Greenwich, CT: JAI.

Bies, R. J., Martin, C. L., \& Brockner, J. (1993). Just laid off, but still a "good citizen?" Only if the process is fair. Employee Responsibilities \& Rights Journal, 6 , $227-238$. 
Bies, R. J., \& Tripp, T. M. (1996). Beyond distrust "Getting Even" and the

need for revenge. In R. M. Kramer and T. R. Tyler (Eds.), Trust in Organizations (pp. 246-260).Thousand Oaks, CA: Sage.

Bies, R. J., Tripp, T. M., \& Kramer, R. M. (1997). At the breaking point: Cognitive and social dynamics of revenge in organizations. In Antisocial behavior in organizations, R. A. Giacalone \& J. Greenberg (Eds.). Thousand Oaks, CA: Sage. Blau, P. M. (1964). Exchange and power in social life. New York: Wiley. Bridges, W. (1994). Job shift: How to prosper in a workplace without jobs. Reading, MA: Addison-Wesley.

Brockner, J., \& Siegel, P. (1996). Understanding the interaction between procedural and distributive justice: The role of trust. In R. M. Kramer and T. R. Tyler (Eds.), Trust in organizations (pp. 390-413). Thousand Oaks, CA: Sage.

Brockner, J., \& Wiesenfeld, B. M. (1996). An integrative framework for explaining reaction to decisions: Interactive effects of outcomes and procedures. Psychological Bulletin, 120, 189-208.

Brown, R., \& Herrnstein, R. J. (1975). Psychology. Boston: Little, Brown.

Butler, J. K. (1991). Toward understanding and measuring conditions of trust: Evolution of a conditions of trust inventory. Journal of Management, 17, 643-663.

Butler, J. K., \& Cantrell, R. S. (1984). A behavioral decision theory approach to modeling dyadic trust in superiors and subordinates. Psychological Reports, 55, 1928.

Chun, K. J., \& Campbell, J. D. (1975). Dimensionality of the Rotter Interpersonal Trust Scale. Psychological Reports, 37, 983-986. 
Cohen, J. (1988). Statistical power analysis for the behavioral sciences $\left(2^{\text {nd }} 249\right.$ ed.). Hillsdale, NJ: Erlbaum.

Colquitt, J. A. (2001). On the dimensionality of organizational justice: A construct validation of a measure. Journal of Applied Psychology, 86, 386-400.

Colquitt, J. A., Conlon, D. E., Wesson, M. J., Porter, C. O., \& Ng, K. Y. (2001). Justice at the millennium: A meta-analytic review of 25 years of organizational justice research. Journal of Applied Psychology, 86, 425-445.

Conger, J. A. (1998). Winning 'em over: A new model for managing in the age of persuasion. New York: Simon \& Schuster.

Conlon, E. J., \& Mayer, R. C. (1994). The effect of trust on principle-agent dyads: An empirical investigation of stewardship and agency. Paper presented at the annual meeting of the Academy of Management. Dallas, TX.

Creed, W. E. D., \& Miles, R. E. (1996). Trust in organizations: A conceptual framework linking organizational forms, managerial philosophies, and the opportunity costs of controls. In R. M. Kramer \& T. R. Tyler (Eds.), Trust in organizations: Frontier of theory and research, (pp. 16-38). Thousand Oaks, CA: Sage.

Cropanzano, R., \& Greenberg, J. (1997). Progress in organizational justice: Tunneling through the maze. In C. Cooper \& I. Robertson (Eds.), International review of industrial and organizational psychology (pp. 317-372). New York: John Wiley.

Dansereau, F., Alutto, J. A., Markham, S. E., \& Dumas, M. (1982). Multiplexed supervision and leadership: An application of within and between analysis. In J. G. Hunt, U. Sekaran, \& C. A. Schriesheim (Eds.), Leadership beyond establishment view (pp. 81-103). Carbondale, IL: Southern Illinois University Press. 
Dansereau, F., Graen, G., \& Haga, W. J. (1975). A vertical dyad approach

to leadership within formal organizations. Organizational Behavior and Human

Performance, 13, 46-78. (This or Graen \& Cashman, 1975).

Day, D. V., \& Crain, E. C. (1992). The role of affect and ability in initial exchange quality perceptions. Group \& Organization Management, 17, 380-397.

Deluga, R. J., (1994). Supervisor trust building, leader-member exchange and organizational citizenship behaviour. Journal of Occupational and Organizational Psychology; 67, 315-326.

Deluga, R. J. (1998). Leader-member exchange quality and effectiveness ratings. Group \& Organization Management, 23, 189-216.

Deluga, R. J., \& Perry, J. T. (1994). The role of subordinate performance and ingratiation in leader-member exchanges. Group \& Organization Management, 19, 67 86.

Dienesch, R. M., \& Liden, R. C. (1986). Leader-member exchange model of leadership: A critique and further development. Academy of Management Review, 11, 618-634.

Dipboye, R. L., \& de Pontbraind, R. (1981). Correlates of employee reactions to performance appraisals and appraisal systems. Journal of Applied Psychology, 66, 248-251.

Dockery, T. M., \& Steiner, D. D. (1990). The role of the initial interaction in leader-member exchange. Group \& Organization Studies, 15, 395-413.

Driscoll, J. W. (1978). Trust and participation in organizational decision making as predictors of satisfaction. Academy of Management Journal, 21, 44-56. 
Duarter, N. T., Goodson, J. R., \& Klich, N. R. (1994). Effects of dyadic quality and duration on performance appraisal. Academy of Management Journal, 37, 499-521.

Duchon, D., Green, S. G., \& Taber, T. D. (1986). A longitudinal assessment of antecedents, measures, and consequences. Journal of Applied Psychology, 71, 56-60.

Dunegon, K. J., Duchon, D., \& Uhl-Bien, M. (1992). Examining the link between leader-member exchange and subordinate performance: The role of task analyzability and variety as moderators. Journal of Management, 18, 59-76.

Early, P. C. (1986). Trust, perceived importance of praise and criticism, and work performance: An examination of feedback in the United States and England. Journal of Management, 12, 457-473.

Fiedler, F. E. (1967). A theory of leadership effectiveness. New York: McGraw-Hill.

Flanagan, J. C. (1954). The critical incident technique. Psychological Bulletin, $\underline{51}, 327-358$.

Fleishman, E. A., Harris, E. F., \& Burtt, H. E. (1955). Leadership and supervision in industry; an evaluation of a supervisory training program. Ohio State University Bureau of Educational Research Monograph, 33.

Folger, R. (1977). Distributive and procedural justice: Combined impact of "voice" and improvement on experienced inequity. Journal of Personality and Social Psychology, 35, 108-119.

Folger, R. \& Baron, R.A. (1996). Violence and hostility at work: A model of reactions to perceived injustice. In G.R. VandenBos, \& E.Q. Bulatao, (Eds.). 
Violence on the job: Identifying risks and developing solutions, (pp. 51-85).

Washington DC: APA Books.

Folger, R., \& Cropanzano, R. (1998). Organizational justice and human

resource management. Thousand Oaks, CA: Sage.

Folger, R. \& Konovsky, M. A. (1989). Effects of procedural justice, distributive justice, and reactions to pay raise decisions. Academy of Management Journal, 32, 115-130.

Folger, R, Rosenfeld, D., Grove, J. \& Corkran, L. (1979). Effects of "voice" and peer opinions on responses to inequity. Journal of Personality and Social Psychology, 37, 2243-2261.

Forret, M. L., \& Turban, D. B. (1996). Implications of the elaboration likelihood model for interviewer decision processes. Journal of Business \& Psychology, 10, 415-428.

Gabarro, J. J. (1978). The development of trust, influence and expectations. In A. G. Athos \& J. J. Gabarro (Eds.), Interpersonal behaviors: Communication and understanding in relationships, 290-303. Engelwood Cliffs, NJ: Prentice Hall.

Gerstner, C. R., \& Day, D. V. (1997). Meta-analytic review of leader-member exchange theory: Correlates and construct issues. Journal of Applied Psychology, 82, $827-844$.

Ghiselli, E. (1963). Managerial talent. American Psychologist, 18, 631-641.

Gilliland, S. W. (1993). The perceived fairness of selection systems: An organizational justice perspective. Academy of Management Review, 18, 694-734. 
Gilliland, S. W., \& Steiner, D. D. (2001). Causes and consequences of

applicant perceptions of unfairness. In Cropanzano, R. (Ed), Justice in the workplace:

From theory to practice (Vol. 2. pp. 175-195). Mahwah, NJ: Lawrence Erlbaum Associates, Publishers.

Gouldner, A. W. (1960). The norm of reciprocity. American Sociological Review, 25, 161-178.

Graen, G. B. (1976). Role of making processes with complex organizations. In M. D. Dunnette (Ed.), Handbook of industrial and organizational psychology (pp. 1201-1245). Chicago: Rand-McNally.

Graen, G. B. (1990). Designing productive leadership systems to improve both work motivation and organizational effectiveness. In U. Kleinbeck and H. Quast (Eds.), Work motivation: Series in applied psychology. (pp. 133-156). Hillsdale, NJ: Lawrence Erlbaum.

Graen, G., \& Cashman, J. F. (1975). A role-making processes within complex organizations. In M. D. Dunnette (Ed.), Handbook of industrial and organizational psychology (pp. 1201-1245). Chicago: Rand McNally.

Graen, G. B., \& Ginsburgh, S. (1977). Job resignation as a function of role orientation and leader acceptance: A longitudinal investigation of organizational assimilation. Organizational Behavior and Human Performance, 19, 1-17.

Graen, G. B., \& Scandura, T. A. (1987). Toward a psychology of dyadic organizing. In L. L. Cummings \& B. M. Staw (eds.), Research in organizational behavior, 9, (pp. 175-208). 
Graen, G. B., \& Uhl-Bien, M. (1995). Development of Leader-Member

Exchange (LMX) theory of leadershipover 25 years: Applying a multi-level multidomain perspective. The Leadership Quarterly, 6, 219-247.

Graen, G. B., Novak, M. A., \& Sommerkamp, P. (1982). The effects of leadermember exchange and job design on productivity and satisfaction: Testing a dual attachment model. Organizational Behavior \& Human Decision Processes, 30, 109 131.

Graen, G. B., Novak, M., \& Sommerkamp, P. (1982). The effects of leadermember exchange and job design on productivity and satisfaction: Testing a dual attachment model. Organizational Behavior and Human Performance, 30, 109-131.

Graen, G. B., Scandura, T. A., \& Graen, M. R. (1986). A field experimental test of the moderating effects of growth need strength on productivity. Journal of Applied Psychology, 71, 484-491.

Granovetter, M. (1985). Economic action and social structure: The problem of embeddedness. American Journal of Sociology, 91, 481-510.

Green, S. G., \& Mitchell, T. (1979). Attributional processes of leaders in leader-member interactions. Organizational Behavior and Human Performance, 23, $429-458$.

Green, S. G., Anderson, S. E., \& Shivers, S. L. (1996). An examination of organizational constraints on leader-member exchange. Organizational Behavior and Human Decision Making Processes, 66, 203-21. 
Green, S. G., Blank, W., \& Liden, R. C. (1983). Market and organizational influences on bank employees' work attitudes and behaviors. Journal of Applied Psychology, 68, 298-306.

Greenberg, J. (1986). Determinants of perceived fairness of performance evaluations. Journal of Applied Psychology, 71, 340-342.

Greenberg, J. (1990a). Organizational justice: Yesterday, today, and tomorrow. Journal of Management, 16, 399-432.

Greenberg, J. (1990b). Employee theft as a reaction to underpayment inequity: The hidden cost of pay cuts. Journal of Applied Psychology, 75, 561-568.

Hackman, J. R., \& Oldham, G. R. (1980). Work redesign. Reading, MA: Addison-Wesley.

Hayduk, L. A. (1987). Structural equation modeling with LISREL. Baltimore: Johns Hopkins University.

Hom, P. W., Griffeth, R. W., \& Sellard, C. L. (1984). The validity of Mobley's (1977) model of employee turnover. Organizational Behavior and Human Decision Processes, 34, 141-174.

Homans, G. C. (1961). Social behavior: Its elementary forms. New York: Plemun.

Hosmer, L. T. (1995). Trust: The connecting link between organizational theory and philosophical ethics. Academy of Management Review, 20, 379-403.

House, R. J. (1971). A path-goal theory of leader effectiveness. Administrative Science Quarterly, 16, 321-339. 
Jarvenpaa, S. L., Knoll, K., \& Leider, D. E. (1998). Is anybody out there? Antecedents of trust in global virtual teams. Journal of Management Information Systems, 14, 29-64.

Jennings, E. E. (1971). Routes to the executive suite. New York: McGraw-Hill.

Jöreskog, K. G., \& Sörbom, D. (1989). LISREL 7: A guide to the program and applications. Chicago: SPSSX.

Katz, D., \& Kahn, R. L. (1978). The social psychology of organizations $\left(2^{\text {nd }}\right.$ Edition). New York: John Wiley \& Sons.

Katzenberg, R., \& Hom, P. (1981). Effects of within-group and between-group variation in leadership. Journal of Applied Psychology, 66, 218-223.

Kinicki, A. J., \& V.ecchio, R. P. (1994). Influences on the quality of supervisor-subordinate relations: The role of time-pressure, organizational commitment, and locus of control. Journal of Organizational Behavior, 15, 75-84.

Klein, K. J., Dansereau, F., \& Hall, R. J. (1994). Levels issues in theory development, data collection and analysis. Academy of Management Review, 19, 195229.

Konovsky, M. A., \& Cropanzano, R. (1991). Perceived fairness of employee drug testing as a predictor of employee attitudes and job performance. Journal of Applied Psychology, 76, 698-707.

Konovsky, M. A., \& Pugh, S. D. (1994). Citizenship behavior and social exchanges. Academy of Management Journal, 37, 656-669. 
Kozlowski, S. W., \& Klein, K. J. (2000). A multilevel approach to theory and research in organizational: Contextual, temporal, and emergent processes. In S. W. Kozlowski \& K. J. Klein (Eds.) Multilevel Theory, Research, and Methods in Organizations (pp. 3-90). San Francisco: Jossey-Bass.

Kramer, R. M. (1996). Divergent realities and convergent disappointments in the hierarchic relation: Trust and the intuitive auditor at work. In R. M. Kramer and T. R. Tyler (Eds.), Trust in organizations (pp. 216-245). Thousand Oaks, CA: Sage.

Lagace, R. R. (1991). An exploratory study of reciprocal trust between sales managers and salespersons. Journal of Personnel Selling and Sales Management, 11, 49-58.

Landy, F. J., Barnes, J. L., \& Murphy, K. R. (1978). Correlates of perceived fairness and accuracy of performance evaluations. Journal of Applied Psychology, 63, $751-754$.

Larzelere, R., \& Huston, T. (1980). The dyadic trust scale: Toward understanding interpersonal trust in close relationships. Journal of Marriage and the Family, 42, 595-604.

Lee, K., \& Allen, N. J. (2002). Organizational citizenship behavior and workplace deviance: The role of affect and cognitions. Journal of Applied Psychology, $\underline{87}, 131-142$.

Legace, R. R., \& Rhoads, G. K. (1988). Evaluation of the MacDonald, Kessel, and Fuller Self-Report Trust Scale. Psychological Reports, 63, 961-962.

Lendaris, G. G. (1986). On systemness and the problem solver: Tutorial comments. Systems, Man, and Cybernetics, 16, 604-610. 
Leventhal, G. S. (1980). What should be done with equity theory? New approaches to the study of fairness in social relationships. In K. Gergen, \& R. Willis (Eds.), Social exchange : Advances in theory and research (27-55). New York: Plemun Press.

Leventhal, G. S., Karuza, J., \& Fry, W. R. (1980). Beyond fairness: A theory of allocation preferences. In G. Mikula (Ed.), Justice and social interaction (pp. 167218). New York: Springer-Verlag.

Lewicki, R. J., McAllister, D. J., \& Bies, R. J. (1998). Trust and distrust: New relationships and realities. Academy of Management Review, 23, 438-458.

Lewis, J. D., \& Weigert, A. (1985). Trust as social reality. Social Forces, 63, 967-985.

Liden, R. C., \& Graen, G. (1980). Generalizability of the vertical dyad linkage model of leadership. Academy of Management Journal, 23, 451-465.

Liden, R. C., \& Maslyn, J. M. (1998). Multidimensionality of leader-member exchange: An empirical assessment through scale development. Journal of Management, 24, 43-72.

Liden, R. C., Sparrowe, R. T., \& Wayne, S. J. (1997). Leader-member exchange theory: The past and potential future. Research in personnel and human resource management, $15,47-119$.

Liden, R. C., Wayne, S. J., \& Stilwell, D. (1993). A longitudinal study on the early development of leader-member exchanges. Journal of Applied Psychology, 78, 662-674. 
Lind, E. A. (2001). Fairness heuristic theory: Justice judgments as pivotal cognitions in organizational relations. In J. Greenberg \& R. Cropanzano (Eds.), Advances in Organizational Justice (pp. 56-88). Stanford, CA: Stanford University Press.

Lind, E. A., \& Tyler, T. R. (1988). The Social Psychology of Procedural Justice. New York: Plemun Press.

Lind, E. A., Kanfer, R., \& Earley, P. C. (1990). Voice, control, and procedural justice: Instrumental and non instrumental concerns in fairness judgements. Journal of Personality and Social Psychology, 59, 952-959.

Liou, T. K. (1995). Understanding employee commitment in the public organization: A study of the juvenile detention center. International Journal of Public Administration, 18, 1269-1295.

Lipnack, J., \& Stamps, J. (1997). Virtual teams: Reaching across space, time, and organizations with technology. New York: Wiley.

MacDonald, A. P, Kessel, V. S., \& Fuller, J. B. (1972). Self-disclosure and two kinds of trust. Psychological Reports, 30, 143-148.

MacNeil, I. R. (1985). Relational contract: What we do and do not know. Wisconsin Law Review, 483-525.

Mayer, R. C., Davis, J. H., \& Schoorman, F. D. (1995). An integrative model of organizational trust. Academy of Management Review, 20, 709-734.

McAllister, D. J. (1995). Affect- and cognition-based trust as foundation for interpersonal cooperation in organizations. Academy of Management Journal, 38, 2459. 
McFarlin, D. B., \& Sweeney, P. D. (1992). Distributive and procedural justice as predictors of satisfaction with personal and organizational outcomes. Academy of Management Journal, 35, 626-637.

Moore, S. F., Shaffer, L. S., Pollak, E. L., \& Taylor-Lemke, P. (1987). The effects of interpersonal trust and prior common problem experience on common management. Journal of Social Psychology, 127, 19-29.

Moorman, R. H. (1991). Relationship between organizational justice and organizational citizenship behaviors: Do fairness perceptions influence employee citizenship? Journal of Applied Psychology, 76, 845-855.

Moskowitz, R., \& Warwick, D. (1996). The 1994-2005 job outlook in brief. Occupational Outlook Quarterly, 40, 2-41.

Mowday, R. T. (1996). Equity theory predictions of behavior in organizations. In R. M. Steers, L. W. Porter, \& G. A. Bigley (Eds.), Motivation and leadership at work (pp. 53-71). New York: McGraw-Hill.

Niehoff, B. P., \& Moorman, R. H. (1993). Justice as a mediator of the relationship between methods of monitoring and organizational citizenship behavior. Academy of Management Journal, 36, 527-556.

Nunnally, J. C. (1978). Psychometric theory. New York: McGraw-Hill. Organ, D. W. (1988). Organizational citizenship behavior: The good soldier syndrome. Lexington, MA: Lexington Books.

Organ, D. W. (1990). The motivational basis of organizational citizenship behavior. Research in Organizational Behavior, 12, 43-72. 
Organ, D. W., \& Moorman, R. H. (1993). Fairness and organizational citizenship behavior: What are the connections? Social Justice Research, 6, 5-18.

Phillips, A. S., \& Bedian, A. G. (1994). Leader-follower exchange quality: The role of personal and interpersonal attributes. Academy of Management Journal, 37, 990-1001.

Pillai, R., Schriesheim, C. A., \& Williams, E. S. (1999). Fairness perceptions and trust as mediators for transformational and transactional leadership: A two-sample study. Journal of Management, 25, 897-933.

Podsakoff, P. M., MacKenzie, S. B., Moorman, R. H., \& Fetter, R. (1990). Transformational leader behaviors and their effects on followers' trust in leader, satisfaction and organizational citizenship behaviors. Leadership Quarterly, 1, 107142.

Price, J. L., \& Mueller, C. W. (1986). Handbook of organizational measurement. Marshfield, MA: Pittman.

Robinson, S. L., \& Bennett, R. J. (1995). A typology of deviant workplace behaviors: A multi-dimensional scaling study. Academy of Management Journal, 38, $555-572$.

Robinson, S. L., Kraatz, M. S., \& Rousseau, D. M. (1994). Changing obligations and the psychological contract: A longitudinal study. Academy of Management Journal, 37, 137-152.

Rotter J. (1967). A new scale for the measurement of interpersonal trust. Journal of Personality, 35, 651-665. 
Rotter, J. B. (1971). Generalized expectancies for interpersonal trust. American Psychologist, 26, 443-452.

Rousseau, D. (1985). Issues of level in organizational research: Multi-level and cross level perspectives. In L.L. Cummings \& B.M. Staw (Eds.) Research in organizational behavior (vol. 7, pp. 1-37). Greenwich, CT: JAI Press.

Rousseau, D. M. (1989). Psychological and implied contracts in organizations. Employee Responsibilities \& Rights Journal, 2, 121-139.

Rousseau, D. M. (1995). Psychological contract in organizations: Understanding written and unwritten agreements. London: Sage.

Sabatelli, R. M., Buck, R., \& Dreyer, A. (1993). Locus of control, interpersonal trust, and nonverbal communication accuracy. Journal of Personality and Social Psychology, 44, 399-409.

Sahlins, M. (1972). Stone age economics. New York: Aldine De Gruyter.

Scandura, T. A. (1999). Rethinking leader-member exchange: An organizational justice perspective. Leadership Quarterly. 10, 25-40.

Scandura, T. A., \& Schriesheim, C. A. (1994). Leader-member exchange and supervisor career mentoring as complementary constructs in leadership research. Academy of Management Journal, 37, 1588-1602.

Schaubroeck, J., May, D. R., \& Brown, F. W. (1994). Procedural justice explanations and employee reactions to economic hardship: A field experiment. Journal of Applied Psychology, 79, 455-460.

Schriesheim, C. A., \& Gardiner, C. C. (1992). A comparative test of magnitude estimation and pair-comparison treatment of complete ranks for scaling a small 
number of equal-interval frequency responses anchors. Educational \&

Psychological Measurement, 52, 867-877.

Senge, P. M. (1990). The fifth discipline. New York: Doubleday.

Settoon, R. P., Bennett, N., \& Liden, R. C. (1996). Social exchange in organizations: Perceived organizational support, leader-member exchange, and employee reciprocity. Journal of Applied Psychology, 81, 219-227.

Shapiro, D. L., Trevino, L. K., \& Victor, B. (1995). Correlates of employee theft: A multi-dimensional justice perspective. International Journal of Conflict Management, 6, 404-414.

Sheppard, B. H., Hartwick, J., \& Warshaw, P. R. (1988). The theory of reasoned action: A meta-analysis of past research with recommendations for modifications and future research. Journal of Consumer Research, 15, 325-343.

Skarlicki, D. P., \& Folger R. (1997). Retaliation in the workplace: The roles of distributive, procedural, and interactional justice. Journal of Applied Psychology, 82, 434-443.

Skarlicki, D. P., Folger, R., \& Tesluk, P. (1999). Personality as a moderator in the relationship between fairness and retaliation. Academy of Management Journal, 42, $100-108$.

Smoyer, J., \& Way, C. (2000). Number reveal the reality of violence in the workplace. HR-News, 14, 18.

Society for Human Resource Management (1996). Workplace violence. Society of Human Resource Management Issues Management Program. Alexandria: VA. 
Sparrowe, R. T., \& Liden, R. C. (1997). Process and structure in leadermember exchange. Academy of Management Review, 22, 522-552.

Stack, L. C. (1978). Trust. In H. London \& J. Exner (Eds.), Dimensions of personality. New York: Wiley.

Stodgill, R. (1948). Personal factors associated with leadership. Journal of Applied Psychology, 25, 35-71.

Sweeney, P. D., \& McFarlin, D. B. (1993). Workers' evaluations of the "ends" and "means": An examination of four models of distributive and procedural justice. Organizational Behavior \& Human Decision Processes, 55, 23-40.

Taylor, D. M., \& Moghaddam, F. M. (1987). Theories of intergroup relations: International social psychological perspectives. New York, NY: Praeger Publishers.

Tedeschi, R. G., \& Wright, T. L. (1980). Cross-validation of the WrightTedeschi factors of the interpersonal trust scale. Psychological Reports, 47, 111-114.

Thibaut, J. W., \& Walker, L. (1975). Procedural justice: A psychological perspective. Hillsdale, NJ: Lawrence Erlbaum.

Tierney, P., \& Bauer, T. N. (1996). A longitudinal assessment of LMX on extra-role behavior. Best Paper Proceedings, Academy of Management Meeting, Cincinnati, $\mathrm{OH}$.

Tierney, P., Framer, S. M., \& Graen, G. B. (1999). An examination of leadership and employee creativity: The relevance of traits and relationships. Personnel Psychology, 52, 591-620. 
Tyler, T. (1994). Psychological models of the justice motive: Antecedents of distributive and procedural justice. Journal of Personality and Social Psychology, 67. $850-863$.

Tyler, T. R., \& Bies, R. J. (1990). Beyond formal procedures: The interpersonal context of procedural justice. In J. Carroll (Ed.). Applied social psychology and organizational settings (pp. 77-98). Hillsdale, NJ: Erlbaum.

Tyler, T. R., \& Lind, E. A. (1992). A relational model of authority in groups. In M. Zanna (Ed.). Advances in experimental social psychology (Vol. 25, pp. 115191). New York: Academic Press.

Van den Bos, K., Lind, E. A., Vermunt, R., \& Wilke, H. A. (1997). How do I judge my outcome when I do not know the outcome of others? The psychology of the fair process effect. Journal of Personality and Social Psychology, 72, 1034-1046.

Vecchio, R., (1982). A further test of leadership effects due to between-group variation and within-group variation. Journal of Applied Psychology, 67, 200-208.

Vecchio, R. P., \& Gobdel, B. C. (1984). The vertical dyad linkage model of leadership: Problems and prospects. Organizational Behavior \& Human Performance, 34, 5-20.

Vecchio, R. P., Griffeth, R. W., \& Hom, P. W (1986). The predictive utility of the vertical dyad linkage approach. Journal of Social Psychology, 126, 617-625.

Wakabayashi, M., \& Graen, G. B. (1984). The Japanese career progress study: A 7-year follow-up. Journal of Applied Psychology, 69, 603-614. 
Wakabayashi, M., Graen, G. B., Graen, M. R., \& Graen, M. G. (1988).

Japanese management progress: Mobility into middle management. Journal of Applied Psychology, 73, 217-227.

Wall, J. A., \& Nolan, L. L. (1987). Small group conflict: A look at equity, satisfaction, and styles of conflict. Small Group Behavior, 18, 188-211.

Walster, E., Walster, W., \& Bersheid, E. (1978). Equity: Theory and research. Boston: Allyn \& Bacon.

Warchol, G. (1998). National crime victimization survey: Workplace violence 1992-96 (NJC No. 168364). Washington, DC: National Criminal Justice Reference Service.

Watson, D., Clark, L. A:, \& Tellegen, A. (1988). Development and validation of brief measures of positive and negative affect: The PANAS scales. Journal of Personality \& Social Psychology, 54, 1063-1070.

Wayne, S. J., \& Ferris, G. R. (1990). Influence tactics, affect, and exchange qulaity in supervisor-subordinate interactions: A laboratory experience and field study. Journal of Applied Psychology, 75, 487-499.

Wayne, S. J., Liden, R. C., Graf, I. K., \& Ferris, G. R. (1997). The role of upward influence tactics in human resource decisions. Personnel Psychology, 50, 9791006.

Wayne, S. J., Shore, L. M., \& Liden, R. C. (1997). Perceived organizational support and leader-member exchange: A social exchange perspective. Academy of Management Journal, 40, 82-111. 
Weiner, B. (1986). An attributional theory of motivation and emotion. New York: Springer-Verlag.

Whitener, E. M., Brodt, S. E., Korsgaard, M. A., \& Werner, J. M. (1998). Mangers as initiators of trust: An exchange relationship framework for understanding managerial trustworthy behavior. Academy of Management Review, 23, 513-530.

Williams, L. J., \& Anderson, S. (1991). Job satisfaction and organizational commitment as predictors of organizational citizenship and in-role behaviors. Journal of Management, 17, 601-617.

Williamson, O. E. (1993). Calculativeness, trust, and economic organization. Journal of Law and Economics, 36, 453-486.

Yukl, G. (1989). Managerial leadership: A review of theory and research. Journal of Management, 15, 251-289.

Zand, D. E. (1972). Trust and managerial problem solving. Administrative Science Quarterly, 17, 229-239. 
Appendix A

Laboratory Study Cover Letter

Summer 2001

The purpose of this survey is to get your opinion about how organizations provide rewards to employees, your working relationship with your work supervisor, and your behavior on the job. You will be asked to complete a survey about your current job. Then, you will be asked to read a short scenario and complete a survey after you read the scenario. These two surveys will take a total of approximately 25 minutes to complete. Although you may not receive any direct benefit from participating in this study, others may benefit in the future as your responses may inform organizations on how to establish fair policies and encourage high quality working relationships between supervisors and subordinates.

Participation in this study is strictly voluntary. All information you provide is confidential. You will not be asked to provide your name or student identification number. The final report of this study will contain only group-level data. Your decision to participate or not will not affect your relationship with the researcher, your instructor, or with Portland State University in any way. If you decide to take part in the study, you may choose to withdraw at any time without penalty. If you decide not to participate, you may leave the room at any time. Also, you may skip any items on the survey to which you feel uncomfortable responding. However, please be assured that your responses will be kept confidential, and there is no way to match responses to the individuals who provide them, since neither your name nor any identification number is on the survey.

When you have completed the survey, please return it to the survey administrator. Results of this survey should be completed by July 2001. A summary of the results will be available from Rudolph J. Sanchez upon request.

If you have any questions concerning the survey, this study, or its results, please contact Rudolph J. Sanchez at 503.725.8141. If you have concerns or problems about participation in this study or your rights as a research participant, please contact the Human Subjects Research Review Committee, Office of Research and Sponsored Project, 111 Cramer Hall, Portland State University, 503.725.8182. Please keep this letter for your records.

Thank you very much for your participation.

Sincerely,

Rudolph J. Sanchez

School of Business Administration

Portland State University 
Appendix B

Laboratory Study Pre-Manipulation Survey

Please complete this survey based on your opinions about your current job, your current supervisor, and the organization for which you currently work. If you do not currently work, please complete the survey based on your most recent job, supervisor, and organization.

When you have completed this survey place it back in the envelope. Then, please begin the survey printed on blue paper in the envelope.

THANK YOU FOR YOUR PARTICIPATION.

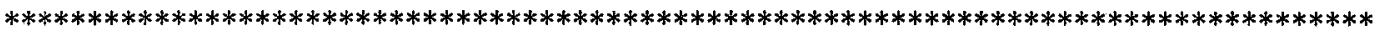

PART I BACKGROUND DATA

Please answer the following background questions that are necessary for this study.

1. Gender (check one): $\square$ Male $\square$ Female

2. Which of the following BEST describes your race/ethnicity? (Check one)

$\square$ African American/Black $\square$ Asian/Pacific Islander $\square$ Caucasian/White

$\square$ Hispanic $\quad \square$ Native American $\quad \square$ Other

3. Are you currently employed? (Check one) $\square$ YES $\square$ NO

4. How would you classify your current position? (Please Check One Box)

aClerical

Customer Service (bank teller, call center operator)

JFood Service (waitperson, cashier)

Drofessional

$\square$ Retail (salesperson, cashier)

Dother

5. How many hours per week do you work?

6. On what basis are you paid? (Please check the most appropriate box.)

$\square$ Salary $\square$ Hourly $\square$ Commission

7. How long have you worked with your current supervisor?

8. Approximately how many employees does your supervisor supervise?

9. What is your age?

10. What is your current class status in school? (Check one)
$\square$ Freshman
$\square$ Sophomore
$\square$ Junior $\square_{\text {Senior }} \square_{\text {Post-Baccalaureate/Graduate }}$

Have you completed all 5 pages of this survey? 
PART II When completing this portion of the survey, think about how you feel about your current supervisor, your current job, and your current organization. If you do not currently work, please complete the survey based on your most recent job, supervisor, and organization. Please circle the appropriate number to the right of each item using the scale below.

\begin{tabular}{|c|c|c|c|c|}
\hline 1 & 2 & 3 & 4 & 5 \\
\hline Strongly Disagree & Disagree & $\begin{array}{c}\text { Neither Agree or } \\
\text { Disagree }\end{array}$ & Agree & Strongly Agree \\
\hline
\end{tabular}

Thoughts about the about My Current Supervisor

11. I would justify my supervisor's decisions to others when he or she is not present to do so.

12. My supervisor understands my problems and needs.

Circle One

13. I can count on my supervisor to "bail me out" even at his or her expense when I really need it.

14. My supervisor recognizes my potential.

$\begin{array}{lllll}1 & 2 & 3 & 4 & 5 \\ 1 & 2 & 3 & 4 & 5\end{array}$

15. My supervisor would use his or her power to help me solve problems at work.

16. I usually know how satisfied my supervisor is with me.

17. I usually know where I stand with my supervisor. $\begin{array}{lllll}1 & 2 & 3 & 4 & 5\end{array}$

18. I have an effective working relationship with my supervisor.

19. I trust my supervisor.

20. I feel that my supervisor can be trusted.

21. Sometimes I can not trust my supervisor.

22. I can count on my supervisor to be trustworthy. 
32. My organization has procedures in place to make sure that decisions are consistent with all employees

33. My organization has procedures in place that allow employees the chance to have a say and express their concerns regarding company decisions.

34. My organization has procedures in place to make sure that the company is informed about employees' needs in order to make fair decisions.

35. My organization has procedures in place to make sure the information being used for decisions is accurate.

$\begin{array}{lllll}1 & 2 & 3 & 4 & 5 \\ 1 & 2 & 3 & 4 & 5 \\ 1 & 2 & 3 & 4 & 5\end{array}$

36. My organization has procedures in place to make sure all parties affected by a company decision are represented in the decision.

$\begin{array}{llllll}. . & 1 & 2 & 3 & 4 & 5 \\ & 1 & 2 & 3 & 4 & 5 \\ & & & & & \\ . . & 1 & 2 & 3 & 4 & 5 \\ 1 & 2 & 3 & 4 & 5 \\ . . & 1 & 2 & 3 & 4 & 5\end{array}$

40. I find that my values and the organization's values are very similar.

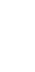

41. I am willing to put a great deal of effort beyond that normally expected in order to help this organization be successful.

42. I would accept almost any type of assignment in order to keep working for this organization.

43. Generally speaking, I am very satisfied with this job.

44. I am generally satisfied with the kind of work I do in this job.

45. I frequently think of quitting this job.

46. Most people on this job are very satisfied with this job.

47. People on this job often think of quitting.

Thoughts about How I Behave in My Current Job

48. I adequately complete assigned duties.

49. I fulfill responsibilities specified in the job description............................ $1122 \quad 3 \quad 4 \quad 5$

50. I perform tasks that are expected of me...................................... $1 \quad 2 \quad 2 \quad 3 \quad 4 \quad 5$

51. I meet formal performance requirements of the job................................ 1 1 $2 \quad 3 \quad 3 \quad 4 \quad 5$

52. I engage in activities that will directly affect my performance evaluation.. $\quad \begin{array}{lllllll}1 & 2 & 3 & 4 & 5\end{array}$

53. I neglect aspects of the job I am obligated to perform........................ $1 \quad 2 \quad 2 \quad 3 \quad 4 \quad 5$

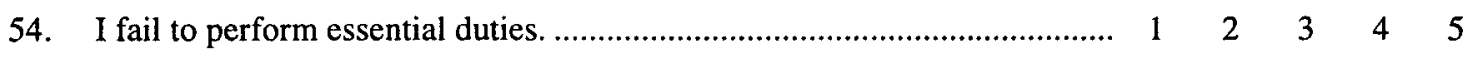

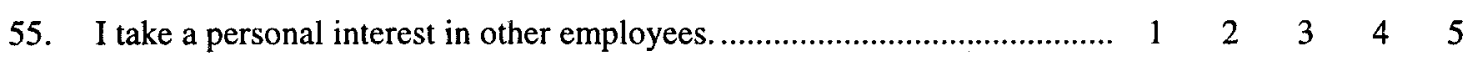

56. I pass along information to co-workers. ............................................ $1 \quad 2 \quad 2 \quad 3 \quad 4 \quad 5$

Have you completed all 5 pages of this survey? 
1

Strongly Disagree
2

Disagree
3

Neither Agree or

Disagree

57. I go out of my way to help new employees

4

Agree
5

Strongly Agree

$\begin{array}{lll}3 & 4 & 5 \\ 3 & 4 & 5 \\ 3 & 4 & 5 \\ 3 & 4 & 5 \\ 3 & 4 & 5 \\ 3 & 4 & 5 \\ 3 & 4 & 5 \\ 3 & 4 & 5 \\ 3 & 4 & 5 \\ 3 & 4 & 5 \\ 3 & 4 & 5\end{array}$
5 5

58. I assist my supervisor with his/her work when not asked...

59. I help others who have been absent..

60. I help others who have heavy workloads.

61. I take time to listen to co-workers' problems and worries.

62. I give advance notice when unable to come to work.

63. I take undeserved work breaks.

64. I spend a great deal of time on personal phone conversations.

65. I complain about insignificant things at work. 5

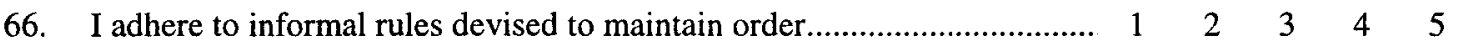

67. My attendance at work is above the norm. $\begin{array}{lllll}1 & 2 & 3 & 4 & 5\end{array}$

Please indicate the degree to which you agree with the following statements below.

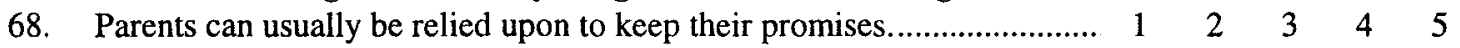

69. Most experts can be relied upon to tell the truth about the limits of their knowledge.

70. Most parents can be relied upon to carry out their threats of punishments.

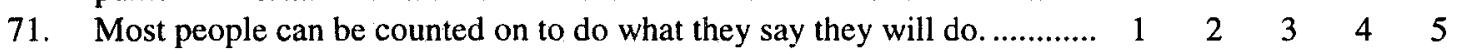

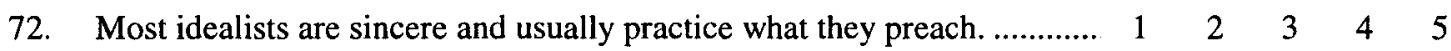

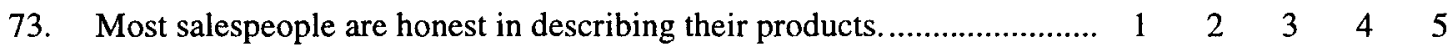

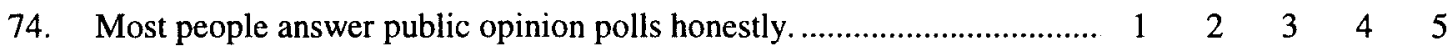

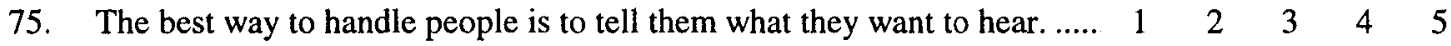

76. When you ask someone to do something for you, it is best to give the real reason for wanting it rather than giving reasons that might carry more weight.

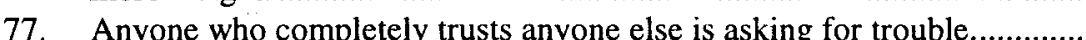

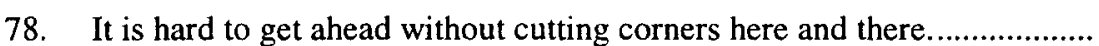

79. It is safest to assume that all people have a vicious streak, and it will come out when they are given a chance.

80. One should take action only when it is morally right.

81. Most people are basically good and kind.

82. There is no excuse for lying to someone else.

$\begin{array}{lllll}1 & 2 & 3 & 4 & 5\end{array}$

83. Most people more easily forget the death of their father than the loss of property.

$\begin{array}{lllll}1 & 2 & 3 & 4 & 5\end{array}$

$\begin{array}{lllll}1 & 2 & 3 & 4 & 5\end{array}$

84. Generally, people won't work hard unless they're forced to do so.

$\begin{array}{lllll}1 & 2 & 3 & 4 & 5 \\ 1 & 2 & 3 & 4 & 5 \\ 1 & 2 & 3 & 4 & 5 \\ 1 & 2 & 3 & 4 & 5 \\ 1 & 2 & 3 & 4 & 5 \\ 1 & 2 & 3 & 4 & 5\end{array}$

Have you completed all 5 pages of this survey? 
When responding to the items below, please indicate how frequently you engaged in these behaviors in the last year, using the following scale:

\begin{tabular}{|c|c|c|c|c|c|c|}
\hline 1 & 2 & 3 & 4 & 5 & 6 & 7 \\
\hline Never & $\begin{array}{c}\text { Once in the } \\
\text { Past Year }\end{array}$ & $\begin{array}{c}\text { Twice in the } \\
\text { Past Year }\end{array}$ & $\begin{array}{c}\text { Several } \\
\text { Times in the } \\
\text { Past Year }\end{array}$ & Monthly & Weekly & Daily \\
\hline
\end{tabular}

85. Said something hurtful to someone at work.

86. Cursed at someone at work.

$\begin{array}{llllll}2 & 3 & 4 & 5 & 6 & 7 \\ 2 & 3 & 4 & 5 & 6 & 7 \\ 2 & 3 & 4 & 5 & 6 & 7 \\ 2 & 3 & 4 & 5 & 6 & 7 \\ 2 & 3 & 4 & 5 & 6 & 7 \\ 2 & 3 & 4 & 5 & 6 & 7\end{array}$

91. Falsified a receipt to get reimbursed for more money than I spent

o2. Littered my work environment $\ldots$

87. Made fun of someone at work.

88. Made an ethnic, religious, or racial remark at work.

89. Played a mean prank on someone at work. 1

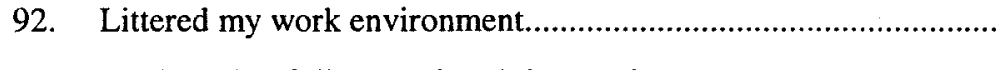

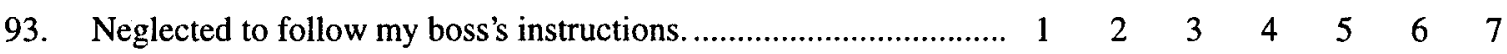

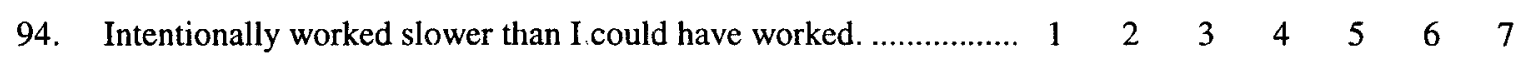

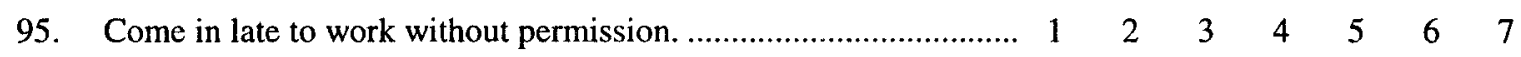

96. Taken an additional or longer break than is acceptable at my $\quad \begin{array}{lllllllllllllll}1 & 2 & 3 & 4 & 5 & 6 & 7\end{array}$ workplace.

97. Taken property from work without permission..

98. Dragged out work in order to get overtime.

99. Spent too much time fantasizing or daydreaming instead of working......

100. Discussed confidential company information with an unauthorized person......

101. Used an illegal drug or consumed alcohol on the job.

102. Put little effort into my work.

$\begin{array}{llllllll}. . & 1 & 2 & 3 & 4 & 5 & 6 & 7 \\ . . & 1 & 2 & 3 & 4 & 5 & 6 & 7 \\ . . & 1 & 2 & 3 & 4 & 5 & 6 & 7 \\ . . & 1 & 2 & 3 & 4 & 5 & 6 & 7 \\ . . & 1 & 2 & 3 & 4 & 5 & 6 & 7 \\ & 1 & 2 & 3 & 4 & 5 & 6 & 7 \\ . . & 1 & 2 & 3 & 4 & 5 & 6 & 7 \\ 1 & 2 & 3 & 4 & 5 & 6 & 7 \\ 1 & 2 & 3 & 4 & 5 & 6 & 7\end{array}$

\section{PLEASE PUT THIS SURVEY BACK INTO THE ENVELOPE AND PULL-OUT THE SURVEY ON THE BLUE PAPER.}


Appendix C

Laboratory Study Post-Manipulation Survey

In responding to this survey, imagine that the situation you just read actually happened to you in your current job (the job you actually hold) with your current supervisor. If you do not currently work, imagine the situation actually happened on the job you most recently held and your supervisor for that job.

When you have completed this survey place it back in the envelope and return the envelope to the survey administrator.

$* * * * * * * * * * * * * * * * * * * * * * * * * * * * * * * * * * * * * * * * * * * * * * * * * * * * * * * * * * * * * * * * * * * * * * * * * * * * * * * * * * * * * * * *$

PLEASE RESPOND TO THE FOLLOWING ITEMS ASSUMING THE SITUATION YOU JUST READ ACTUALLY HAPPENED.

1. My organization has an established procedure for determining bonuses....... YES NO

2. I received a bonus this year. ...................................................................... YES NO

Please circle the appropriate number to the right of each item using the scale below.

\begin{tabular}{|c|c|c|c|c|}
\hline 1 & 2 & 3 & 4 & 5 \\
\hline Strongly Disagree & Disagree & $\begin{array}{c}\text { Neither Agree or } \\
\text { Disagree }\end{array}$ & Agree & Strongly Agree \\
\hline
\end{tabular}

Assume the situation you just read actually happened to you.

Circle One

3. I have been able to express my views and feelings during the procedures used to determine bonuses.

4. I have had influence over the bonus decision arrived at by the procedures used to determine bonuses.

$\begin{array}{lllll}1 & 2 & 3 & 4 & 5\end{array}$

5. The procedures used to determine bonuses have been applied consistently.. $\quad \begin{array}{llllll}1 & 2 & 3 & 4 & 5\end{array}$

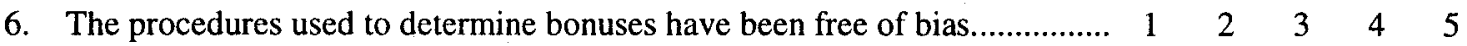

7. The procedures used to determine bonuses have been based on accurate information.

8. I have been able to appeal the outcome arrived at by the procedures used to determine bonuses.

$\begin{array}{lllll}1 & 2 & 3 & 4 & 5\end{array}$

9. The procedures used to determine bonuses have upheld ethical and moral standards.

10. My bonus reflects the effort I have put into my work.

11. My bonus is appropriate for the work I have completed.

12. My bonus reflects what I have contributed to the organization.

13. My bonus is justified, given my performance.

$\begin{array}{lllll}1 & 2 & 3 & 4 & 5\end{array}$


Please circle the appropriate number to the right of each item using the scale below.

\begin{tabular}{|c|c|c|c|c|}
\hline 1 & 2 & 3 & 4 & 5 \\
\hline Strongly Disagree & Disagree & $\begin{array}{c}\text { Neither Agree or } \\
\text { Disagree }\end{array}$ & Agree & Strongly Agree \\
\hline
\end{tabular}

Assume this situation happened to you. What are your thoughts about the about your current supervisor Circle One

14. I would justify my supervisor's decisions to others when he or she is not present to do so.

15. My supervisor understands my problems and needs.

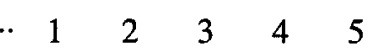

16. I can count on my supervisor to "bail me out" even at his or her expense when I really need it.

17. My supervisor recognizes my potential.

18. My supervisor would use his or her power to help me solve problems at work.

19. I usually know how satisfied my supervisor is with me.

$\begin{array}{lllll}1 & 2 & 3 & 4 & 5\end{array}$

20. I usually know where I stand with my supervisor.

21. I have an effective working relationship with my supervisor.

22. I trust my supervisor.

23. I feel that my supervisor can be trusted.

24. Sometimes I can not trust my supervisor.

25. I can count on my supervisor to be trustworthy. 
Thoughts about How Would I Behave in My Current Job if the Situation I Just Read Actually Happened to Me

37. I would adequately complete assigned duties. $\begin{array}{lllll}1 & 2 & 3 & 4 & 5\end{array}$

38. I would fulfill responsibilities specified in the job description...

$\begin{array}{lllll}1 & 2 & 3 & 4 & 5\end{array}$

39. I would perform tasks that are expected of me.

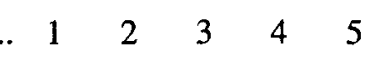

40. I would meet formal performance requirements of the job. $\begin{array}{lllll}1 & 2 & 3 & 4 & 5\end{array}$

41. I would engage in activities that would directly affect my performance evaluation.

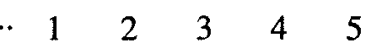

42. I would neglect aspects of the job I am obligated to perform.

43. I would fail to perform essential duties.

44. I would take a personal interest in other employees.

45. I would pass along information to co-workers

46. I would go out of my way to help new employees.

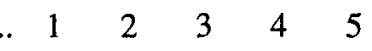

47. I would assist my supervisor with his/her work when not asked..

48. I would help others who have been absent.

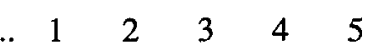

49. I would help others who have heavy workloads.

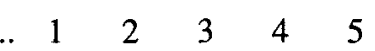

50. I would take time to listen to co-workers' problems and worries.

51. I would give advance notice when unable to come to work.

52. I would take undeserved work breaks.

53. I would spend a great deal of time on personal phone conversations.

54. I would complain about insignificant things at work.

55. I would adhere to informal rules devised to maintain order.

56. My attendance at work would be above the norm.

When responding to the items below, please indicate how likely you would be to engage in these behaviors in the next year if the situation you just read actually happened to you, using the following scale:

$$
\begin{array}{ccccc}
1 & 2 & 3 & 4 & 5 \\
\text { Very Unlikely } & \begin{array}{c}
\text { Somewhat } \\
\text { Unlikely }
\end{array} & \begin{array}{c}
\text { Neither Likely } \\
\text { nor Unlikely }
\end{array} & \begin{array}{c}
\text { Somewhat } \\
\text { Likely }
\end{array} & \text { Very Likely }
\end{array}
$$

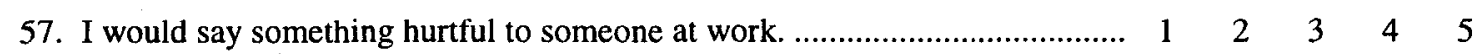

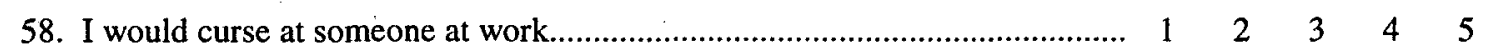

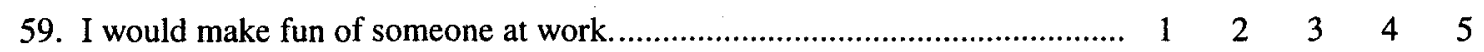




$\begin{array}{ccccc}1 & 2 & 3 & 4 & 5 \\ \text { Very Unlikely } & \begin{array}{c}\text { Somewhat } \\ \text { Unlikely }\end{array} & \begin{array}{c}\text { Neither Likely } \\ \text { nor Unlikely }\end{array} & \begin{array}{c}\text { Somewhat } \\ \text { Likely }\end{array} & \text { Very Likely }\end{array}$

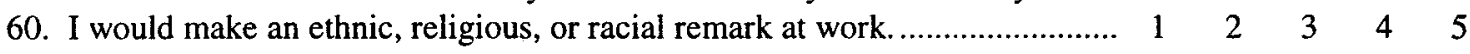

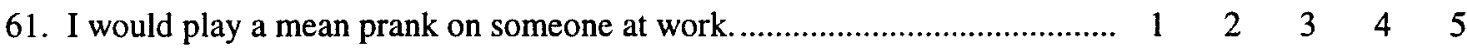

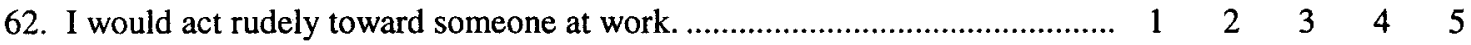

63. I would falsify a receipt to get reimbursed for more money than I spent on business expenses.

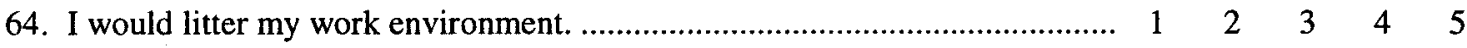

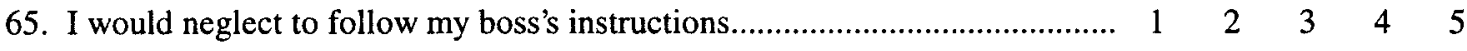

66. I would intentionally work slower than I could work. ..................................... $112 \begin{array}{llll}2 & 3 & 4 & 5\end{array}$

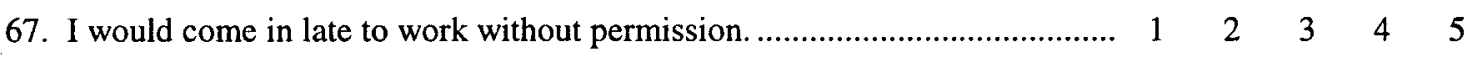

68. I would take an additional or longer break than is acceptable at my workplace.

69. I would take property from work without permission. $\begin{array}{lllll}1 & 2 & 3 & 4 & 5\end{array}$

70. I would drag out work in order to get overtime. $\begin{array}{lllll}1 & 2 & 3 & 4 & 5\end{array}$

71. I would spend too much time fantasizing or daydreaming instead of working.

72. I would discuss confidential company information with an unauthorized person. $\begin{array}{lllll}1 & 2 & 3 & 4 & 5\end{array}$

73. I would use an illegal drug or consume alcohol on the job............................ $1 \begin{array}{llllll}1 & 2 & 3 & 4 & 5\end{array}$

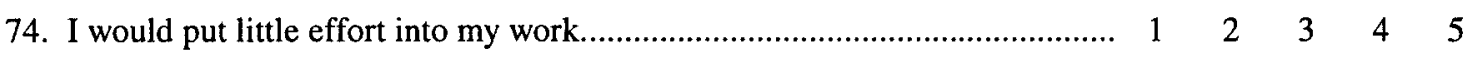

Please indicate the degree to which you agree with the following statements using the scale below.

\begin{tabular}{|c|c|c|c|c|}
\hline 1 & 2 & 3 & 4 & 5 \\
\hline Strongly Disagree & Disagree & $\begin{array}{c}\text { Neither Agree or } \\
\text { Disagree }\end{array}$ & Agree & Strongly Agree \\
\hline
\end{tabular}

75. Parents can usually be relied upon to keep their promises............................. $1128 \begin{array}{llll}2 & 3 & 4 & 5\end{array}$

76. Most experts can be relied upon to tell the truth about the limits of their knowledge.

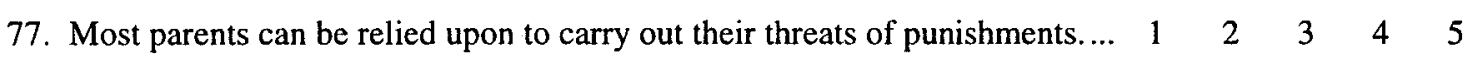

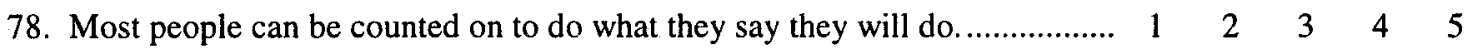

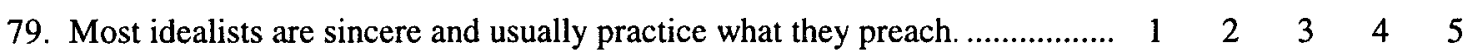

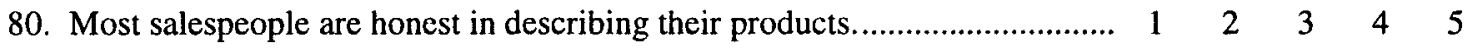

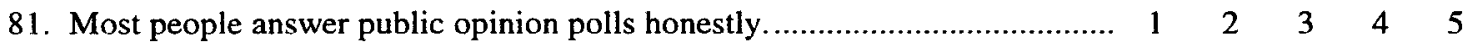

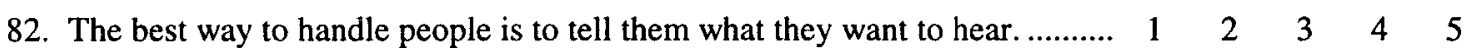

83. When you ask someone to do something for you, it is best to give the real reason for wanting it rather than giving reasons that might carry more weight. 
84. Anyone who completely trusts anyone else is asking for trouble.

85. It is hard to get ahead without cutting corners here and there.

86. It is safest to assume that all people have a vicious streak, and it will come out when they are given a chance.

87. One should take action only when it is morally right.

88. Most people are basically good and kind...

89. There is no excuse for lying to someone else.

\begin{tabular}{|c|c|c|c|}
\hline & 2 & 3 & 4 \\
\hline 1 & 2 & 3 & 4 \\
\hline & 2 & 3 & 4 \\
\hline 1 & 2 & 3 & 4 \\
\hline
\end{tabular}

90. Most people more easily forget the death of their father than the loss of property.

$\begin{array}{lllllll}\text { 91. Generally speaking, people won't work hard unless they're forced to do so.. } & 1 & 2 & 3 & 4 & 5\end{array}$

\section{PLEASE PUT THIS SURVEY BACK INTO THE ENVELOPE AND WAIT FOR FURTHER INSTRUCTIONS FROM THE SURVEY ADMINISTRATOR. THANK YOU VERY MUCH FOR YOUR PARTICIPATION!}


Appendix D

Field Study Subordinate Cover Letter

December 2001

The purpose of this survey is to get your opinion about your working relationship with your manager and other team members, the fairness of your organization's policies and procedures, and your behavior on the job. You will be asked to complete a survey about your current job. This survey will take approximately 10-15 minutes to complete. Although you may not receive any direct benefit from participating in this study, <work unit name> may benefit in the future as your responses may inform $<$ work unit name $>$ on how to encourage high quality working relationships between managers and direct reports and enhance teamwork.

Participation in this study is strictly voluntary. All information you provide is confidential. You will not be asked to provide your name or any identification number. The final report of this study will contain only group-level data. Your decision to participate or not will not affect your relationship with your manager, <work unit name>, or <organization name> in any way. If you decide to take part in the study, you may choose to withdraw at any time without penalty. You may feel uncomfortable responding to some of the items on the survey. You may skip any items on the survey to which you feel uncomfortable responding. However, please be assured that your responses will be kept confidential, and there is no way <work unit name> or <organization name> will be able to match responses to the individuals who provide them, since 1) neither your name nor any identification number is on the survey; 2) only group-level responses will be shared with your organization; 3) no <organization name> employee will have access to completed surveys or electronic data files. In order to gather information on the working relationships betweer managers and direct reports in your organization, your manager will be completing a similar survey in which he or she provides his or her opinion about your behavior in the workplace. This survey will have your name on it, so that your manager provides accurate information. You will notice a code at the top of your survey. This code will be used by the survey administrator to match your survey responses with those of your manager. Again, the information you provide will be confidential.

When you have completed the survey, please put the survey in the enclosed self-addressed stamped envelope and put the envelope in the US mail. TO PROTECT YOUR IDENTITY, DO NOT GIVE THE SURVEY TO ANYONE IN < work unit name> OR <organization name>. Results of this project will be completed by February 2002. A summary of the results will be available from Rudolph J. Sanchez upon request.

If you have any questions concerning the survey, this study, or its results, please contact Rudolph J. Sanchez at 559.278.2344. If you have concerns or problems about participation in this study or your rights as a research participant, please contact the Human Subjects Research Review Committee, Office of Research and Sponsored Project, 111 Cramer Hall, Portland State University, 503.725.8182. Please keep this letter for your records.

Thank you very much for your participation.

Sincerely,

Rudolph J. Sanchez

Craig School of Business

California State University, Fresno 
Appendix E

Field Study Subordinate Survey

The code at the top of this page will allow the researcher to match information you provide with that of your manager. However, no record will exist of your individual identity. Your responses to this survey are completely anonymous.

Please complete this survey based on your opinions about your current job, your current manager, <work unit name>, and <organization name>.

When you have completed this survey place it in the self-addressed stamped envelope and place it in the US Mail. DO NOT GIVE THIS SURVEY TO ANYONE IN YOUR ORGANIZATION.

THANK YOU VERY MUCH FOR YOUR PARTICIPATION.

***************************************************************************************1

PART I BACKGROUND DATA

Please answer the following background questions that are necessary for this study.

1. Gender (check one): $\quad \square$ Male $\quad \square$ Female

2. Which of the following BEST describes your race/ethnicity? (Check one)

$\square$ African American/Black $\square$ Asian/Pacific Islander $\square$ Caucasian/White

$\square$ Hispanic $\quad \square$ Native American $\quad$ Other

3. How would classify your current position? (Please Check One Box)

$\square$ Level 9x, 58-60 Technical

$\square$ Level 62 and aböve, Technical

口Level 62 and above, Management

4. How many hours per week do you work?

5. How long have you worked for <organization name>? Years ___ Months

6. How long have you worked with your current manager? Years Months

7. What is your age?

8. What is the highest level of education that you have completed? (Check one)

$\square$ High School/GED
$\square$ Some College
$\square$ Associates Degree
$\square$ Bachelors Degree
$\square$ Graduate Degree (e.g., MBA, MA, MA, PhD, JD)

Have you completed all 6 pages of this survey? 
PART II When completing this portion of the survey, think about how you feel about your current manager, your current job, and <organization name>. Please circle the appropriate number to the right of each item using the scale below.

\begin{tabular}{|c|c|c|c|c|}
\hline 1 & 2 & 3 & 4 & 5 \\
\hline Strongly Disagree & Disagree & $\begin{array}{c}\text { Neither Agree or } \\
\text { Disagree }\end{array}$ & Agree & Strongly Agree \\
\hline
\end{tabular}

Thoughts about the about My Manager

1. I would justify my manager's decisions to others when he or she is not present to do so.

Circle One

2. My manager understands my job problems and needs

$\begin{array}{lllll}1 & 2 & 3 & 4 & 5\end{array}$

3. I can count on my manager to "bail me out" even at his or her expense when I really need it.

4. My manager recognizes my potential.

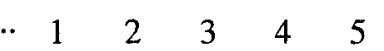

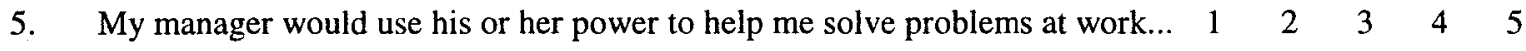

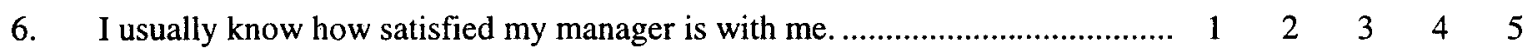

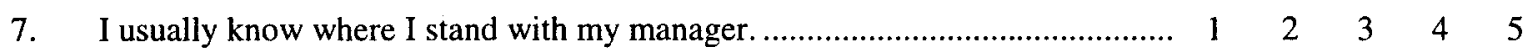

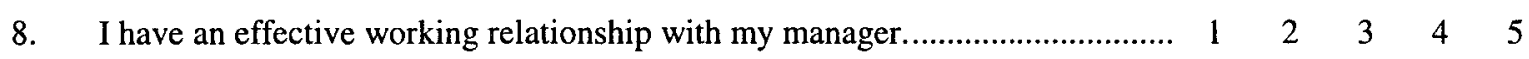

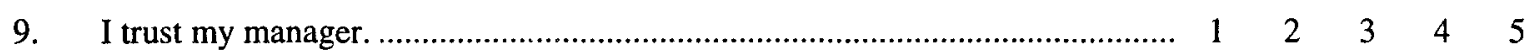

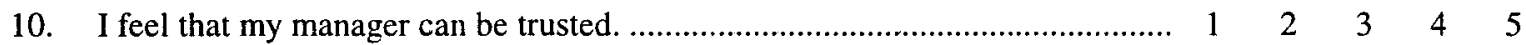

11. Sometimes I cannot trust my manager............................................................. $11 \quad 2 \quad \begin{array}{llll}3 & 4 & 5\end{array}$

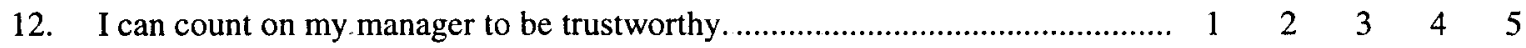

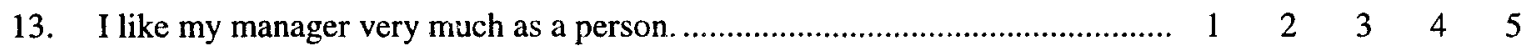

14. My manager is the kind of person one would like to have as a friend............. $11 \quad 2 \quad \begin{array}{llll}3 & 4 & 5\end{array}$

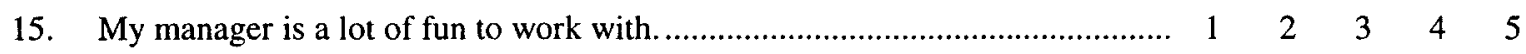

16. My manager defends my work actions to a superior, even without complete $\begin{array}{llllll}1 & 2 & 3 & 4 & 5\end{array}$ knowledge of the issue in question...............................................................

17. My manager would come to my defense if I were "attacked" by others........... $11 \quad 2 \quad \begin{array}{lllll} & 1 & 4 & 4 & 5\end{array}$

18. I do work for my manager that goes beyond what is specified in my job description. .

19. I am willing to apply extra efforts, beyond those normally required, to meet my manager's work goals.

20. I do not mind working my hardest for my manager.

$\begin{array}{llll}2 & 3 & 4 & 5\end{array}$

21. I am impressed with my manager's knowledge of his/her job.

$\begin{array}{llll}2 & 3 & 4 & 5\end{array}$

22. I respect my manager's knowledge of and competence on the job.

23. I admire my manager's professional skills. 2345

$\begin{array}{llll}2 & 3 & 4 & 5\end{array}$

2345

Have you completed all 6 pages of this survey? 
12

Strongly Disagree
2

Disagree
3

Neither Agree or

Disagree

4

Agree

5

Strongly Agree

Thoughts about <organization name> and <work unit name>

24. I am fairly rewarded for the work I have done well.

25. I am fairly rewarded considering the responsibilities of my job.

$\begin{array}{lllll}1 & 2 & 3 & 4 & 5 \\ 1 & 2 & 3 & 4 & 5 \\ 1 & 2 & 3 & 4 & 5 \\ 1 & 2 & 3 & 4 & 5 \\ 1 & 2 & 3 & 4 & 5\end{array}$

28. I am fairly rewarded for the amount of effort I put forth. 1

29. I am fairly rewarded taking into account the amount of education and training I have.

$\begin{array}{lllll}1 & 2 & 3 & 4 & 5\end{array}$

30. <organization name $>$ has procedures in place that provide employees the chance to challenge company decisions..

31. <organization name > has procedures in place to make sure that information is supplied to employees when it is requested.

$\begin{array}{lllll}1 & 2 & 3 & 4 & 5\end{array}$

<organization name> has procedures in place to make sure explanations are provided to employees regarding company decisions.

$\begin{array}{lllll}1 & 2 & 3 & 4 & 5\end{array}$

<organization name> has procedures in place to make sure that decisions are consistent with all employees.

34. <organization name> has procedures in place that allow employees the chance to have a say and express their concerns regarding company decisions.

$\begin{array}{lllll}1 & 2 & 3 & 4 & 5\end{array}$

35. <organization name> has procedures in place to make sure that the company is informed about employees' needs in order to make fair decisions.

36. <organization name> has procedures in place to make sure the information being used for decisions is accurate.

37. <organization name> has procedures in place to make sure all parties affected by a company decision are represented in the decision.

38. For me, <organization name> is the best of all possible organizations for which to work.

39. <organization name> really inspires the very best in me in the way of performance.

40. I am proud to tell others that I am part of <organization name>.

41. I find that my values and <organization name>'s values are very similar.........

42. I am willing to put a great deal of effort beyond that normally expected in order to help <organization name> be successful.

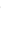




\section{Strongly Disagree}

44. For me, <work unit name $>$ is the best of all possible organizations for which to work.

45. <work unit name> really inspires the very best in me in the way of performance.

46. I am proud to tell others that I am part of <work unit name $>$.

47. I find that my values and < work unit name>'s values are very similar..

48. I am willing to put a great deal of effort beyond that normally expected in order to help < work unit name $>$ be successful.

49. I would accept almost any type of assignment in order to keep working for $<$ work unit name>

50. Generally speaking, I am very satisfied with the job I currently have.

51. I am generally satisfied with the kind of work I do in the job I currently have

52. I frequently think about quitting the job I currently have.

53. I intend to quit the job I currently have.

\section{Thoughts about How I Behave in My Current Job}

54. I adequately complete assigned duties.

55. I fulfill responsibilities specified in the job description.

56. I perform tasks that are expected of me.

57. I meet formal performance requirements of the job.

58. I engage in activities that will directly affect my performance evaluation....

59. I neglect aspects of the job I am obligated to perform.

60. I fail to perform essential duties.

61. I take a personal interest in other employees.

62. I pass along information to co-workers.

63. I go out of my way to help new employees.

64. I assist my manager with his/her work when not asked.

65. I help others who have been absent.

66. I help others who have heavy workloads.

67. I take time to listen to co-workers' problems and worries.

68. I give advance notice when unable to come to work.

69. I take undeserved work breaks.

70. I spend a great deal of time on personal phone conversations.

$\begin{array}{rrrrrr}. . & 1 & 2 & 3 & 4 & 5 \\ . . & 1 & 2 & 3 & 4 & 5 \\ & & & & & \\ . & 1 & 2 & 3 & 4 & 5\end{array}$


71. I complain about insignificant things at work

72. I adhere to informal rules devised to maintain order.

73. My attendance at work is above the norm.

$\begin{array}{llll}2 & 3 & 4 & 5\end{array}$

The following items refer to your opinions about the project team you are a part of within <work unit name>.

74. Other members of my team usually let me know when I do something that makes their jobs harder or easier.

75. I let other team members know when they have done something that makes my job harder or easier.

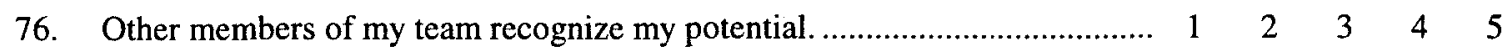

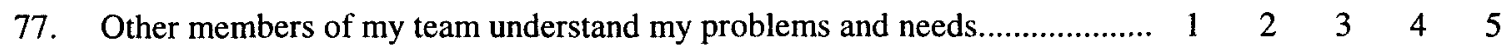

78. I am flexible about switching job responsibilities to make things easier for other team members.

79. In busy situations, other team members ask me to help out.......................... $1121 \quad 2 \quad 3 \quad 4 \quad 5$

80. In busy situations, I volunteer my efforts to help others out.......................... $11 \quad 2 \quad \begin{array}{llll}3 & 4 & 4 & 5\end{array}$

81. I am willing to help finish work that has been assigned to others.................... $11 \quad 2 \quad 2 \quad 3 \quad 4 \quad 4 \quad 5$

82. Other members of my team are willing to help finish work that was assigned to me.

Please indicate the degree to which you agree with the following statements.

83. Parents can usually be relied upon to keep their promises.............................. $11 \quad 2 \quad 2 \quad 3 \quad 4 \quad 4 \quad 5$

84. Most experts can be relied upon to tell the truth about the limits of their knowledge.

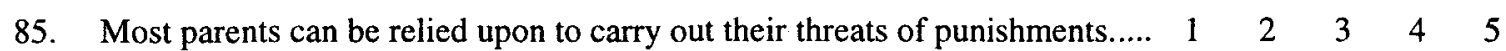

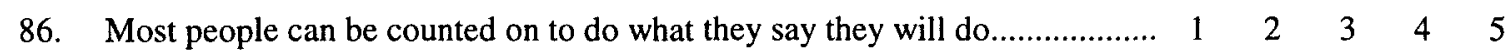

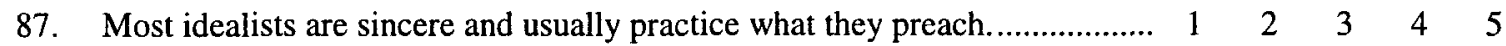

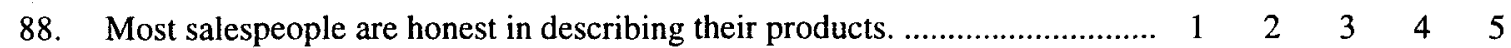

89. Most people answer public opinion polls honestly........................................ $1120 \begin{array}{lllll}2 & 2 & 3 & 4 & 5\end{array}$

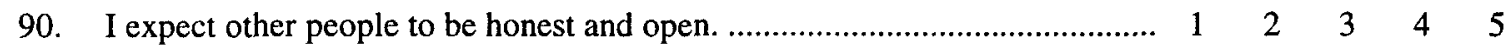

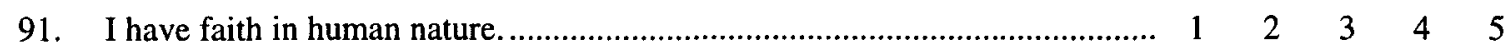

92. I feel that other people can be relied upon to do what they say they will do. . $11 \quad 2 \quad \begin{array}{lllll}3 & 4 & 5\end{array}$

93. I have faith in the promises or statements of other people. ............................ $11 \quad 2 \quad \begin{array}{llll}3 & 4 & 5\end{array}$ 
When responding to the items below, please indicate how frequently you engaged in these behaviors in the last year, using the following scale:

$\begin{array}{cccccrr}1 & 2 & 3 & 4 & 5 & 6 & 7 . \\ \text { Never } & \begin{array}{c}\text { Once in the } \\ \text { Past Year }\end{array} & \begin{array}{c}\text { Twice in the } \\ \text { Past Year }\end{array} & \begin{array}{c}\text { Several } \\ \text { Times in the }\end{array} & \text { Monthly } & \text { Weekly } & \text { Daily }\end{array}$

\section{Past Year Past Year Times in the}

Past Year

94. Tried to look busy while wasting time.

$\begin{array}{lllllll}1 & 2 & 3 & 4 & 5 & 6 & 7 \\ 1 & 2 & 3 & 4 & 5 & 6 & 7 \\ 1 & 2 & 3 & 4 & 5 & 6 & 7 \\ 1 & 2 & 3 & 4 & 5 & 6 & 7 \\ 1 & 2 & 3 & 4 & 5 & 6 & 7 \\ 1 & 2 & 3 & 4 & 5 & 6 & 7 \\ 1 & 2 & 3 & 4 & 5 & 6 & 7 \\ 1 & 2 & 3 & 4 & 5 & 6 & 7 \\ 1 & 2 & 3 & 4 & 5 & 6 & 7 \\ 1 & 2 & 3 & 4 & 5 & 6 & 7 \\ 1 & 2 & 3 & 4 & 5 & 6 & 7\end{array}$

104. Said something hurtful to someone at work

105. Falsified a receipt to get reimbursed for more money than I spent on business expenses.

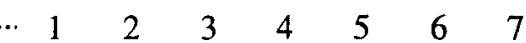

106. Taken property from work without permission.

107. Put little effort into my work.

108. Neglected to follow my manager's instructions

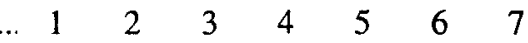

109. Discussed confidential company information with an unauthorized person

$\begin{array}{lllllll}1 & 2 & 3 & 4 & 5 & 6 & 7\end{array}$

110. Spread rumors about coworkers. $\begin{array}{lllllll}1 & 2 & 3 & 4 & 5 & 6 & 7\end{array}$

111. Gave a coworker the "silent treatment" $\begin{array}{lllllll}1 & 2 & 3 & 4 & 5 & 6 & 7\end{array}$

112. Spent too much time surfing the web instead of working

$\begin{array}{lllllll}1 & 2 & 3 & 4 & 5 & 6 & 7\end{array}$


Please respond to the next two open-ended items by writing any comments you may have. Please remember that your responses are confidential. Comments will be rephrased and summarized.

What do you think is the one strongest aspect of <work unit name> leadership and/or teamwork?

What would be the single most important thing you would like to see changed in how <work unit name> leadership operates or your team operates?

$>$ PLEASE PUT THE COMPLETED SURVEY IN THE STAMPED SELF-ADDRESSED ENVELOPE AND PLACE IN THE US MAIL. THANK YOU VERY MUCH FOR YOUR PARTICIPATION.

Have you completed all 6 pages of this survey? 
Appendix F

Field Study Supervisor Cover Letter

December 2001

The purpose of this study is to get your opinion about your working relationship with your supervisor and other team members, the fairness of your organization's policies and procedures, and your behavior on the job. Additionally, you will be asked your opinion about your working relationship with your direct reports and their behavior on the job. The initial survey will take a approximately 15-20 minutes to complete. The surveys referencing each of your direct reports will take approximately 10 minutes each to complete. Although you may not receive any direct benefit from participating in this study, $<$ work unit name > may benefit in the future as your responses may inform <work unit name > on how to encourage high quality working relationships between managers and direct reports and enhance teamwork.

Participation in this study is strictly voluntary. All information you provide is confidential. You will not be asked to provide your name or any identification number. The final report of this study will contain only group-level data. Your decision to participate or not will not affect your relationship with your manager, <work unit name>, or <organization name> in any way. If you decide to take part in the study, you may choose to withdraw at any time without penalty. You may feel uncomfortable responding to some of the items on the survey. You may skip any items on the survey to which you feel uncomfortable responding. However, please be assured that your responses will be kept confidential, and there is no way <work unit name> or <organization name> will be able to match responses to the individuals who provide them, since 1) neither your name nor any identification number is on the survey; 2) only group-level responses will be shared with your organization; 3) no <organization name> employee will have access to completed surveys or electronic data files. In order to gather information on the working relationships between managers and direct reports in your organization, your manager will be completing a similar survey in which he or she provides his or her opinion about your behavior in the workplace. This survey will have your name on it, so that your manager provides accurate information. You will notice a code at the top of the survey printed on white paper. This code will be used by the survey administrator to match your survey responses with those of your manager. Again, the information you provide will be confidential.

When you have completed the surveys, please put the surveys in the enclosed self-addressed stamped envelope and put the envelope in the US mail. TO PROTECT YOUR IDENTITY, DO NOT GIVE THE SURVEY TO ANYONE IN < work unit name> OR < organization name>. Results of this project will be completed by February 2002. A summary of the results will be available from Rudolph J. Sanchez upon request.

If you have any questions concerning the survey, this study, or its results, please contact Rudolph J. Sanchez at 559.278.2344. If you have concerns or problems about participation in this study or your rights as a research participant, please contact the Human Subjects Research Review Committee, Office of Research and Sponsored Project, 111 Cramer Hall, Portland State University, 503.725.8182. Please keep this letter for your records.

Thank you very much for your participation.

Sincerely,

Rudolph J. Sanchez

Craig School of Business

California State University, Fresno 


\section{Appendix G \\ $<$ Work Unit Name $>$ Manager Instruction Page}

Thank you for agreeing to participate in this project.

If you have not read the letter signed by Rudy J. Sanchez, please do so before reading these instructions. Please read this entire instruction page before beginning to complete the surveys.

The first survey you will complete is the one with the blue colored cover sheet. This survey asks you to provide some background information about yourself and your opinions about the nature of your working relationship with your manager, <work unit name>, and <name of organization >.

After you have completed the survey with the blue cover sheet, please complete the surveys printed on white paper. You will notice that you have multiple copies of this survey. Each survey has an employee's name at the top of the first page. These surveys ask you to respond to items describing your working relationship with this particular direct report and how that direct report behaves on the job.

After you have completed all the surveys, put them in the self-addressed stamped envelope provided and put the envelope in the US Mail. Do not give the surveys to anyone in <work unit name> or <name of organization>.

If you have any questions about how to complete the surveys, please contact Rudy J. Sanchez via email at rjsanchez@csufresno.edu or phone at 559.278.2344.

Again, thank you very much for your participation! 
Appendix $\mathrm{H}$

Field Study Supervisor Survey

Please complete this survey based on your opinions about the direct report whose name appears at the top of this page. Do not put your name or any identification number on this survey. Please remember that your responses are completely confidential and only group level data will be shared with your organization.

When you have completed this survey, please complete the remaining surveys printed on blue paper. When you have completed all the surveys, place them (the white survey and the all the blue surveys) in the self-addressed stamped envelope and place it in the US Mail. DO NOT GIVE THIS SURVEY TO ANYONE IN YOUR ORGANIZATION.

\section{THANK YOU VERY MUCH FOR YOUR PARTICIPATION.}

$* * * * * * * * * * * * * * * * * * * * * * * * * * * * * * * * * * * * * * * * * * * * * * * * * * * * * * * * * * * * * * * * * * * * * * * * * * * * * * * * * *$

1. How long have you worked with this direct report? Years Months

When completing this portion of the survey, think about your relationship with this direct report. Please circle the appropriate number to the right of each item using the scale below.

\begin{tabular}{|c|c|c|c|c|}
\hline 1 & 2 & 3 & 4 & 5 \\
\hline Strongly Disagree & Disagree & $\begin{array}{c}\text { Neither Agree or } \\
\text { Disagree }\end{array}$ & Agree & Strongly Agree \\
\hline
\end{tabular}

Thoughts about the direct report whose name is above.

2. I would justify this direct report's decisions to others when he or she is not

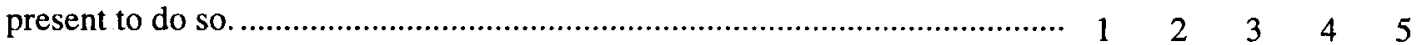

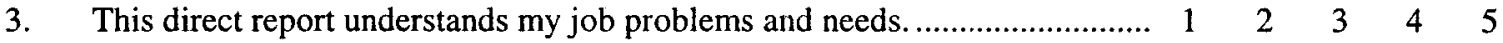

4. I can count on this direct report to "bail me out" even at his or her expense when I really need it.

Circle One

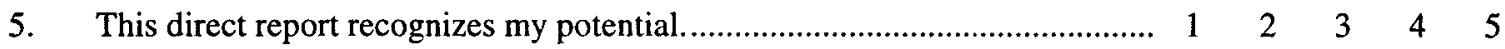

6. This direct report would use his or her power to help me solve problems at work.

7. I usually know how satisfied this direct report is with me.

$\begin{array}{llll}2 & 3 & 4 & 5\end{array}$

8. I usually know where I stand with this direct report. $\begin{array}{llll}2 & 3 & 4 & 5\end{array}$

9. I have an effective working relationship with this direct report... $\begin{array}{llll}2 & 3 & 4 & 5\end{array}$

10. I trust this direct report.

11. I feel that this direct report can be trusted.

12. Sometimes I cannot trust this direct report.

13. I can count on this direct report to be trustworthy

14. I like this direct report very much as a person.

15. This direct report is the kind of person one would like to have as a friend....

16. This direct report is a lot of fun to work with.

17. This direct report defends my work actions to a superior, even without complete knowledge of the issue in question. 
$\begin{array}{lllll}1 & 2 & 3 & 5\end{array}$

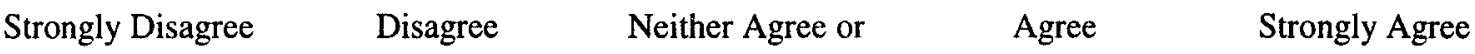
Disagree

18. This direct report defends my work actions to a superior, even without

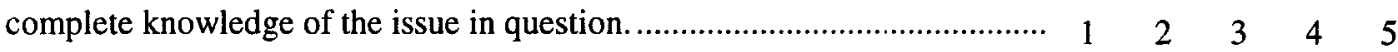

19. This direct report would come to my defense if I were "attacked" by $\quad \begin{array}{llllllll}1 & 2 & 3 & 4 & 5\end{array}$ others.

20. I do work for this direct report that goes beyond what is specified in my job description.

21. I am willing to apply extra efforts, beyond those normally required, to meet this direct report's work goals.

22. I do not mind working my hardest for this direct report.

$\begin{array}{lll}3 & 4 & 5\end{array}$

23. I am impressed with this direct report's knowledge of his/her job.

$\begin{array}{llll}2 & 3 & 4 & 5\end{array}$

24. I respect this direct report's knowledge of and competence on the job. ....... $1142 \begin{array}{llll}2 & 2 & 4 & 5\end{array}$

25. I admire this direct report's professional skills

$\begin{array}{llll}2 & 3 & 4 & 5\end{array}$

26. I believe that generally speaking, this direct report is very satisfied with the job he or she currently has.

27. I believe that this direct report thinks <work unit name> is the best of all possible organizations for which to work.

Your Thoughts about How This Direct Report Behaves on the Job

28. This direct report adequately completes assigned duties.

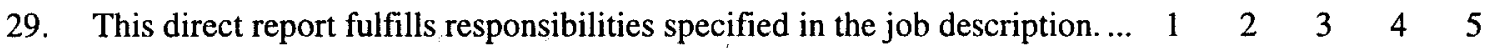

30. This direct report performs tasks that are expected of him/her..................... $1120 \begin{array}{lllll}2 & 3 & 4 & 5\end{array}$

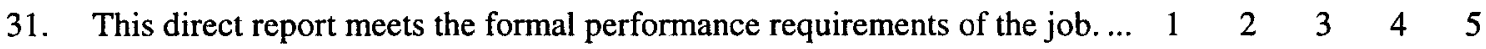

32. This direct report engages in activities that will directly affect his/her performance evaluation

33. This direct report neglects aspects of the job he/she is obligated to perform.

34. This direct report fails to perform essential duties.

35. This direct report takes a personal interest in other employees...................... $11 \quad 2 \quad 2 \quad 3 \quad 4 \quad 4 \quad 5$

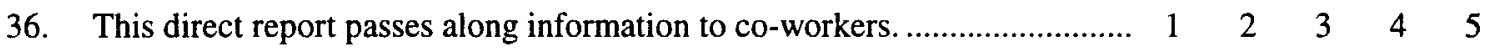

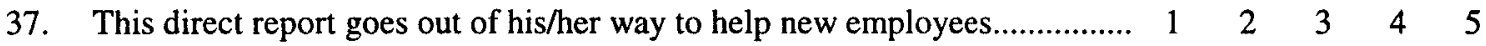

38. This direct report assists me with my work when not asked....................... $11 \quad 2 \quad \begin{array}{llll}2 & 3 & 4 & 5\end{array}$

39. This direct report helps others who have been absent................................. $11 \quad 2 \quad \begin{array}{llll}3 & 4 & 4 & 5\end{array}$

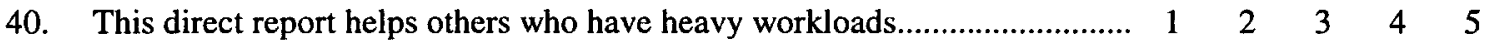

41. This direct report takes time to listen to co-workers' problems and worries. $\begin{array}{llllll}1 & 2 & 3 & 4 & 5\end{array}$

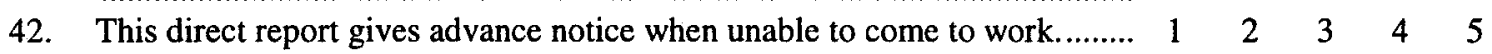

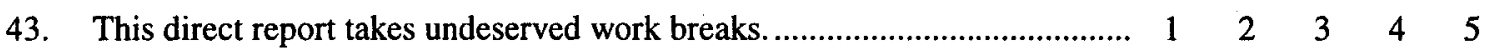


1

Strongly Disagree
2

Disagree
3

Neither Agree or
5

Strongly Agree

Agree

Disagree

44. This direct report spends a great deal of time on personal phone

conversations.

45. This direct report complains about insignificant things at work.

$\begin{array}{lllll}1 & 2 & 3 & 4 & 5\end{array}$

46. This direct report adheres to informal rules devised to maintain order......... $11 \quad 2 \quad 2 \quad 3 \quad 4 \quad 4 \quad 5$

47. This direct report's attendance at work is above the norm.

When responding to the items below, please indicate how frequently this direct report engaged in these behaviors in the last year, using the following scale:

\begin{tabular}{|c|c|c|c|c|c|c|c|}
\hline 1 & 2 & 3 & 4 & 5 & 6 & 7 & DK \\
\hline Never & $\begin{array}{c}\text { Once in the } \\
\text { Past Year }\end{array}$ & $\begin{array}{c}\text { Twice in } \\
\text { the Past } \\
\text { Year }\end{array}$ & $\begin{array}{c}\text { Several } \\
\text { Times in } \\
\text { the Past } \\
\text { Year }\end{array}$ & Monthly & Weekly & Daily & $\begin{array}{c}\text { Don't } \\
\text { Know }\end{array}$ \\
\hline
\end{tabular}

48. Tried to look busy while wasting time.

$\begin{array}{llllllll}1 & 2 & 3 & 4 & 5 & 6 & 7 & \text { DK } \\ 1 & 2 & 3 & 4 & 5 & 6 & 7 & \text { DK } \\ 1 & 2 & 3 & 4 & 5 & 6 & 7 & \text { DK } \\ 1 & 2 & 3 & 4 & 5 & 6 & 7 & \text { DK } \\ 1 & 2 & 3 & 4 & 5 & 6 & 7 & \text { DK } \\ 1 & 2 & 3 & 4 & 5 & 6 & 7 & \text { DK } \\ 1 & 2 & 3 & 4 & 5 & 6 & 7 & \text { DK } \\ 1 & 2 & 3 & 4 & 5 & 6 & 7 & \text { DK } \\ 1 & 2 & 3 & 4 & 5 & 6 & 7 & \text { DK } \\ 1 & 2 & 3 & 4 & 5 & 6 & 7 & \text { DK } \\ 1 & 2 & 3 & 4 & 5 & 6 & 7 & \text { DK } \\ 1 & 2 & 3 & 4 & 5 & 6 & 7 & \text { DK } \\ 1 & 2 & 3 & 4 & 5 & 6 & 7 & \text { DK } \\ 1 & 2 & 3 & 4 & 5 & 6 & 7 & \text { DK } \\ 1 & 2 & 3 & 4 & 5 & 6 & 7 & \text { DK } \\ 1 & & & & & & & \\ 1 & 2 & 3 & 4 & 5 & 6 & 7 & \text { DK } \\ 1 & 2 & 3 & 4 & 5 & 6 & 7 & \text { DK } \\ 1 & 2 & 3 & 4 & 5 & 6 & 7 & \text { DK }\end{array}$

49. On purpose, damaged equipment or work processes.

50. Wasted company materials.

51. Called in sick when not ill.

52. Spoke poorly about the company to others.

53. Failed to give a coworker required information.

54. Took an extended coffee or lunch break

55. Intentionally worked slower than he/she could have.

56. Spoke poorly about me to others.

57. Spent time on personal matters while at work.

58. Said something hurtful to someone at work.

59. Falsified a receipt to get reimbursed for more money than he/she spent on business expenses.

60. Taken property from work without permission.

61. Put little effort into his/her work.

62. Neglected to follow my instructions

63. Discussed confidential company information with an unauthorized person

64. Spread rumors about coworkers.

65. Gave a coworker the "silent treatment".

66. Spent too much time surfing the web instead of working.

\section{ONCE YOU HAVE COMPLETED ALL OF THE SURVEYS, PLEASE PUT THEM IN THE STAMPED SELF-ADDRESSED ENVELOPE AND PLACE IN THE US MAIL. THANK YOU VERY MUCH FOR YOUR PARTICIPATION.}

Have you completed all 3 pages of this survey? 